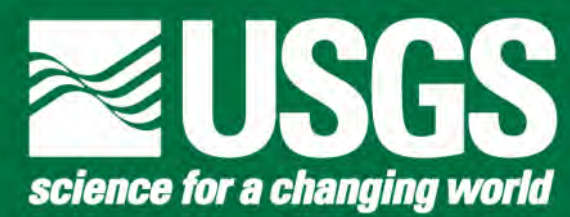

Prepared in cooperation with U.S. Fish and Wildlife Service

Final Report for Sea-level Rise Response Modeling for San Francisco Bay Estuary Tidal Marshes

Open-File Report 2013-1081

U.S. Department of the interior

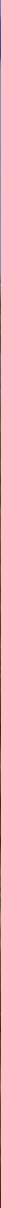


Photo credit: Karen Thorne (author)

Description: Using a RTK GPS a USGS technician (Kyle Spragens) takes elevation surveys on San Pablo Bay National Wildlife Refuge in northern San Francisco Bay, California. 


\section{Final Report for Sea-level Rise Response Modeling for San Francisco Bay Estuary Tidal Marshes}

By John Y. Takekawa, Karen M. Thorne, Kevin J. Buffington, Kyle A. Spragens, Kathleen M. Swanson, Judith Z. Drexler, David H. Schoellhamer, Cory T. Overton, and Michael L. Casazza

Prepared in cooperation with U.S. Fish and Wildlife Service

Open-File Report 2013-1081

U.S. Department of the Interior

U.S. Geological Survey 


\section{U.S. Department of the Interior \\ SALLY JEWELL, Secretary}

\section{U.S. Geological Survey \\ SUZETTE M. KIMBALL, Acting Director}

U.S. Geological Survey, Reston, Virginia: 2013

For product and ordering information:

World Wide Web: http://www.usgs.gov/pubprod

Telephone: 1-888-ASK-USGS

For more information on the USGS - the Federal source for science about the Earth,

its natural and living resources, natural hazards, and the environment:

World Wide Web: http://www.usgs.gov

Telephone: 1-888-ASK-USGS

Suggested Citation:

Takekawa, J.Y., Thorne, K.M., Buffington, K.J., Spragens, K.A., Swanson, K.M., Drexler J.Z., Schoellhamer, D.H., Overton, C.T., Casazza M.L. 2013. Final report for sea-level rise response modeling for San Francisco Bay estuary tidal marshes. U.S. Geological Survey Open File Report 2012$1081,161 \mathrm{p}$.

Any use of trade, product, or firm names is for descriptive purposes only and does not imply endorsement by the U.S. Government.

Although this report is in the public domain, permission must be secured from the individual copyright owners to reproduce any copyrighted material contained within this report. 


\section{TABLE OF CONTENTS}

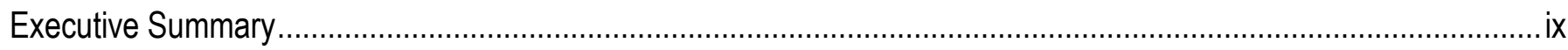

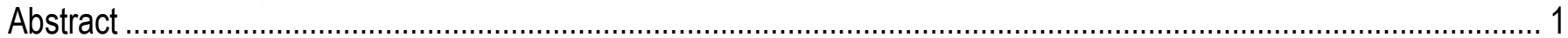

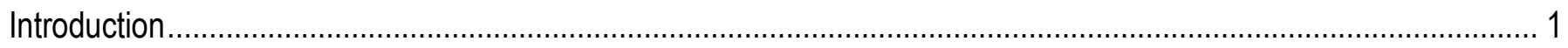

Study Area

Methods

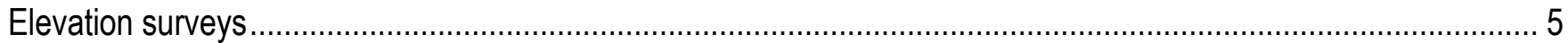

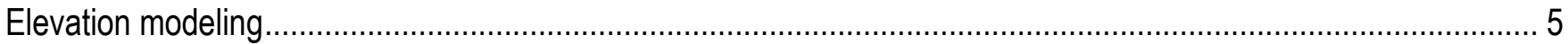

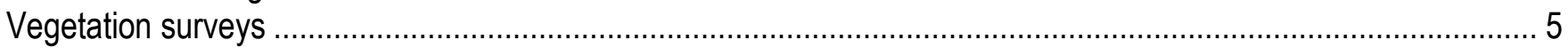

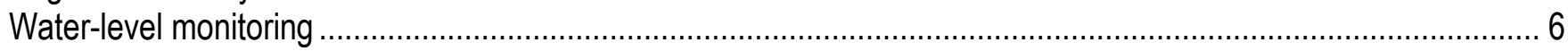

The Wetland Accretion Rate Model for Ecosystem Resilience (WARMER)........................................................ 7

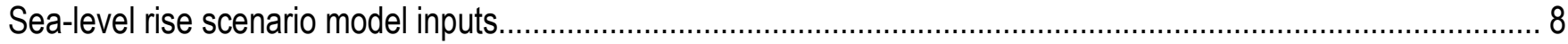

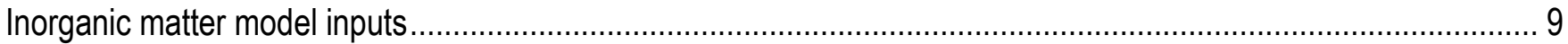

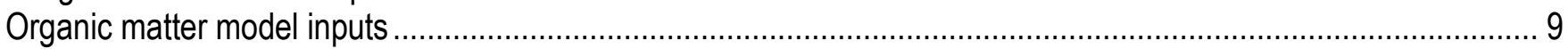

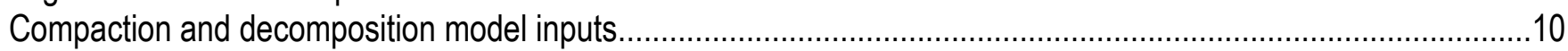

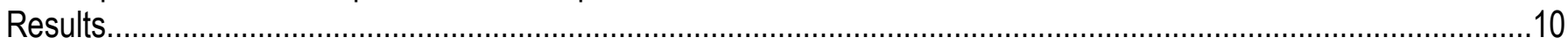

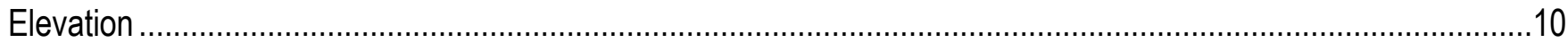

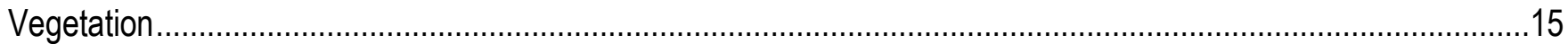

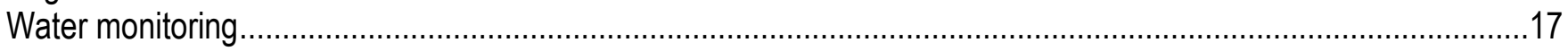

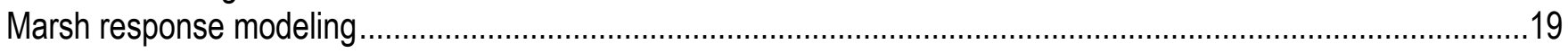

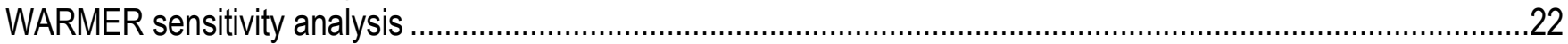

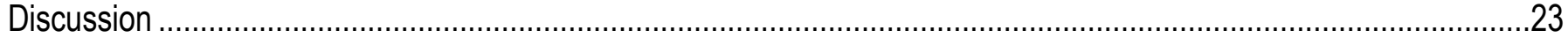

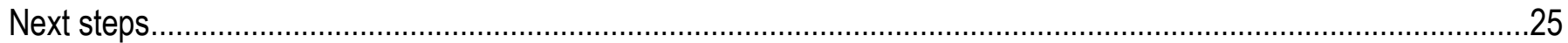

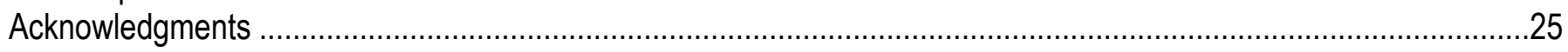

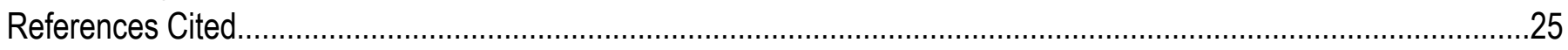

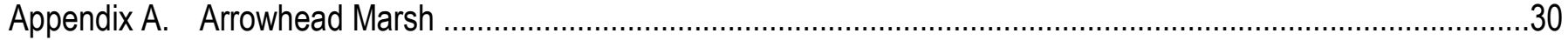

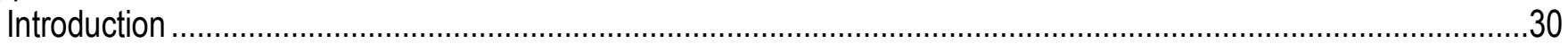

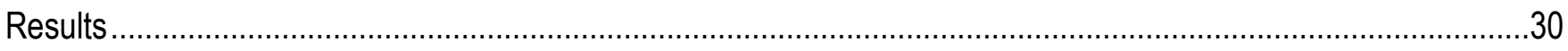

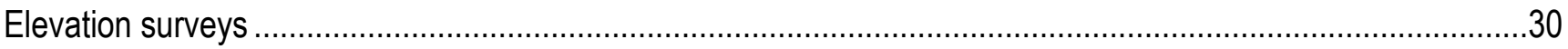

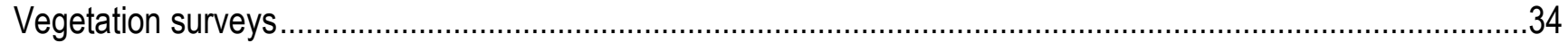

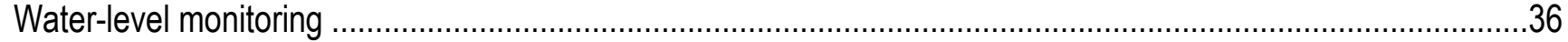

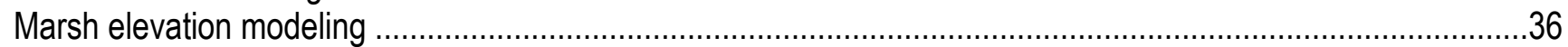

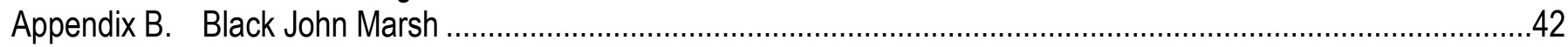

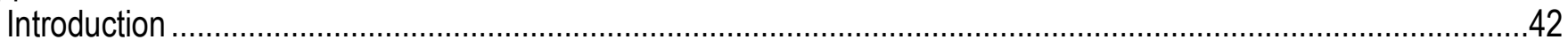

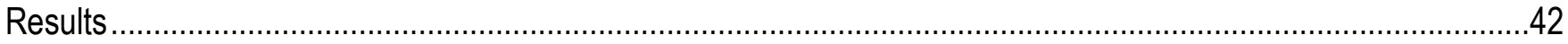

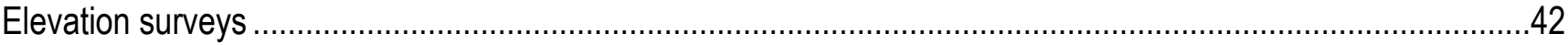

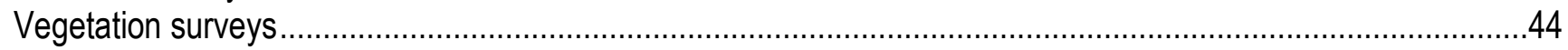

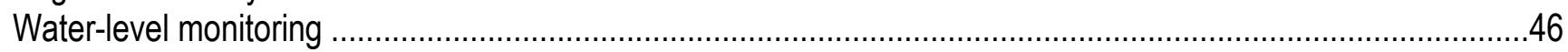

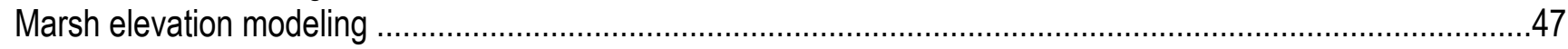

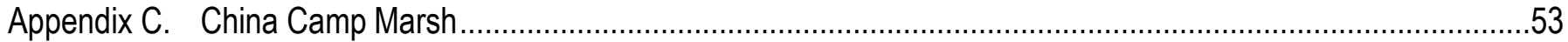

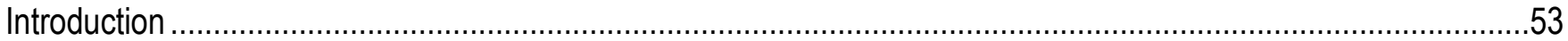

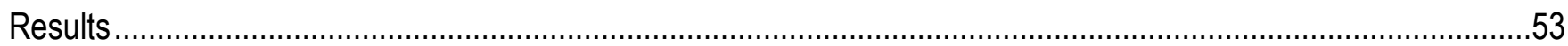

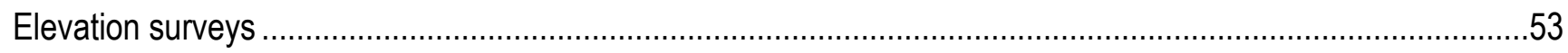

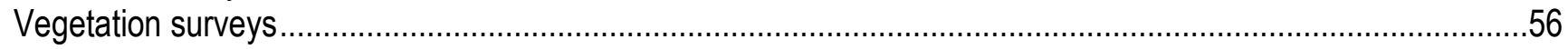

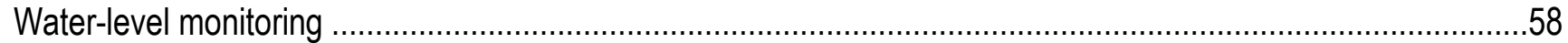

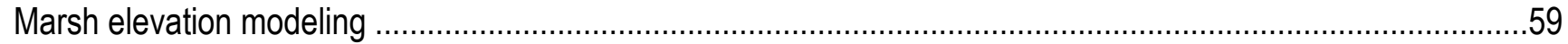




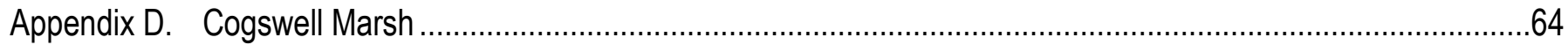

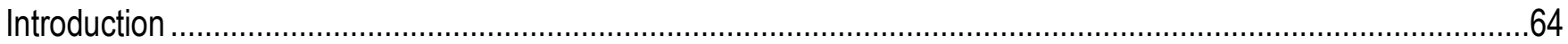

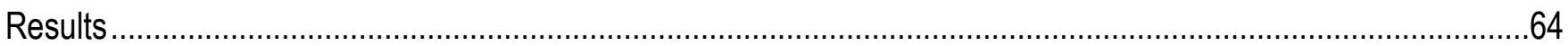

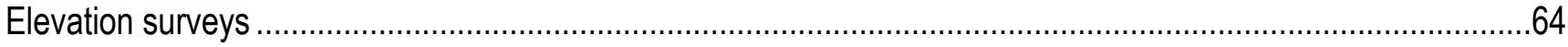

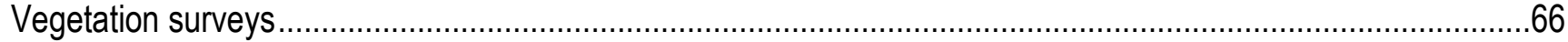

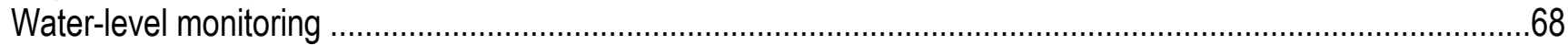

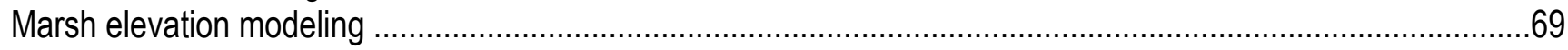

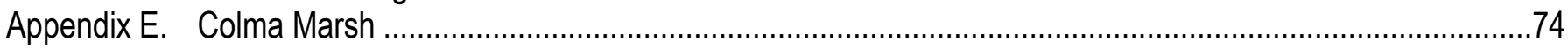

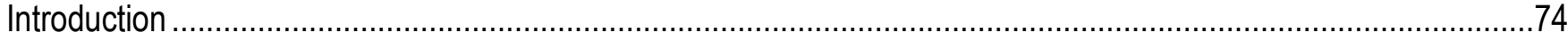

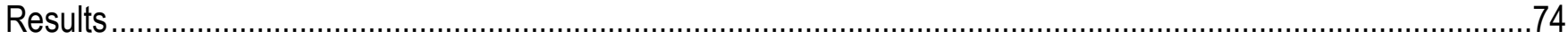

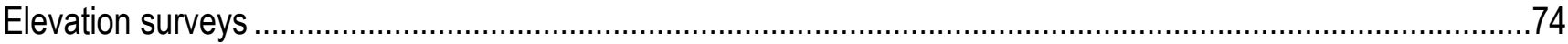

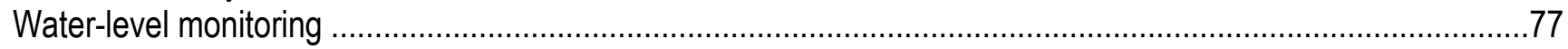

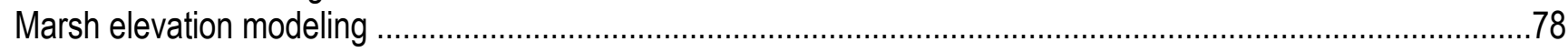

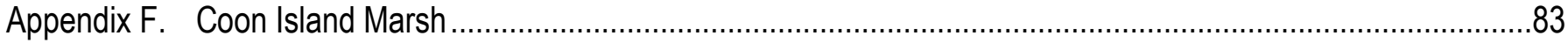

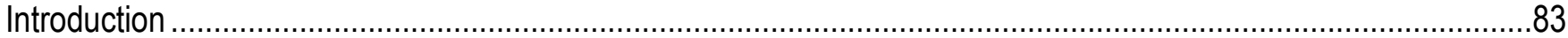

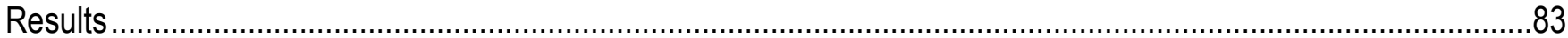

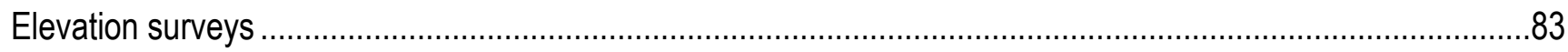

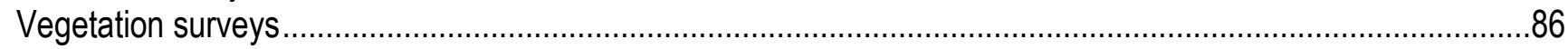

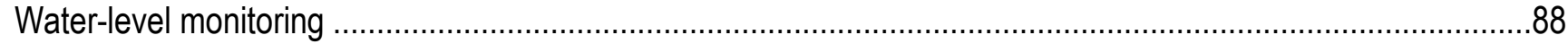

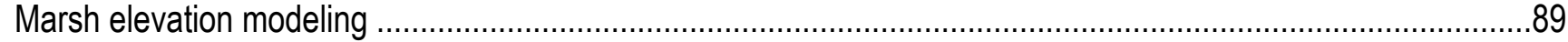

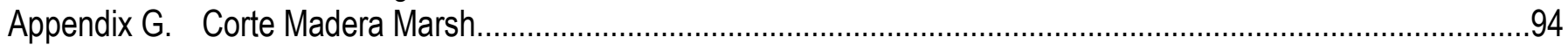

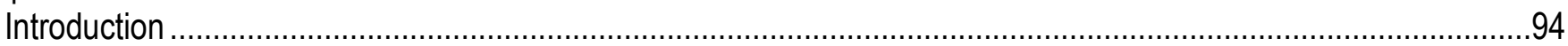

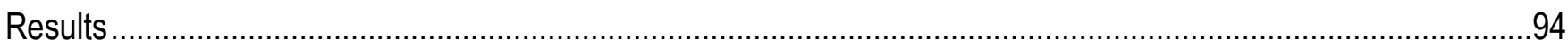

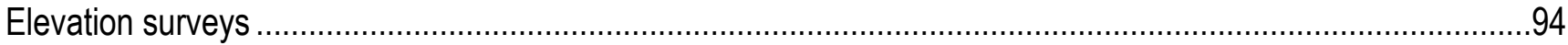

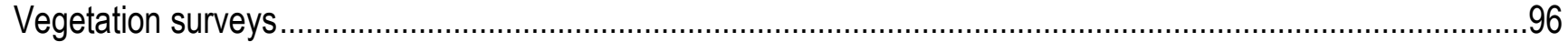

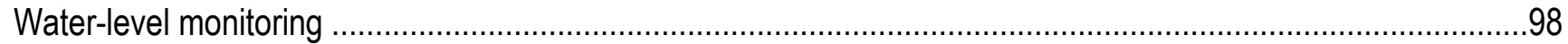

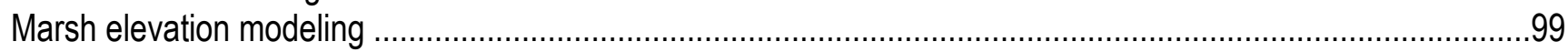

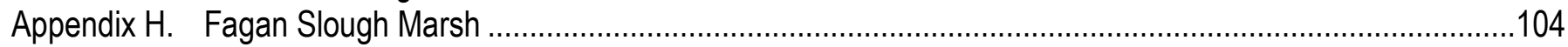

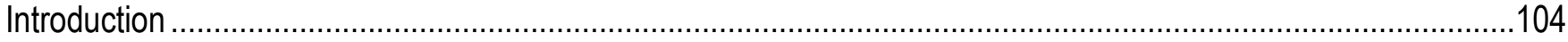

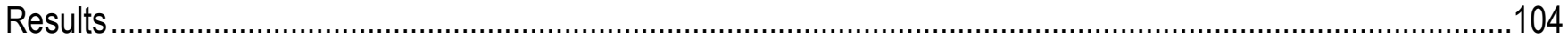

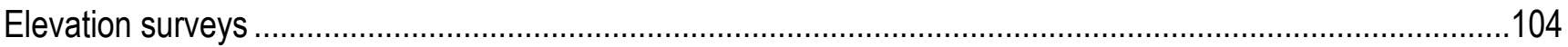

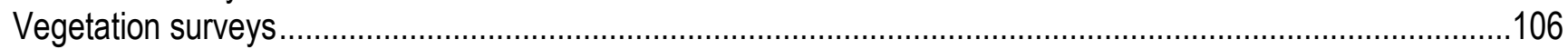

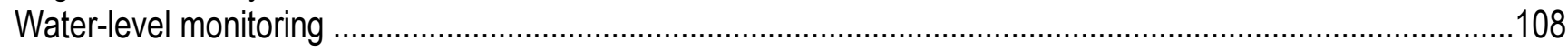

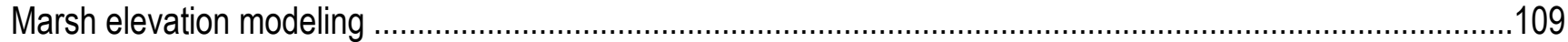

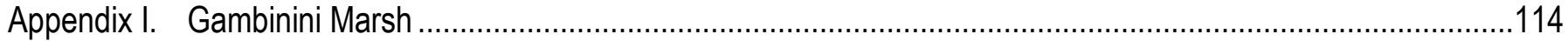

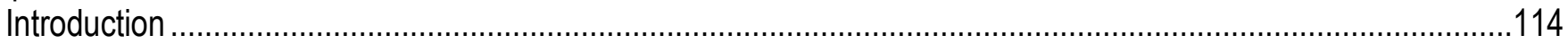

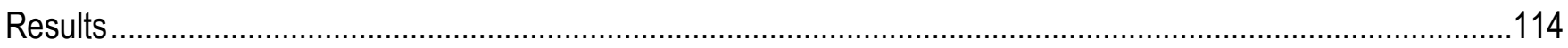

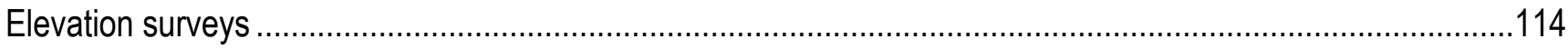

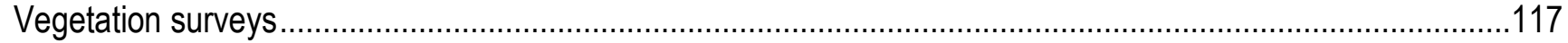

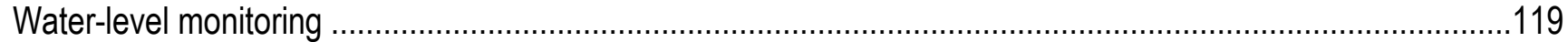

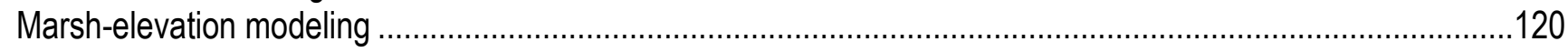

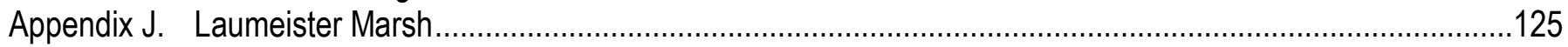

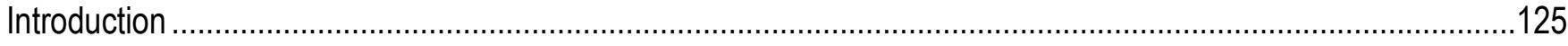

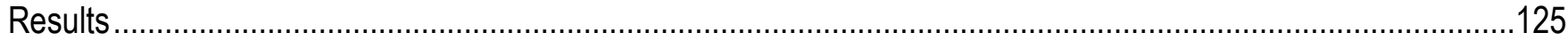

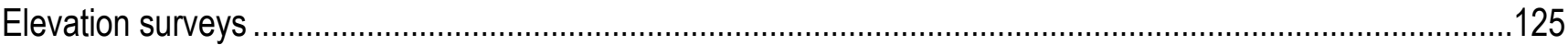

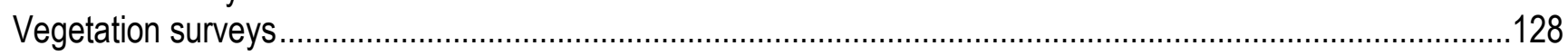

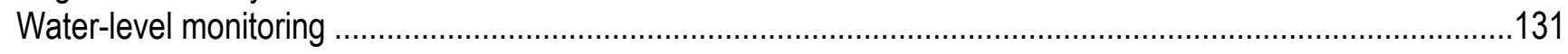

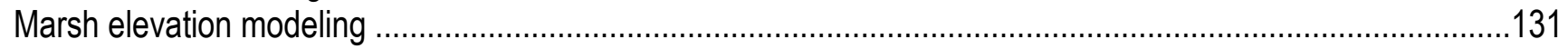




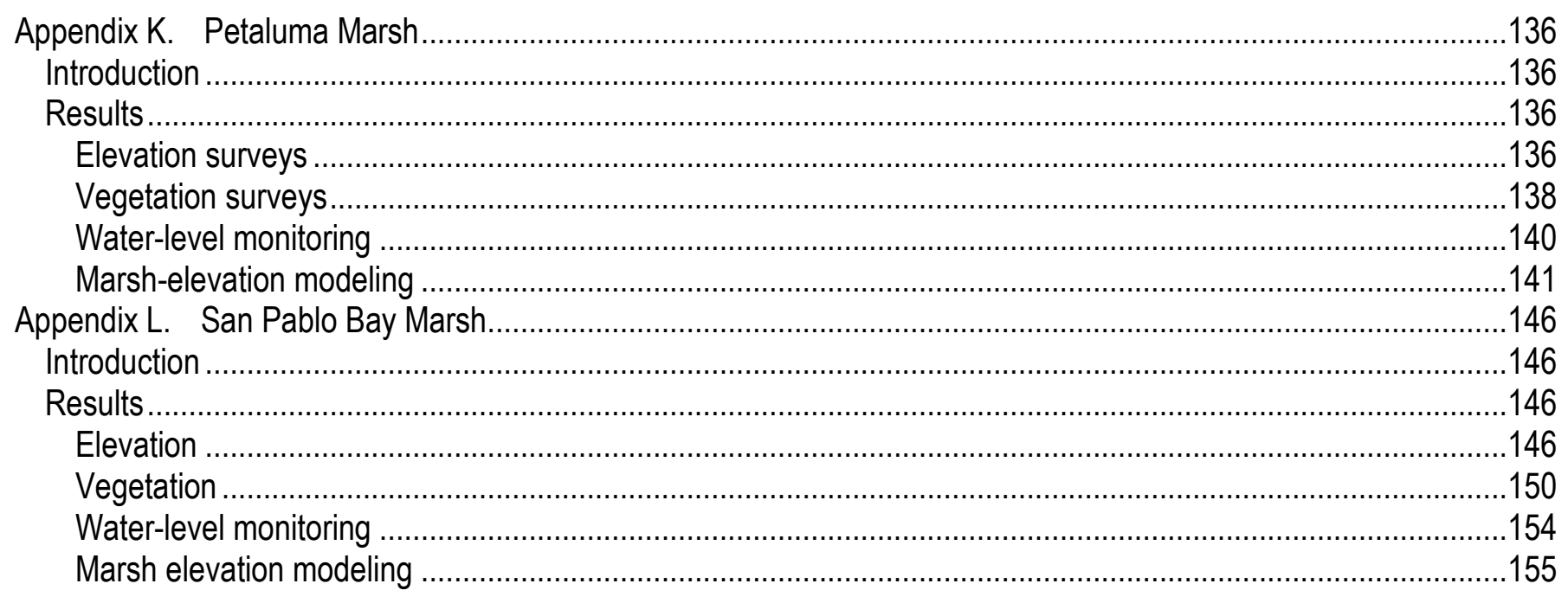




\section{LIST OF FIGURES}

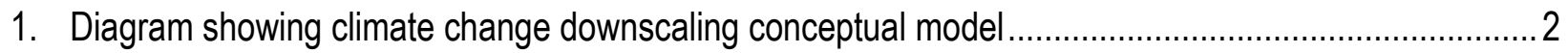

2. Diagram showing program conceptual model ....................................................................... 3

3. Map showing San Francisco Bay estuary marsh study sites.........................................................

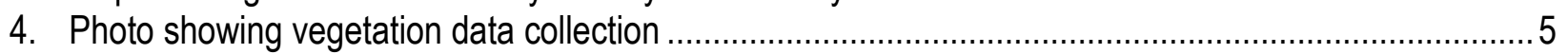

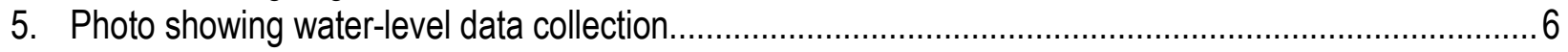

6. Diagram showing WARMER conceptual model..........................................................................

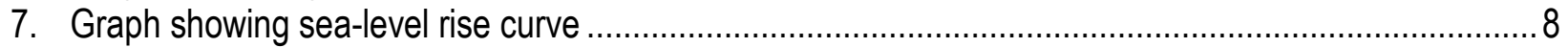

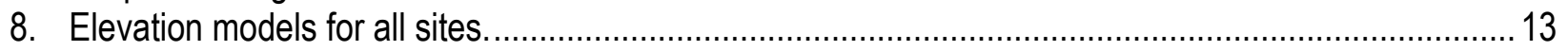

9. Graph showing distribution of marsh elevation relative to mean high water for all sites........................ 14

10. Graph showing marsh elevation relative to mean high water by site............................................... 15

11. Graph showing dominant vegetation species composition in relation to elevation across study sites... 16

12. Graph showing salinity during 2010 at a subset of study sites ....................................................... 19

13. Graph showing calculated sediment accumulation for representative sites ......................................2 21

14. Graph showing calculated organic matter accumulation for representative sites .................................22

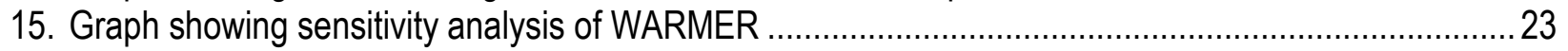

\section{LIST OF TABLES}

1. Summary of the amount of elevation and vegetation data collected for each site................................11

2. ArcGIS elevation model root-mean-square error (RMS) and standard error (SE) by site...................... 12

3. Plant communities were categorized on the basis of observed elevation distributions to develop marsh zones to model with sea-level rise................................................................... 16

4. Summary of the most common plant species found across all sites. ...............................................17

5. Water elevations (NAVD88), in meters (m), for each marsh site in 2010 ........................................ 18

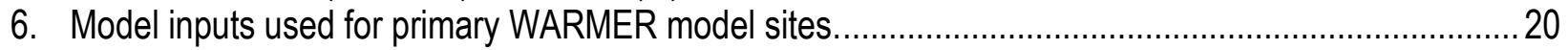

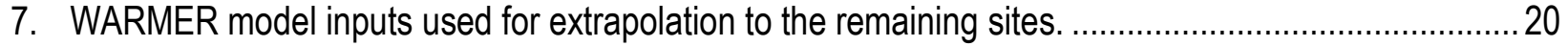




\section{Executive Summary}

- San Francisco Bay estuary contains the largest remaining expanse of tidal salt marsh on the Pacific coast of the United States. We collected baseline elevation, tidal inundation, and vegetation data at 12 marsh sites to examine potential effects of climate change. We used Real-Time Kinematic Global Positioning System (RTK GPS; measured \pm 2 centimeter vertical accuracy) to survey elevation. Vegetation was surveyed within 0.25 square meter quadrats for species composition, percent cover, and height. We established water-level monitoring stations at all sites to capture local annual variation in tidal inundation and to relate elevations to site-specific tidal datums.

- Study sites included San Pablo Bay National Wildlife Refuge, China Camp State Park, Corte Madera Ecological Reserve, Fagan Ecological Reserve, Cogswell Marsh, Arrowhead Marsh, Colma Creek Marsh, Laumeister Marsh, Coon Island Marsh, Black John Marsh, Petaluma Marsh, and Gambinini Marsh. Across all sites, 19.94 square kilometers of marsh was surveyed, which is roughly 12 percent of the remaining tidal marshes in the San Francisco Bay estuary.

- Ground-elevation data were interpolated in ArcGIS 9.3 (kriging method) into continuous $3 \times 3$ meter grid cell raster. Mean root-mean-square error for all interpolations was less than 0.10 meters.

- Sediment cores collected along elevation transects at four representative sites (China Camp, Coon Island, Petaluma, and Laumeister) were used to determine historic accretion rates with horizon marker dating techniques $\left({ }^{210} \mathrm{~Pb},{ }^{137} \mathrm{Cs}\right.$; Callaway and others, 2012). Percentage organic matter, porosity, compaction, and decomposition were incorporated with accretion rates, elevation, and tidal range data as inputs into a Wetland Accretion Response Model for Ecosystem Resilience (WARMER). Results at the representative sites were extrapolated to the remaining eight sites.

- Across all sites, 7,437 elevation points were surveyed, and 88 percent of the data were between 1.5 and 2.1 meters (North American Vertical Datum of 1988). Sites were located at different elevations within the San Francisco Bay tidal range. Sites ordered by decreasing mean elevation were Fagan (highest mean elevation), Laumeister, Gambinini, Coon Island, Petaluma, San Pablo, Black John, China Camp, Cogswell, Arrowhead, and Colma (lowest mean elevation).

- A total of 3,302 vegetation plots were surveyed across all sites. Low plant species richness was recorded, with 21 plant species identified within plots across all sites. The plant community composition also reflected variation in tidal inundation and water salinity. For example, the highest species diversity was found in marshes along the Napa River, presumably as a result of lower water salinity levels.

- Pickleweed (Sarcocornia pacifica) was the most common species recorded and was found in 91 percent of the plots, followed by Schoenoplectus spp. (12 percent), Distichlis spicata (9 percent), Spartina spp. (9 percent), Jaumea carnosa (7 percent), Grindelia stricta (7 percent), and Frankenia salina (4 percent).

- Plant communities were categorized on the basis of observed elevation relative to local tidal datum to develop marsh zones for sea-level rise response model interpretation. Upland transition (greater than 1.0 meter relative to mean sea level) was characterized by coyote bush (Baccharis pilularis). 
High marsh (0.7-1.0 m MSL) was characterized by Frankenia salina and Jaumea carnosa, whereas mid marsh (0.45-0.7 m MSL) was dominated by Sarcocornia pacifica. Low marsh (0.2$0.45 \mathrm{~m} \mathrm{MSL}$ ) was characterized by Spartina spp. or, in brackish areas, by Schoenoplectus spp. Mudflat habitat (less than $0.2 \mathrm{~m} \mathrm{MSL}$ ) was unvegetated or sparsely covered with Spartina spp.

- Results from the WARMER modeling showed that 96 percent (1,942 hectares) of the study area, or nine of the sites, would become mudflats by 2100 with a 1.24 meter sea-level rise. The three sites with the remaining 4 percent ( $85 \mathrm{ha}$ ) of the study area were projected to be low-marsh habitat dominated by Spartina spp. by 2100 . All upland transition, high-, and mid-marsh habitats were projected to be lost by 2100 .

- Accretion rates used in the WARMER model were relatively high in south San Francisco Bay (Callaway and others, 2012), and those marshes withstood sea-level rise longer, with areas transitioning from high to low marsh vegetation by 2100 (for example, Cogswell, Laumeister, and Colma).

- Napa River sites were parameterized with higher sediment accretion rates and higher starting elevations with WARMER and showed the maintenance of high marsh until 2030 (0.24 meter sealevel rise) for Coon Island and 2040 ( 0.32 meter sea-level rise) for Fagan marsh. Between 2040 ( 0.32 meter sea-level rise) and 2060 (0.57 meter sea-level rise), mid-marsh vegetation was maintained. Low marsh was dominate to 2090 (1.05 meter sea-level rise), at which time both marshes transitioned to mudflats.

- All other marsh sites had relatively low accretion rates relative to sea-level rise. WARMER projected all of these marshes to transition to mudflat by 2100. Corte Madera, China Camp, and San Pablo Bay National Wildlife Refuge marshes lost all high marsh by 2030 (0.24 meter sea-level rise), briefly transitioned to mid- and low-marsh plant communities, but ultimately transitioned to areas dominated by mudflat by 2080 ( 0.85 meter sea-level rise). The three marshes located on the Petaluma River (Gambinini, Petaluma, and Black John) lost most high-marsh habitat by 2030 (0.24 meter sea-level rise) and transitioned to mostly mudflat by 2080 (0.85 meter sea-level rise).

- Projected loss of pickleweed (Sarcocornia pacifica) habitats by 2100 could affect many tidal marsh wildlife species, such as the federally endangered salt marsh harvest mouse (Reithrodontomys raviventris) and state threatened California black rail (Laterallus jamaicensis coturniculus). Only 4 percent of the marsh area was projected to support cordgrass (Spartina spp.) habitats by 2100, which also would affect distribution of the federally endangered California clapper rail (Rallus longirostris obsoletus).

- The modification of the San Francisco Bay estuary makes it especially susceptible to sea-level rise since there are few areas available for upslope marsh transgression. Seven of the marsh sites we surveyed had adjacent open space, but five marshes were surrounded by urban infrastructure prohibiting upslope movement. 
This page intentionally left blank. 


\section{Abstract}

The International Panel on Climate Change has identified coastal ecosystems as areas that will be disproportionally affected by climate change. Current sea-level rise projections range widely with 0.57 to 1.9 meters increase in mea sea level by 2100 . The expected accelerated rate of sea-level rise through the $21^{\text {st }}$ century will put many coastal ecosystems at risk, especially those in topographically low-gradient areas.

We assessed marsh accretion and plant community state changes through 2100 at 12 tidal salt marshes around San Francisco Bay estuary with a sea-level rise response model. Detailed ground elevation, vegetation, and water level data were collected at all sites between 2008 and 2011 and used as model inputs. Sediment cores (taken by Callaway and others, 2012) at four sites around San Francisco Bay estuary were used to estimate accretion rates. A modification of the Callaway and others (1996) model, the Wetland Accretion Rate Model for Ecosystem Resilience (WARMER), was utilized to run sea-level rise response models for all sites. With a mean sea level rise of $1.24 \mathrm{~m}$ by 2100 , WARMER projected that the vast majority, 95.8 percent (1,942 hectares), of marsh area in our study will lose marsh plant communities by 2100 and to transition to a relative elevation range consistent with mudflat habitat. Three marshes were projected to maintain marsh vegetation to 2100 , but they only composed 4.2 percent ( 85 hectares) of the total marsh area surveyed.

\section{Introduction}

Climate change effects for coastal ecosystems include projected changes in mean and extreme ambient temperatures, precipitation patterns, ocean temperature and acidity, extreme storm events, and sea-level rise (Cayan and others, 2005; Hansen and others, 2006; International Panel on Climate Change, 2007). Projections of mean sea-level rise (SLR) to the year 2100 are characterized by high uncertainty because of the difficulty in modeling melting ice-sheet dynamics and other ocean processes. Global sea level has risen 1.8 millimeters per year (mm/year) between 1961 and 1993 and $3.1 \mathrm{~mm} /$ year between 1993 and 2007 (International Panel on Climate Change, 2007). While earlier SLR projections ranged from 0.19 to 0.58 meters (m) by 2100 (International Panel on Climate Change, 2007), more recent projections have ranged from 0.6 to $1.6 \mathrm{~m}$ (Jevrejeva and others, 2010) and 0.9 to $1.3 \mathrm{~m}$ (Grinsted and others, 2010). Vermeer and Rahmstorf (2009) projected SLR up to $1.9 \mathrm{~m}$ by 2100 , contingent upon carbon dioxide $\left(\mathrm{CO}_{2}\right)$ emissions and ambient temperature conditions. Local rates of observed SLR in San Francisco Bay estuary (SFBE) have been 2.2 centimeters $(\mathrm{cm})$ per decade for a total of 19.3 $\mathrm{cm}$ between 1900 and 2000 (Cayan and others, 2006). SFBE projected SLR is as much as $1.24 \mathrm{~m}$ by 2100, depending on $\mathrm{CO}_{2}$ emissions (Cayan and others, 2008).

Although global in distribution, the extent of tidal salt marshes is limited to the lowenergy intertidal zones of temperate estuaries, with 16,000 square kilometers $\left(\mathrm{km}^{2}\right)$ found in North America (Greenberg and others, 2006). Marshes are dominated by plant communities that have varying tolerance to tidal inundation and salinity, resulting in zonation along the elevation gradient (Mancera and others, 2005). These low-lying areas are particularly vulnerable where variation in tidal depth and duration plays a major role in structuring these plant communities (Brittain and Craft, 2012). Marshes will be affected by climate change through accelerating SLR (Holgate and Woodworth, 2004; Kemp and others, 2011), shifting precipitation patterns (Hamlet and Lettenmaier, 2007; Bengtsson and others, 2009), erosion (Leatherman and others, 2000), and 
changing frequency and intensity of storms (Emanuel, 2005; Webster and others, 2005; International Panel on Climate Change, 2007). Marshes can keep pace with changes in local sea level through accretion processes that include sediment deposition and organic matter accumulation (Morris and others, 2002; Geden and others, 2011) if suspended-sediment concentrations and organic production are high enough (Kirwan and Gutenspergen, 2010). However, marshes can be lost if SLR outpaces vertical accretion processes (Morris and others, 2002; Callaway, 2007).

We evaluated SLR effects for tidal salt marshes with a site-specific, bottom-up approach. We included plant community state changes that can help identify effects on resident wildlife species. The scope of our quantitative assessments of SLR effects on wildlife in tidal marshes was developed at an ecologically relevant parcel scale, which will help local management strategies and climate change adaptation plans (fig. 1). The coupling of a bottom-up approach that includes modeling of marsh physical process and plant communities with top-down SLR models allowed the assessment of marsh plant community state changes through 2100 (fig. 2). The objectives of the study were to (1) establish baseline conditions for all marsh sites, (2) develop a simulation model for tidal marshes, (3) synthesize results into site-specific parcel-scale plant community state change models, and (4) compare SLR vulnerability across the range of study sites.

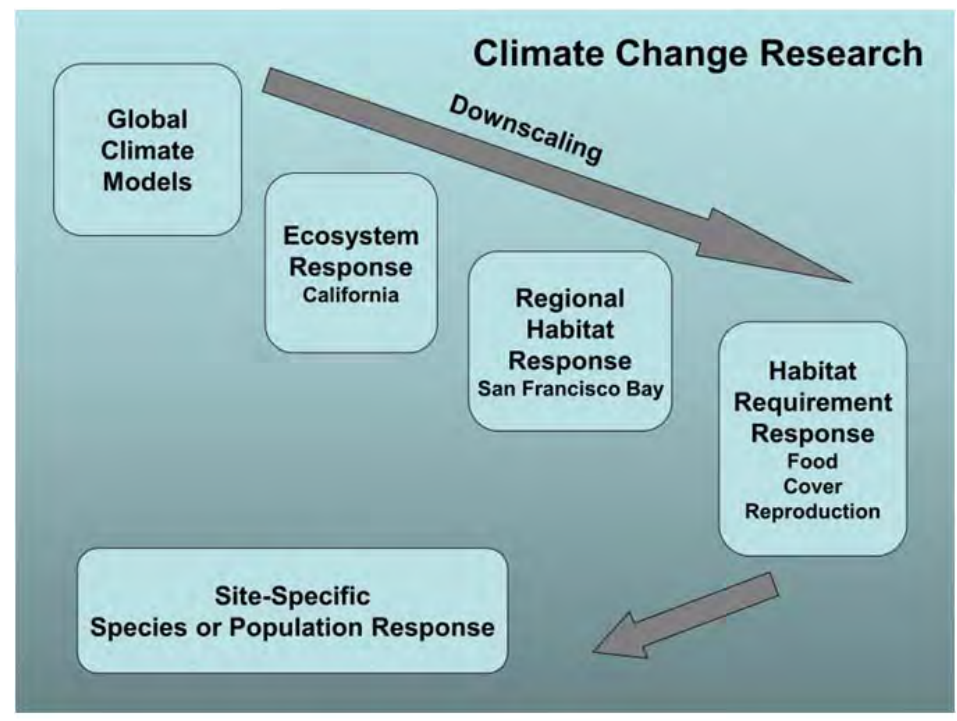

Figure 1. Climate change research requires the downscaling of global climate models to site-specific habitats and wildlife species. 


\section{Study Area}

The San Francisco Bay estuary (SFBE; California, USA) has been heavily affected by human development, which has resulted in the loss of 80 percent of the historic tidal salt marshes, greatly affecting the local marsh wildlife (Goals Project, 1999). Eleven wildlife species of concern are named in the multispecies tidal salt marsh recovery plan for northern and central California (USFWS, 2009), and the SFBE is the single largest habitat block remaining (Takekawa and others, 2006). The SFBE marshes support a variety of habitats for federal and state protected endemic species, such as the California clapper rail (Rallus longirostris obsoletus), the California black rail (Laterallus jamaicensis coturniulus), and

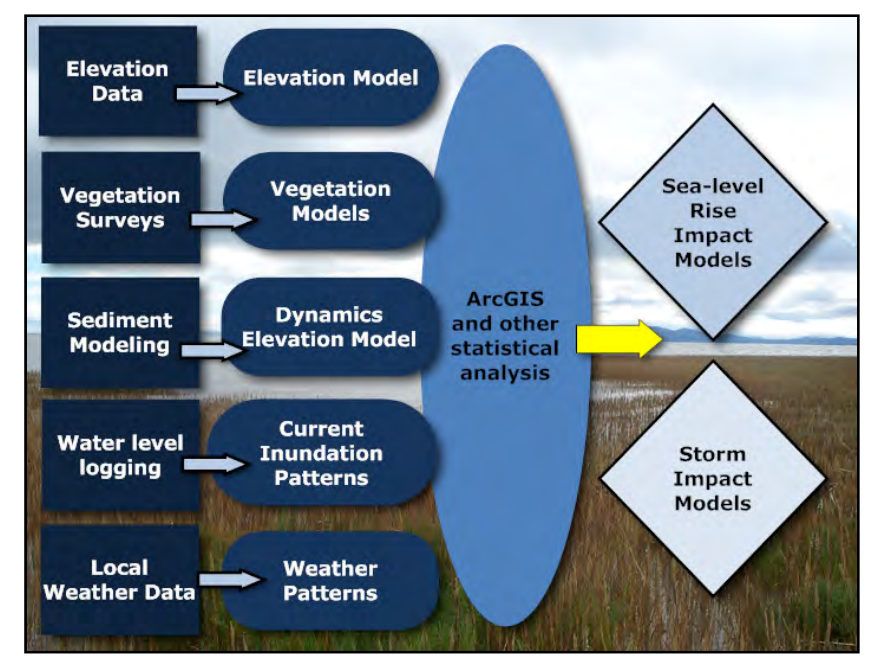

Figure 2. USGS climate change research program conceptual model for a bottom-up local level approach.

the salt marsh harvest mouse (Reithrodontomys raviventris) (Spautz and others, 2006; Tsao and others, 2009; Takekawa and others, 2011). The estuary is located on the Pacific Flyway and is a Western Hemisphere Shorebird Reserve Network site of hemispheric importance used by migrating and wintering birds (Accurso, 1992). Bird species such as sparrows (Alameda Song Sparrow Melospiza melodia pusillula, Suisun Song Sparrow M. m. maxillaris, and San Pablo Song Sparrow M. m. samuelis) and Salt Marsh Common Yellowthroat (Geothlypis trichas sinuosa) are found here.

Twelve marsh sites covering $19.94 \mathrm{~km}^{2}$ (about 12 percent of the remaining marsh in the SFBE) were sampled and modeled for SLR response (fig. 3). Four sites were located in the southern portion of SFBE (Arrowhead, Cogswell, Laumeister, and Colma), and three sites were located within San Pablo Bay (Corte Madera, China Camp, and San Pablo). Two marshes were sampled along the Napa River (Fagan and Coon Island), and three sites along the Petaluma River (Black John, Petaluma, and Gambinini). Marsh sites varied in age, position within the tidal range, and adjacent land-cover type and comprised a wide variety of land owners, including federal and state agencies, as well as NGOs and private landowners. 


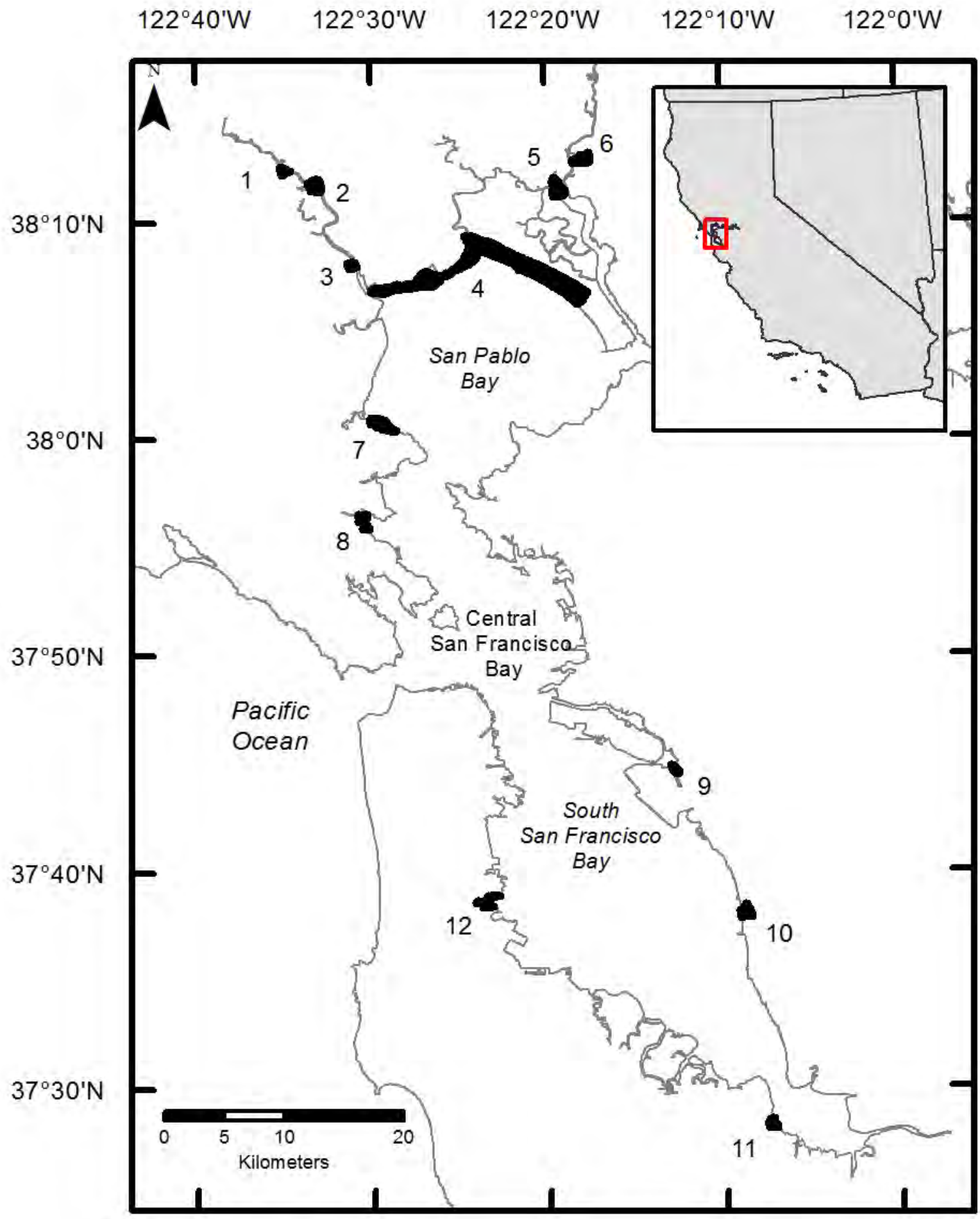

Figure 3. Location of San Francisco Bay estuary marsh study sites: $1=$ Gambinini; $2=$. Petaluma; $3=$ Black John; 4 = San Pablo Bay National Wildlife Refuge; 5 = Coon Island; 6 = Fagan; 7 = China Camp State Park; 8 = Corte Madera; 9 = Arrowhead; 10 = Cogswell; 11 = Laumeister; 12 = Colma. 


\section{Methods}

\section{Elevation surveys}

We completed survey-grade elevation surveys at marshes throughout the SFBE between 2008 and 2010 by using a Leica RX1200 Real Time Kinematic (RTK) Global Positioning System (GPS) rover ( $\pm 1 \mathrm{~cm} \mathrm{x}, \mathrm{y}, \pm 2 \mathrm{~cm}$ z accuracy; Leica Geosystems Inc., Norcross, Georgia; fig. 4). The rover positions were received in real time from the Leica Smartnet system by using a Code Division Multiple Access (CDMA) modem (www.lecia-geosystems.com). We used the WGS84 ellipsoid model for vertical and horizontal positioning. Positions were referenced to a National Geodetic Survey (NGS) benchmark (X 5521956 Mare Island). The average measured vertical error for the benchmark during the study was $\pm 2.5 \mathrm{~cm}$, similar to the stated error of the RTK GPS. Elevation was surveyed along transects perpendicular to the major sediment source (San Francisco Bay, Napa River, Petaluma River), with a survey point taken every $25 \mathrm{~m} ; 50 \mathrm{~m}$ separated transect lines. The Geoid03 model was used in calculating elevations from orthometric heights (North American Vertical Datum of 1988, NAVD88), and all points were projected to North American Datum of 1983 (NAD83) Universal Transvers Mercator (UTM) zone 10 by using Leica GeoOffice (Leica Geosystems Inc, Norcross, Georgia, v 7.0.1). Orthometric heights were calculated on the basis of NAVD88 and the NGS Geiod03 Model.

\section{Elevation modeling}

We synthesized the survey data to create an elevation raster in ArcGIS 9.3 Spatial Analyst (ESRI 2009, Redlands, Calif.) with kriging methods ( 3 x 3 m cell size). We used the exponential model for ordinary kriging and adjusted model parameters to minimize the rootmean-square error (RMS), an internal measure of model performance. Lag size and number of lags were optimized for the site (lag size times lag number less than half the maximum distance among points, ESRI); an anisotropy adjustment was applied because of a trend in the elevation data. Resultant models were externally cross-validated by comparing models created with 70 percent of the data with the remaining 30 percent of the points. We then used the elevation models as the basis for subsequent analysis, such as tidal inundation patterns, WARMER modeling, and vegetation correlations. The mean and range of elevation was calculated by randomly sampling locations from the interpolated model at a density of 3 per hectare (ha) to produce an unbiased sample for each site. We tested for unequal variance in marsh elevations grouped by site using Levene's homogeneity variance test. A significant result indicted the need for non-parametric analysis, thus we used the Kruskal-Wallis test for significant differences.

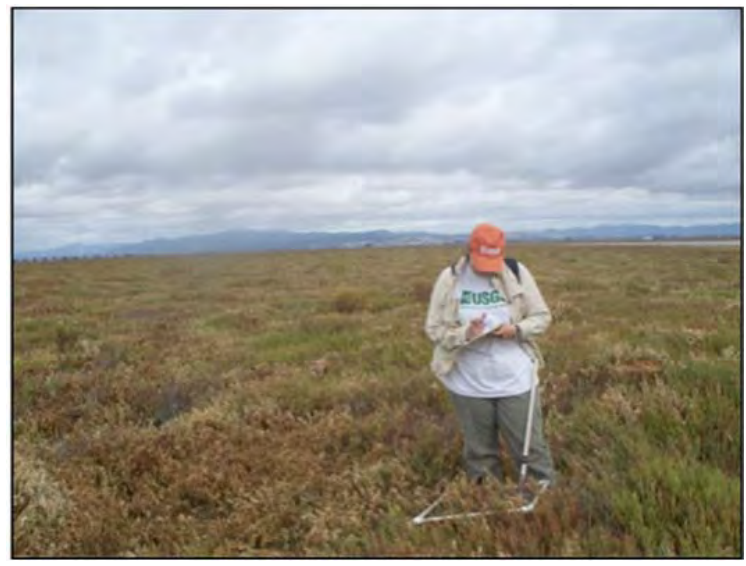

Figure 4. Vegetation and elevation data were collected concurrently. [Photo by K. Spragens]

\section{Vegetation surveys}

We recorded plant species diversity and elevation concurrently at 50 percent of the elevation points within a 0.25 square meter $\left(\mathrm{m}^{2}\right)$ quadrat (fig. 4 ). We measured height (mean, 
maximum, measured within $0.05 \mathrm{~m}$ ) and estimated percentage cover for each species. We combined all recorded Spartina spp. in analysis because of the difficulty in distinguishing native, hybrid, and non-native species. We categorized plant species into low, mid, high-marsh, and upland transition by measured elevation relative to mean sea level (MSL, in meters), which changed relative to elevation with SLR. We used the vegetation and elevation relationships to predict transitions or state changes of wildlife habitats to assess vulnerability and better understand outcomes for habitat persistence to 2100 .

\section{Water-level monitoring}

We deployed water-level data loggers (Model 3001, 0.01 percent FS resolution, Solinst Canada Ltd., Georgetown, Ontario) at all sites during the study period (fig. 5). Each site had one to four loggers ( $\mathrm{n}=$ 28) depending on its size. Loggers were placed at the mouth and upper reaches of second-order channels (tidal creeks) to capture the local tidal cycle and inundation patterns. We collected continuous data every six minutes throughout 2009 and 2010 to develop local hydrographs and inundation rates. In addition, water conductivity was collected at a subset of sites; however, these data have not been analyzed. Loggers were surveyed with the RTK GPS at the time of deployment and at each data download to correct for any movement. Water levels were corrected for local barometric pressure with data from independent barometric loggers (Model 3001, 0.05 percent FS accuracy, Solinst Canada Ltd., Georgetown, Ontario).

The local water level data were used to develop elevation and tidal datum relationships for all sites. Water-level peaks from 2010 were averaged to create

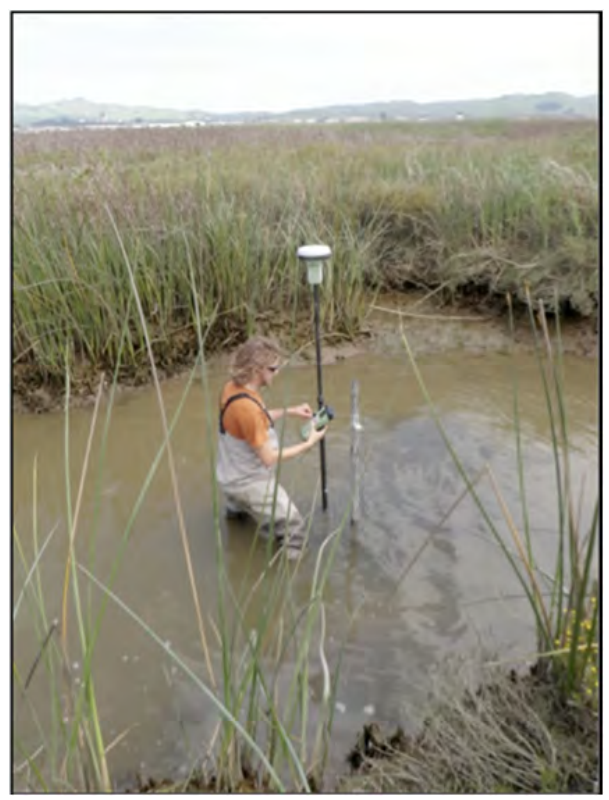

Figure 5. Water-level data were collected at all sites throughout the study period. [Photo by $\mathrm{H}$. Robinson] mean high water (MHW) and mean higher high water (MHHW) datums relative to NAVD88 for each site. The development of local mean sea level (MSL) and mean low water (MLW) tidal datums was not possible because of the relatively high elevation of the water loggers in the marsh channels; therefore, MSL was determined by using VDatum v 2.3.0 (http://vdatum.noaa.gov). All results are reported relative to local MHW calculated from local water data. For SFBE, MHW and MHHW are the most important metrics for understanding marsh plant communities and wildlife habitats. 


\section{The Wetland Accretion Rate Model for Ecosystem Resilience (WARMER)}

We developed the model WARMER, a one-dimensional cohort model of wetland accretion based on Callaway and others (1996), to examine SLR projections for SFBE marshes. WARMER calculated elevation changes relative to MSL on the basis of projected changes in relative sea-level, subsidence, inorganic sediment accumulation, aboveground and belowground organic matter productivity, compaction, and decay (fig. 6) for a representative marsh area. Each modeled cohort provided the mass of inorganic and organic matter accumulated at the surface in a single year plus any subsequent belowground organic matter productivity (root growth) minus decay. Cohort density, a function of mineral, organic, and water content, was calculated at each time step to account for decay of organic material and autocompaction of the soil column. The change in relative

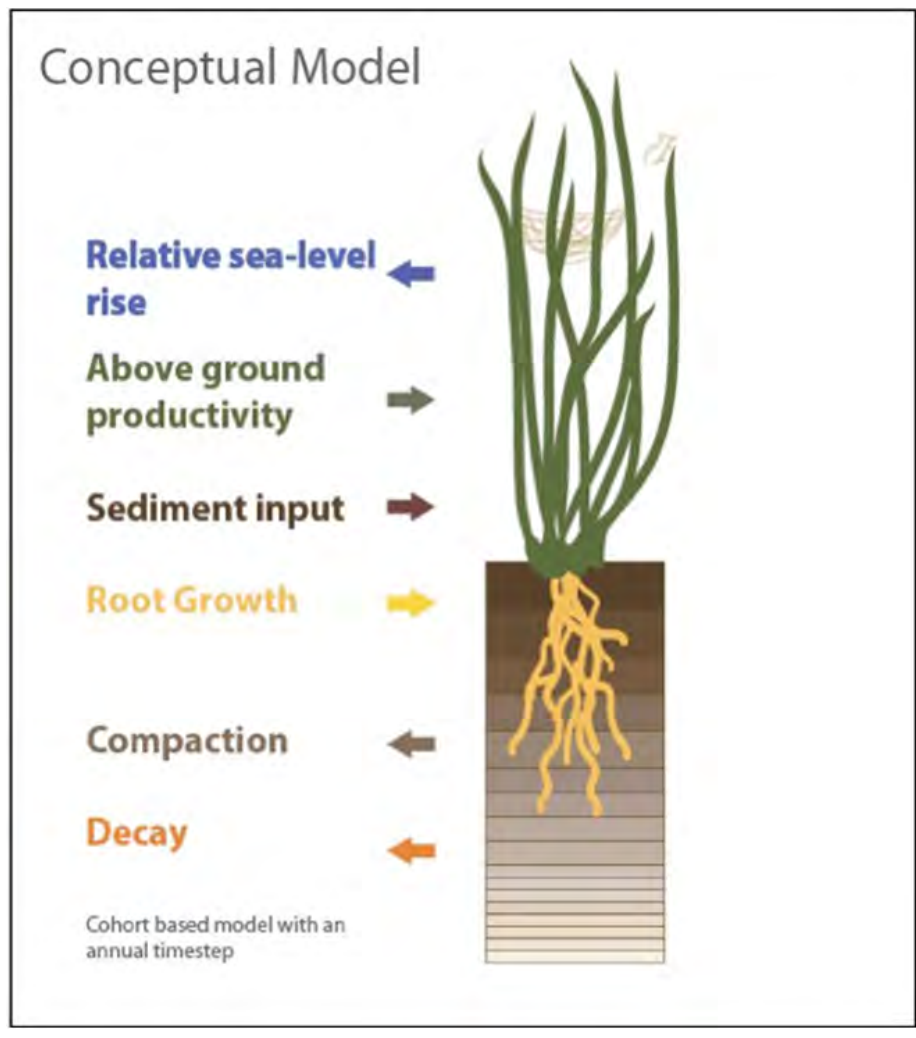

Figure 6. WARMER 1-D conceptual model. elevation was then calculated as the difference between the change in modeled sea level and the change in height of the soil column, which was estimated as the sum of the volume of all cohorts over the unit area model domain.

WARMER expanded upon the Callaway and others (1996) model by including (1) feedback between organic matter accumulation and elevation, (2) development of a non-linear relationship between inorganic matter accumulation and elevation, and (3) incorporation of a temporally variable SLR. The elevation of the marsh surface, $\mathrm{E}$, at time, $\mathrm{t}$, relative to local MSL was estimated as follows:

$$
E(t)=E(0)-S L R(t)+\sum_{i=0}^{t} V_{i}(t)
$$

where

$\mathbf{E ( 0 )}$ is the initial elevation relative to MSL;

SLR(t) is the sea-level at time, $\mathbf{t}$, relative to the initial sea level; and

$\mathbf{V}_{\mathbf{i}}(\mathbf{t}) \quad$ is the volume per unit area, or height, at time $\mathbf{t}$, of the cohort formed during year, $\mathbf{i}$.

The total volume of an individual cohort was estimated as the sum of the mass of water, calculated from the porosity of the cohort, sediment, and organic matter divided by the cohort bulk density. 
We developed WARMER models from the elevation, vegetation, and water-level data collected at each site (see Methods). For this study, accretion rates for four marshes (Coon Island, a portion of Petaluma Marsh, China Camp Marsh, and Whale's Tail Marsh) were determined from ${ }^{210} \mathrm{~Pb}$ and ${ }^{137} \mathrm{Cs}$ dating of sediment cores (Callaway and others, 2012). Accretion data from the most comparable of these four sites were used to calibrate the accumulation and sediment properties at the remaining sites for WARMER modeling (see appendix). All results are presented as elevation relative to MHW.

\section{Sea-level rise scenario model inputs}

In WARMER, we incorporated a recent forecast for San Francisco Bay SLR (Cayan and others, 2009) based on a moderate emissions scenario (A2 in International Panel on Climate Change Fourth Assessment Report, Bindoff and others, 2007), which forecasts $1.24 \mathrm{~m}$ of SLR by 2100 (fig. 7). The average annual SLR curve was used as the input function for the WARMER model. We assumed that the tide range remains constant through time, and only MSL changes annually.

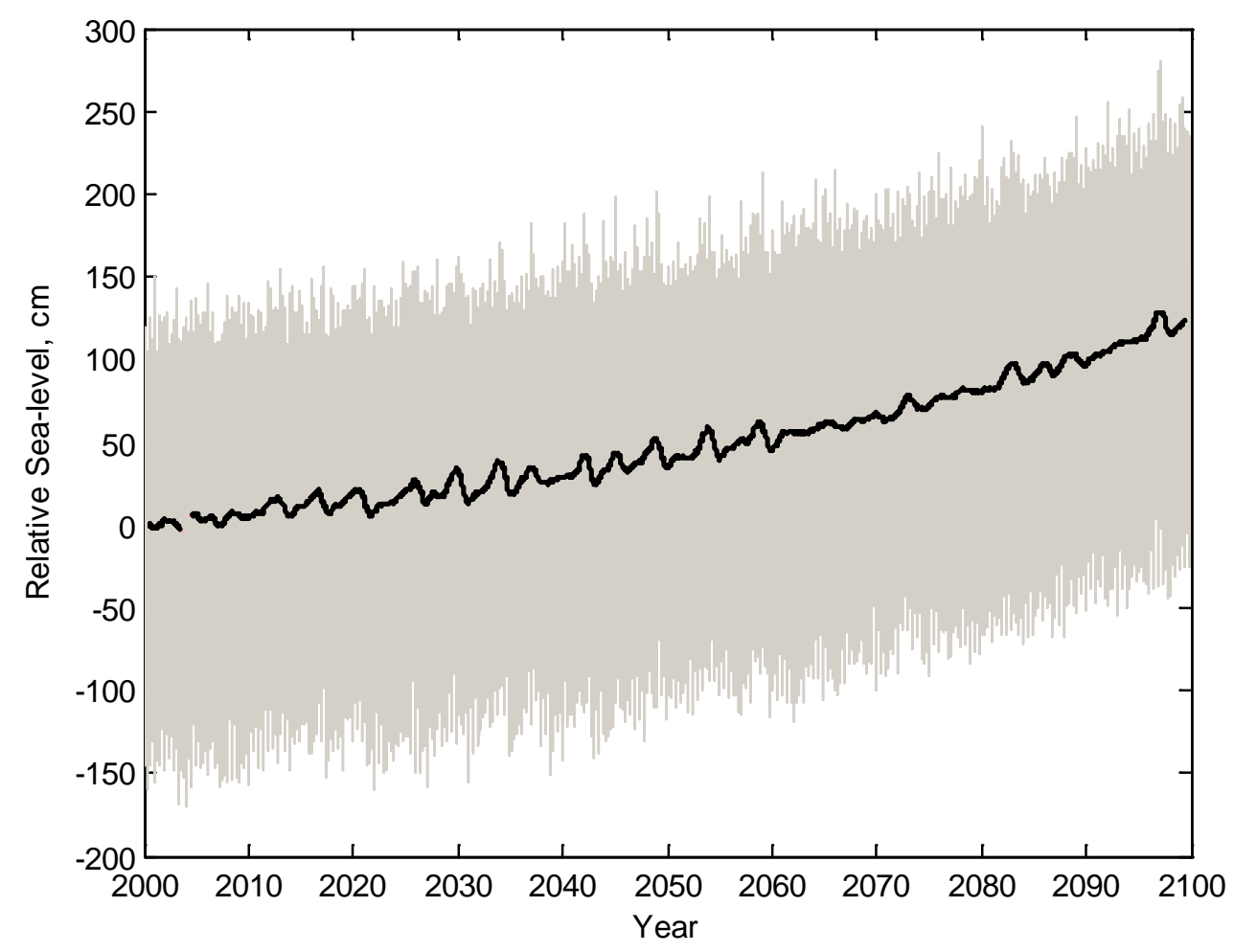

Figure 7. Hourly water-level prediction from Cayan and others (2009) with a 1-year running mean of hourly data. 


\section{Inorganic matter model inputs}

Sediment flux from the water column to the marsh surface at a given elevation, $\mathrm{z}$, was estimated as the product of suspended-solids concentration, SSC, and settling velocity summed over all times during which elevation $\mathrm{z}$ was inundated. For the case of constant SSC and settling velocity, the mass accumulation was directly proportional to the inundation frequency and calibrated without any direct measurement of concentration or settling velocity. Thus, sediment flux at a given elevation, $\boldsymbol{z}$, measured in mass per unit area per year, $\boldsymbol{M}_{\boldsymbol{s}}(\boldsymbol{z})$, was calculated as follows:

$$
M_{S}(z)=S S C * w_{S} * f(z)
$$

where

$f(z) \quad$ is the inundation frequency as a function of elevation, and $\boldsymbol{S S C} * \boldsymbol{w}_{\mathrm{S}}$ is the maximum potential sediment flux determined by calibration to sediment accumulation data.

To calibrate the sediment input function, sediment accumulation rates were determined by using the Constant Rate of Supply (CRS) method for ${ }^{210} \mathrm{~Pb}$ from sediment cores from each of the four reference marshes (Robbins, 1978; Callaway and others, 2012). If the CRS method could not be applied because the sediment core did not capture the complete excess ${ }^{210} \mathrm{~Pb}$ profile, the sediment accumulation rate was determined by using the 1963 peak ${ }^{137} \mathrm{Cs}$ horizon identified in the soil column.

\section{Organic matter model inputs}

The base organic input function developed by Morris and others (2002) was used in WARMER. However, Morris and others (2002) used Spartina alterniflora as the basis of the functional relationship, although most SFBE marshes are dominated by native Sarcocornia pacifica (pickleweed). S. alterniflora and its hybrids have invaded parts of the estuary, but they are the target of an intensive control program; therefore, the Morris and others (2002) function was adapted for the vegetation in the SFBE. The shape of the curve that Morris and others (2002) developed for $S$. alterniflora marshes was retained, but the elevation range of the vegetation, the roots of the parabolic equation, and the magnitude of organic matter input were adjusted for SFBE marsh vegetation, primarily represented by $S$. pacifica. This was accomplished by fixing the roots of the parabolic function at MSL and maximum astronomical tide (MAT) for each site and then calibrating the magnitude of the predicted organic matter accumulation to measured organic matter input rates from the sediment cores. The parabolic equation describing the annual mass of organic matter accumulated per unit area, $\boldsymbol{M}_{\boldsymbol{0}}$, was then as follows:

$$
M_{0}(z)=(a+b)(z-M S L)(z-M A T)
$$

In this equation, $\mathrm{a}$ and $\mathrm{b}$ are constants with units of $\frac{\boldsymbol{M}}{\left[\boldsymbol{L}^{\mathbf{4}} \boldsymbol{T}\right]}[\mathrm{M}$, mass, $\mathrm{L}$, length, $\mathrm{T}$, Time $]$ for above, and belowground production, respectively, fit to the measured organic matter accumulation rates in the surface layer of each sediment core for each marsh at specified elevations. The organic matter accumulation rate was determined from the sediment accumulation rate and the ratio of sediment to organic matter in the surface layer of each sediment core. Organic matter input was divided between above- and belowground input with a shoot to root ratio $(\mathrm{a} / \mathrm{b})$ of 0.57 based on 
the work of Scarton and others (2002) and Curcó and others (2002) on Sarcocornia spp. The mass of organic material generated belowground each year was distributed exponentially with depth, and the coefficient of exponential decay, kdist, was set equal to 1.0 (Deverel and others, 2008).

\section{Compaction and decomposition model inputs}

Compaction and decomposition functions of WARMER followed Callaway and others (1996). Compaction of highly porous marsh sediment was determined by the rate of decrease in porosity from the average measured porosity of the top $5 \mathrm{~cm}$ of each sediment core to a lower limit of porosity measured at the bottom $5 \mathrm{~cm}$ of each sediment core. The rate of decrease, $\boldsymbol{r}$, in porosity of a given cohort was estimated as a function of the density of all of the material above that cohort:

$$
r=1-\frac{p_{b}}{k_{1}-p_{b}}
$$

where

$\boldsymbol{p}_{\boldsymbol{b}}$ is the density of the material above a cohort, and

$\boldsymbol{k}_{\mathbf{1}}$ is a calibration constant.

Decomposition was modeled as a three-stage process where the youngest organic material, less than 1-year old, decomposed at the fastest rate; organic matter 1- to 2-years old decayed at a moderate rate; and organic matter greater than 2-years old decayed at the slowest rate. Decomposition also decreased exponentially with depth. The percentage of refractory organic material was determined from the organic content in the sediment cores. The constants used to parameterize the compaction and decomposition functions follow those used by Deverel and others (2008).

WARMER was run for 243 simulations with a range of values for sediment input, organic matter input, SLR, and initial marsh elevation in order to evaluate model sensitivity. The values were chosen to reflect the expected and extreme values of sediment and organic matter accumulation, porosity, SLR, and the initial measured or assumed marsh elevation for the SFBE (Callaway and others, 2012). Low and high estimates of the magnitude of sea-level rise over the next century (50 and $150 \mathrm{~cm}$; Cayan and others, 2009) were included in the modeling.

\section{Results}

\section{Elevation}

Low slope elevation gradients characteristic of marshes were observed at the SFBE sites (fig. 8). A total of 7,437 elevation points were measured from 2008 to 2010 (table 1). Overall, elevation fell within a small range, with 88 percent of surveyed points between 1.5 and $2.1 \mathrm{~m}$ (NAVD 88; fig. 9). Most of the marshes surveyed were located above MHW. Across all sites, mean elevation was $0.03 \mathrm{~m}(\mathrm{SD}=0.13)$ above $\mathrm{MHW}$. Mean elevation relative to $\mathrm{MHW}$ varied significantly across sites (Levene's homogeneity variance test, $\mathrm{p}<0.0001$; Kruskal-Wallis $\chi^{2}=$ 808.241, $\mathrm{df}=11, \mathrm{p}<0.0001$, comparisons shown in fig. 10). Marshes located along rivers (Gambinini, Petaluma, Black John, Coon Island, and Fagan) were at higher elevations than those located along the bay edge (fig. 10). Grouped by their location within the bay, marsh elevation 
(relative to MHW) was lowest in the south SFBE sites, higher in San Pablo Bay sites, even higher in Petaluma River sites, and highest in Napa River sites (ANOVA: $F_{3}=179.28$; $\mathrm{p}<$ 0.0001). The interpolated elevation models for all sites had a root-mean-square error (RMS) of $0.1 \mathrm{~m}$ (table 2).

Table 1. Summary of the amount of elevation and vegetation data collected for each site.

[SPB refers to San Pablo Bay, SSFB refers to south San Francisco Bay, and Petaluma and Napa refers to the rivers draining from the north into San Pablo Bay; ha, hectare, $m$, meter; $n$, sample number; -, not sampled]

\begin{tabular}{clccccc}
\hline Region & Site & $\begin{array}{c}\text { Area } \\
\text { (ha) }\end{array}$ & $\begin{array}{c}\text { Elevation } \\
(\mathbf{n})\end{array}$ & $\begin{array}{c}\text { Mean } \\
\text { Elevation }(\mathbf{m})\end{array}$ & $\begin{array}{c}\text { Elevation } \\
\text { Range }(\mathbf{m})\end{array}$ & $\begin{array}{c}\text { Vegetation } \\
(\mathbf{n})\end{array}$ \\
\hline Petaluma & Gambinini & 25 & 217 & 1.9 & 0.35 & 110 \\
Petaluma & Petaluma & 81 & 655 & 1.8 & 0.63 & 356 \\
Petaluma & Black John & 31 & 213 & 1.8 & 0.45 & 108 \\
SPB & San Pablo East & 963 & 434 & 1.9 & 0.72 & 271 \\
SPB & San Pablo West & 450 & 962 & 2.0 & 1.49 & 691 \\
Napa & Coon Island & 99 & 799 & 1.8 & 1.24 & 364 \\
Napa & Fagan & 68 & 609 & 1.9 & 0.61 & 308 \\
SPB & China Camp & 97 & 753 & 1.8 & 0.55 & 422 \\
SPB & Corte Madera & 77 & 744 & 1.6 & 0.59 & 361 \\
SSFB & Arrowhead & 17 & 274 & 1.6 & 0.37 & 50 \\
SSFB & Cogswell & 60 & 523 & 1.8 & 0.55 & 228 \\
SSFB & Laumeister & 37 & 717 & 2.1 & 0.47 & 72 \\
SSFB & Colma & 25 & 537 & 1.4 & 1.58 & - \\
\hline & Total & 2,027 & 7437 & 1.9 & 1.60 & 3,302 \\
\hline
\end{tabular}

Table 2. ArcGIS elevation model root-mean-square error (RMS) and standard error (SE) by site.

\begin{tabular}{lcc}
\hline Study Site & Model RMS & Model Mean SE \\
\hline Gambinini & 0.09 & 0.09 \\
Petaluma & 0.09 & 0.09 \\
Black John & 0.05 & 0.04 \\
San Pablo & 0.10 & 0.11 \\
East & & \\
San Pablo & 0.15 & 0.15 \\
West & 0.07 & 0.05 \\
Coon Island & 0.08 & 0.08 \\
Fagan & 0.09 & 0.09 \\
China Camp & 0.09 & 0.08 \\
Corte Madera & 0.06 \\
Arrowhead & 0.07 & 0.09 \\
Cogswell & 0.09 & 0.08 \\
Laumeister & 0.08 & 0.21 \\
\hline Colma & 0.21 & 0.09 \\
\hline Mean & 0.10 & \\
\hline
\end{tabular}




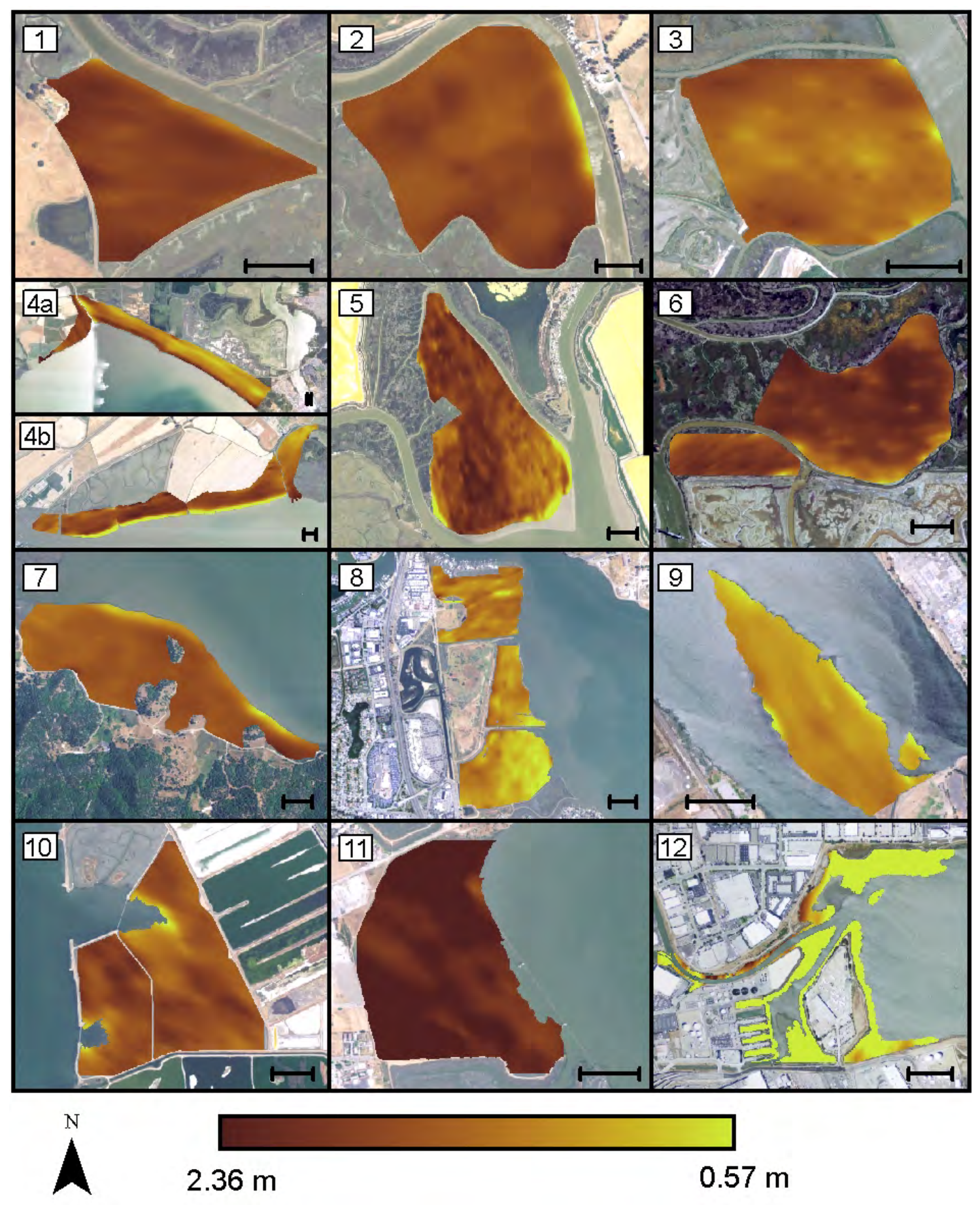

Figure 8. Elevation models for all marsh sites (NAVD88). Model parameters were optimized to reduce root-mean-square error. Scale bar $=200$ meters $(\mathrm{m}) .1=$ Gambinini, $2=$ Petaluma, $3=$ Black John, 4a = east San Pablo Bay NWR, $4 \mathrm{~b}=$ west San Pablo Bay NWR, 5 = Coon Island, $6=$ Fagan, 7 = China Camp State Park, $8=$ Corte Madera, $9=$ Arrowhead, $10=$ Cogswell, $11=$ Laumeister, $12=$ Colma. 


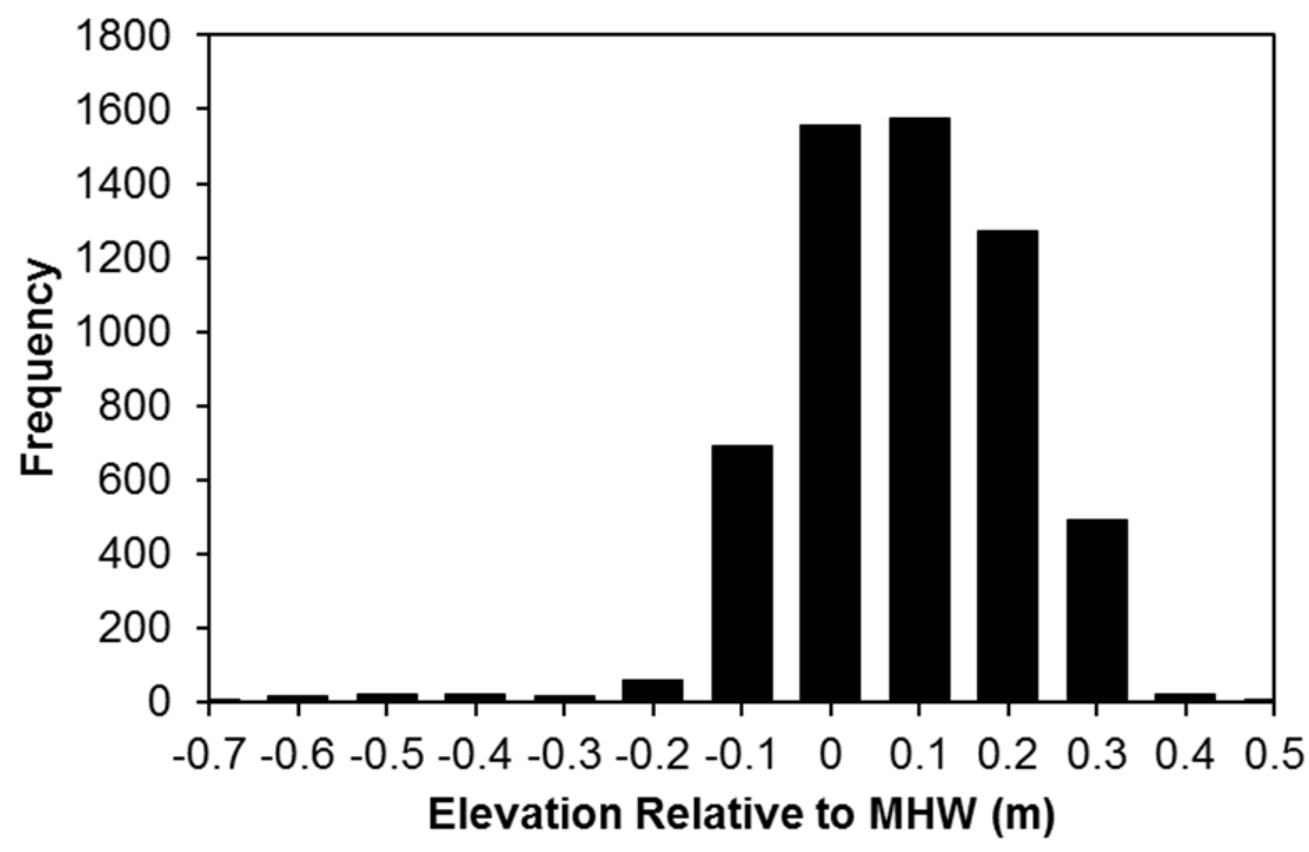

Figure 9. Distribution of marsh elevations relative to mean high water (MHW) in meters ( $\mathrm{m}$ ), for all sites. Random points were sampled from the elevation models at a density of 3 per hectare to produce an unbiased distribution. 


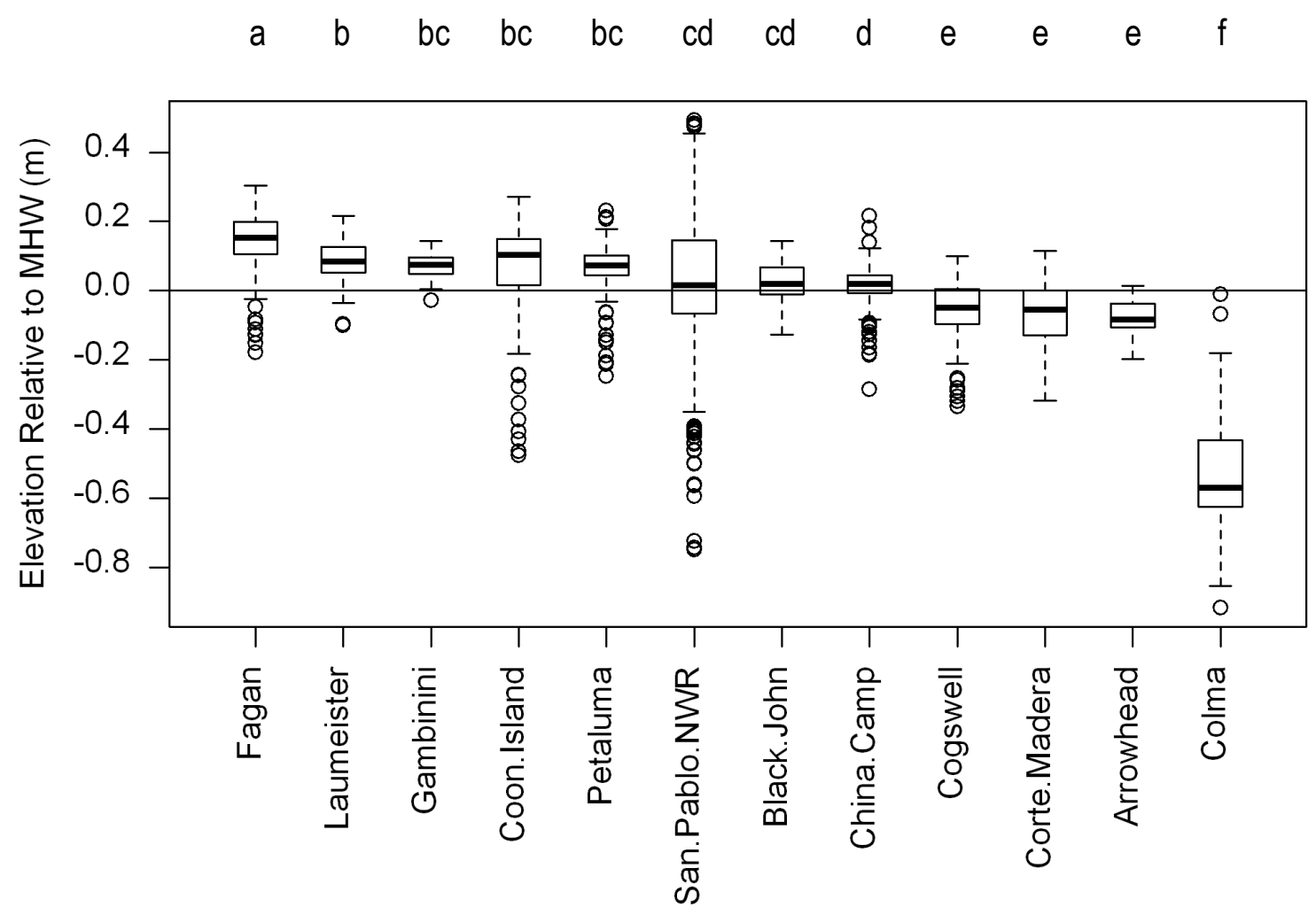

Figure 10. Vegetation relative to marsh mean high water (MHW), in meters $(\mathrm{m})$, by site. Median (solid line), 25 and 75 percentiles (box), and 1.5 interquartile range (whiskers). Circles indicate outliers. Letters denote significant differences from a Kruskal-Wallis test $(a$ lpha $=0.05)$.

\section{Vegetation}

Vegetation was sampled at 3,302 locations across all marsh sites (table 1). Distinct zonation in plant communities was observed in relation to MHW because plants are typically restricted by their inundation tolerance and soil salinities. Plant species were categorized into low, mid, and high marsh, and upland transition communities by measured elevation relative to mean sea level (MSL; table 3). Categories were determined by comparing the elevation mean and standard deviations of each species and grouping overlapping distributions (fig. 11). These categories were then used to infer changes in plant community associated with changes in elevation due to SLR. Most of the surveyed marshes were typified by high marsh vegetation (table 4). 


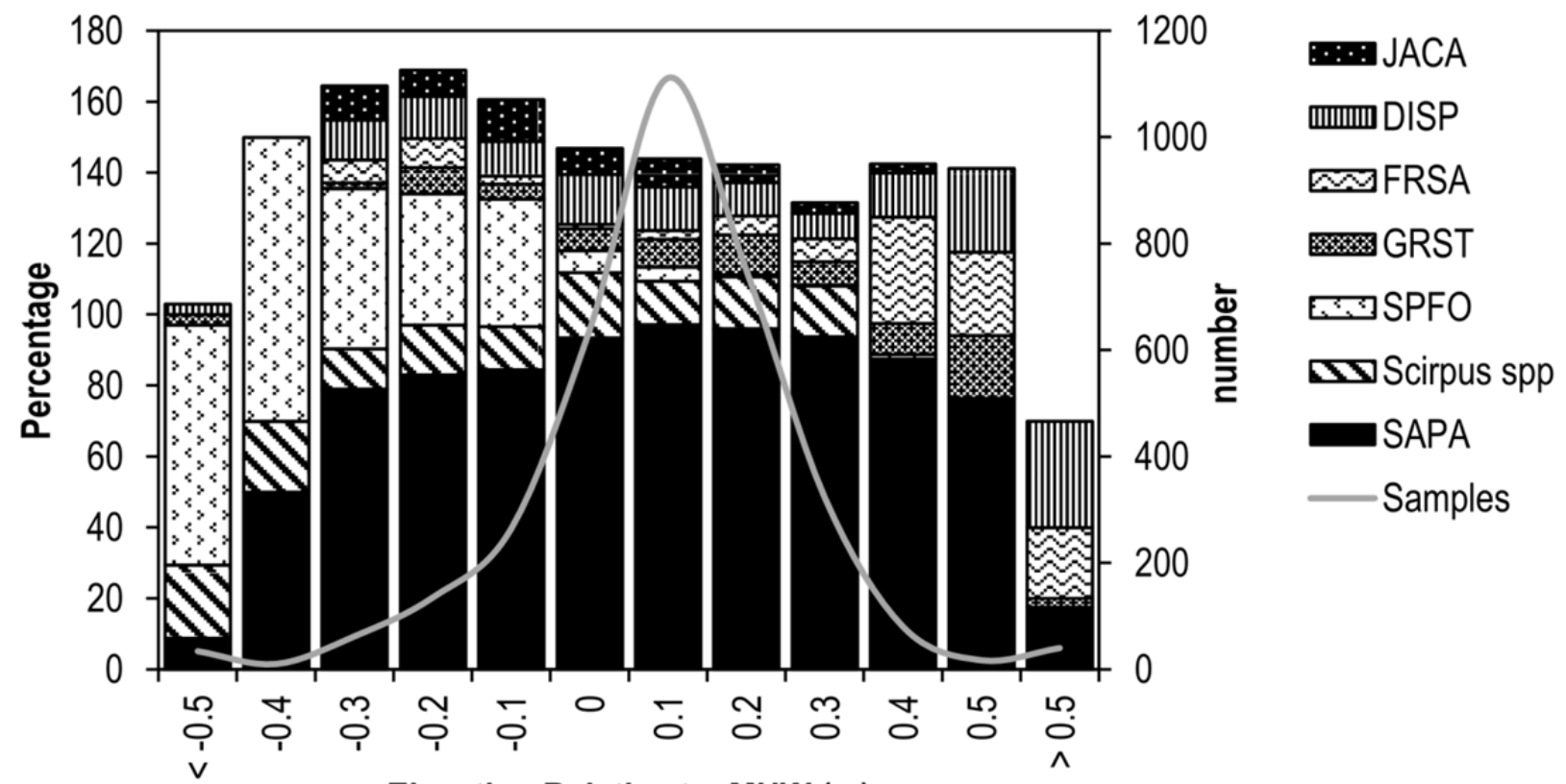

Elevation Relative to MHW (m)

Figure 11. Dominant marsh plant species by elevation relative to mean high water (MHW), in meters $(m)$, across study sites. GRST = Grindelia stricta; SPFO = Spartina spp.; SAPA = Sarcocornia pacifica; JACA = Jaumea carnosa; DISP = Distichlis spicata; FRSA = Frankenia salina. Grey line represents sampling distribution. Plant canopy cover, which often overlaps, was estimated for each species, thus greater than 100 percent in a given plot was possible.

Table 3. Plant communities were categorized on the basis of observed elevation distributions to develop marsh zones to model with sea-level rise.

[Species are ordered by abundance from high to low. MSL, mean sea level; $m$, meter; >, greater than; $<$, less than]

\begin{tabular}{|c|c|c|c|c|}
\hline $\begin{array}{c}\text { Upland Transition } \\
\text { (>1.0 m MSL) }\end{array}$ & $\begin{array}{c}\text { High Marsh } \\
\text { (0.7 - } 1.0 \mathrm{~m} \mathrm{MSL})\end{array}$ & $\begin{array}{c}\text { Mid Marsh } \\
\text { (0.45- } 0.7 \mathrm{~m} \mathrm{MSL})\end{array}$ & $\begin{array}{c}\text { Low Marsh } \\
(0.2-0.45 \mathrm{~m} \mathrm{MSL})\end{array}$ & $\begin{array}{c}\text { Mudflat } \\
(<0.2 \mathrm{~m} \mathrm{MSL})\end{array}$ \\
\hline $\begin{array}{c}\text { Baccharis } \\
\text { pilularis } \\
\text { Frankenia salina }\end{array}$ & $\begin{array}{c}\text { Distichlis spicata } \\
\text { Frankenia salina } \\
\text { Sarcocornia } \\
\text { pacifica }\end{array}$ & $\begin{array}{c}\text { Sarcocornia } \\
\text { pacifica } \\
\text { Distichlis spicata } \\
\text { Frankenia salina } \\
\text { Spartina spp. }\end{array}$ & Spartina spp. & $\begin{array}{l}\text { Sparse Spartina } \\
\text { spp. }\end{array}$ \\
\hline
\end{tabular}


Table 4. Summary of the most common plant species found across all sites.

[Colma marsh was not surveyed for vegetation because of Spartina removal efforts, which left most of the marsh unvegetated during our study. SAPA, Sarcocornia pacifica; FRSA, Frankenia salina; GRST, Grindelia stricta; JACA, Jaumea carnosa; DISP, Distichlis spicata; n, number]

\begin{tabular}{|l|c|c|c|c|c|c|c|c|}
\hline & \multicolumn{7}{|c|}{ Percentage Present } & \\
\hline Study Site & SAPA & $\begin{array}{c}\text { Schoenoplectus } \\
\text { spp. }\end{array}$ & $\begin{array}{c}\text { Spartina } \\
\text { spp. }\end{array}$ & FRSA & GRST & JACA & DISP & $\mathbf{n}$ \\
\hline Gambinini & 99.1 & 3.6 & 0.0 & 6.4 & 4.5 & 0.9 & 8.2 & 110 \\
\hline Petaluma & 97.2 & 6.5 & 0.0 & 12.9 & 6.5 & 17.4 & 9.6 & 356 \\
\hline Black John & 98.4 & 46.3 & 0.0 & 0.0 & 14.8 & 0.0 & 8.3 & 108 \\
\hline San Pablo East & 85.7 & 0.9 & 7.4 & 0.5 & 2.8 & 0.0 & 0.0 & 217 \\
\hline San Pablo West & 86.8 & 1.7 & 9.1 & 11.1 & 10.3 & 4.8 & 7.7 & 691 \\
\hline Coon Island & 87.9 & 38.5 & 0.8 & 0.5 & 7.4 & 7.7 & 1.4 & 364 \\
\hline Fagan & 87.3 & 51.0 & 0.3 & 0.3 & 0.3 & 0.3 & 1.9 & 308 \\
\hline China Camp & 96.9 & 1.7 & 4.3 & 1.4 & 8.3 & 8.1 & 12.8 & 422 \\
\hline Corte Madera & 97.2 & 0.0 & 27.4 & 0.6 & 5.0 & 10.2 & 23.9 & 361 \\
\hline Arrowhead & 76.0 & 0.0 & 98.0 & 0.0 & 0.0 & 64.0 & 26.0 & 50 \\
\hline Cogswell & 92.5 & 0.0 & 9.2 & 0.0 & 0.0 & 0.0 & 0.0 & 228 \\
\hline Laumeister & 86.1 & 0.0 & 37.5 & 1.4 & 27.8 & 4.2 & 40.3 & 72 \\
\hline
\end{tabular}

Sarcocornia pacifica was the most common species surveyed across sites, occurring at 91 percent of 3,287 YH HMNRQWXUH ISRQW. Schoenoplectus spp. was the second most common species (12.8 percent), [followed by Distichlis spicata (10.3 percent), Spartina spp. (8.9 percent), Jaumea carnosa (7Lpercent), and Grindelia stricta (6.8 percent). The sites located along more brackish river waterhhad higher species richness - Coon Island and Fagan, both on the Napa River, had the highest overall species richness.

All of the surveyed marshes had high S. pacifica abundance, the characteristic species of SFBE tidal marshes; however, several species of the marsh community differed by region (table 4). Schoenoplectus spp. commonly associated with brackish conditions were found in the sites along the Petaluma and Napa Rivers but not in the south San Francisco Bay sites. Spartina spp. were prevalent at south San Francisco Bay, not present on the Petaluma River, very sparse on the Napa River, and in low abundance at San Pablo Bay sites. These patterns in Spartina spp. and Schoenoplectus spp. distribution were likely in response to differences in water and soil salinity across the SFBE (see fig. 12).

\section{Water monitoring}

Water loggers recorded tide levels from January 2010 to May 2011 for use in our analyses, but we continued monitoring at a majority of the sites for future analyses. The loggers did not capture the bottom portion of the tidal curve because they were located relatively high in the marsh channels. Peak tide levels for 1 year (2010-2011) were averaged for each site, producing sites-specific tidal datums for MHW and MHHW (table 5).

Conductivity measurements at a subset of the sites showed the influence of freshwater runoff on water salinity (fig. 12). The most prominent pattern was seasonality, with a peak in October (except for Laumeister) corresponding to the end of the dry season in the SFBE. Coon Island, along the Napa River, had the lowest mean salinity in 2010, while San Pablo, located on the edge of the bay, had the highest. In contrast, Laumeister did not show a seasonal salinity 
pattern. Laumeister was the only site in south San Francisco Bay where we measured conductivity; thus, it is difficult to know whether it represented a different salinity regime from the San Pablo Bay and northern river sites or if there were problems with the conductivity sensor.

Table 5. Water elevations (NAVD88), in meters (m), for each marsh site in 2010.

[Mean sea-level (MSL) was derived from VDatum (National Oceanic and Atmospheric Administration). Mean high water (MHW) and mean higher high water (MHHW) were calculated from in situ data loggers. NWR, National Wildlife Refuge]

\begin{tabular}{lccc}
\hline Site & MSL & MHW & MHHW \\
Arrowhead & 1.03 & 1.71 & 1.91 \\
Black John & 1.06 & 1.73 & 1.91 \\
China Camp & 1.02 & 1.77 & 1.95 \\
Cogswell & 1.14 & 1.86 & 1.99 \\
Colma & 1.03 & 1.77 & 1.98 \\
\hline Coon Island & 1.03 & 1.78 & 1.94 \\
Corte Madera & 0.99 & 1.7 & 1.87 \\
\hline Fagan & 1.07 & 1.75 & 1.9 \\
Gambinini & 1.07 & 1.8 & 1.96 \\
\hline Laumeister & 1.21 & 1.92 & 2.09 \\
Petaluma & 1.04 & 1.76 & 1.92 \\
\hline San Pablo Bay NWR & 1.04 & 1.69 & 1.85 \\
\hline
\end{tabular}

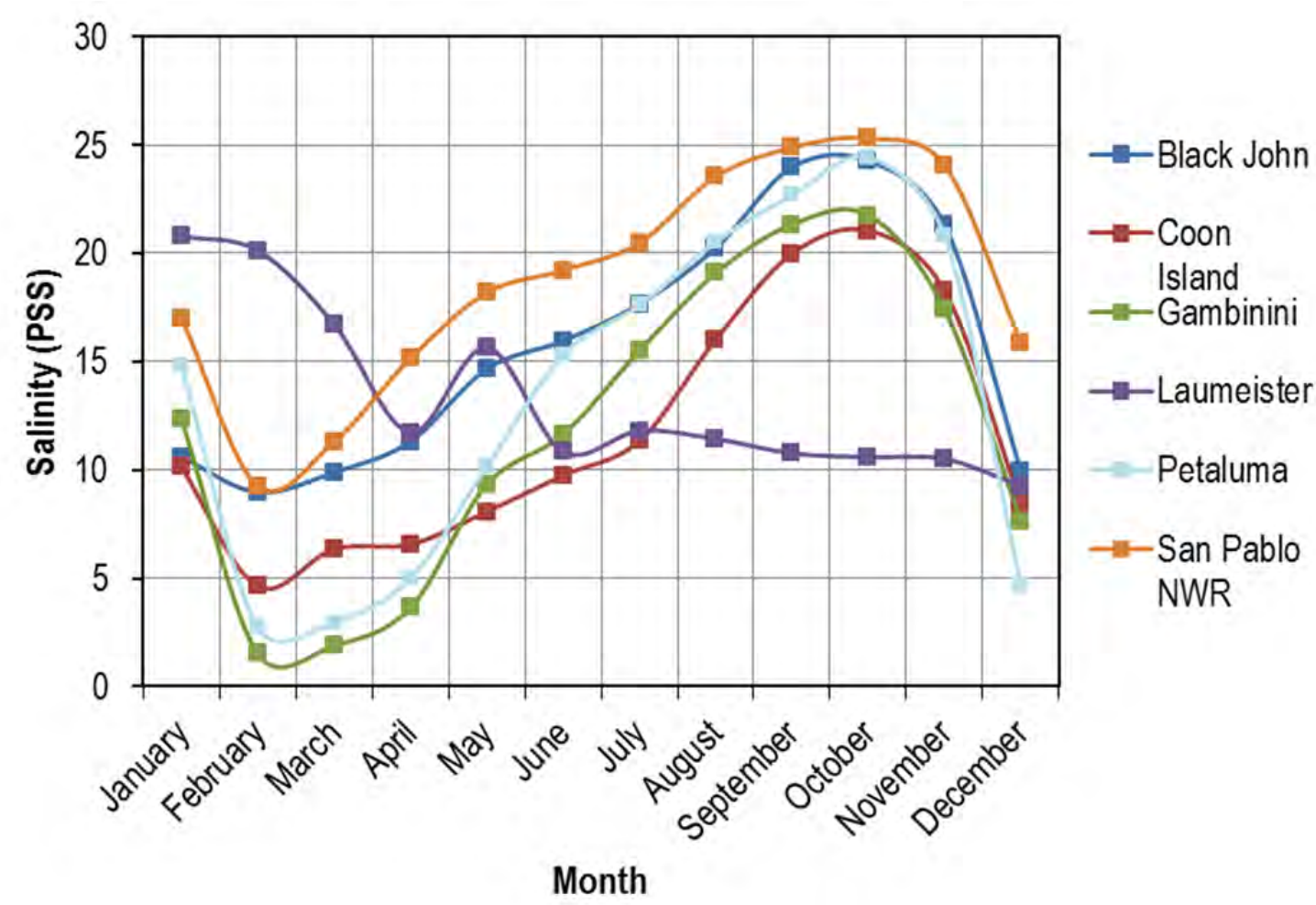

Figure 12. Salinity, in Practical Salinity Scale (PSU) during 2010 across a subset of study sites calculated by taking the monthly mean of salinity from daily high tides. Seawater has a PSU of 35. 


\section{Marsh response modeling}

SFBE spatial variability in tidal range, accretion rate, and initial marsh elevation resulted in differences in SLR risk (see appendix for site details). Sediment core data at reference sites (table 6) were used to inform accretion rates (sediment and organic accumulation) for all sites (table 7). Measured sediment accumulation used in WARMER showed higher sediment accumulation rates at Laumeister and Coon Island compared to China Camp and Petaluma (table 5). Sediment accumulation and organic matter accumulation curves were then developed for the reference sites (figs. 13 and 14).

Generally, sites with lower initial elevations and located lower in the tidal range (for example, Corte Madera, Colma, and Arrowhead) became inundated more frequently and with longer duration than sites with higher initial elevation and located higher in the tidal range (for example, Laumeister, Gambinini, and Fagan). Accretion rates used in the WARMER model were relatively higher in south San Francisco Bay; thus, those marshes withstood SLR to 2100, with areas of transition from high to low marsh vegetation by 2100 (for example, Cogswell, Laumeister, and Colma). Arrowhead, located in central San Francisco Bay, showed a large transition from mid to low marsh around 2040 (0.32 m SLR) and to mudflat by 2080 (0.85 m SLR).

Table 6. Model inputs used for primary WARMER model sites.

[Z represents a standardizing metric. $\mathrm{M}_{\mathrm{s}}$, mass of sediment; MSL, mean sea level; cm, centimeter; $\mathrm{g} \mathrm{cm}^{-2} \mathrm{yr}^{-1}$, grams per square centimeter per year; $\mathrm{mg} \mathrm{cm}^{-2} \mathrm{yr}^{-1}$, milligrams per square centimeter per year]

\begin{tabular}{|c|c|c|c|c|c|c|c|c|c|}
\hline \multirow[t]{3}{*}{ Site } & \multirow{2}{*}{$\frac{\text { Sediment }}{\left(\mathrm{g} \mathrm{cm}^{-2} \mathrm{yr}^{-1}\right)}$} & \multicolumn{2}{|c|}{ Organic matter } & \multicolumn{2}{|c|}{ Porosity } & \multirow{2}{*}{$\frac{\text { Decay }}{\text { (percent) }}$} & \multicolumn{3}{|c|}{ Elevation } \\
\hline & & $(\mathrm{mg} \mathrm{Cr}$ & $\left.-2 y r^{-1}\right)$ & (per & & & $(\mathrm{cm}$ & bov & $\overline{M S L)}$ \\
\hline & $\mathrm{M}_{\mathrm{s}}(\mathrm{MSL})$ & a & b & Surface & Depth & $\begin{array}{c}\text { Refractory } \\
\text { C }\end{array}$ & $Z-2 s$ & Z & $Z+2 s$ \\
\hline $\begin{array}{l}\text { China } \\
\text { Camp }\end{array}$ & 0.32 & -0.00257 & -0.00452 & 82 & 77 & 12 & 64 & 77 & 90 \\
\hline Petaluma & 0.10 & -0.00113 & -0.00199 & 83 & 80 & 14 & 65 & 77 & 89 \\
\hline $\begin{array}{l}\text { Coon } \\
\text { Island }\end{array}$ & 0.59 & -0.00142 & -0.00250 & 83 & 78 & 55 & 49 & 75 & 101 \\
\hline Laumeister & 1.34 & -0.00443 & -0.00777 & 76 & 72 & 49 & 69 & 83 & 96 \\
\hline
\end{tabular}


Table 7. WARMER model inputs used for extrapolation to the remaining sites.

[The reference site was chosen based on proximity to marsh. CC, China Camp; PRM, Petaluma; Lau, Laumeister; CI, Coon Island; SPB NWR, San Pablo Bay National Wildlife Refuge; $\mathrm{M}_{\mathrm{s}}$, mass of sediment ;MSL, mean sea level; cm, centimeter; OM, maximum organic matter; $\mathrm{g} \mathrm{cm}^{-2} \mathrm{yr}^{-1}$, grams per square centimeter per year]

\begin{tabular}{|c|c|c|c|c|c|c|c|c|}
\hline & Arrowhead & $\begin{array}{l}\text { Black } \\
\text { John }\end{array}$ & Cogswell & Colma & $\begin{array}{c}\text { Corte } \\
\text { Madera }\end{array}$ & Fagan & Gambinini & $\begin{array}{l}\text { SPB } \\
\text { NWR }\end{array}$ \\
\hline Reference site & CC & PRM & Lau & Lau & $\mathrm{CC}$ & $\mathrm{Cl}$ & PRM & CC \\
\hline $\mathrm{OM}\left(\mathrm{g} \mathrm{cm}^{-2} \mathrm{yr}^{-1}\right)$ & 0.019 & 0.005 & 0.029 & 0.029 & 0.019 & 0.005 & 0.005 & 0.019 \\
\hline $\begin{array}{l}\text { Sediment Ms(MSL) } \\
\left(\mathrm{g} \mathrm{cm}^{-2} \mathrm{yr}^{-1}\right)\end{array}$ & 0.320 & 0.097 & 1.338 & 1.338 & 0.320 & 0.588 & 0.097 & 0.320 \\
\hline $\begin{array}{l}\text { Surface Porosity } \\
\text { (percent) }\end{array}$ & 82 & 83 & 78 & 78 & 82 & 83 & 83 & 82 \\
\hline $\begin{array}{l}\text { Depth Porosity } \\
\text { (percent) }\end{array}$ & 77 & 80 & 77 & 77 & 77 & 78 & 80 & 77 \\
\hline $\begin{array}{l}\text { Refractory Carbon } \\
\text { (percent) }\end{array}$ & 12 & 14 & 55 & 55 & 12 & 12 & 14 & 12 \\
\hline
\end{tabular}

\begin{tabular}{lllllllll}
\hline Elevation (cm MSL) & & & & & & & & \\
\hline Z-2s & 51 & 58 & 55 & -11 & 47 & 65 & 73 & 34 \\
$\mathbf{Z}$ & 63 & 70 & 71 & 31 & 64 & 83 & 81 & 64 \\
$\mathbf{Z}+2 \mathbf{s}$ & 74 & 81 & 86 & 73 & 81 & 101 & 90 & 93 \\
\hline
\end{tabular}




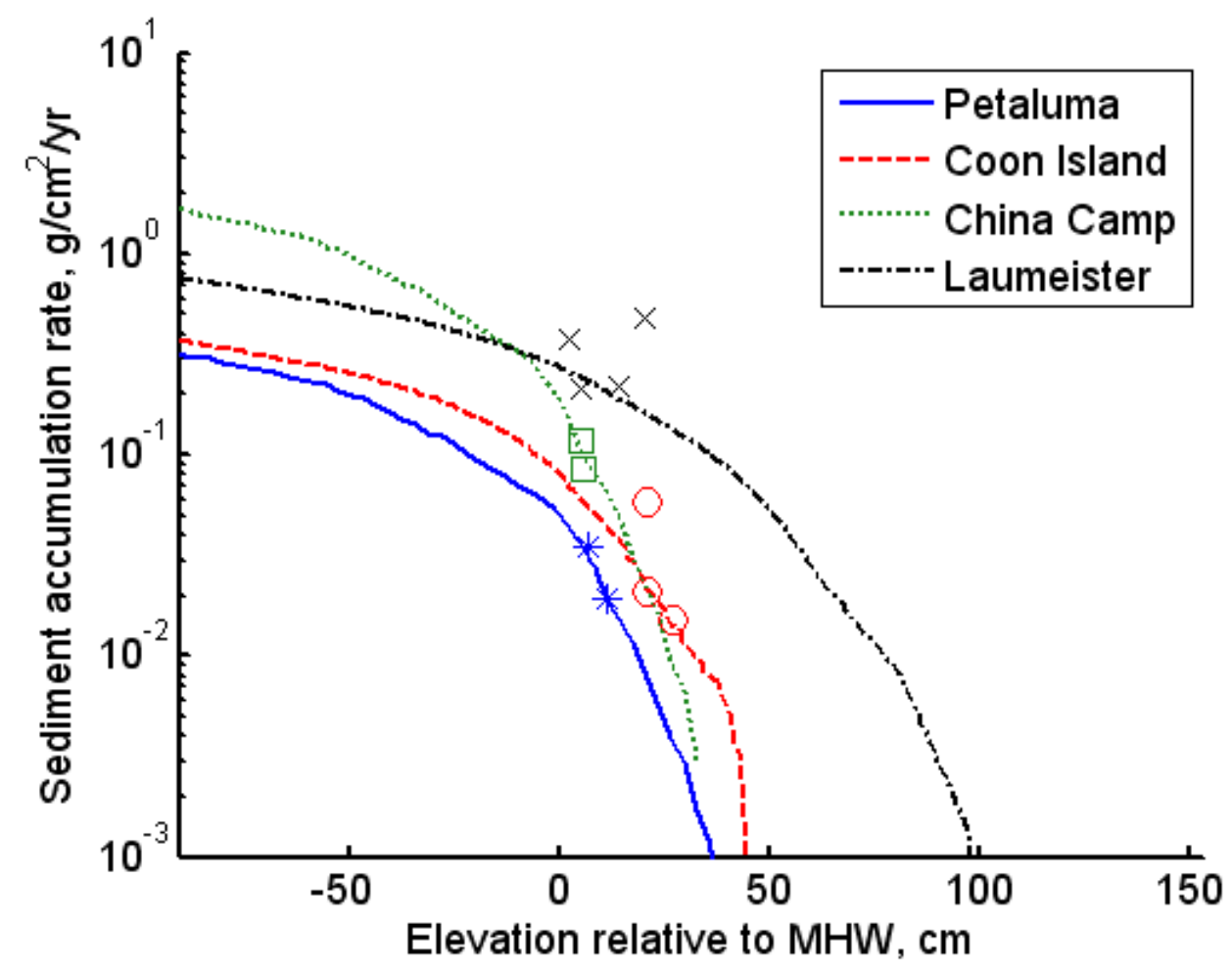

Figure 13. Calculated sediment accumulation curves (lines) and measured accumulation rates (points) for representative marsh sites relative to mean high water (MHW). Curves are calculated from inundation frequency and calibrated to accumulation rates measured by Callaway and others (2012). These rates were extrapolated to nearby marshes in the study. [ $\mathrm{g} \mathrm{cm}^{-2} \mathrm{yr}^{-1}$, grams per square centimeter per year; $\mathrm{cm}$, centimeters]

The remaining sites had accretion rates that were relatively low; the WARMER simulations projected that these marshes would transition to mudflat by the end of the century. For example, Corte Madera, China Camp, and San Pablo lost all high marsh by 2030 (0.24 m SLR), briefly transitioned to mid- and low-marsh vegetation, and ultimately transitioned to areas dominated by mudflats by 2080 ( $0.85 \mathrm{~m} \mathrm{SLR})$. The three marshes located on the Petaluma River (Gambinini, Petaluma, and Black John) also lost most high marsh by 2030 (0.24 m SLR) and transitioned to mostly mudflat by 2080 ( $0.85 \mathrm{~m} \mathrm{SLR})$. Because the WARMER model for the Napa River sites was parameterized with higher sediment accretion rates, Coon Island maintained high marsh until 2030 (0.24 m SLR) and Fagan until 2040 (0.32 m SLR). Mid-marsh vegetation was maintained between 2030 and 2040 for Coon Island ( $0.32 \mathrm{~m} \mathrm{SLR}$ ) and between 2040 and 2060 for Fagan (0.57 m SLR). Low-marsh vegetation was dominant until 2090 (1.05 m SLR), at which time both marshes transitioned to predominantly mudflat. Both of these sites had higher initial elevations than other marshes. 


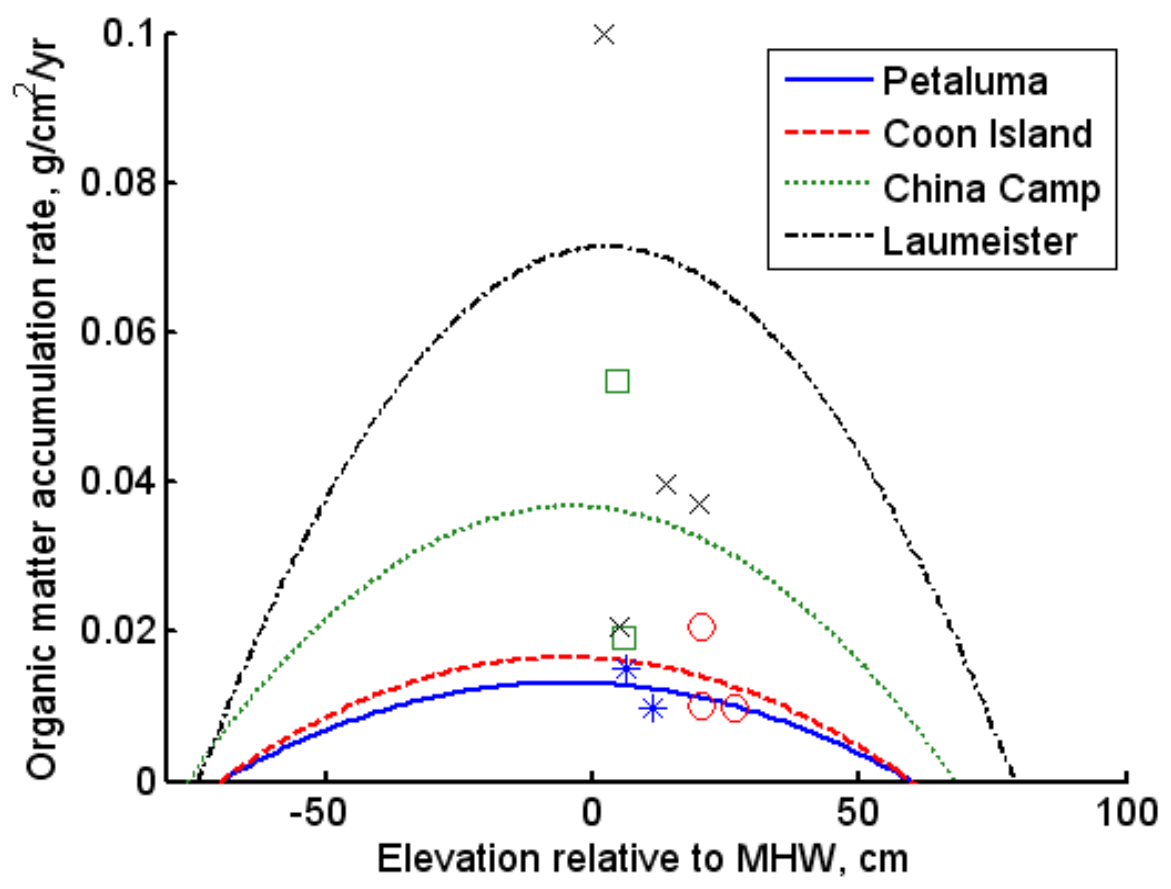

Figure 14. Calculated organic matter accumulation (lines) and measured accumulation rates (points) for representative marsh sites relative to mean high water (MHW). These rates were extrapolated to nearby marshes in the study. [ $\mathrm{g} \mathrm{cm}^{-2} \mathrm{yr}^{-1}$, grams per square centimeter per year; $\mathrm{cm}$, centimeters]

Nine of the marshes transitioned to mudflat by 2100 (1.23 m SLR), whereas only three marshes maintained vegetation to 2100. All marshes lost upland transition and high marsh by 2100 , and mid-marsh vegetation was lost at nine marshes by 2100 . These results illustrate the spatial variability of SLR effects across the SFBE. The three marshes that maintained marsh vegetation to 2100 composed only 4 percent ( $85 \mathrm{ha}$ ) of the total marsh area surveyed, whereas a total of 96 percent (1,942 ha) of the marsh area in our study transitioned to mudflat by 2100 (site-specific results are described in appendices A-L).

\section{WARMER sensitivity analysis}

Callaway and others (1996) and Deverel and others (2008) noted that their respective models were sensitive to both initial elevation and porosity. The sensitivity analysis of WARMER showed the greatest differences in final elevation when SLR and sediment accumulation were varied (fig. 15). On average, the scenarios with the largest sediment accumulation were able to keep pace with SLR. Scenarios with only $50 \mathrm{~cm}$ of SLR by the end of the century had an average increase in elevation of 7 percent. The small variations in porosity that were observed in the marsh sediment cores did not lead to large changes in final elevation despite the strong non-linearity between porosity and volume. The influence of organic matter accumulation was also small, despite varying the observed range of accumulation rates by approximately \pm 50 percent in the sensitivity analysis. The scenarios with the lowest sediment accumulation rates had a greater dependence on initial elevation compared to other accumulation rate scenarios. The negative feedback between elevation and sediment accumulation was strong enough to mitigate this influence in the mean and high sediment input scenarios. 


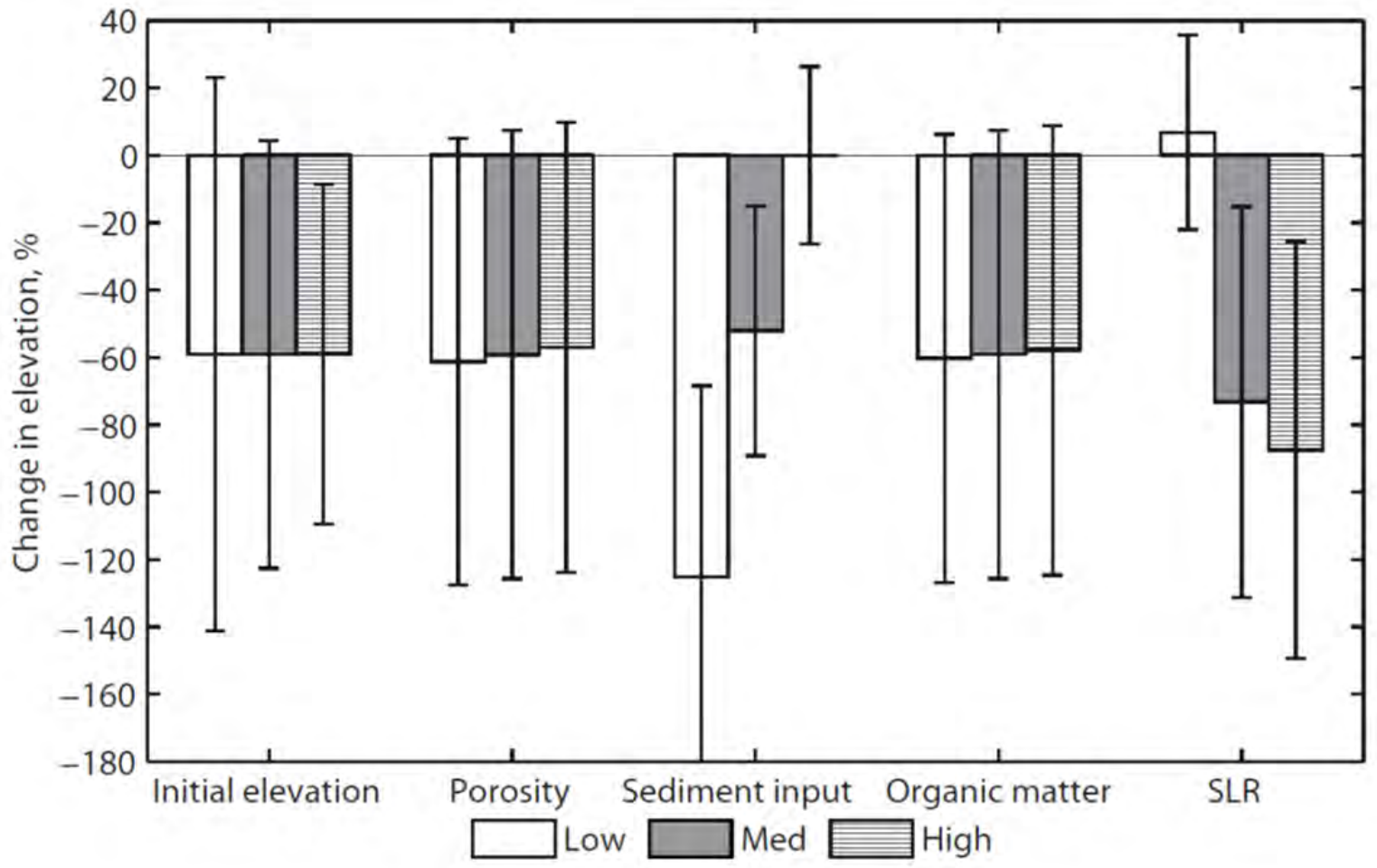

Figure 15. Results of the sensitivity analysis of WARMER. Each bar is the mean final elevation for 81 runs with the indicated parameter. Error bars indicate \pm 1 standard deviation from the mean. [SLR, sea-level rise; \%, percentage]

The current WARMER model could be expanded and improved for site-specific results. For example, a better understanding of local suspended-sediment supply (across the SFBE and marsh sites), settling velocity of suspended sediment and how that relates to vegetation, and temporal variability in deposition rates would improve the accretion function. In addition, the model currently does not address marsh erosion, which also would have negative feedbacks for marsh elevation. Any changes in hydrological conditions beside SLR and sediment availability over time were not incorporated into the models.

\section{Discussion}

Resource land managers responsible for the protection of wildlife species and their habitats were our focus in developing site-specific projections and plant-community response to SLR. By identifying SLR habitat thresholds, our project aimed to provide land managers with the science support necessary to make informed decisions and develop climate change adaptation strategies. Our models identified differences in risk for individual marshes from SLR in the SFBE, including the timing of habitat transitions. 


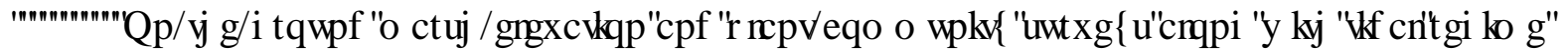

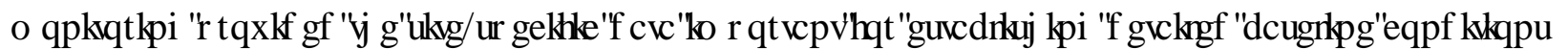

to develop SLR models. The most common method for obtaining SLR modeling elevation data has been aerial LiDAR (Light Detection And Ranging). However, LiDAR is generally unable to penetrate dense marsh-vegetation cover and produces elevation errors $10-40 \mathrm{~cm}$ greater than ground-based measurements (Foxgrover and others, 2011; Schmid and others, 2011). The error in LiDAR can represent nearly half of the total marsh slope and can skew SLR response modeling results, especially from early in the century through the year 2050. Our results showed that initial elevation, along with tidal range and suspended-sediment availability, were key inputs for effectively modeling marsh response from SLR in the SFBE.

Sediment accretion can partially offset increased SLR through 2100. South San Francisco Bay marshes are projected to maintain mid-marsh vegetation throughout most of this century, with a transition to low-marsh vegetation in the later part of the century, largely as a result of high sediment accretion rates. In contrast, San Pablo Bay sites are not projected to have high enough accretion rates to maintain elevations that keep pace with SLR, and they represent some of the largest remaining parcels in the estuary. San Pablo Bay is generally considered to be at a turbidity maximum within the estuary (Rhul and others, 2004; Stralberg and others, 2011); thus, the limited sediment-core data might not reflect the current rate of sediment accumulation there. The accuracy of marsh accretion models is largely dependent on accurate sediment accumulation functions and calibration data. While the accretion models might not accurately reflect the accretion at a specific site, the ranges of input values do represent a cross section of possible marsh accretion simulations for the SFBE. Our results show that three marshes would maintain marsh vegetation to 2100 , but these marshes only composed 4 percent ( $85 \mathrm{ha}$ ) of the total marsh area surveyed, while the remaining 96 percent $(1,942 \mathrm{ha})$ of the marsh area in our study transition to mudflat by 2100 .

Urbanization in the SFBE estuary makes it especially susceptible to SLR because there are limited opportunities for upslope transition. Seven of our marsh sites have open space (nonurban) surrounding the sites. With management actions and restoration, these marshes have potential to respond to SLR by moving upslope. In contrast, five sites are surrounded by urban infrastructure and, therefore, will have no opportunity to move upslope with SLR. If these marshes are unable to transition upslope because of levees or development, they will become mudflats.

The added effects of climate change on marsh ecosystems could greatly increase threats to already vulnerable wildlife populations and species (Ohlemuller and others, 2008). Increased rates of inundation will be ecologically significant for obligate marsh species, especially those that are already limited in number (for example, California clapper rail) and those that also have low dispersal ability (for example, salt marsh harvest mouse). Species that rely on marsh habitat for feeding, reproduction, or cover from predators will be negatively affected by SLR. Our projections show the loss of high and mid-marsh vegetation by 2050 in most areas. These areas are dominated by Sarcocornia pacifica, a plant that is critical for providing habitat structure for the salt marsh harvest mouse, California black rail, and nesting song birds. Low-marsh vegetation will persist in most areas until 2070 and is dominated by Spartina spp., which provides habitat used by the California clapper rail. However, low marsh was projected to be lost at 96 percent of the surveyed areas by 2100 , and, if representative, could result in the loss of a significant amount of habitat for the California clapper rail population. 


\section{Next steps}

Our program recognizes the importance of extensive and improved integration of physical and biological monitoring that could facilitate the discovery of important trends and signals for SLR. A better understanding of the spatial variability of available suspendedsediment and deposition rates for both organic matter and sediment would greatly improve these site-specific results and is a future goal of the program. We believe this type of baseline data collection can be used to identify and prioritize restoration sites and land acquisitions that can be good candidates for marsh perpetuation in light of SLR. In addition, the continued risk to listed species needs to be assessed by evaluating movements, nesting requirements, and food availability for species. A better understanding of wildlife response to increased inundation is especially needed. The Coastal Ecosystem Response to Climate Change (CERCC) program recently has been expanded to Humboldt Bay, Anaheim Bay, and the San Diego estuary, as well as to a range of coastal sites in California, Oregon, and Washington. Consistent with the goal of the USGS Science Strategy, the CERCC program will support models that predict ecosystem change and assess consequences of climate change and its effects on coastal ecosystems, and it will do so at a bottom-up local level appropriate for land managers developing adaptation plans.

\section{Acknowledgments}

The authors would like to thank the USGS Western Ecological Research Center and the USGS National Climate Change and Wildlife Science Center for funding support and recent program contributions from the U. S. Fish and Wildlife Service California Landscape Conservation Cooperative and Fish and Wildlife Service Region 8 Inventory and Monitoring and Science Applications Program. We also would like to thank the USGS Native American Internship Program and participants, B. Hoskinson, C. Hudson, and H. Vaska. The authors would like to thank T. Bui, D. Drolette, T. Edgarian, P. Elsen, J. Felis, T. Henner, L. Smith, and L. Terrazas for project field assistance. Helpful review comments were provided by G. Wylie and N. Athearn. 


\section{References Cited}

Accurso, L. M., 1992, Distribution and abundance of wintering waterfowl on San Francisco Bay 1988-1990: M. S. thesis, Humboldt State University, Arcata, Calif.

Bengtsson, L., Hodges, K. I., and Keenlyside. N., 2009, Will extratropical storms intensify in a warmer climate?: Journal of Climate, v. 22, p. 2276-2301.

Bindoff, N. L., Willebrand J., Artale, V., Cazenave, A., Gregory, J., Gulev, S., Hanawa, K., Le Quéré, C., Levitus, S., Nojiri, Y., Shum, C. K., Talley, L. D., and Unnikrishnan, A., 2007, Observations: Oceanic Climate Change and Sea Level: In Climate Change 2007: The Physical Science Basis. Contribution of Working Group I to the Fourth Assessment Report of the Intergovernmental Panel on Climate Change, eds. Solomon, S., D. Qin, M. Manning, Z. Chen, M. Marquis, K. B. Averyt, M. Tignor and H. L. Miller New York: Cambridge University Press.

Brittian, R. A., Craft, C. B., 2012, Effects of Sea-Level Rise and Anthropogenic Development on Priority Bird Species Habitats in Coastal Georgia, USA: Environmental Management, v. 49, p. 473-482.

Callaway, J.C., Borgnis, E.L, Turner, R.E., and Milan, C.S., 2012, Carbon sequestration and sediment accretion in San Francisco Bay tidal wetlands: Estuaries and Coasts, v. 35, no. 5, p. 1163-1181.

Callaway, J., Nyman, J. A., and DeLaune, R. D., 1996, Sediment accretion in coastal wetlands: A review and simulation model of processes: Current Topics in Wetland Biogeochemistry, $\mathrm{V}$. 2, p. 2-23.

Callaway, J., Parker, V. T., Vasey, M. C., and Schile L. M. 2007, Emerging issues for the restoration of tidal marsh ecosystems in the context of predicted climate change: Madroño, $\mathrm{v}$. 54, no. 3, p 234-248.

Cayan, D., Bromirski, P., Hayhoe, K., Tyree, M., Dettinger, M. and Flick, R., 2005, Projecting Future Sea Level: California Climate Change Center Report (CEC-500-2005 202-SD), December 2005. http://www.energy.ca.gov/2005publications/2005_pubs_alpha_order.html

Cayan, D., Luers, A. L., Hanemann, M., Franco, G., and Croes, B., 2006, Scenarios of climate change in California: An overview. Sacramento, Calif.: California Climate Change Center (CEC-500-2005-186-SF), 53 p.

http://www.climatechange.ca.gov/climate_action_team/reports/index.html

Cayan, D. R., Bromirski, P. D., Hayhoe, K., Tyree, M., Dettinger, M. D., and Flick, R. E., 2008, Climate change projections of sea level extremes along the California coast: Climate Change, v. 87, p. S57-S73.

Cayan D., Tyree M., Dettinger M., Hidalgo H., Das T., Maurer E., Bromirski P., Graham N., and Flick R., 2009, Climate change scenarios and sea level rise estimates for California 2008 climate change scenarios assessment: California Climate Change Center, CEC-500-2009-014F.

Curcó, A., Ibañez, C., Day, J. W., and Prat, N., 2002, Net primary production and decomposition of salt marshes of the Ebre Delta (Catalonia, Spain): Estuaries, v. 25, p. 309-324.

Deverel, S. J., Drexler, J. Z., Ingrum, T., and Hart, C., 2008, Simulated Holocene, recent, and future accretion in channel marsh islands and impounded marshes for subsidence mitigation, Sacramento -San Joaquin Delta, California, USA. REPEAT Project Final Report to the CALFED Science Program of the Resources Agency of California, $60 \mathrm{pp}$. 
Emanuel, K., 2005, Increasing destructiveness of tropical cyclones over the past 30 years: Nature v. 436, p. $686-688$.

Foxgrover, A. C., Finalyson, D. P., Jaffe, B. E., Takekawa, J. Y., Thorne, K. M., and Spragens, K. A., 2011, 2010 Bathymetric survey and digital elevation model of Corte Madera Bay, California: U.S. Geological Survey Open-File Report 2011-1217, 20 p., available at http://pubs.usgs.gov/of/2011/1217/.

Geden, K. B., Kirwin, M. L., Wolanski, E., Barbier, E. B., and Silliman, B. R., 2011, The present and future role of coastal wetland vegetation in protecting shorelines: Answering recent challenges to the paradigm: Climate Change, v. 106, p. 7-29.

Goals Project, 1999, Bayland ecosystem habitat goals. A report of habitat recommendations prepared by the San Francisco Bay Area Wetlands Ecosystems Goals Project. Joint publication of the U.S. Environmental Protection Agency, San Francisco, California, and San Francisco Bay Regional Water Quality Control Board, Oakland, Calif.

Greenberg, R., Maldonado, J. E., Droege, S., and McDonald, M. V., 2006, Tidal marshes: a global perspective on the evolution and conservation of their terrestrial vertebrates: Bioscience, v. 56, p. 675-685.

Grinsted, A., Moore, J. C., and Jevrejeva, S., 2010, Reconstructing sea level from paleo and projected temperatures 200 to 2100 AD: Climate Dynamics, v. 42, p. 461-472.

Hamlet, A. F., and Lettenmaier, D.P., 2007, Effects of 20th century warming and climate variability on flood risk in the western U.S.: Water Resources Research, v. 43, p. W06427.

Hansen, J., Sato, M., Ruedy, R., Lo, K., Lea, D.W., and Medina-Elizade, M., 2006, Global temperature change: Proceedings of the National Academy of Science, v. 103, p. 1428814293.

Holgate, S. J., and Woodworth, P. L., 2004, Evidence for enhanced coastal sea level rise during the 1990s: Geophysical Research Letters, v. 31, p. L07305.

International Panel on Climate Change, 2007, Summary for Policymakers: In Climate Change 2007: The Physical Science Basis. Contribution Working Group I to the Fourth Assessment Report of the Intergovernmental Panel on Climate Change [Solomon, S., D. Qin, M. Manning, Z. Chen, M. Marquis, K.B. Averyt, M. Tignor and H.L. Miller (eds.)]. Cambridge University Press, Cambridge, United Kingdom and New York, NY, USA.

Jevrejeva, S., Moore J. C., and Grinsted, A., 2010, How will sea level respond to changes in natural and anthropogenic forcings by 2100?: Geophysical Research Letters, v. 37, p. L07703.

Jevrejeva, S., Moore J. C., and Grinsted, A., 2012, Sea level projections to AD2500 with a new generation of climate change scenarios: Global and Planetary Change, v. 80-81, p. 14-20.

Kemp, A. C., Horton, B. P., Donnelly, J. P., Mann, M. E., Vermeer, M., and Rahmstorf, S., 2011, Climate related sea-level variations over the past two millennia: Proceedings of the National Academy of Science of the United States of America: v. 108, p. 11017-11022.

Kirwan M. L., and Guntenspergen, G. R., 2010, Influence of tidal range on the stability of coastal marshland: Journal of Geophysical Research, v. 115, no. F2, p. 1-11.

Leatherman, S. P., Zhang, K., and Douglas, B. C., 2000, Sea level rise shown to drive coastal erosion: Eos Trans. AGU, v. 81, no.6, p. 55.

Mancera, J. E., Meche, G. C., Cardona-Olarte, P. P., Castaneda-Moya, E., Chiasson, R. L., Geddes, N. A., Schile, L. M., Wang, H. G., Guntenspergen, G. R., and Grace, J. B., 2005, Fine-scale spatial variation in plant species richness and its relationship to environmental conditions in coastal marshlands: Plant Ecology, v. 178, p. 39-50. 
Morris, J.T., Sundareshwar, P. V., Nietch, C. T., Kjerfve, B., and Cahoon, D. R., 2002, Responses of coastal wetland to rising sea level: Ecology, v. 83, p. 2869-2877.

Ohlemuller, R., Anderson, B. J., Araujo, M. B., Butchart, S. H. M., Kudrna, O., Ridgely, R. S., and Thomas, C. D., 2008, The coincidence of climatic and species rarity: high risk to smallrange species from climate change: Biology Letters, v. 4, p. 568-572.

Robbins, J. A., 1978, Geochemical and geophysical applications of radioactive lead: In Biogeochemistry of Lead in the Environment, ed. J. O. Nriagu,p. 285-393, Amsterdam:Elsevier Scientific.

Ruhl, C. A., and Schoellhamer, D. H., 2004, Spatial and temporal variability of suspendedsediment concentration in a shallow estuarine environment: San Francisco Estuary and Watershed Science, v. 2, article 1.

Scarton, F., Day, J. W., and Rismondo, A., 2002, Primary production and decomposition of Sarcocornia fruticosa (L.) Scott and Phragmites australis Trin. Ex Steudel in the Po Delta, Italy: Estuaries, v. 25, p. 325-336.

Schmid, K. A., Hadley, B. C., and Wijekoon, N., 2011, Vertical accuracy and use of topographic LiDAR data in coastal marshes: Journal of Coastal Research, v. 27, p. 116-132.

Spautz, H., Nur, N., Stralberg, D., and Chan, Y., 2006, Multi-scale habitat relationships of tidalmarsh breeding birds in the San Francisco Bay estuary: Studies in Avian Biology, v. 32, p. 247-269.

Stralberg, D., Brennan, M., Callaway, J. C., Wood, J. K., Schile, L. M., Jongsomjit, D., Kelly, M., Parker, V. T., and Crooks, S., 2011, Prospects for tidal marsh sustainability in San Francisco Bay: Spatial habitat scenarios and sensitivity analysis: PLoS ONE, v. 6, no. 11, p. e27388.

Takekawa, J. Y., Woo, I., Spautz, H., Nur, N., Grenier, J. L., Malamud-Roam, K., Nordby, J. C., Cohen, A. N., Malamud-Roam, F., and Wainwright-De La Cruz, S. E., 2006, Environmental threats to tidal marsh vertebrates in the San Francisco Bay estuary: Studies in Avian Biology, v. 32, p. 176-197.

Takekawa $\square$ J. Y., Woo, I., Thorne, K. M., Buffington, K. J., Nur, N., Casazza, M. L., Ackerman, J. T., 2011, Bird communities: effects of fragmentation, disturbance, and sea level rise on population viability: In Ecology, conservation and restoration of tidal marshes: the San Francisco Bay estuary, UC Press., p. 175-194

Tsao, D. C., Takekawa, J. Y., Woo, I., Yee, J. L., and Evens, J. G., 2009, Home range, habitat selection, and movements of California black rails at tidal marshes at San Francisco Bay, California: The Condor v. 111, p. 599-610.

U.S. Fish and Wildlife Service, 2009, Draft Recovery Plan for Tidal Marsh Ecosystems of Northern and Central California. Sacramento, California, xviii 636 p.

Vermeer, M., and Rahmstorf, S., 2009, Global sea level linked to global temperature: Proceedings of the National Academy of Science of the United States of America, v. 106, p. 21527-21532.

Webster, P. J., Holland, G. J., Curry, J. A., and Chang, H. R., 2005, Changes in tropical cyclone number, duration, and intensity in a warming environment: Science, v. 309, p. 1844-1846. 


\section{Appendixes:}

Results by site

Site-specific data are available by request. Contact:

Dr. John Y. Takekawa

USGS Western Ecological Research Center

San Francisco Bay Estuary Field Station

505 Azuar Dr.

Vallejo, Calif. 94592

707-562-2000 


\section{Appendix A. Arrowhead Marsh}

\section{Introduction}

Located in central San Francisco Bay, Arrowhead Marsh (hereafter, "Arrowhead") is a tidal salt marsh that is owned by Oakland Port Authority and managed by East Bay Regional Parks as part of the (300 hectares) Martin Luther King Jr. Regional Park. Arrowhead is recognized as an important stopover on the Pacific Flyway and is part of the Western Shorebird Reserve Network. Arrowhead is also home to the federally-endangered California clapper rail (Rallus longirostris obsoletus), which occupies the low intertidal habitat dominated by cordgrass (Spartina spp.)

This study focused on 17.0 hectares (ha) of Arrowhead. Elevation and vegetation surveys were carried out in the winter of 2009 by using an RTK GPS. To monitor tidal inundation, two water level loggers were deployed from 2009 to 2010. Beginning in 2006, a chemical herbicide (chemical mow) was applied to the western half of the marsh in an attempt to control the invasive Spartina densiflora and the S. densiflora x S. foliosa hybrid. As a result of the treatment, vegetation was not surveyed in the western portion of Arrowhead.

\section{Results}

\section{Elevation surveys}

A total of 274 elevation measurements were taken at Arrowhead (fig. A-1). The elevation range was $0.87-1.84$ meters $(\mathrm{m})$ with a mean of $1.62 \mathrm{~m}$ (NAVD88). Over half (65 percent) of the survey points fell within $1.55-1.70 \mathrm{~m}$, a $0.15 \mathrm{~m}$ range. Arrowhead was the second lowest marsh surveyed in this study, with 87 percent of the elevation points located below mean high water (MHW; fig A-2). Only 13 percent of survey points were located at elevations above MHW. A 3$\mathrm{m}$ resolution elevation model was developed in ArcGIS 9.3 (ESRI, Redlands, Calif.) Spatial Analyst by using the kriging method (fig. A-3). This baseline elevation model was used as the initial state in the Wetland Accretion Response Model for Ecosystem Resilience (WARMER) sea-level rise (SLR) model; WARMER results were extrapolated across the elevation model. 


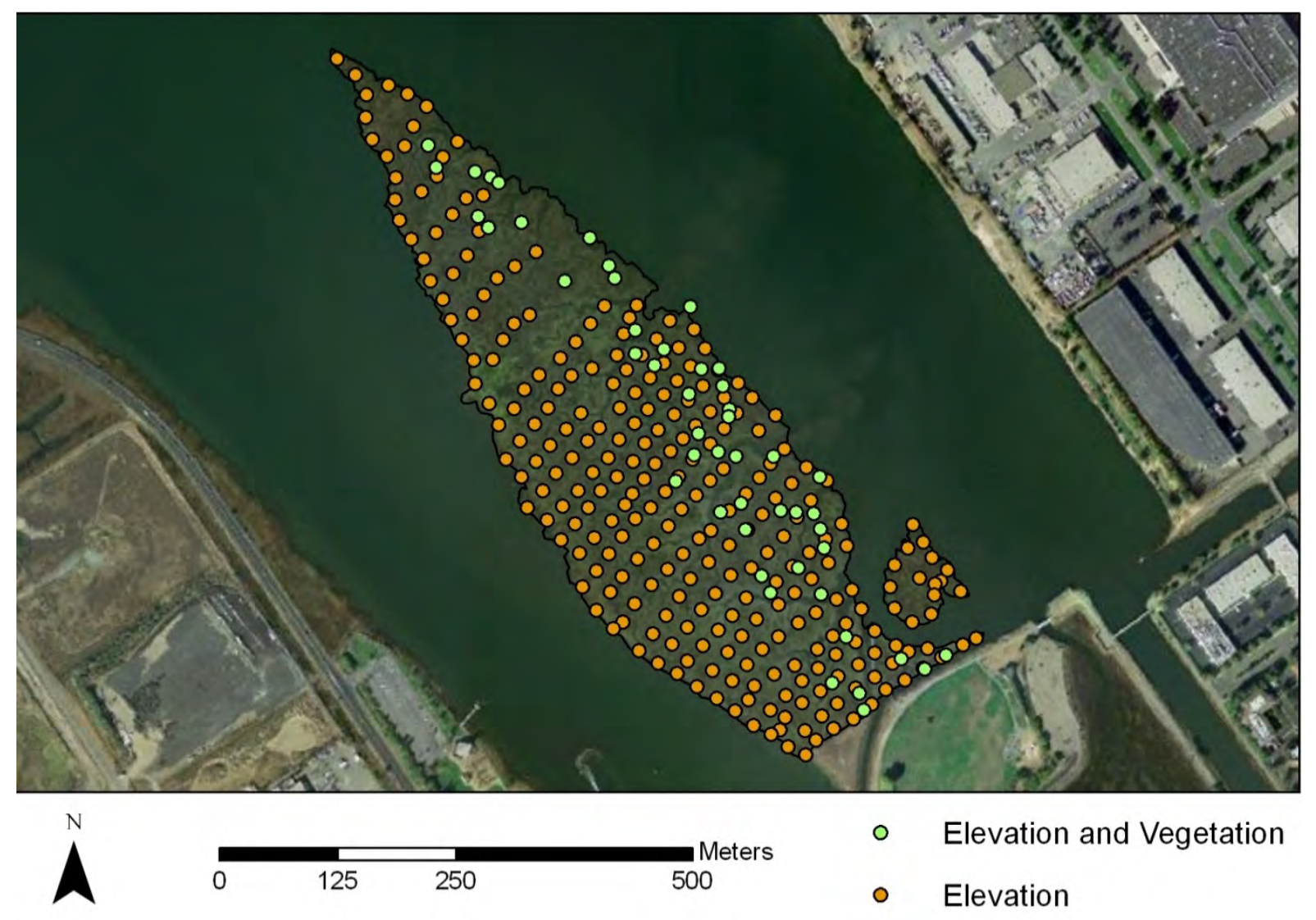

Figure A-1. Arrowhead Marsh with elevation and vegetation survey points from 2009. 


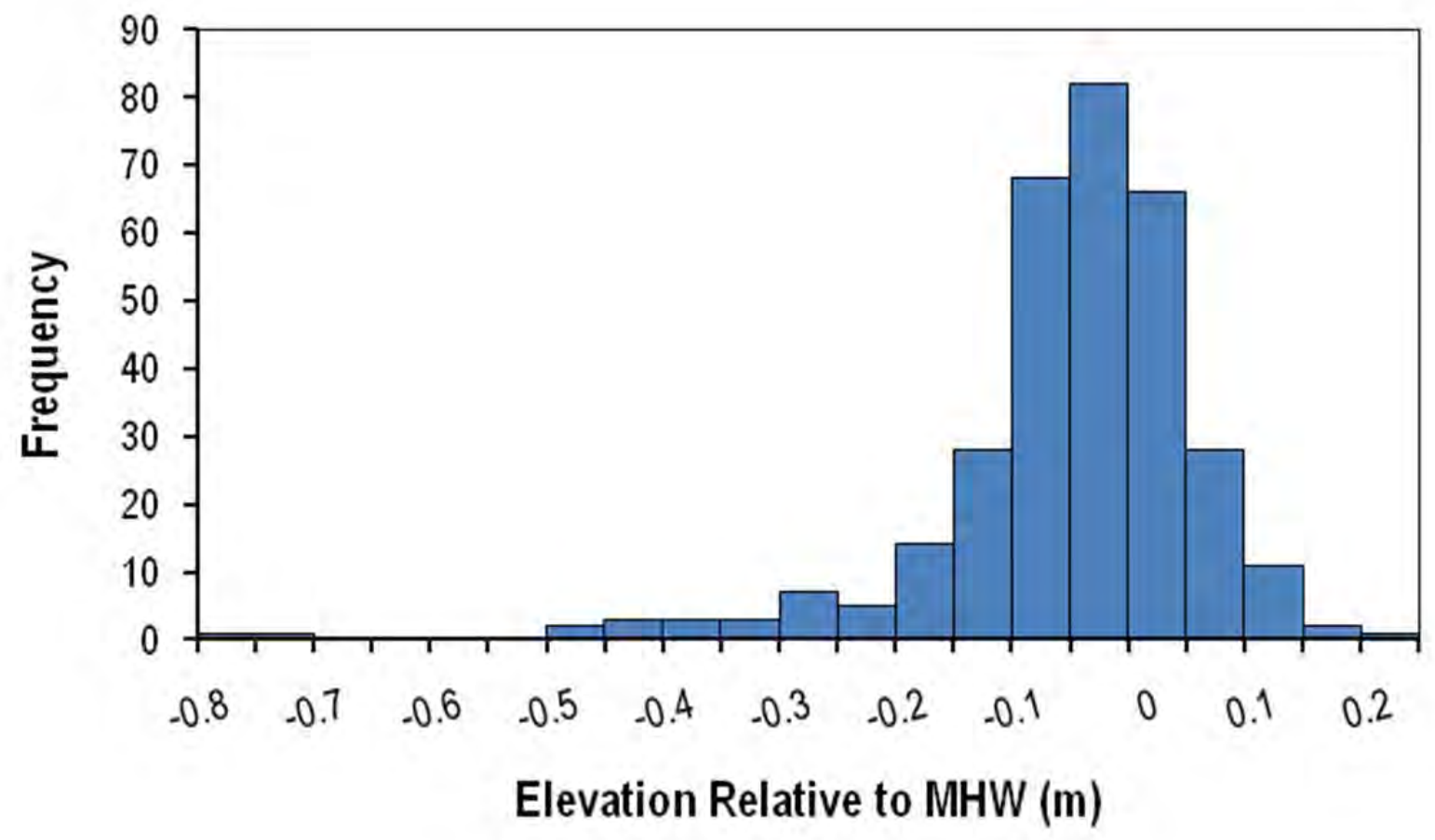

Figure A-2. Distribution of elevation samples relative to local mean high water (MHW), in meters (m), at Arrowhead Marsh. 


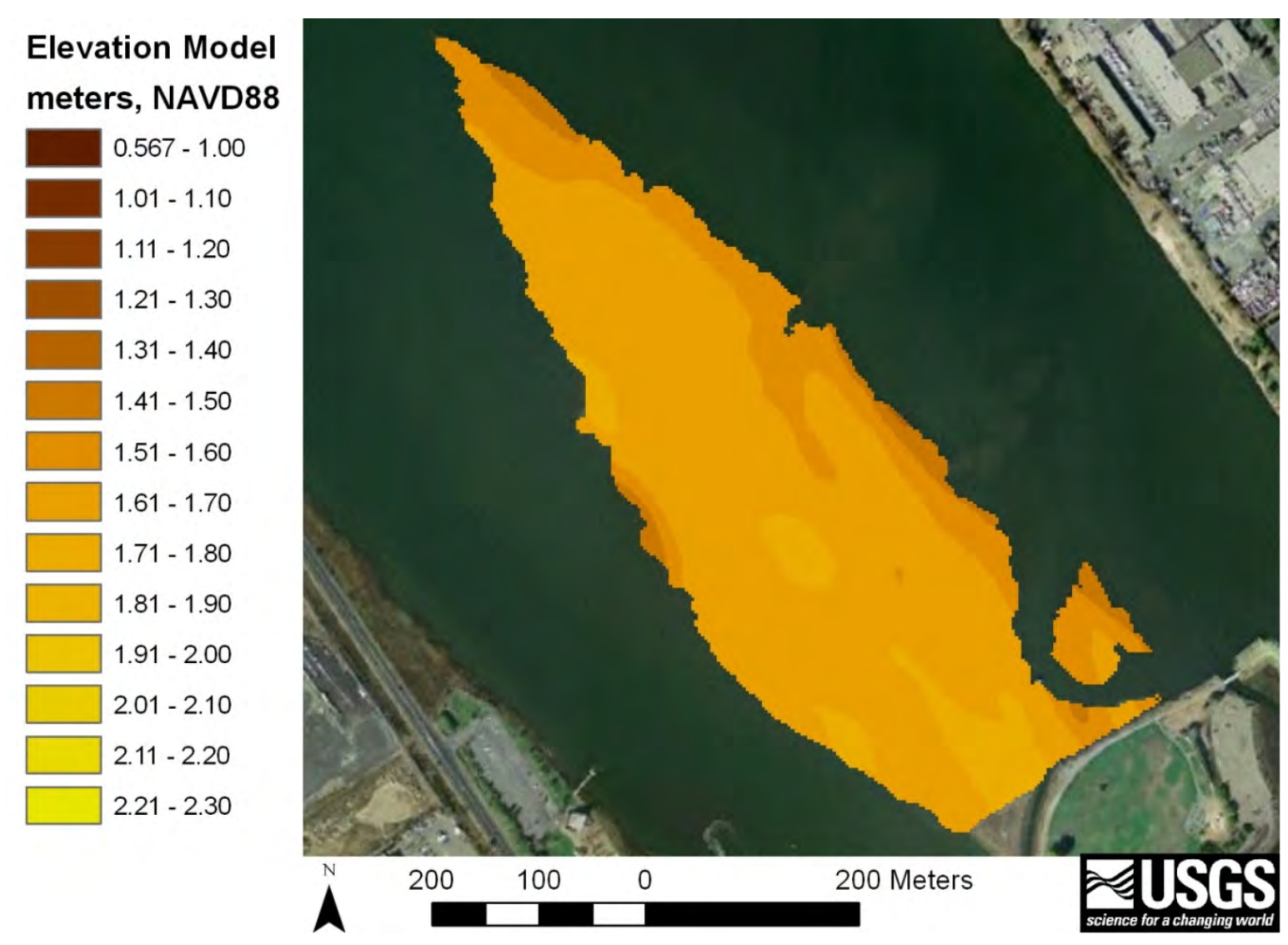

Figure A-3. Elevation model (3-meter resolution) developed from ground RTK GPS elevation data. 


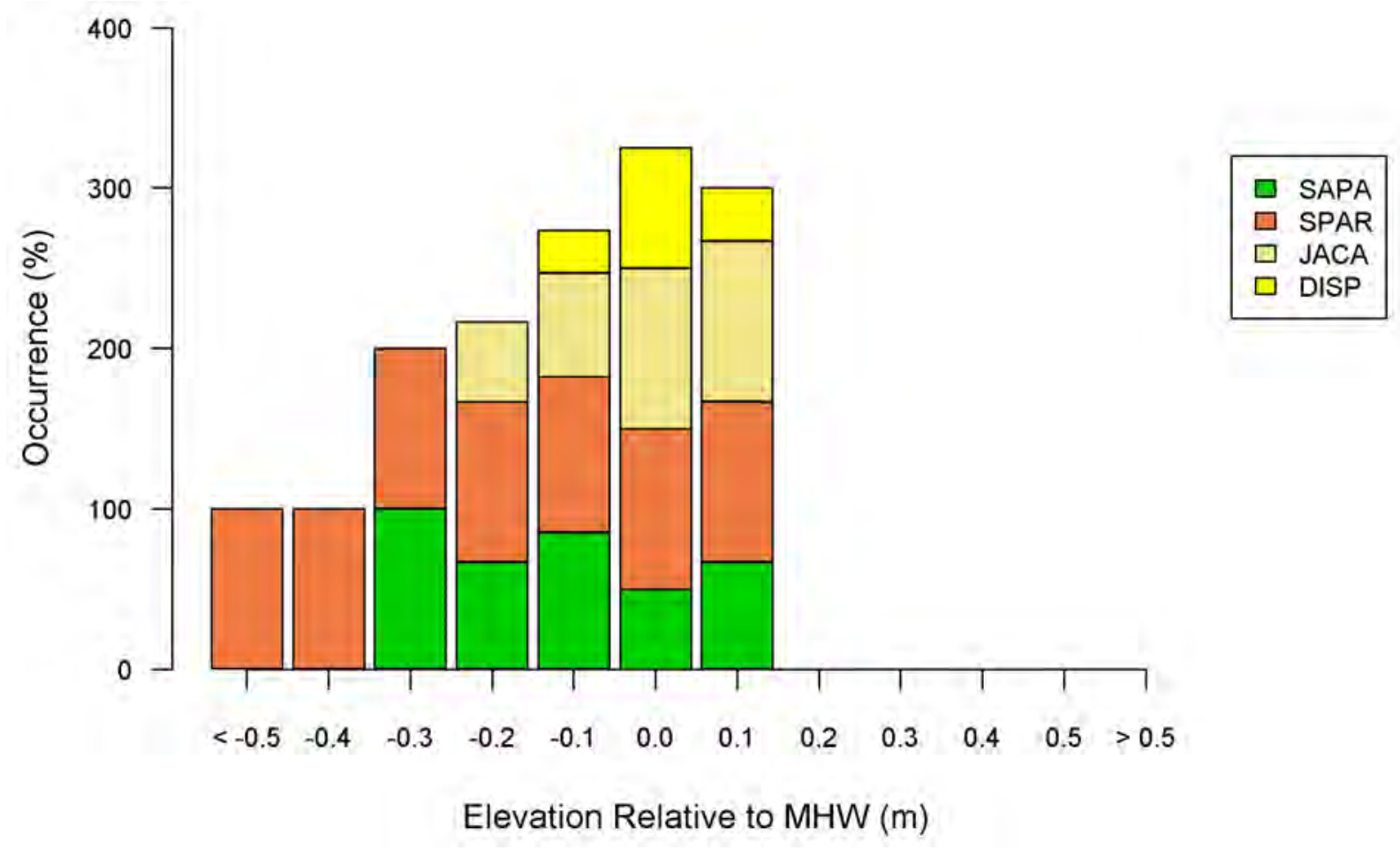

Figure A-4. Stratification of vegetation species was observed relative to mean high water (MHW), in meters (m). Species codes: SAPA = Sarcocornia pacifica; SPAR = Spartina spp.; JACA = Jaumea carnosa; DISP = Distichlis spicata.

\section{Vegetation surveys}

Vegetation and elevation surveys were done concurrently in December of 2009. A total of 50 locations (fig. A-1) were measured for vegetation composition, height (centimeters), and percentage cover (table A-1). We did not distinguish between invasive and native Spartina spp., nor among Schoenoplectus spp., in the survey. Vegetation in marshes is sensitive to soil salinity, inundation patterns, and disturbance; therefore, a stratification of vegetation species relative to MHW (fig. A-4) was observed within this low-slope marsh. 
Table A-1. Mean marsh elevation relative to mean high water (MHW), average, and max height, percentage cover with standard deviations (SD), and presence by species in Arrowhead Marsh.

[cm, centimeter; m, meter; $n$, sample number]

\begin{tabular}{|c|c|c|c|c|c|c|c|c|c|c|}
\hline Species & $\begin{array}{l}\text { Elevation } \\
\text { (MHW, m) }\end{array}$ & $\begin{array}{c}\text { Elevation SD } \\
(\mathrm{MHW}, \mathrm{m})\end{array}$ & $\begin{array}{l}\text { Mean } \\
\text { Height } \\
\text { (cm) }\end{array}$ & $\begin{array}{l}\text { Mean } \\
\text { Height } \\
\text { SD (cm) }\end{array}$ & $\begin{array}{c}\text { Max } \\
\text { Height } \\
\text { (cm) }\end{array}$ & $\begin{array}{c}\text { Max } \\
\text { Height } \\
\text { SD (cm) }\end{array}$ & $\begin{array}{c}\text { Cover } \\
\text { (percent) }\end{array}$ & $\begin{array}{l}\text { Cover SD } \\
\text { (percent) }\end{array}$ & $\mathrm{n}$ & $\begin{array}{l}\text { Presence } \\
\text { (percent) }\end{array}$ \\
\hline Sarcocornia pacifica & -0.15 & 0.07 & 21.63 & 16.40 & 25.97 & 18.88 & 22.18 & 17.05 & 38 & 76.00 \\
\hline Spartina spp. & -0.17 & 0.13 & 41.61 & 26.40 & 53.57 & 33.47 & 44.86 & 32.42 & 49 & 98.00 \\
\hline Jaumea carnosa & -0.13 & 0.07 & 11.88 & 7.25 & 14.47 & 8.58 & 31.38 & 25.40 & 32 & 64.00 \\
\hline Distichlis spicata & -0.11 & 0.06 & 17.00 & 10.10 & 19.69 & 11.46 & 13.00 & 13.92 & 13 & 26.00 \\
\hline
\end{tabular}




\section{Water-level monitoring}

Site-specific water level was monitored at Arrowhead for 1 year between December 2009 and November 2011. Water level was measured by using two data loggers: one deployed at the mouth of a second order channel and one in the marsh interior. During 2010, MHW was $1.72 \mathrm{~m}$ and mean higher high water (MHHW) was 1.91 $\mathrm{m}$ for the site (NAVD88). Water levels were recorded throughout the year to evaluate seasonal patterns in tides. The period when the marsh platform (defined as mean elevation) was inundated most often was from December 2009 through February 2010 (fig. A-5). During those months, above average water levels were recorded because of several record-breaking storms that brought low air pressure and substantial rainfall, resulting in higher than predicted tides. The cumulative rainfall in January 2010 was above average throughout the San Francisco Bay estuary (SFBE), and daily rainfall records were broken in some locations (National Oceanic and Atmospheric Administration). This resulted in longer inundation periods of the marsh platform.

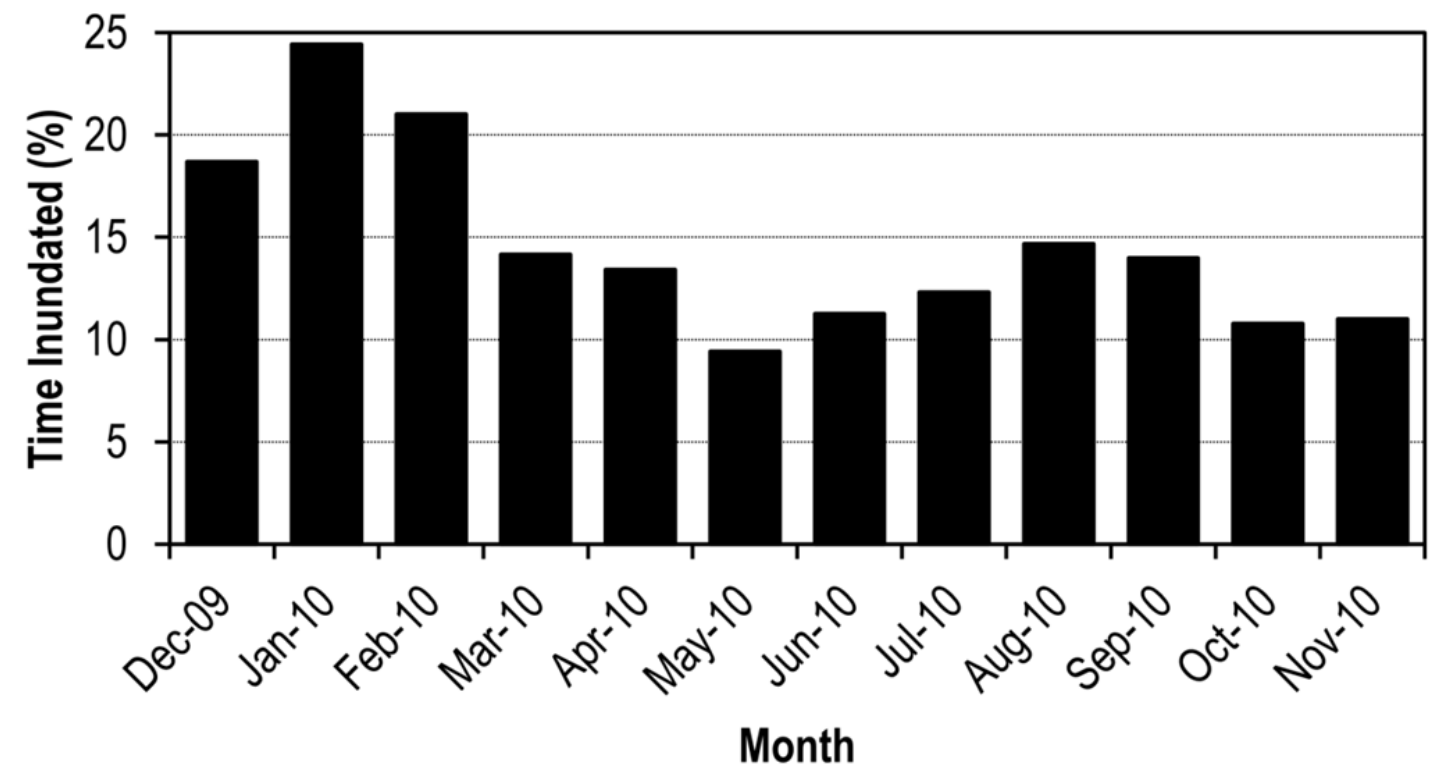

Figure A-5. Percentage of time Arrowhead was inundated monthly, based on the mean elevation of the marsh platform.

\section{Marsh elevation modeling}

Arrowhead had a low starting elevation and was located low in the tidal range, relative to our other study sites. The WARMER model results indicated that Arrowhead will not keep pace with sea-level rise (SLR) through this century. WARMER results showed a gradual reduction in elevation relative to MHW over time, with a more dramatic decline after 2060 (fig. A-6). By 2080, the marsh was projected to be below mean sea level (MSL) and, therefore, to transition to a mudflat (fig. A-7). 


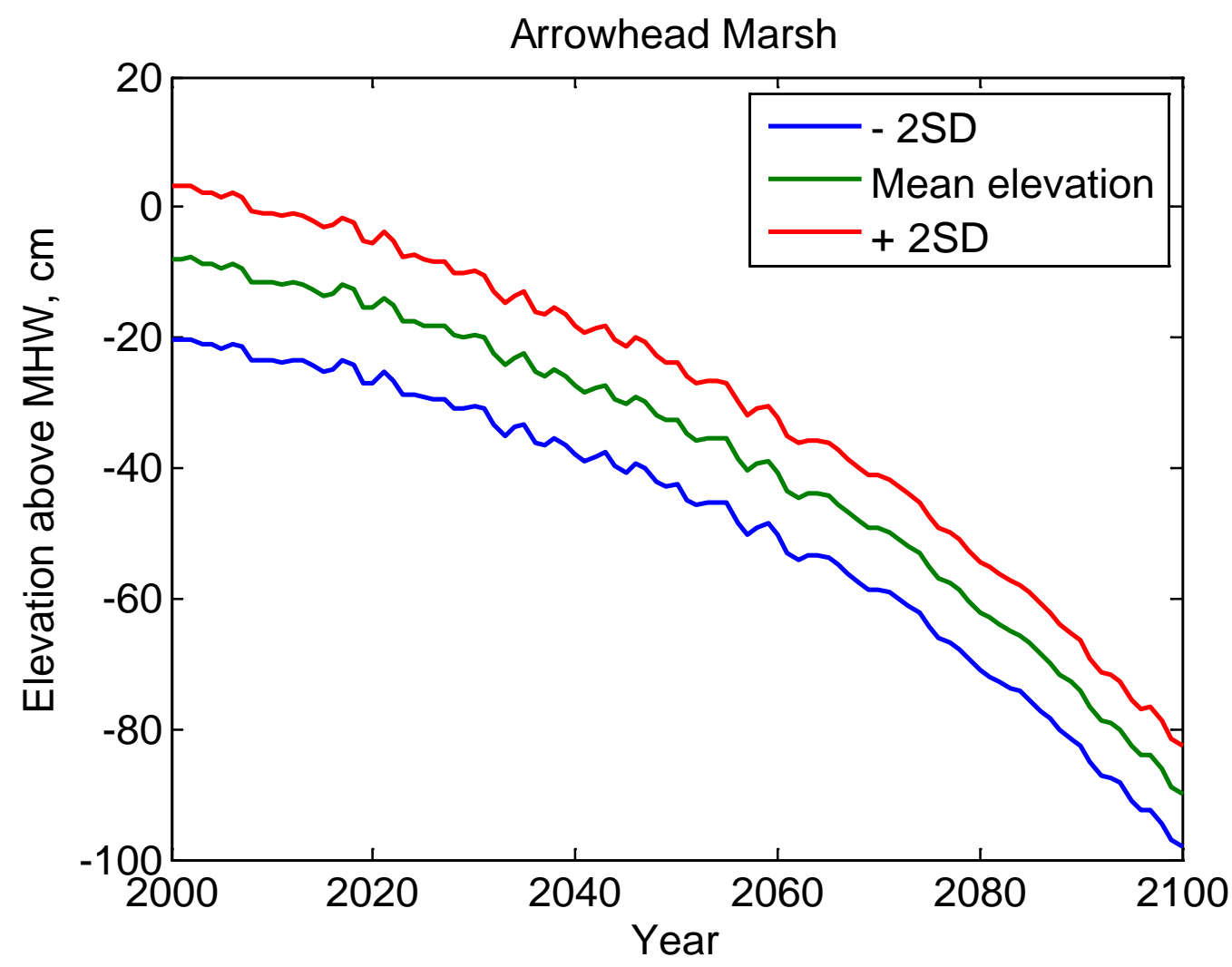

Figure A-6. WARMER scenarios for Arrowhead elevation change. Elevation above mean high water (MHW), in centimeters (cm), is plotted against model year with two standard deviations (SD). 


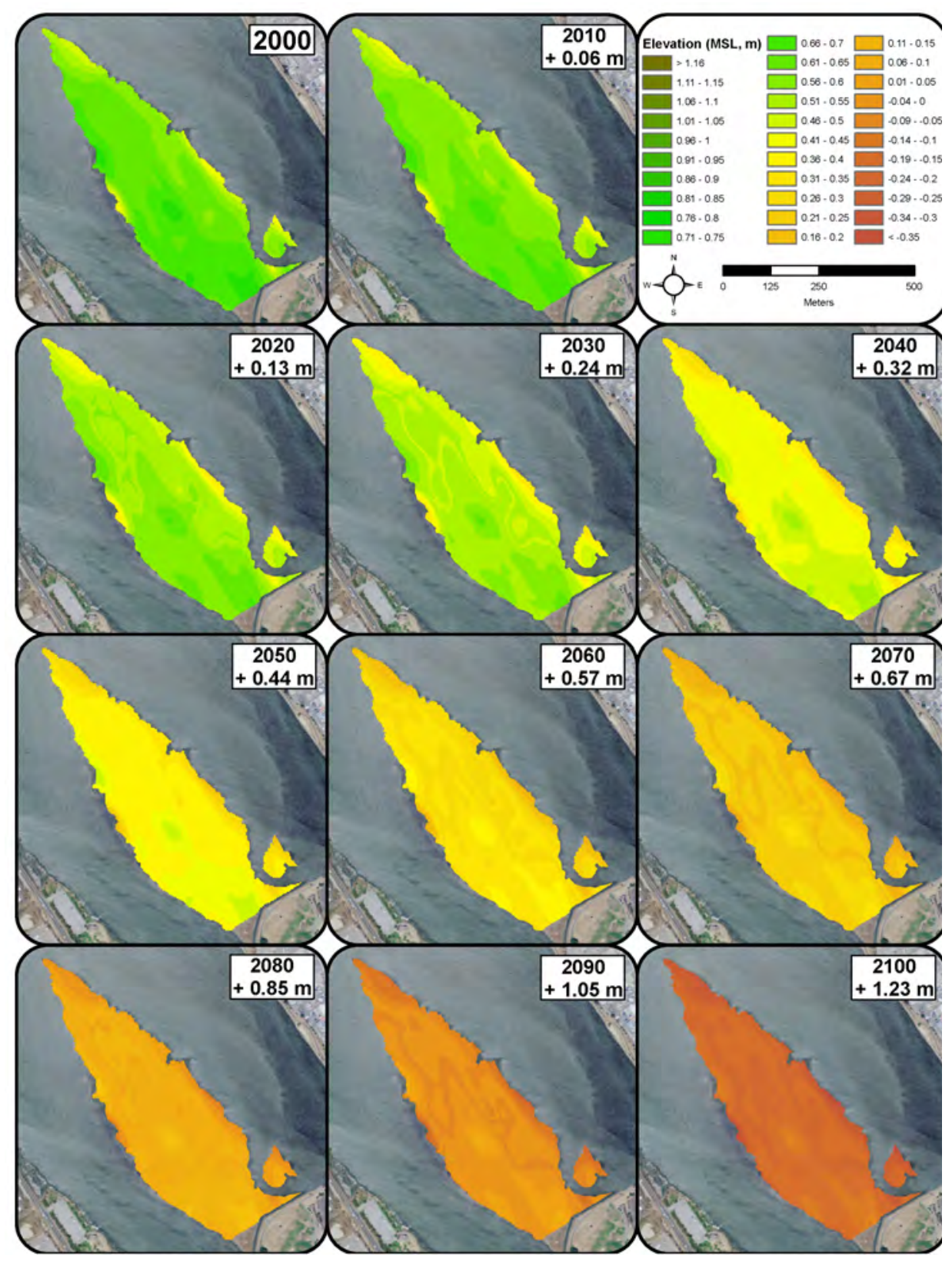

Figure A-7. Spatial WARMER results for Arrowhead. WARMER accounts for changes in relative sea level, subsidence, inorganic sediment accumulation, above and belowground organic matter productivity, compaction, and decay. Non-linear sea-level rise projections for California were used (Cayan and others, 2009). [MSL, mean sea level; $m$, meters] 
Elevation relative to the local tidal datum can be tied to vegetation observations. Vegetation data were categorized as mudflat, low, mid, high marsh, or upland transition plant communities and used to interpret the WARMER SLR results (figs. A-8 and A-9). Upland transition (greater than $1.0 \mathrm{~m}$ MSL) was characterized by coyote bush (Baccharis pilularis). High marsh (0.7-1.0 m MSL) was characterized by Frankenia salina and Jaumea carnosa, whereas mid marsh (0.45-0.7 m MSL) was dominated by Sarcocornia pacifica. Low marsh (0.2-0.45 m MSL) was characterized by Spartina spp. or, in brackish areas, by Schoenoplectus spp. Mudflat habitat (less than $0.2 \mathrm{~m} \mathrm{MSL)} \mathrm{was}$ unvegetated or sparsely covered with Spartina spp. Currently, vegetation at Arrowhead is primarily categorized as mid marsh with some high-marsh vegetation. All high marsh vegetation was projected to disappear with a $0.06 \mathrm{~m}$ SLR. The largest transition was around 2040 (0.32 $\mathrm{m} \mathrm{SLR}$ ), with a projected change from mid- to low-marsh vegetation. A transition to complete mudflat was projected by 2080 (0.85 m SLR).

The WARMER model parameters for Arrowhead were extrapolated by using sediment core data from China Camp marsh; thus, SLR projections need to be interpreted with caution because local sedimentation processes could differ. To improve results, local site-specific sediment core data could be collected along with suspended-sediment concentration data to characterize sediment deposition potential. 


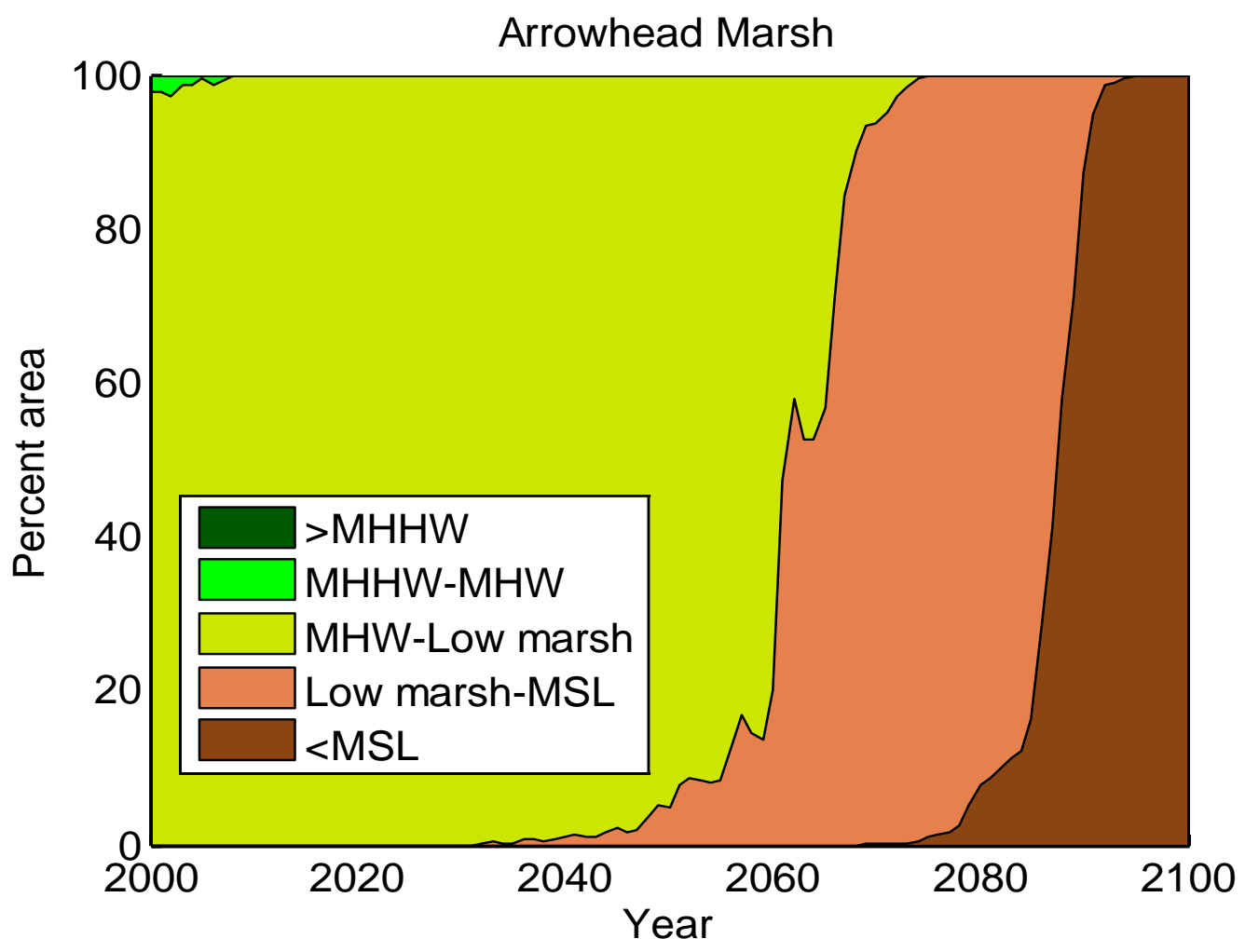

Figure A-8. Area of Arrowhead Marsh within a given tidal range for the duration of the simulation period. [MHHW, mean higher high water; MHW, mean high water; MSL, mean sea level; >, greater than; <, less than]. 


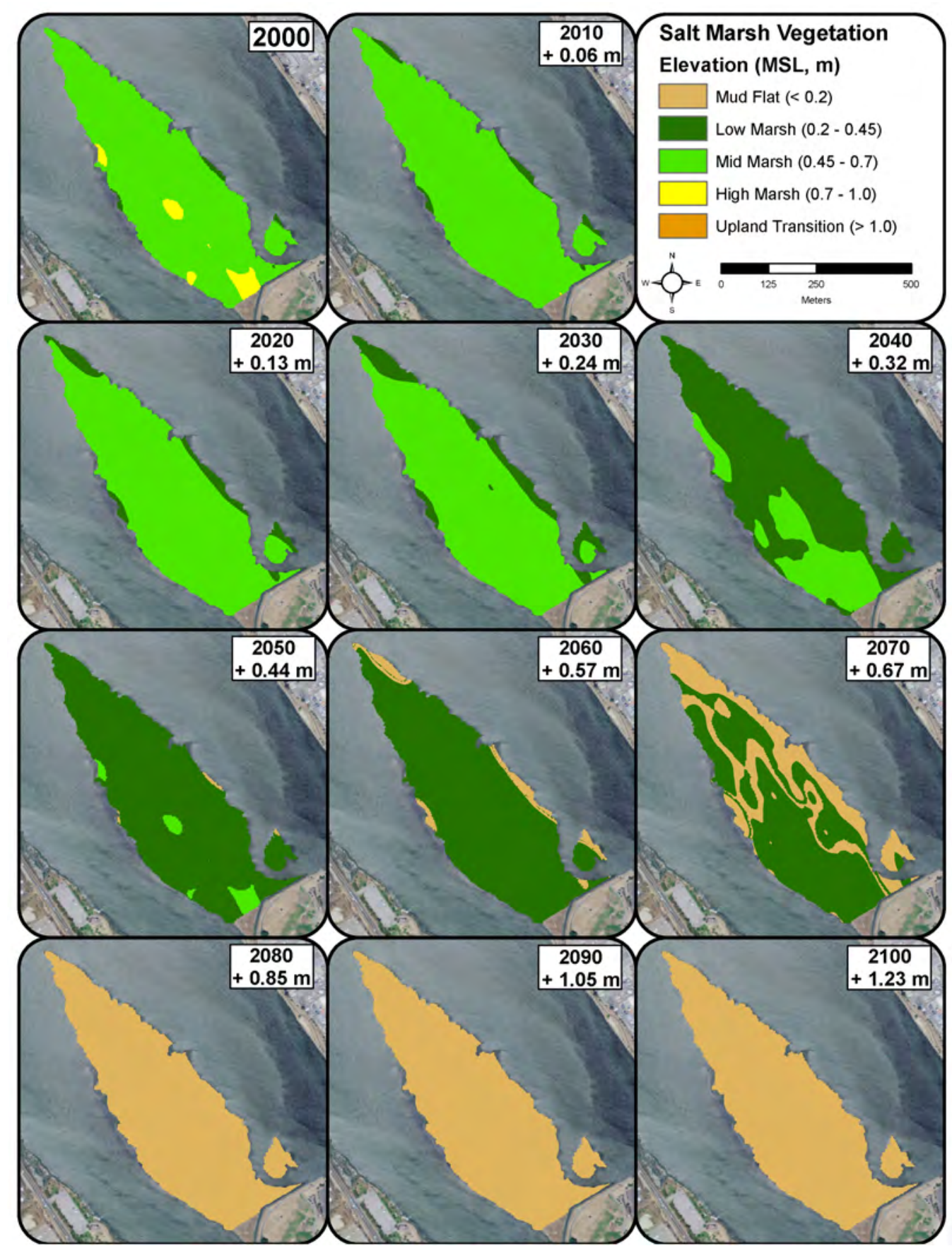

Figure A-9. Arrowhead WARMER results in terms of plant communities relative to mean sea level (MSL), in meters (m): mudflat, low, mid, or high marsh, or upland transition. 


\section{Appendix B. Black John Marsh}

\section{Introduction}

Black John Marsh (hereafter, "Black John") is located in Sonoma County at the confluence of Black John Slough, Rush Creek, and the Petaluma River. It is owned and managed by the California Department of Fish and Game. It is influenced by both tidal flow and freshwater input from the Petaluma River. Black John is part of the Petaluma Marsh complex, which is the largest marsh complex in California that has never been diked or drained. The land surrounding the marsh is used almost exclusively for agriculture and light grazing. In 2003, the California State Coastal Conservancy funded the acquisition and restoration of a 255.8 hectare (ha) parcel just west of Black John, increasing the potential size of the marsh. Black John is home to several endangered species and species of concern such as California black rail (Laterallus jamaicensis coturniculus).

This study focused on 30.9 ha portion of Black John. Elevation and vegetation surveys were completed in 2010 by using an RTK GPS. To monitor tidal inundation and salinity, two water-level loggers were deployed in 2009.

\section{Results}

\section{Elevation surveys}

A total of 213 elevation measurements were taken at Black John (fig. B-1). The elevation range was $1.18-1.97$ meters $(\mathrm{m})$, with a mean of $1.75 \mathrm{~m}$ (NAVD88). Half (50 percent) of the survey points were within $1.70-1.80 \mathrm{~m}$, a $0.1 \mathrm{~m}$ range (fig. B-2). Over half (67 percent) of the survey points were located at elevations above mean high water (MHW). A 3-m resolution elevation model was developed in ArcGIS 9.3 (ESRI, Redlands, Calif.), by using the kriging method (fig. B-3). This baseline elevation model was used as the initial state in the WARMER sea-level rise (SLR) model; WARMER results were extrapolated across the elevation model. 

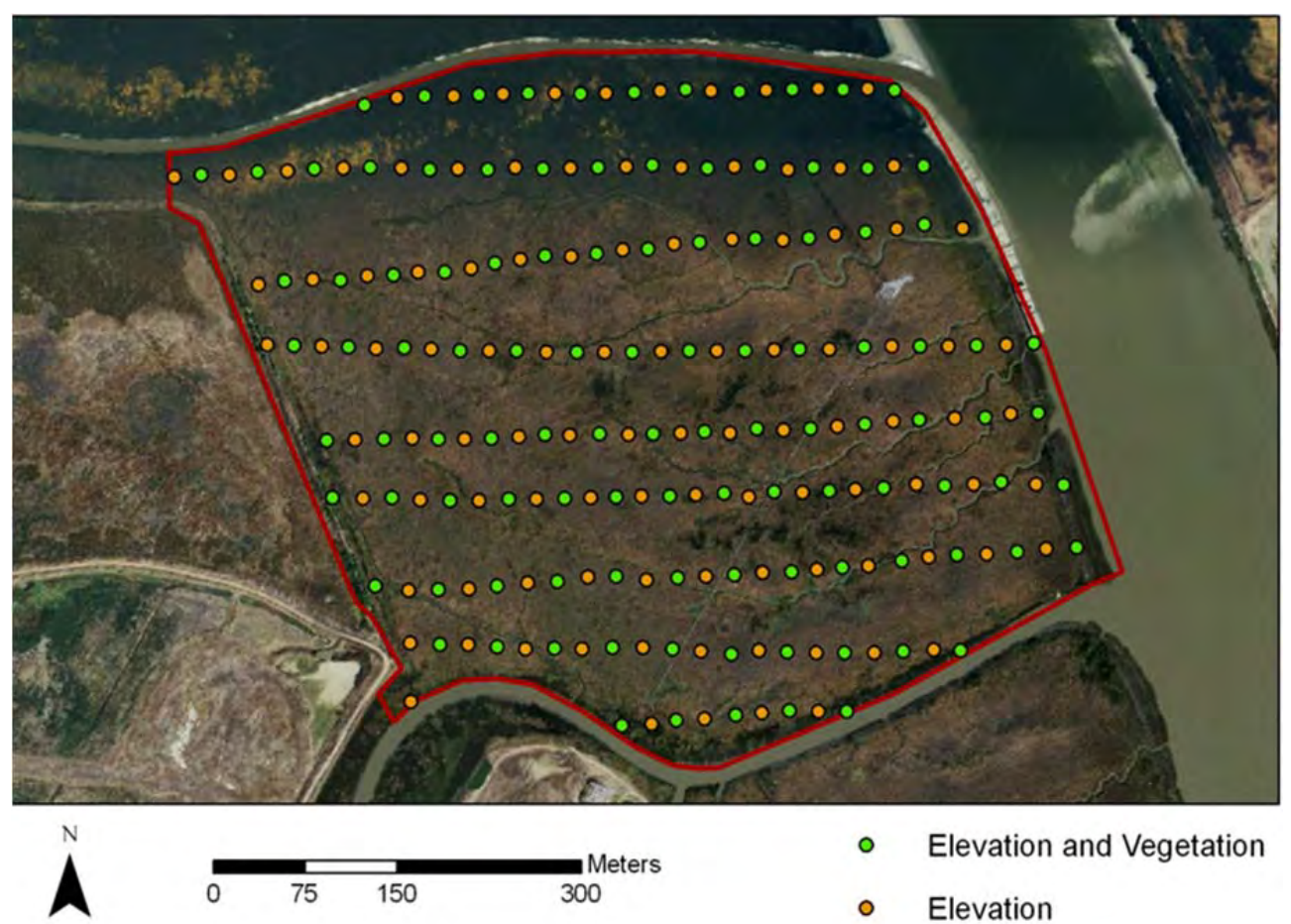

- Elevation and Vegetation

- Elevation

Figure B-1. Elevation and vegetation survey points at Black John in 2010.

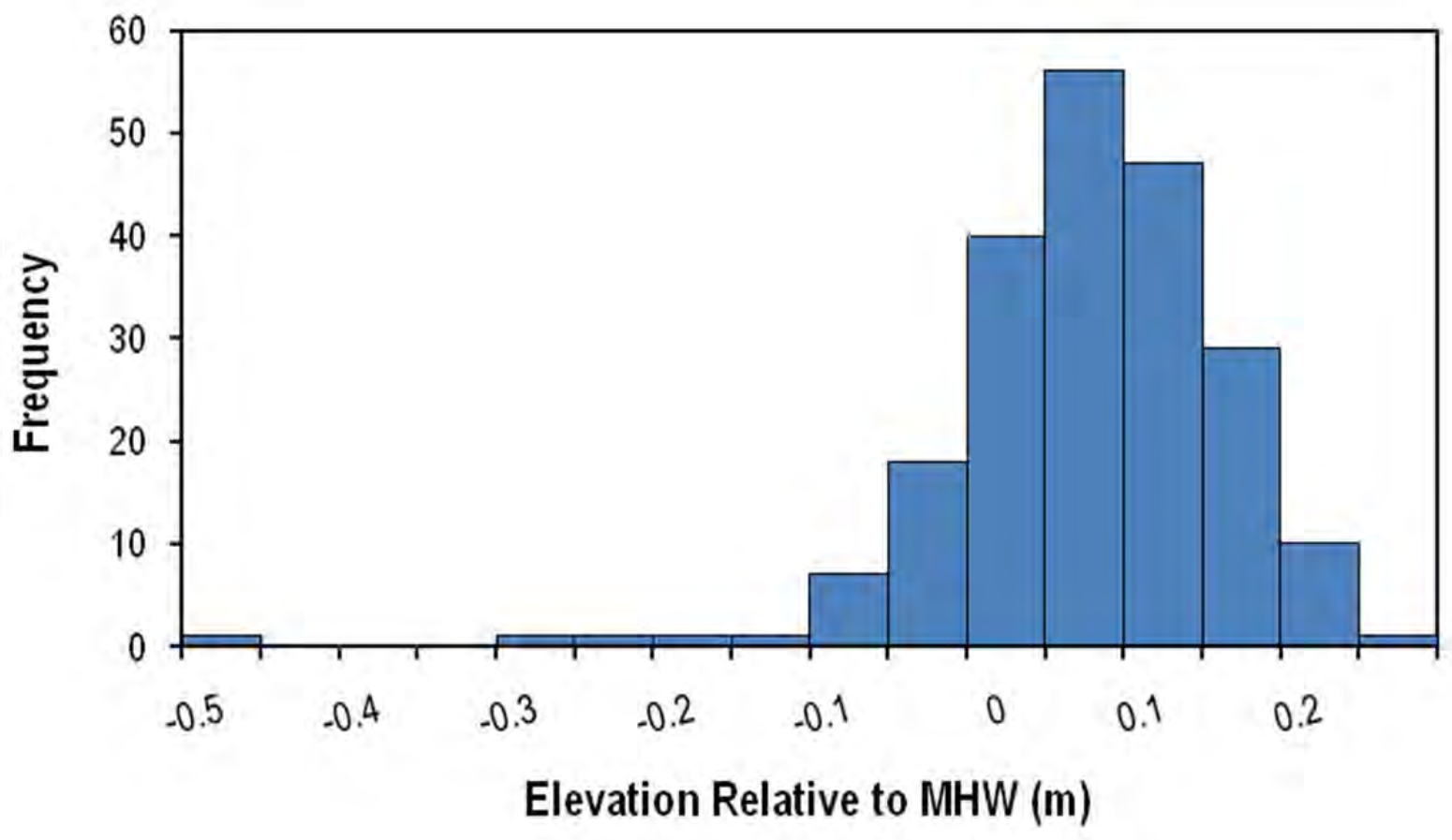

Figure B-2. Distribution of elevation samples relative to local mean high water (MHW), in meters (m), at Black John. 


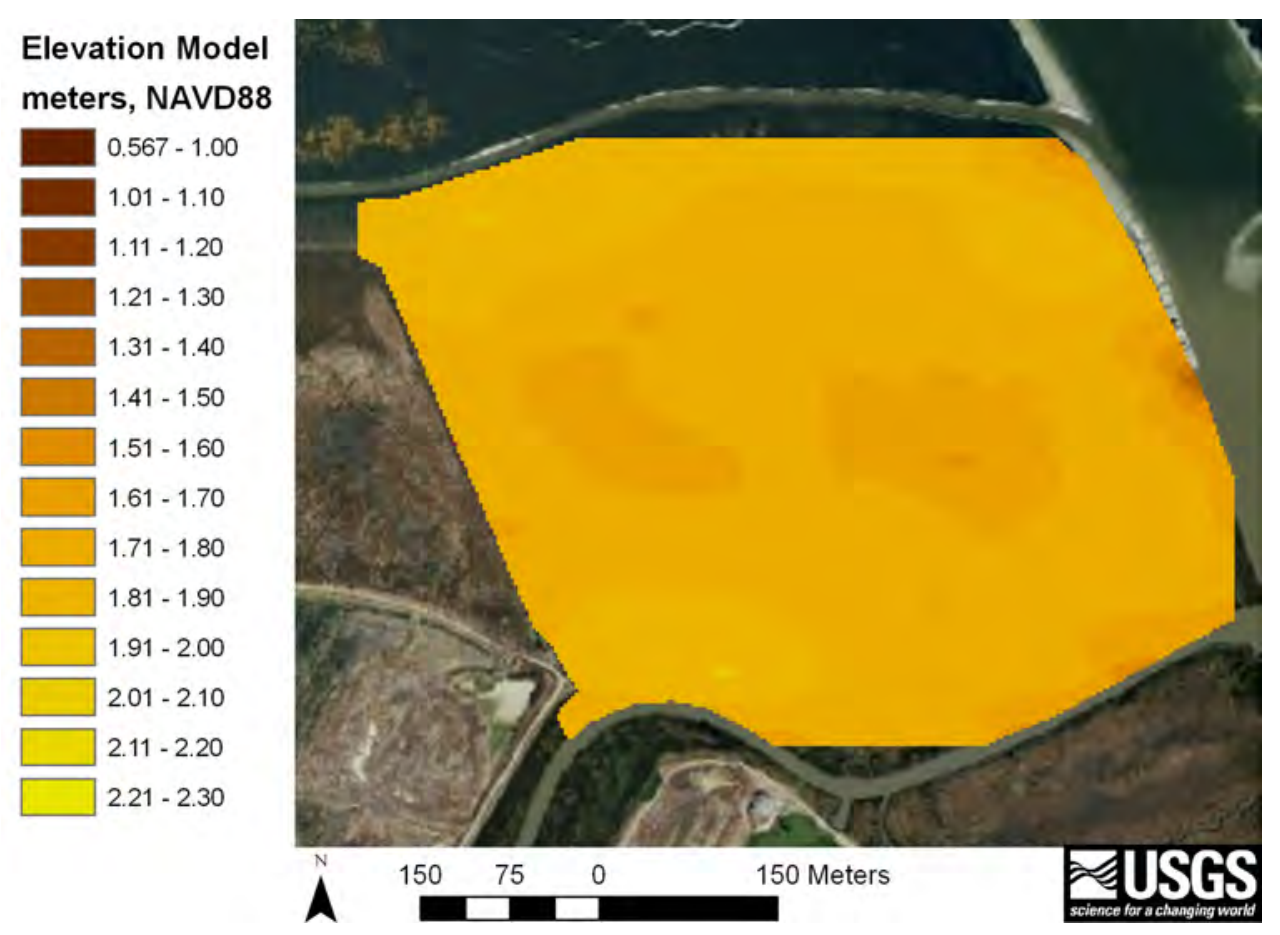

Figure B-3. Elevation model (3-meter resolution), developed from ground RTK GPS elevation data. Parameters were optimized to produce minimal root-mean-square error.

\section{Vegetation surveys}

Vegetation and elevation surveys were carried out concurrently in June 2010. A total of 108 locations (fig. B-1) were measured for vegetation composition, height, and percentage cover (table B-1). We did not distinguish between Spartina spp., or among Schoenoplectus spp., in the survey. Vegetation in marshes is sensitive to soil salinity, inundation patterns, and disturbance; therefore, a stratification of vegetation species relative to MHW (fig. B-4) was observed within this low-slope marsh. 
Table B-1. Mean marsh elevation relative to mean high water (MHW), average, and max height, percentage cover with standard deviations (SD), and presence by species at Black John.

[cm, centimeter; m, meter; $n$, sample number]

\begin{tabular}{|c|c|c|c|c|c|c|c|c|c|c|}
\hline Species & $\begin{array}{c}\text { Elevation } \\
(M H W, \\
m)\end{array}$ & $\begin{array}{c}\text { Elevation } \\
\text { SD (MHW, } \\
m)\end{array}$ & $\begin{array}{c}\text { Mean } \\
\text { Height } \\
(\mathrm{cm})\end{array}$ & $\begin{array}{l}\text { Mean } \\
\text { Height } \\
\text { SD (cm) }\end{array}$ & $\begin{array}{c}\text { Max } \\
\text { Height } \\
\text { (cm) }\end{array}$ & $\begin{array}{c}\text { Max } \\
\text { Height } \\
\text { SD (cm) }\end{array}$ & $\begin{array}{c}\text { Cover } \\
\text { (percent) }\end{array}$ & $\begin{array}{c}\text { Cover } \\
\text { SD } \\
\text { (percent) }\end{array}$ & $n$ & $\begin{array}{l}\text { Presence } \\
\text { (percent) }\end{array}$ \\
\hline Salicornia pacifica & 0.02 & 0.12 & 37.59 & 11.65 & 51.46 & 14.62 & 73.22 & 30.60 & 282 & 91.56 \\
\hline Spartina spp. & -0.29 & 0.03 & 47.50 & 3.54 & 50.00 & 7.07 & 13.00 & 16.97 & 2 & 0.65 \\
\hline Schoenoplectus spp. & 0.02 & 0.10 & 64.66 & 17.01 & 82.18 & 23.42 & 13.10 & 15.46 & 125 & 40.58 \\
\hline Grindelia stricta & 0.09 & 0.13 & 68.09 & 21.71 & 83.26 & 28.38 & 41.05 & 25.88 & 58 & 18.83 \\
\hline Jaumea carnosa & 0.13 & - & 15.00 & - & 20.00 & - & 25.00 & - & 1 & 0.32 \\
\hline Frankenia salina & 0.16 & 0.31 & 27.58 & 8.81 & 35.00 & 11.48 & 45.42 & 38.82 & 12 & 3.90 \\
\hline Distichlis spicata & 0.13 & 0.24 & 25.83 & 9.17 & 33.47 & 9.07 & 38.36 & 28.66 & 66 & 21.43 \\
\hline Lepidium latifolium & 0.38 & 0.34 & 92.00 & 21.63 & 113.38 & 19.60 & 35.75 & 27.76 & 8 & 2.60 \\
\hline Atriplex triangularis & 0.01 & 0.05 & 13.33 & 7.64 & 15.00 & 13.23 & 8.67 & 7.09 & 3 & 0.97 \\
\hline Baccharis pilurais & 0.19 & 0.34 & 60.00 & 22.32 & 91.67 & 33.02 & 28.22 & 28.85 & 27 & 8.77 \\
\hline
\end{tabular}




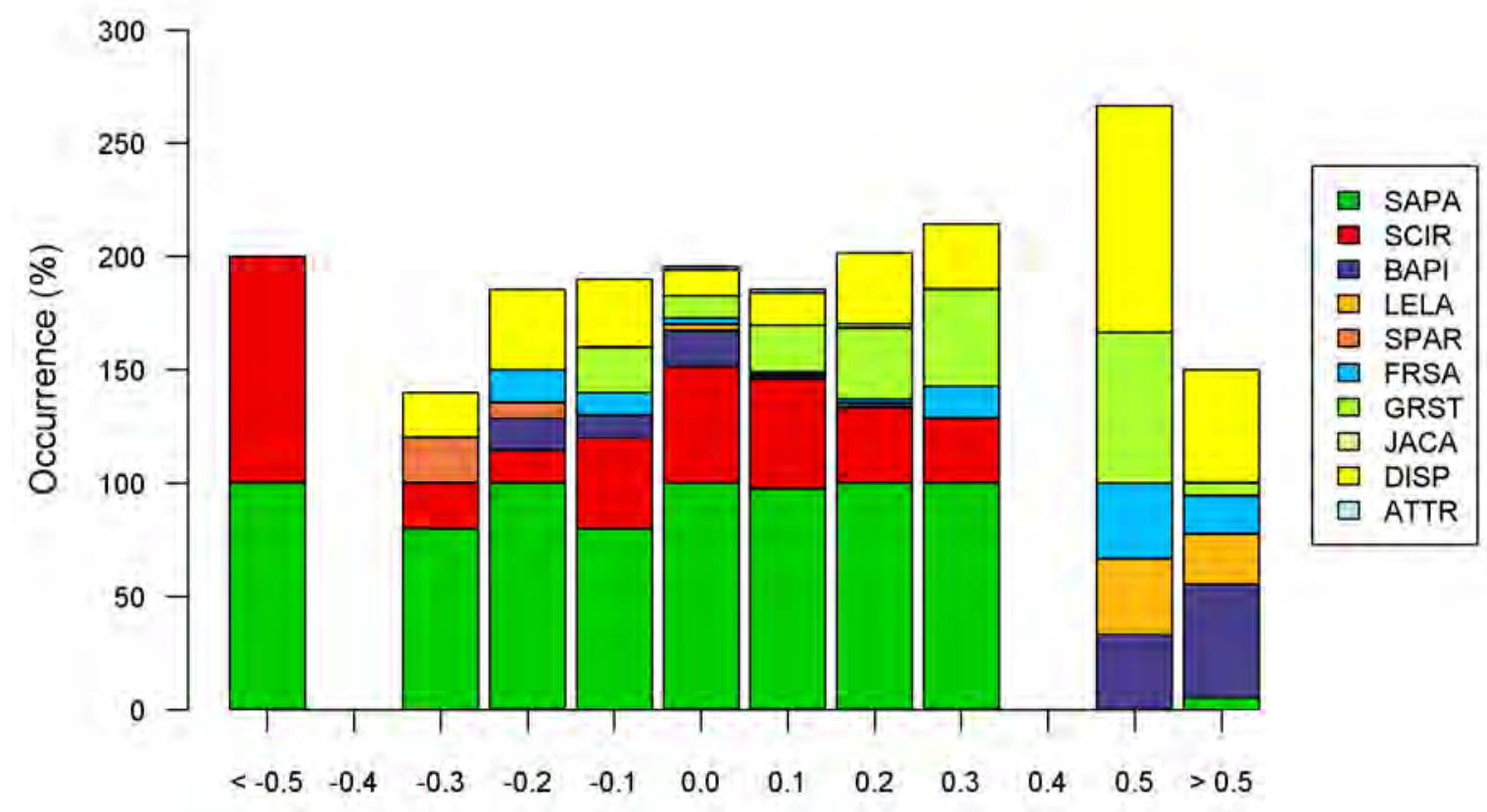

Elevation Relative to $\mathrm{MHW}(\mathrm{m})$

Figure B-4. Stratification of vegetation species was observed relative to mean high water (MHW), in meters (m). Species codes: SAPA = Sarcocornia pacifica; SCIR = Schoenoplectus spp.; BAPI = Baccharis pilurais; LELA: = Lepidium latifolium; SPAR = Spartina spp; FRSA = Frankenia salina; GRST = Grindelia stricta; JACA = Jaumea carnosa; DISP = Distichlis spicata; ATTR = Atriplex triangularis

\section{Water-level monitoring}

Site-specific water level was measured from December 2009 to November 2010. Water level was measured by using two data loggers: one deployed at the mouth of a second order channel and one in the marsh interior. Mean high water (MHW) was 1.73 $\mathrm{m}$, and mean higher high water (MHHW) was $1.91 \mathrm{~m}$ for the site (NAVD88). The period when the salt marsh platform (defined as mean marsh elevation) was inundated most often was during January and February 2010 (fig. B-5). During those months, water levels were above average because of several record breaking storms that brought low air pressure and substantial rainfall, resulting in higher than predicted tides. The cumulative rainfall in January 2010 was above average throughout the San Francisco Bay area, and daily rainfall records were broken in some locations (National Oceanic and Atmospheric Administration). This resulted in longer inundation periods of the marsh platform. Mean salinity during 2010 at Black John was $15.3(\mathrm{SD}=6.6)$ practical salinity scale (PSU). 


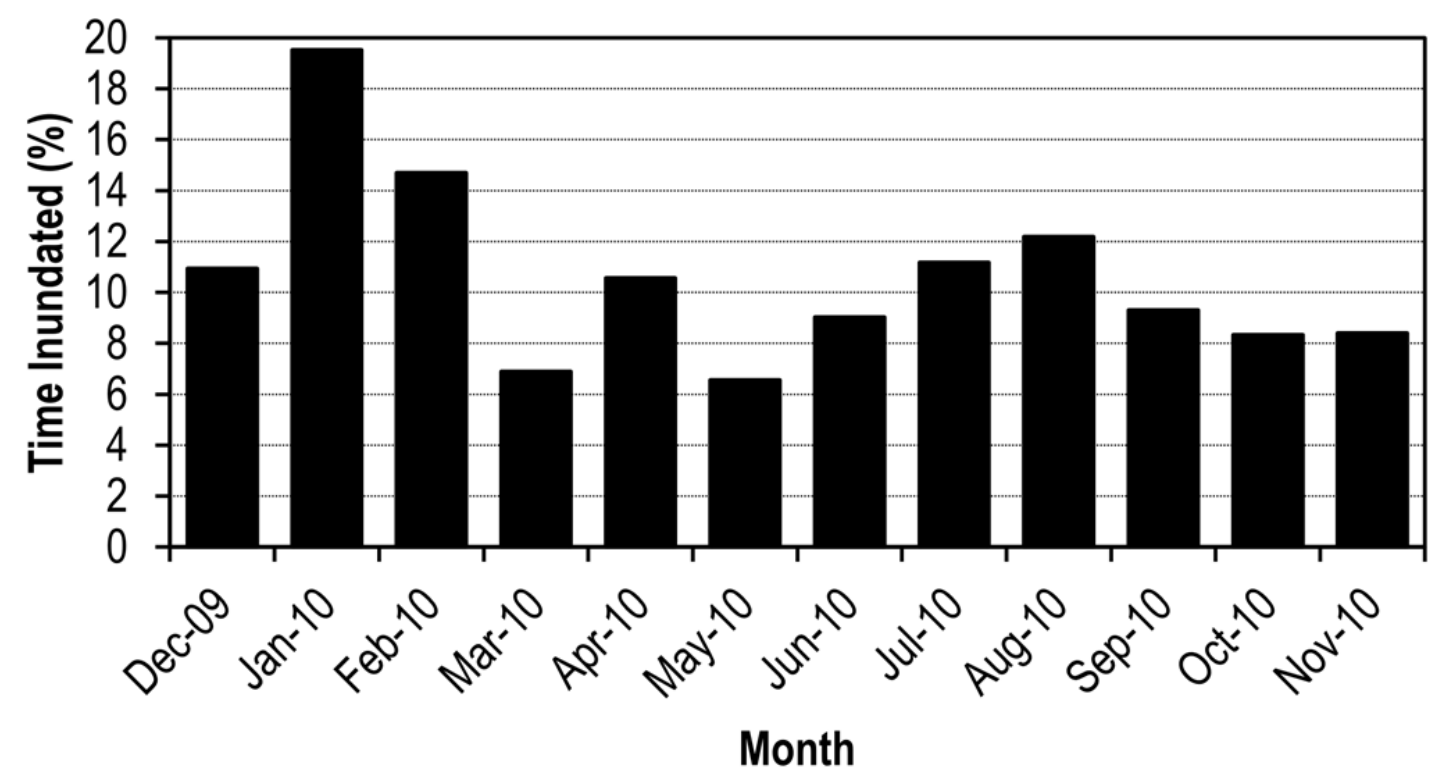

Figure B-5. Percentage of time Black John was inundated monthly, based on the mean elevation of the marsh platform.

\section{Marsh elevation modeling}

The WARMER scenario indicated that Black John will not keep pace with sealevel rise (SLR) through this century. WARMER results showed a gradual reduction in elevation relative to MHW over time, with a more dramatic decline after 2060 (fig. B-6). By 2080, the marsh was projected to be below mean sea level and to transition to mudflat (fig. B-7). 


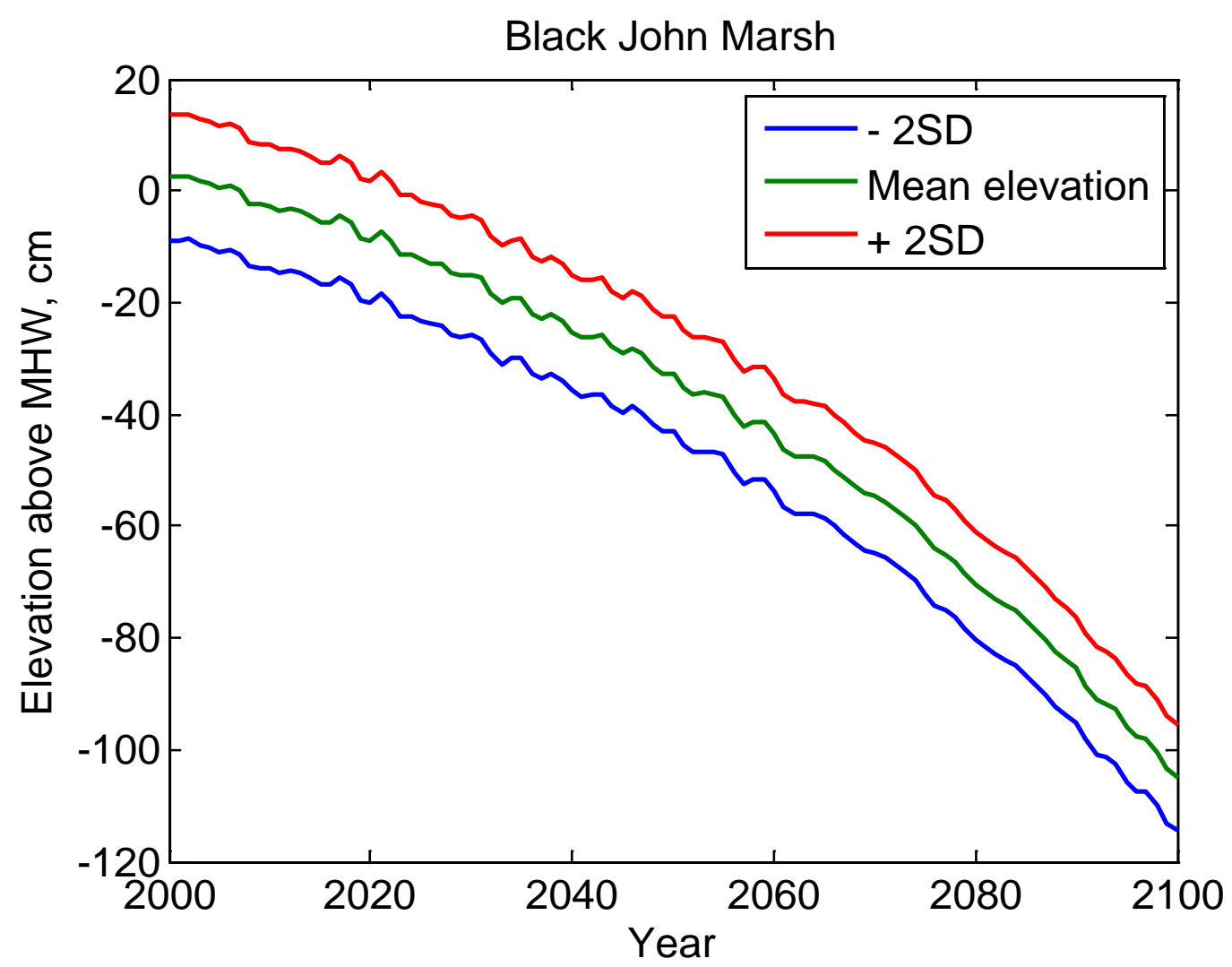

Figure B-6. WARMER scenarios for Black John marsh elevation change. Elevation, in centimeters $(\mathrm{cm})$, above mean high water (MHW) is plotted against model year with two standard deviations (SD). 


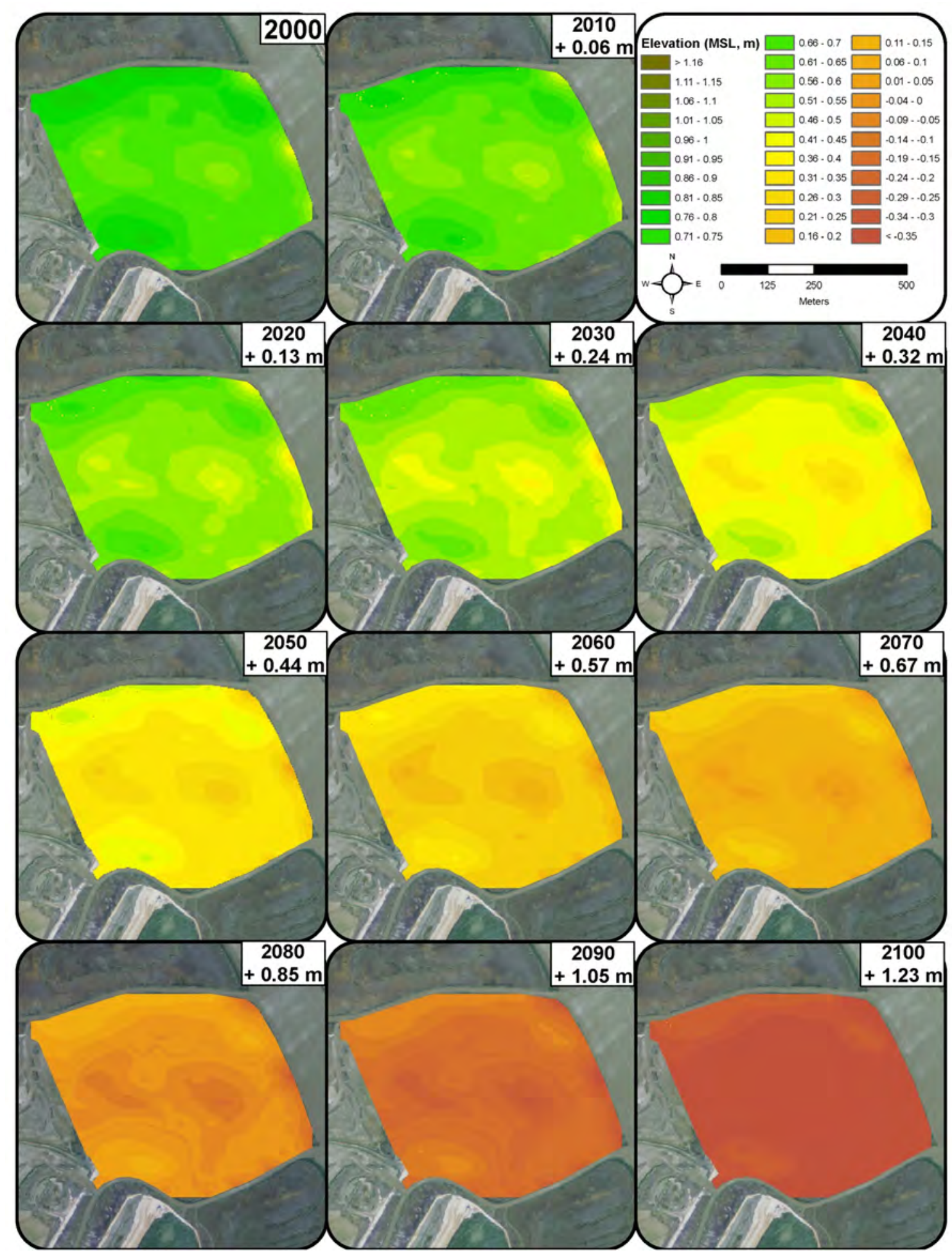

Figure B-7. WARMER results for Black John. WARMER accounts for changes in relative sea level, subsidence, inorganic sediment accumulation, above and belowground organic matter productivity, compaction, and decay. Non-linear sea-level rise projections for California were used (Cayan and others, 2009). [MSL, mean sea level; m, meters] 
Elevation relative to the local tidal datum can be tied to vegetation observations. Vegetation data were categorized as mudflat, low, mid, high marsh, or upland transition plant communities and used to interpret the WARMER SLR results (figs. B-8 and B-9). Upland transition (greater than $1.0 \mathrm{~m}$ MSL) was characterized by coyote bush (Baccharis pilularis). High marsh (0.7-1.0 m MSL) was characterized by Frankenia salina and Jaumea carnosa, whereas mid marsh (0.45-0.7 m MSL) was dominated by Sarcocornia pacifica. Low marsh (0.2-0.45 m MSL) was characterized by Spartina spp. or, in brackish areas, by Schoenoplectus spp. Mudflat habitat (less than $0.2 \mathrm{~m} \mathrm{MSL)} \mathrm{was}$ unvegetated or sparsely covered with Spartina spp. Currently, Black John is a mixture of mid- and high-marsh vegetation. All high-marsh vegetation was projected to disappear by 2040 (0.24 m SLR). The largest change was projected for around 2040 (0.32 m SLR), at which time the majority of the marsh transitions to low marsh, a habitat zone that currently represents a negligible area at Black John. A transition to complete mudflat was projected by 2080 (0.85 $\mathrm{m} \mathrm{SLR})$.

The WARMER model parameters for Black John were extrapolated by using sediment core data from Petaluma Marsh; thus, predictions need be interpreted with caution, as local sedimentation processes can be different between these marshes. In addition, quality-control issues with the Petaluma sediment cores resulted in the removal of data that indicated high sedimentation rates. The Petaluma River is a major source of sediment to San Francisco Bay; therefore, it is likely that the current inputs to WARMER underestimate accretion potential at Black John. To improve results, local site-specific sediment core data could be collected along with suspended-sediment concentration data to characterize sediment deposition potential. 


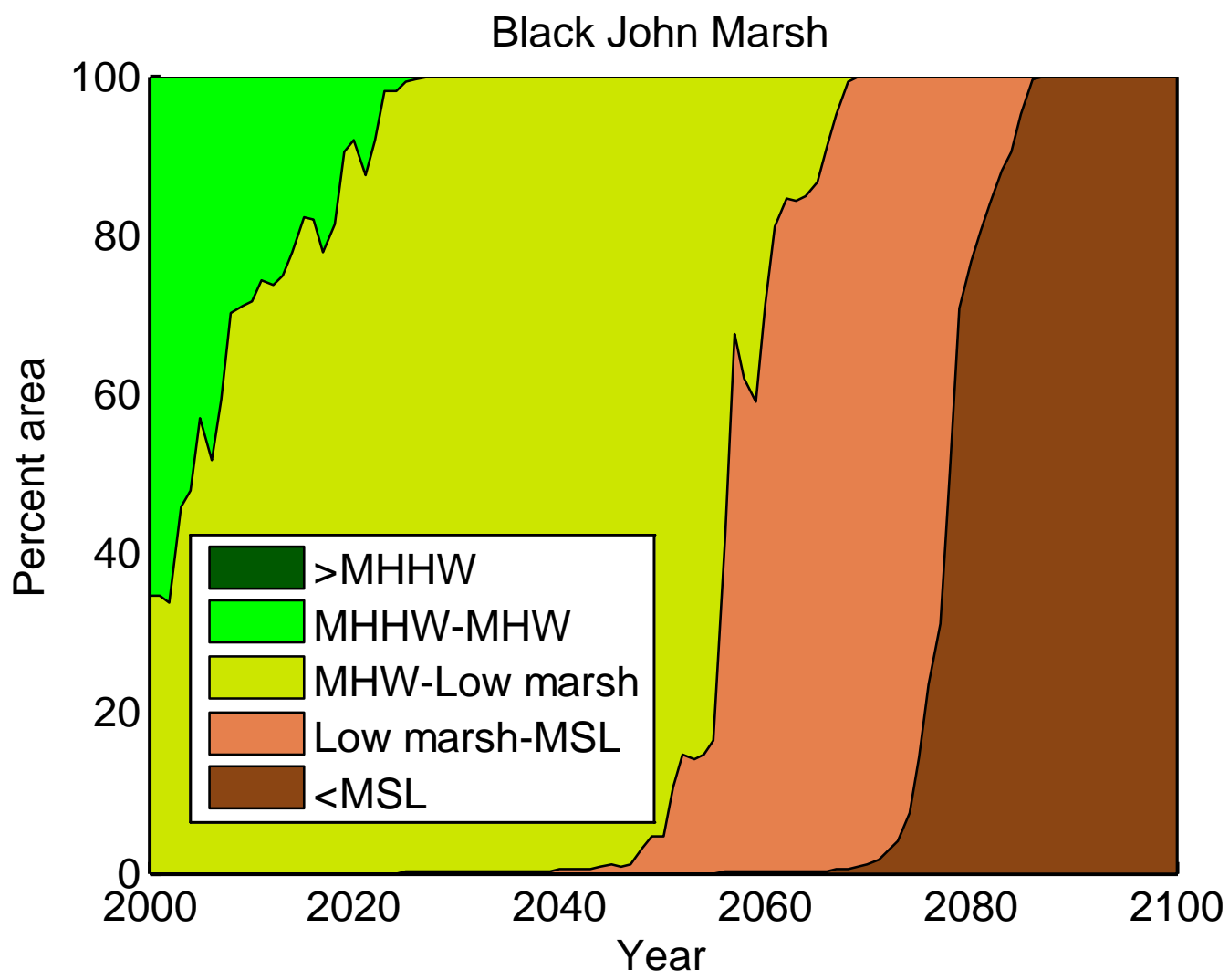

Figure B-8. Percentage of area of Black John within a given tidal range for the duration of the simulation period. [MHHW, mean higher high water; MHW, mean high water; MSL, mean sea level; $>$, greater than; <, less than] 


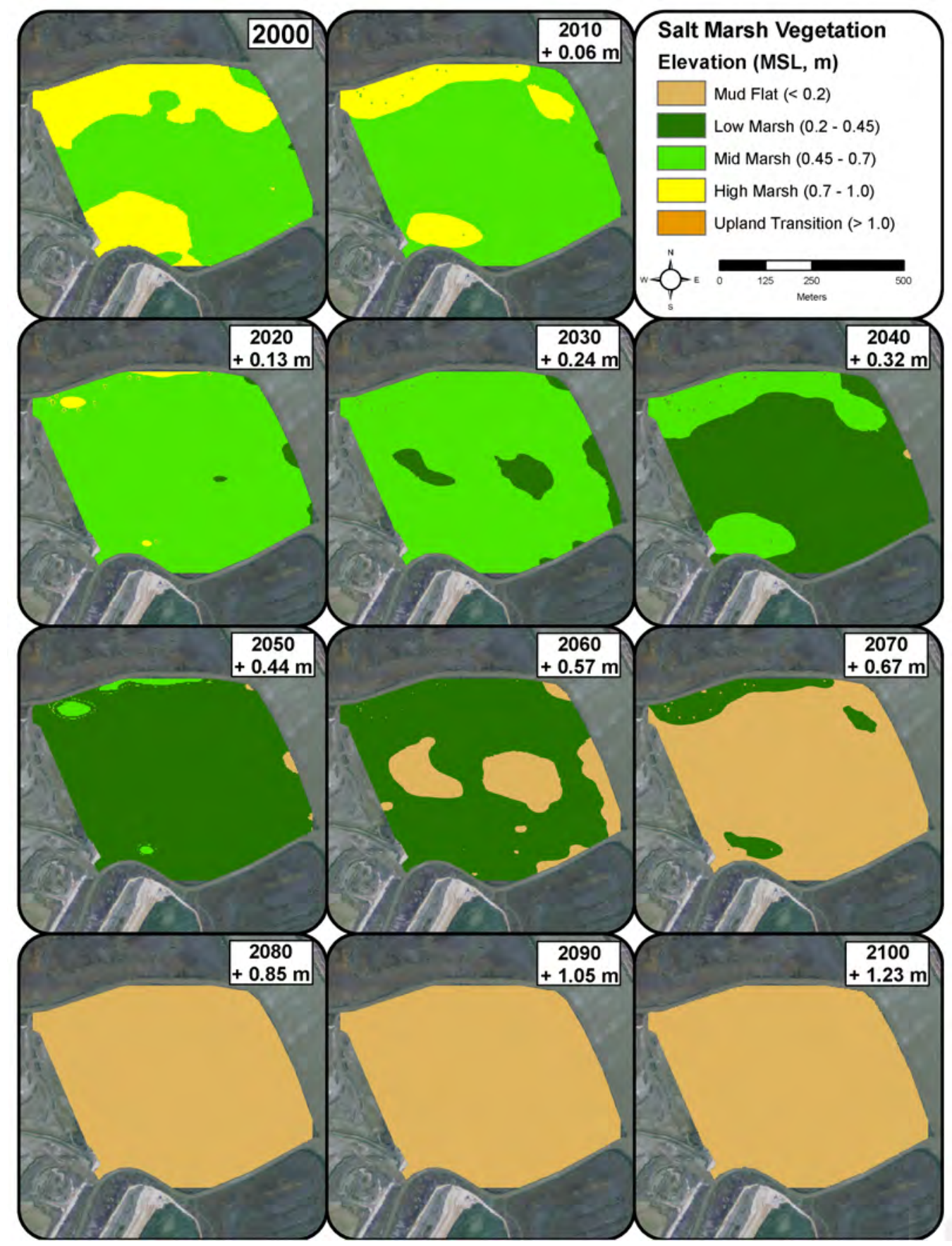

Figure B-9. Black John WARMER results in terms of plant communities relative to mean sea level (MSL), in meters (m): mudflat, low, mid, or high marsh, or upland transition. 


\section{Appendix C. China Camp Marsh}

\section{Introduction}

China Camp State Park (hereafter, "China Camp") is a 613.9 hectare (ha) park owned and managed by California State Parks. China Camp is located in Marin County and the city of San Rafael. It contains a large expanse of undeveloped historic marsh, with adjacent uplands composed of oak woodlands. China Camp is part of the National Oceanic and Atmospheric Administration National Estuarine Research Reserve (NERR) network, where it is used as a reference for healthy marsh and a living laboratory for staff and scientists.

China Camp is located adjacent to Gallinas Creek on San Pablo Bay. It is influenced by tidal flow from the San Pablo Bay as well as freshwater flow from Gallinas Creek. China Camp provides habitat for state listed species, such as the California black rail (Laterallus jamaicensis), and federally endangered species, such as salt marsh harvest mouse (Reithrodontomys raviventris) and California clapper rail (Rallus longirostris obsolete).

This study focused on 96.7 ha of marsh at China Camp. Elevation and vegetation surveys were done in 2010 by using RTK GPS. To monitor tidal inundation, four waterlevel loggers were deployed in 2010.

\section{Results}

\section{Elevation surveys}

A total of 753 elevation measurements were taken at China Camp (fig. C-1). The elevation range was $0.87-2.28$ meters, $(\mathrm{m})$ with a mean of $1.79 \mathrm{~m}$ (NAVD88). Over half (58 percent) of the survey points were within $1.75 \mathrm{~m}-1.85 \mathrm{~m}$, a $0.1 \mathrm{~m}$ range (fig. C-2). China Camp was a relatively high marsh with the majority (67 percent) of survey points at elevations above mean high water (MHW). A 3-m resolution elevation model was developed in ArcGIS 9.3 (ESRI, Redlands, Calif.), Spatial Analyst by using the kriging method (fig. C-3). This baseline elevation model was used as the initial state in the WARMER sea-level rise (SLR) model; WARMER results were extrapolated across the elevation model. 


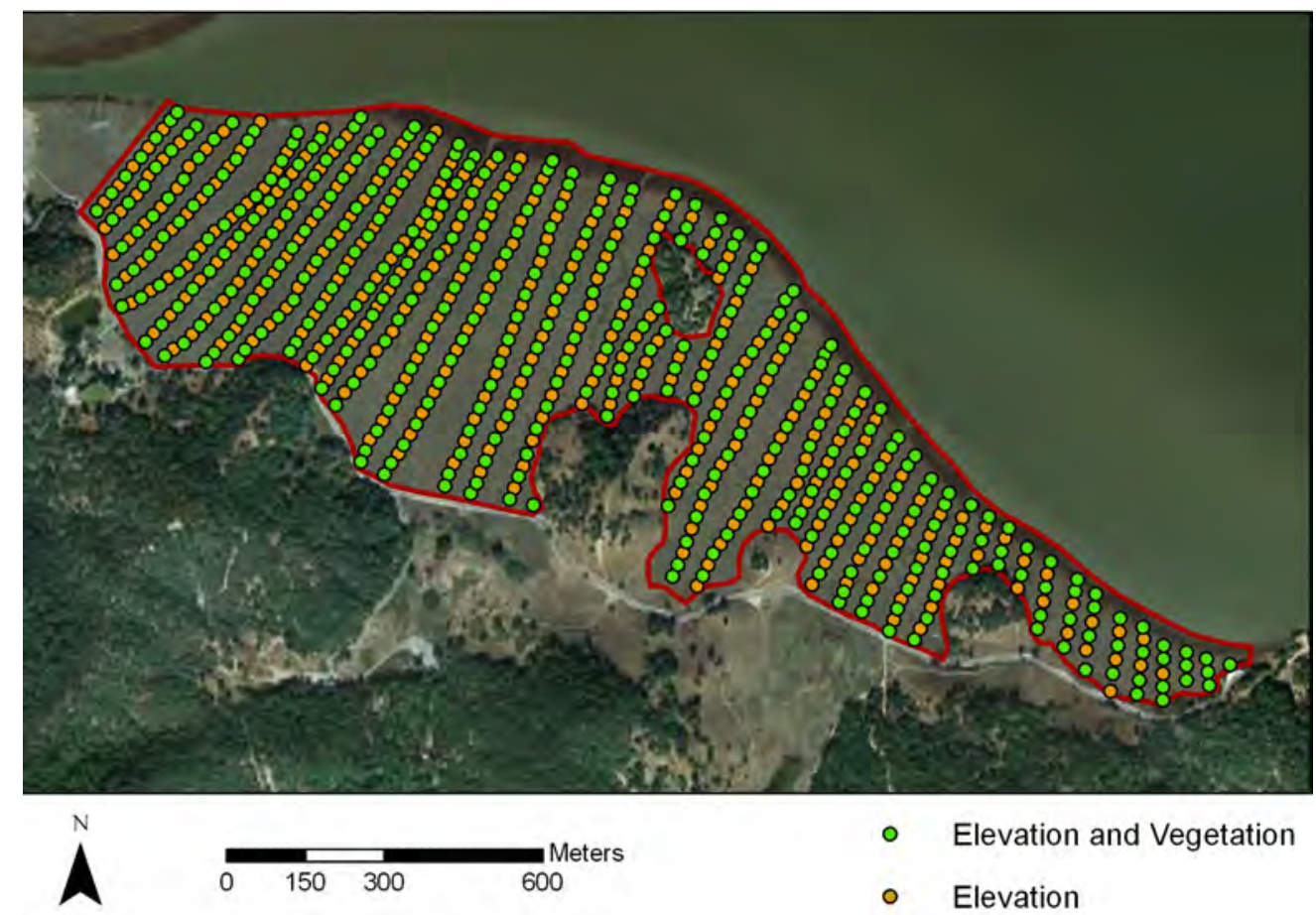

Figure C-1. China Camp with elevation and vegetation survey points from 2010 


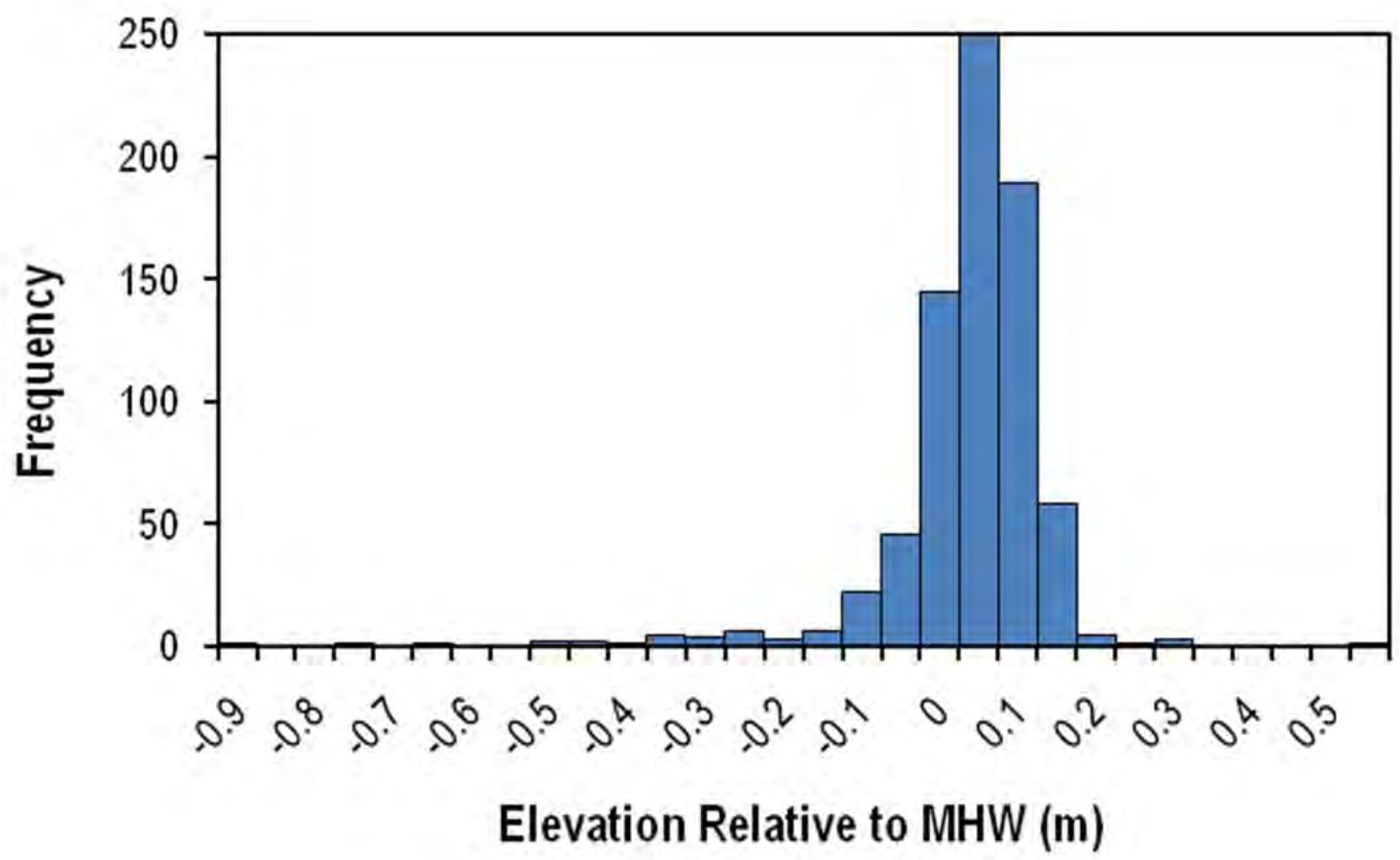

Figure C-2. Distribution of elevation samples relative to local mean high water (MHW), in meters (m), at China Camp. 


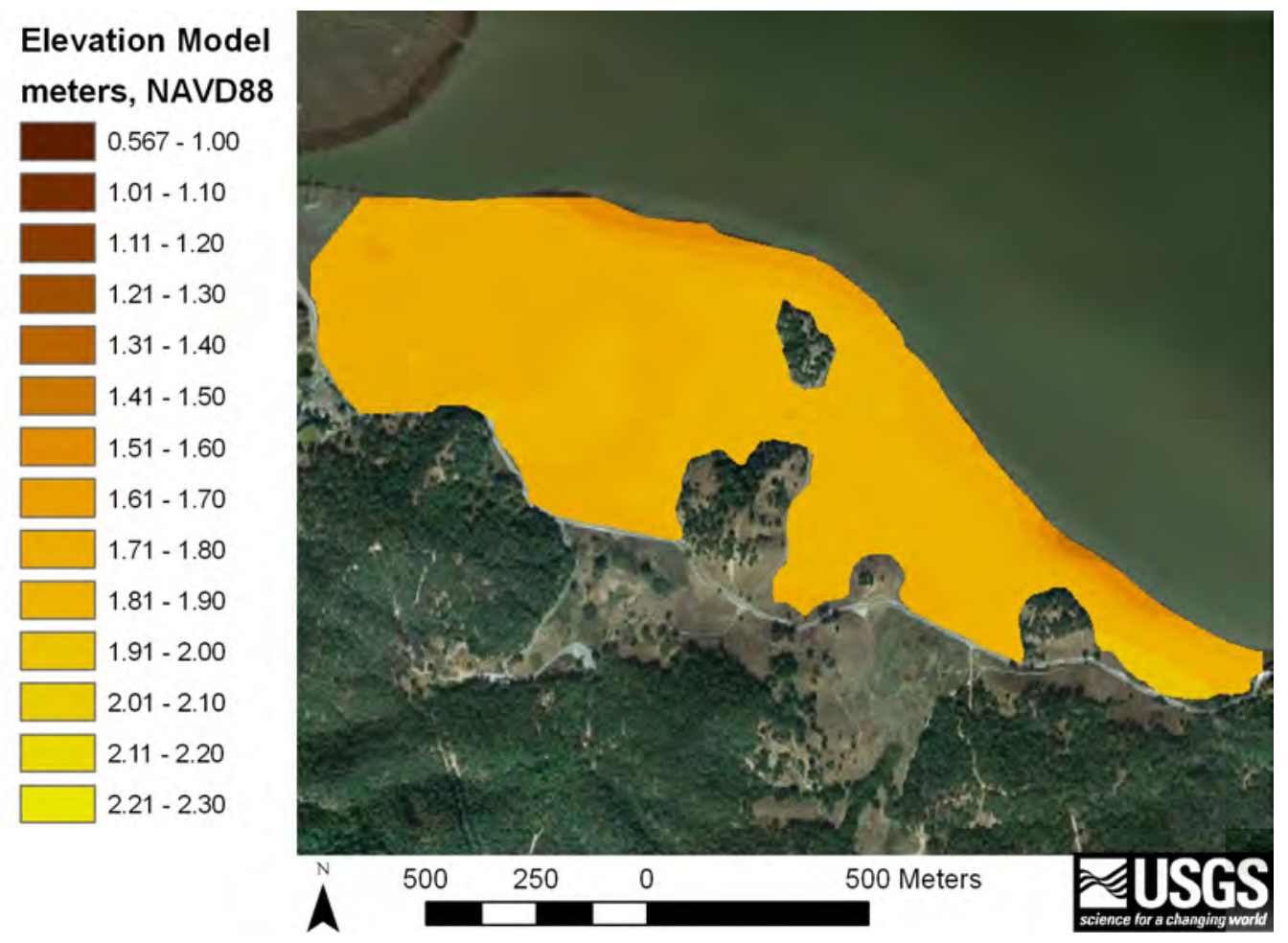

Figure C-3. ArcGIS elevation model (3-meter resolution) developed from ground RTK GPS elevation data.

\section{Vegetation surveys}

Vegetation and elevation were surveyed concurrently at China Camp during February-March of 2010. A total of 423 locations (fig. C-1) were measured for vegetation composition, height, and percentage cover (table C-1). We did not distinguish between invasive and native Spartina, nor among Schoenoplectus species, in the survey. Vegetation in marshes is sensitive to soil salinity, inundation patterns, and disturbance; therefore, a stratification of vegetation species relative to MHW (fig. C-4) was observed within this low-slope marsh. 
Table C-1. Mean marsh elevation relative to mean high water (MHW), average, and max height, percentage cover with standard deviations (SD), and presence by species at China Camp.

[cm, centimeter; m, meter; $n$, sample number]

\begin{tabular}{|c|c|c|c|c|c|c|c|c|c|c|}
\hline Species & $\begin{array}{c}\text { Elevation } \\
\text { (MHW, } \\
m)\end{array}$ & $\begin{array}{c}\text { Elevation } \\
\text { SD } \\
(M H W \\
m)\end{array}$ & $\begin{array}{l}\text { Mean } \\
\text { Height } \\
(\mathrm{cm})\end{array}$ & $\begin{array}{l}\text { Mean } \\
\text { Height } \\
\text { SD (cm) }\end{array}$ & $\begin{array}{c}\text { Max } \\
\text { Height } \\
\text { (cm) }\end{array}$ & $\begin{array}{c}\text { Max } \\
\text { Height } \\
\text { SD (cm) }\end{array}$ & $\begin{array}{c}\text { Cover } \\
\text { (percent) }\end{array}$ & $\begin{array}{c}\text { Cover } \\
\text { SD } \\
\text { (percent) }\end{array}$ & $n$ & $\begin{array}{l}\text { Presence } \\
\text { (percent) }\end{array}$ \\
\hline Sarcocornia pacifica & 0.01 & 0.10 & 29.72 & 8.78 & 41.76 & 10.30 & 81.45 & 24.51 & 408 & 96.68 \\
\hline Spartina spp. & -0.46 & 0.21 & 34.25 & 13.92 & 44.08 & 15.51 & 12.75 & 11.33 & 12 & 2.84 \\
\hline Schoenoplectus spp. & -0.13 & 0.16 & 18.00 & 21.01 & 23.00 & 27.23 & 16.29 & 25.84 & 7 & 1.66 \\
\hline Grindelia stricta & 0.06 & 0.10 & 62.03 & 22.07 & 66.10 & 24.87 & 26.45 & 20.41 & 29 & 6.87 \\
\hline Jaumea carnosa & 0.01 & 0.06 & 12.76 & 3.36 & 16.88 & 4.32 & 19.82 & 26.24 & 34 & 8.06 \\
\hline Frankenia salina & 0.09 & 0.04 & 19.50 & 5.36 & 24.33 & 5.85 & 24.33 & 30.64 & 6 & 1.42 \\
\hline Distichlis spicata & 0.03 & 0.10 & 17.85 & 8.65 & 22.91 & 9.40 & 19.00 & 26.51 & 54 & 12.80 \\
\hline Lepidium latifolium & 0.11 & 0.08 & 20.40 & 22.43 & 24.40 & 23.29 & 12.20 & 11.95 & 5 & 1.18 \\
\hline
\end{tabular}




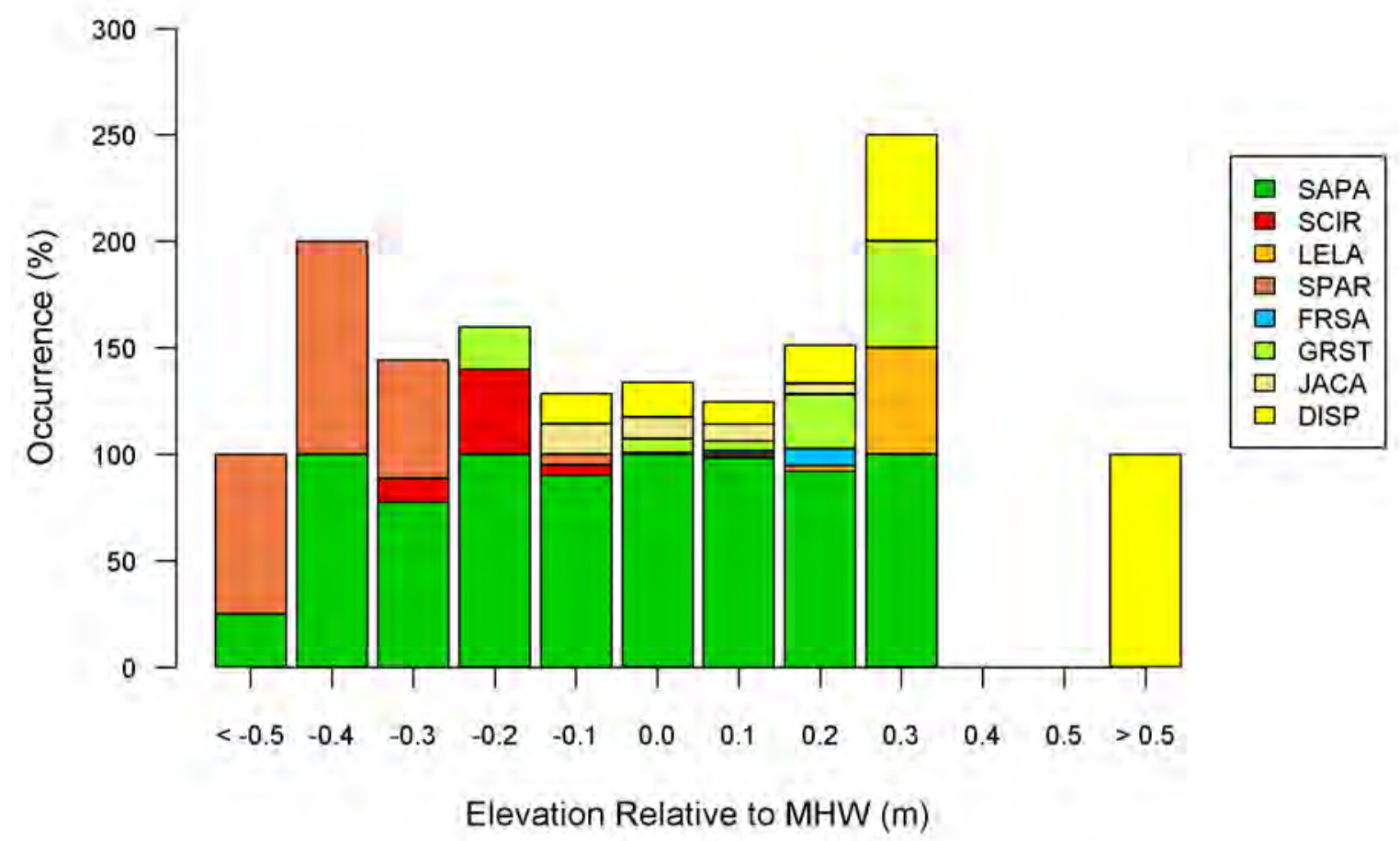

Figure C-4. Stratification of vegetation species was observed relative to mean high water (MHW), in meters (m). Species codes: SAPA = Sarcocornia pacifica; SCIR = Schoenoplectus spp.; LELA = Lepidium latifolium; SPAR = Spartina spp.; FRSA = Frankenia salina; $\mathrm{GRST}=$ Grindelia stricta; JACA = Jaumea carnosa; DISP = Distichlis spicata.

\section{Water-level monitoring}

Site specific water level was monitored at China Camp for 1 year from February 2010 to January 2011. Water level was measured by using two data loggers deployed in second order channels. MHW was $1.77 \mathrm{~m}$, and mean higher high water (MHHW) was $1.95 \mathrm{~m}$ for the site (NAVD88). The period when the marsh platform (defined as mean marsh elevation) was inundated most often was February 2010 (fig. C-5). We believe these long periods of inundation were the result of above average cumulative rainfall in January 2010 throughout the San Francisco Bay (SFB) area (National Oceanic and Atmospheric Administration). 


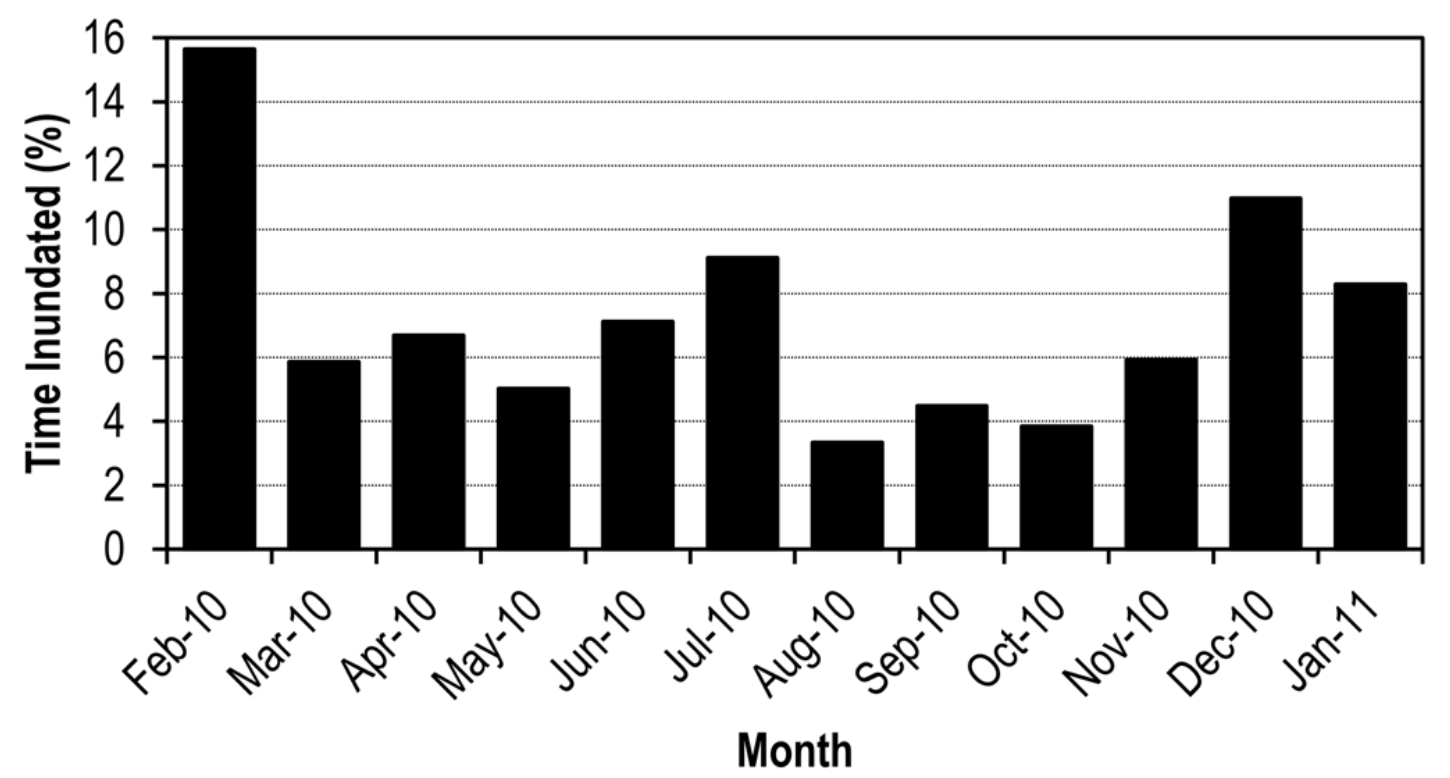

Figure C-5. Percentage of time China Camp was inundated monthly, based on the mean elevation of the marsh platform.

\section{Marsh elevation modeling}

China Camp SLR response modeling showed that the marsh was able to maintain its elevations through 2030, unlike lower elevation marshes around SFB. However, WARMER projections showed a gradual reduction in elevation relative to MHW over time after 2030, with a more dramatic decline after 2060 (fig. C-6). By 2080, the marsh was projected to be under mean sea level (MSL) and to transition to a mudflat (fig. C-7). Despite its relatively high elevation, WARMER results indicated that China Camp will not keep pace with local SLR through this century. 


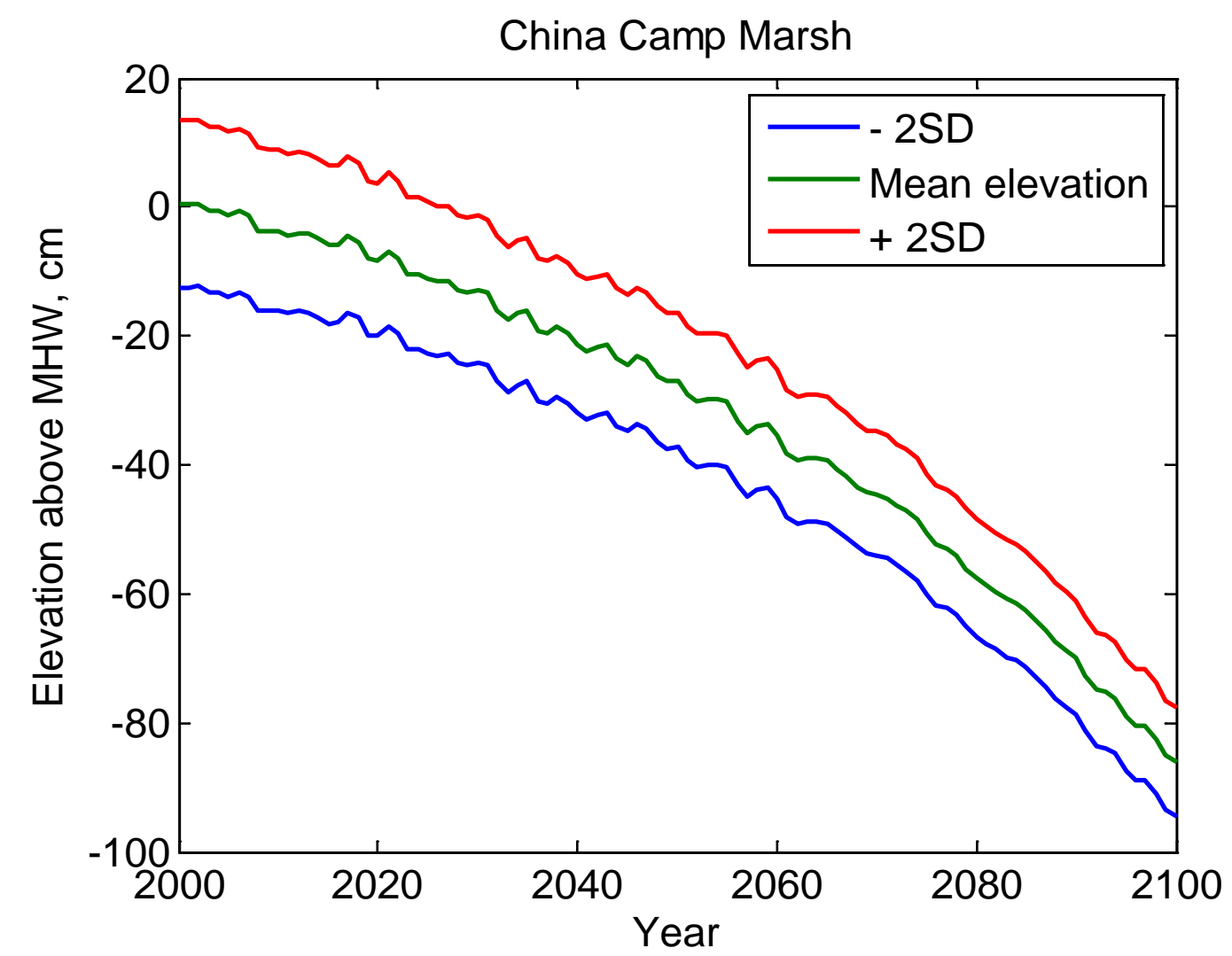

Figure C-6. Modeled WARMER scenarios of marsh elevation change at China Camp. Elevation above mean high water (MHW), in centimeters $(\mathrm{cm})$, is plotted against model year with two standard deviations (SD). 


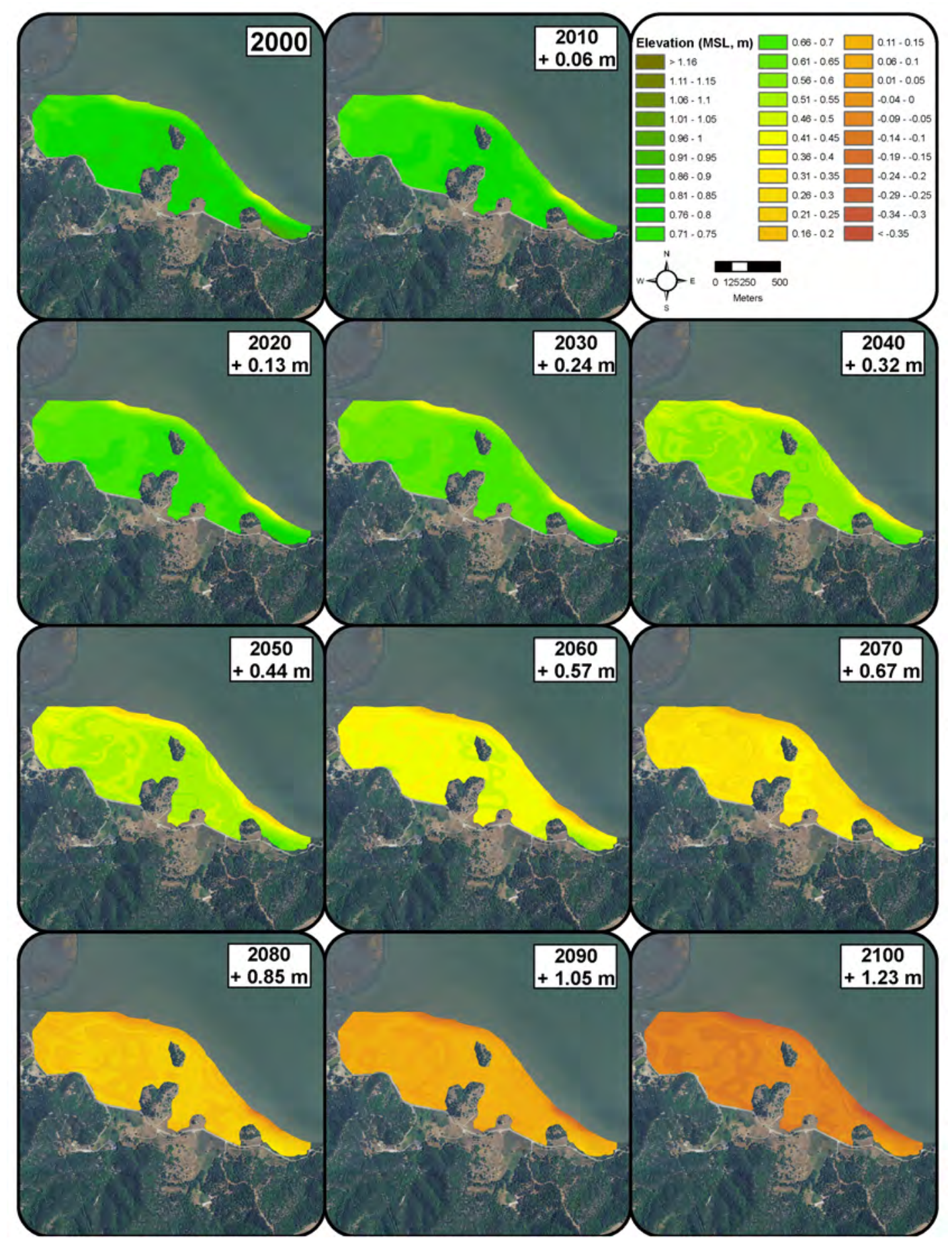

Figure C-7. WARMER results for China Camp. WARMER accounts for changes in relative seallevel, subsidence, inorganic sediment accumulation, above and belowground organic matter productivity, compaction, and decay. Non-linear sea-level rise projections for California were used (Cayan and others, 2009). [MSL, mean sea level; m, meters] 
Elevation relative to the local tidal datum can be tied to vegetation observations. Vegetation data were categorized as mudflat, low, mid, high marsh, or upland transition plant communities and used to interpret the WARMER SLR results (figs. C-8 and C-9). Upland transition (greater than $1.0 \mathrm{~m}$ MSL) was characterized by coyote bush (Baccharis pilularis). High marsh (0.7-1.0 m MSL) was characterized by Frankenia salina and Jaumea carnosa, whereas mid marsh (0.45-0.7 m MSL) was dominated by Sarcocornia pacifica. Low marsh (0.2-0.45 m MSL) was characterized by Spartina spp. or, in brackish areas, by Schoenoplectus spp. Mudflat habitat (less than $0.2 \mathrm{~m} \mathrm{MSL)} \mathrm{was}$ unvegetated or sparsely covered with Spartina spp. China Camp is dominated by midand high-marsh plant communities dominated by Sarcocornia pacifica, with primarily low-marsh vegetation adjacent to the bay. China Camp elevations are between high and mid-marsh plant community classifications; therefore, WARMER showed a brief expansion of high-marsh habitat in 2020 (0.13 m SLR), which was an artifact of the classification bins based on all vegetation observed in SFBE. Plant communities then returned to relatively the same distribution as in 2000 between 2030 (0.13 m SLR) and 2050 (0.44 m SLR). However, by 2060 (0.57 SLR), most of the marsh was projected to transition to low marsh plant communities. By 2090 (1.05 m SLR), the marsh was projected to transition completely to mudflat.

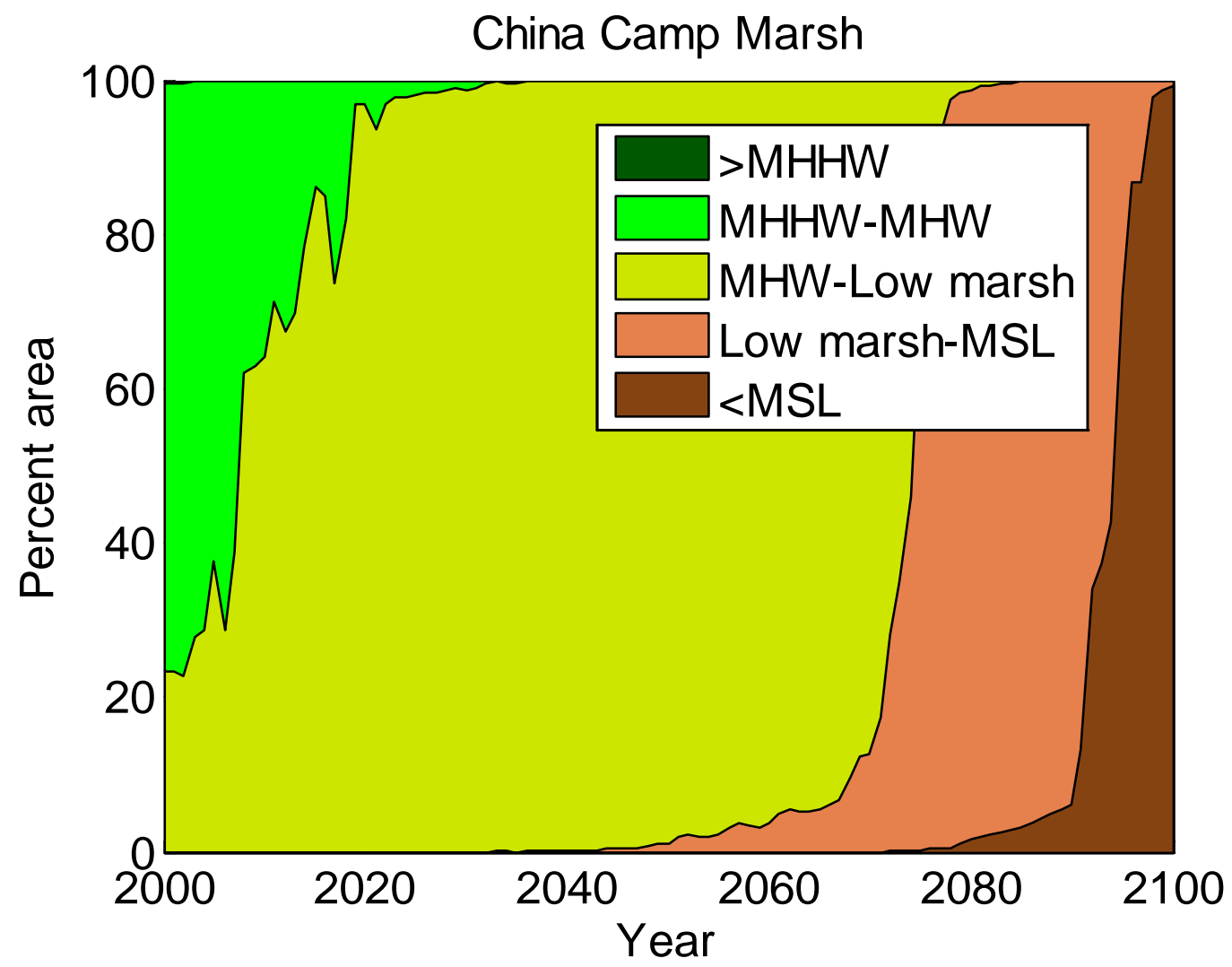

Figure C-8. Percentage of area of China Camp within a given tidal range for the duration of the simulation period. [MHHW, mean higher high water; MHW, mean high water; MSL, mean sea level; $>$, greater than; <, less than] 


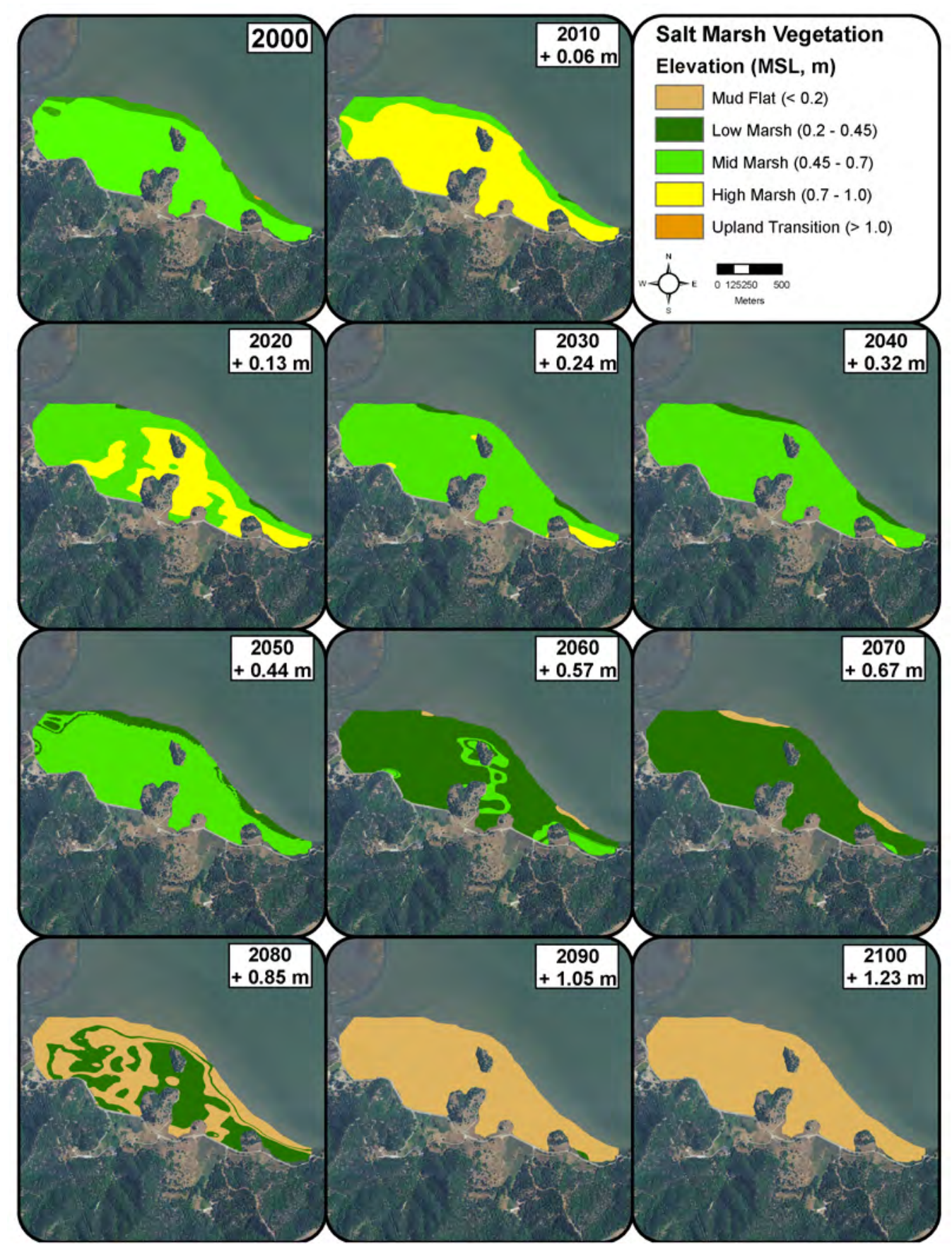

Figure C-9. China Camp WARMER results in terms of plant communities relative to mean sea level (MSL), in meters (m): mudflat, low, mid, or high marsh, or upland transition. 


\section{Appendix D. Cogswell Marsh}

\section{Introduction}

Cogswell marsh (hereafter, "Cogswell") is located in Alameda County within the city of Hayward along the eastern shore of south San Francisco Bay. It is located along the Hayward Regional Shoreline and is part of a 250-hectare (ha) tidal salt marsh restoration and enhancement project that was completed in 1980. It is currently managed by East Bay Regional Park as part of the Hayward Regional Shoreline. This marsh provides habitat for many migratory and marsh species, including the federally endangered California clapper rail (Rallus longirostris obsoletus).

This study focused on 60.3 ha of Cogswell. Elevation and vegetation surveys were done in 2008 and 2009 by using an RTK GPS. To monitor tidal inundation, one water level logger was deployed during 2009-2010.

\section{Results}

\section{Elevation surveys}

A total of 523 elevation measurements were taken at Cogswell (fig. D-1). The elevation range was 1.66-2.71 meters $(\mathrm{m})$, with a mean of $1.83 \mathrm{~m}$ (NAVD88). Half of the survey points were within $1.75-1.90 \mathrm{~m}$, a $0.15 \mathrm{~m}$ range. The majority (64 percent) of survey points were located at elevations above mean high water (MHW; fig. D-2). A 3-m resolution elevation model was developed in ArcGIS 9.3 (ESRI, Redlands, Calif.) Spatial Analyst by using the kriging method (fig. D-3). This baseline elevation model was used as the initial state in the WARMER sea-level rise (SLR) model; WARMER results were extrapolated across the elevation model. 


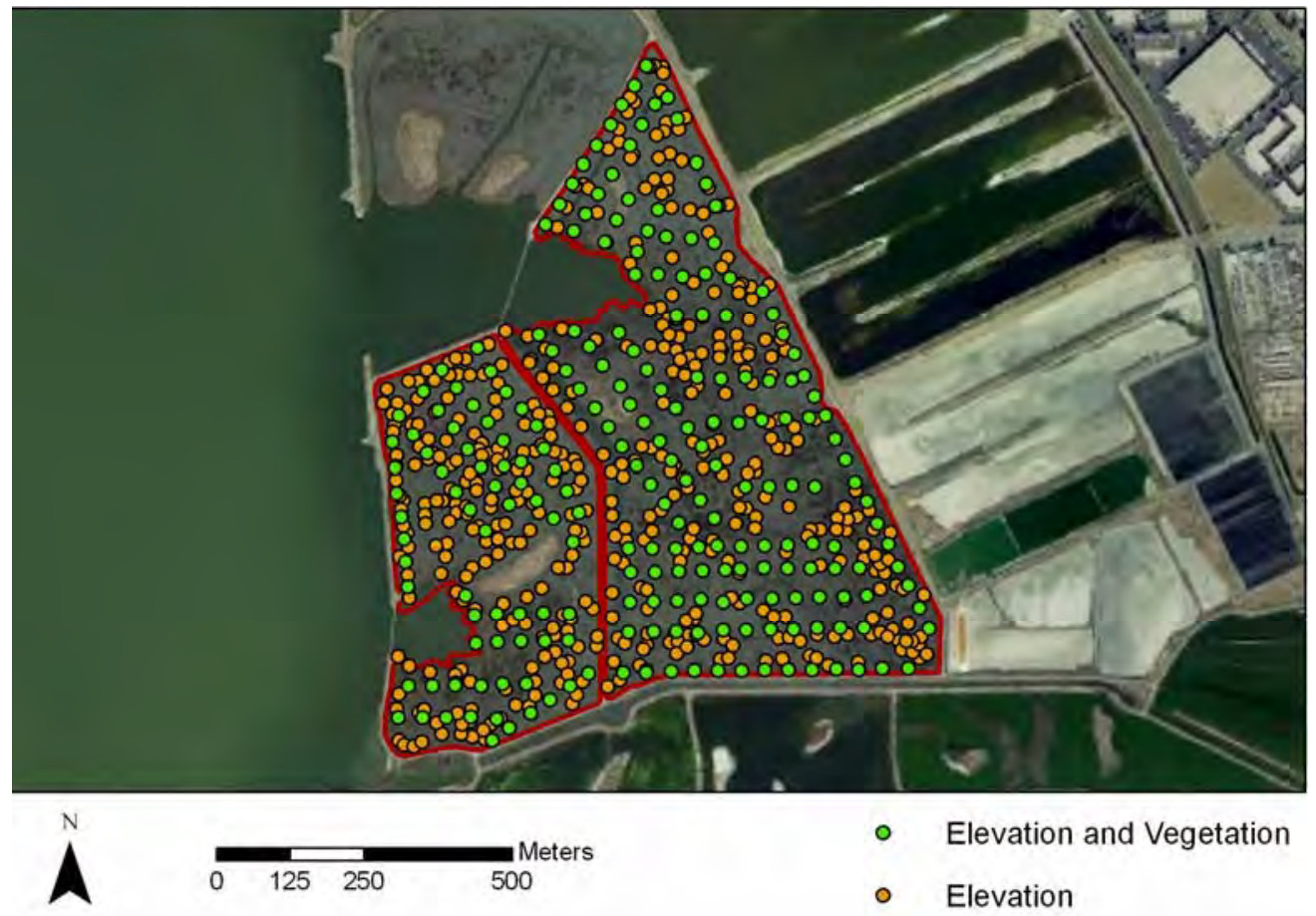

Figure D-1. Cogswell Marsh, with elevation and vegetation survey points from 2008-2009.

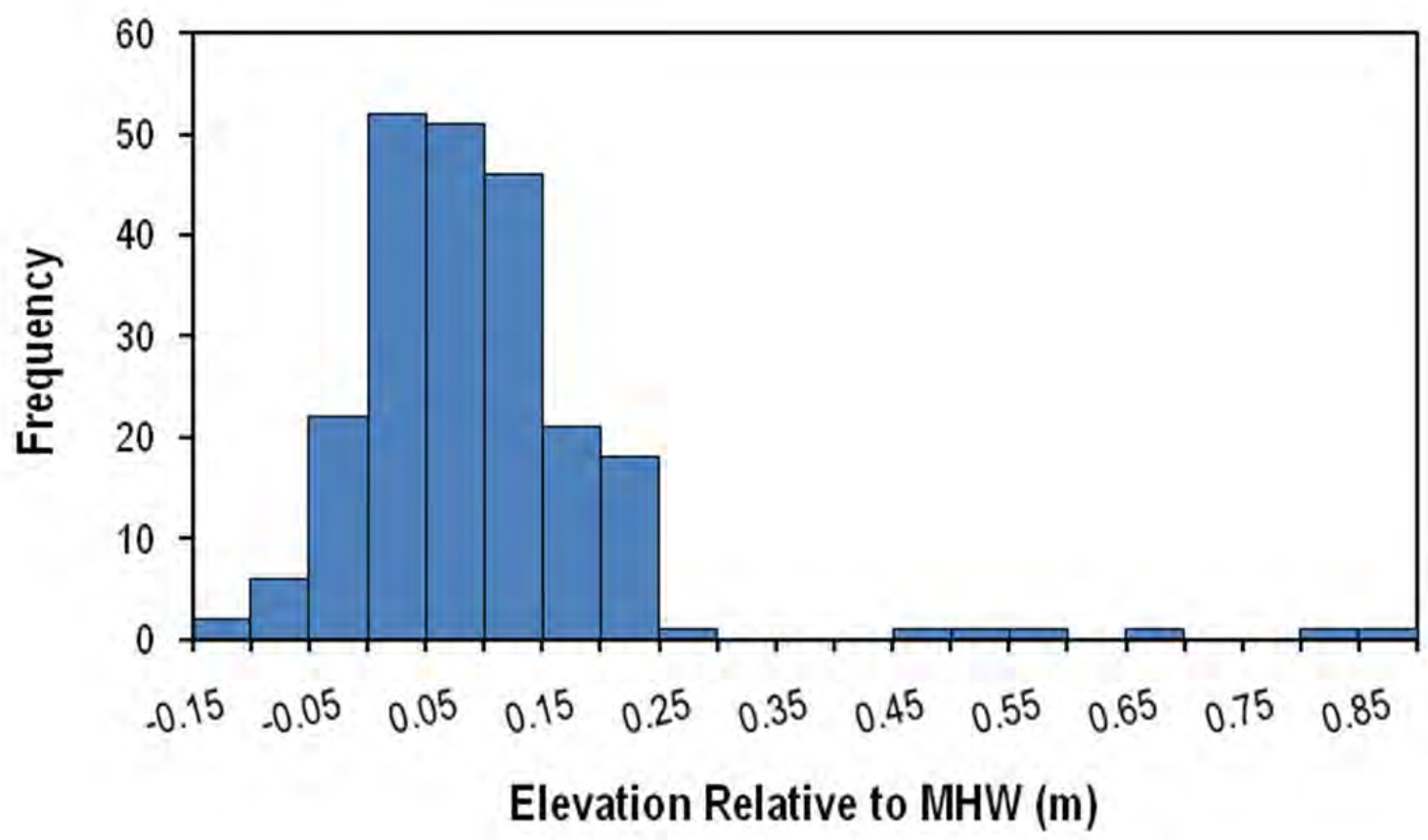

Figure D-2. Distribution of elevation samples relative to local mean high water (MHW, in meters (m), at Cogswell Marsh. 


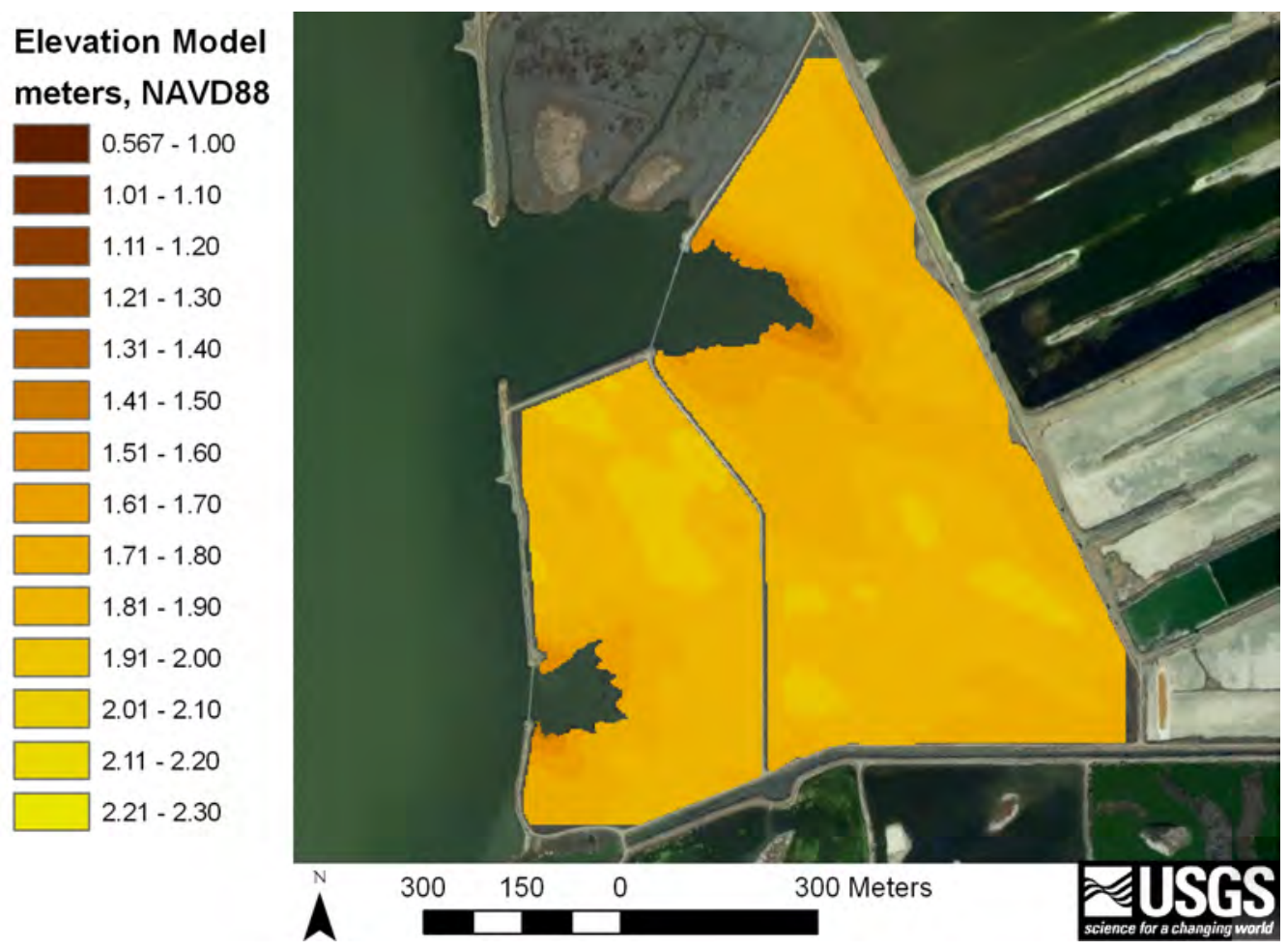

Figure D-3. Elevation model (3-meter resolution) developed from ground RTK GPS elevation data.

\section{Vegetation surveys}

Vegetation and elevation surveys were conducted concurrently in April and May of 2008 and 2009. A total of 228 locations (fig. D-1) were measured for vegetation composition, height, and percentage cover (table D-1). We did not distinguish between invasive and native Spartina spp., nor among Schoenoplectus spp., in the survey. Vegetation in marshes is sensitive to soil salinity, inundation patterns, and disturbance; therefore, a stratification of vegetation species relative to MHW (fig. D-4) was observed within this low-slope marsh. 
Table D-1. Mean marsh elevation relative to mean high water (MHW), average, and max height, percentage cover with standard deviations (SD), and presence by species at Cogswell.

[cm, centimeter; m, meter; n, sample number]

\begin{tabular}{|c|c|c|c|c|c|c|c|c|c|c|}
\hline Species & $\begin{array}{c}\text { Elevation } \\
\text { (MHW, } \\
m)\end{array}$ & $\begin{array}{c}\text { Elevation } \\
\text { SD } \\
(M H W \\
m)\end{array}$ & $\begin{array}{l}\text { Mean } \\
\text { Height } \\
(\mathrm{cm})\end{array}$ & $\begin{array}{l}\text { Mean } \\
\text { Height } \\
\text { SD (cm) }\end{array}$ & $\begin{array}{c}\text { Max } \\
\text { Height } \\
\text { (cm) }\end{array}$ & $\begin{array}{c}\text { Max } \\
\text { Height } \\
\text { SD (cm) }\end{array}$ & $\begin{array}{c}\text { Cover } \\
\text { (percent) }\end{array}$ & $\begin{array}{c}\text { Cover } \\
\text { SD } \\
\text { (percent) }\end{array}$ & $n$ & $\begin{array}{l}\text { Presence } \\
\text { (percent) }\end{array}$ \\
\hline Sarcocornia pacifica & 0.05 & 0.13 & 30.79 & 7.84 & 37.82 & 10.05 & 90.39 & 22.84 & 211 & 94.20 \\
\hline Spartina spp. & 0.03 & 0.08 & 57.19 & 14.45 & 69.50 & 16.78 & 17.94 & 12.59 & 21 & 9.20 \\
\hline
\end{tabular}




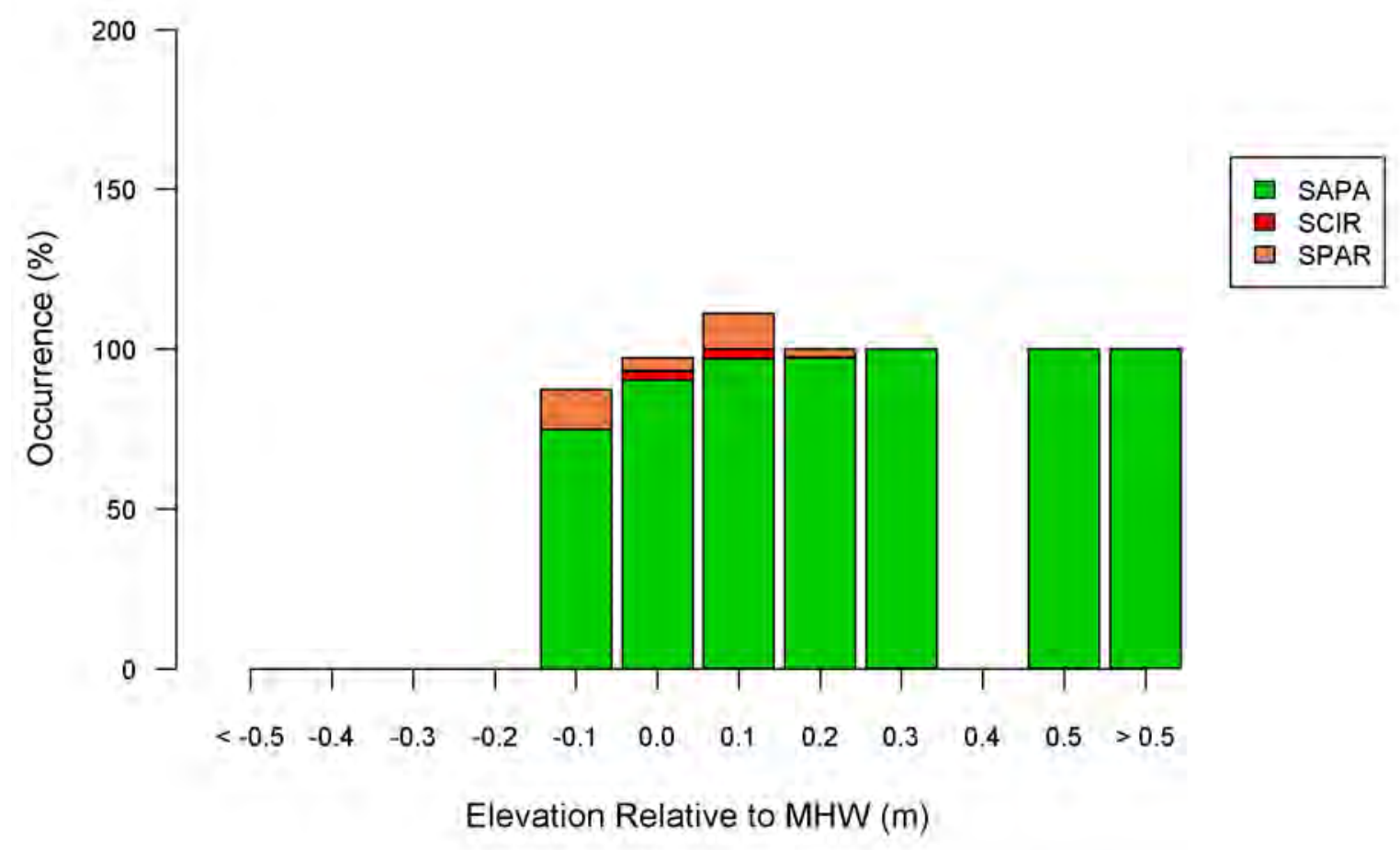

Figure D-4. Stratification of vegetation species was observed relative to mean high water (MHW), in meters $(\mathrm{m})$. Species codes: SAPA = Sarcocornia pacifica; SPAR = Spartina spp.; and SCIR = Schoenoplectus spp.

\section{Water-level monitoring}

Site-specific water level was monitored at Cogswell from December 2009 to November 2010. Water level was measured by using one data logger deployed at the mouth of a second order channel. MHW was $1.86 \mathrm{~m}$, and mean higher high water (MHHW) was $1.98 \mathrm{~m}$ for the site (NAVD88). Water levels were recorded throughout the year to evaluate seasonal patterns in tides. The period when the marsh platform (defined as mean elevation) was inundated most often was from December 2009 through February 2010 (fig. D-5). During January and February 2010, above average water levels were recorded because of several record-breaking storms that brought low air pressure and substantial rainfall, resulting in higher than predicted tides. The cumulative rainfall in January 2010 was above average throughout the San Francisco Bay area, and daily rainfall records were broken in some locations (National Oceanic and Atmospheric Administration). This resulted in longer inundation periods of the marsh platform. 


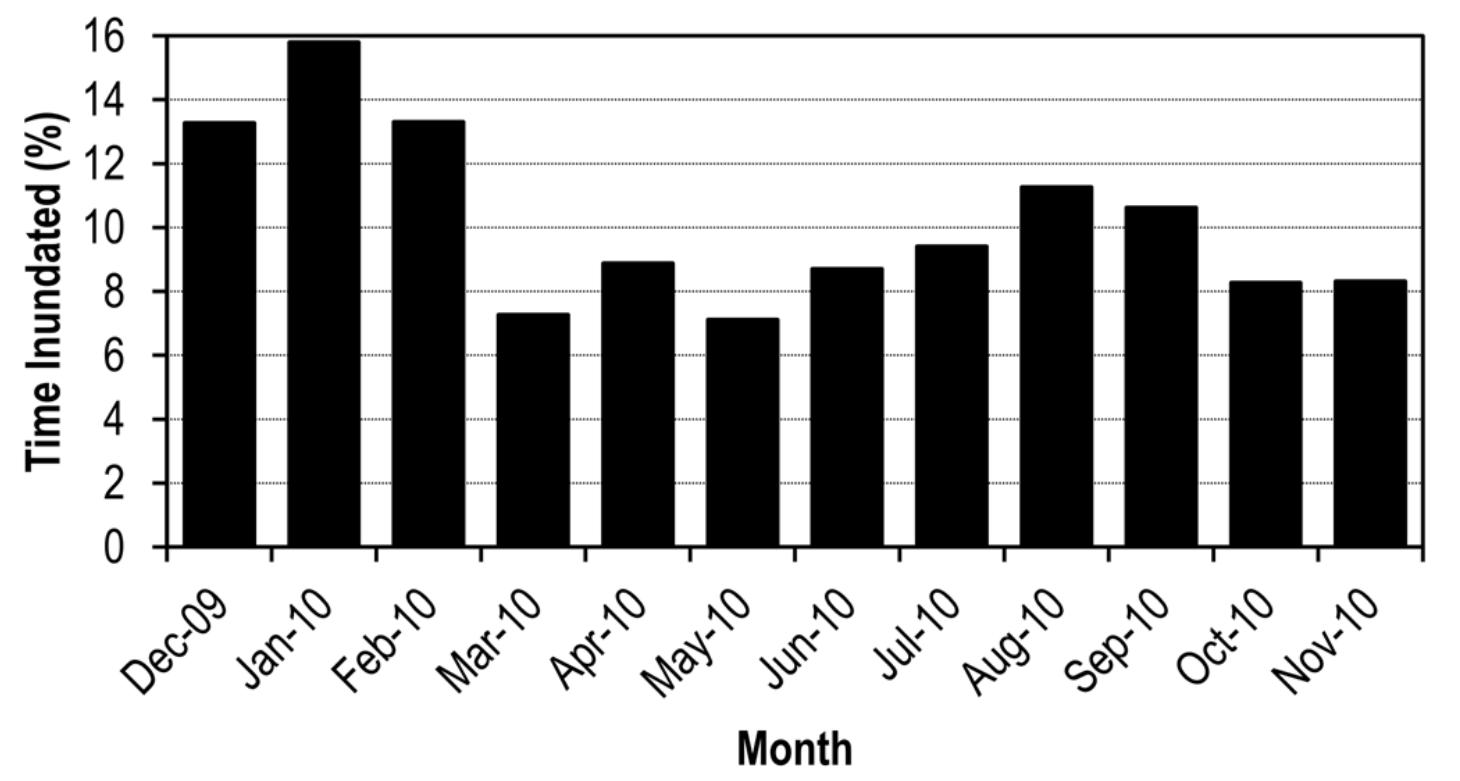

Figure D-5. Percentage of time Cogswell was inundated monthly based on the mean elevation of the marsh platform.

\section{Marsh elevation modeling}

WARMER results showed a gradual reduction in elevation relative to MHW over the century, with a more dramatic decline after 2060 (fig. D-6). By 2100, the marsh was projected to be below MHW (fig. D-7). Sites that had higher starting elevations (thus located higher in the tidal range), such as Cogswell, also had higher accretion rates and were less susceptible to SLR. 


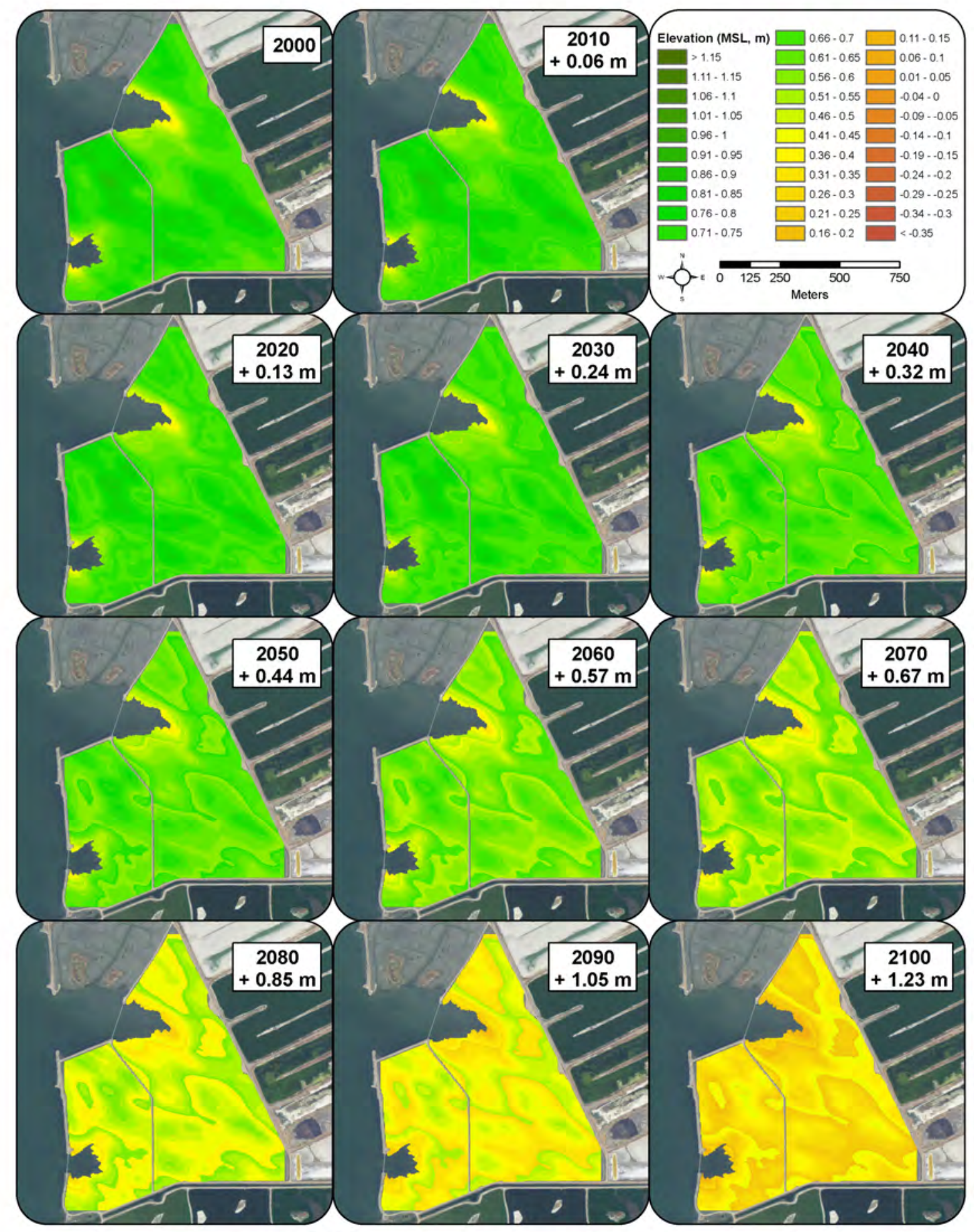

Figure D-6. WARMER results for Cogswell. WARMER accounts for changes in relative sea-level, subsidence, inorganic sediment accumulation, above and belowground organic matter productivity, compaction, and decay. Non-linear sea-level rise projections for California were used (Cayan and others, 2009). [MSL, mean sea level; m, meters] 


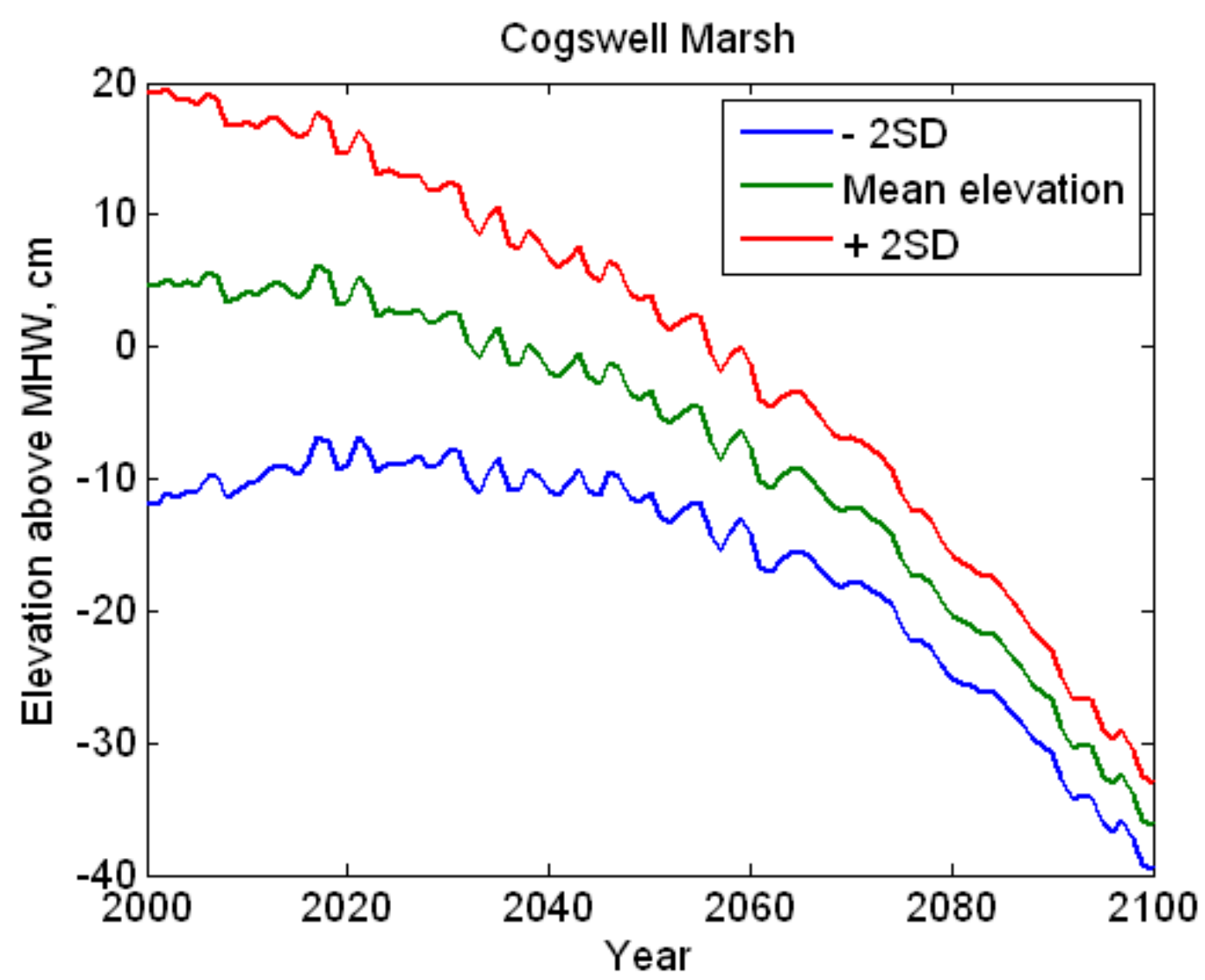

Figure D-7. WARMER scenarios of marsh elevation change for Cogswell. Elevation above mean high water (MHW), in centimeters $(\mathrm{cm})$, is plotted against model year with two standard deviations (SD).

Elevation relative to the local tidal datum can be tied to vegetation observations. Vegetation data were categorized as mudflat, low, mid, high marsh, or upland transition plant communities and used to interpret the WARMER SLR results (figs. D-8 and D-9). Upland transition (greater than $1.0 \mathrm{~m} \mathrm{MSL}$ ) was characterized by coyote bush (Baccharis pilularis). High marsh (0.7-1.0 m MSL) was characterized by Frankenia salina and Jaumea carnosa, whereas mid marsh (0.4-0.7 m MSL) was dominated by Sarcocornia pacifica. Low marsh (0.2-0.45 m MSL) was characterized by Spartina spp. or, in brackish areas, by Schoenoplectus spp. Mudflat habitat (less than $0.2 \mathrm{~m} \mathrm{MSL}$ ) was unvegetated or sparsely covered with Spartina spp. Currently, vegetation at Cogswell is predominantly high- and mid-marsh vegetation. High accretion rates, due, in part, to high suspended-sediment concentrations in South San Francisco Bay, helped maintain the mid-marsh habitat at Cogswell through 2070 (0.67 m SLR). After the rate of sea-level rise increases in the second half of the century, Cogswell was projected to begin decreasing in relative elevation and transition to low-marsh habitat by $2100(1.23 \mathrm{~m}$ SLR). Unlike most marshes within this project, Cogswell did not transition to a mudflat by 2100 . 
The WARMER model parameters for Cogswell were extrapolated by using sediment core data near Laumeister marsh; thus, predictions need to be interpreted with caution because local sedimentation processes could differ between these marshes. To improve results, local site-specific sediment core data can be collected along with suspended sediment concentrations to characterize sediment deposition potential.

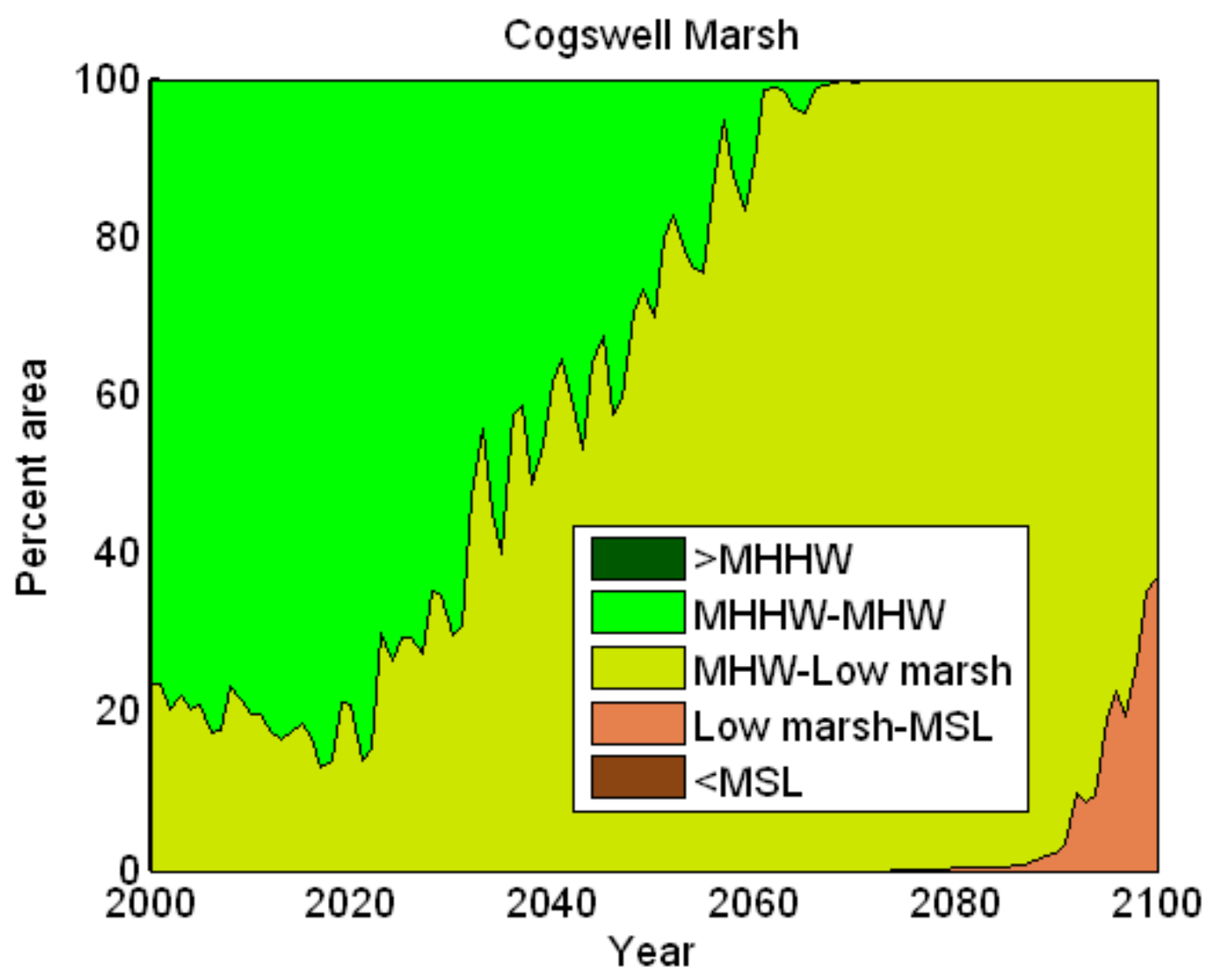

Figure D-8. Percentage of area in Cogswell within a given tidal range for the duration of the simulation period. [MHHW, mean higher high water; MHW, mean high water; MSL, mean sea level; $>$, greater than; <, less than] 


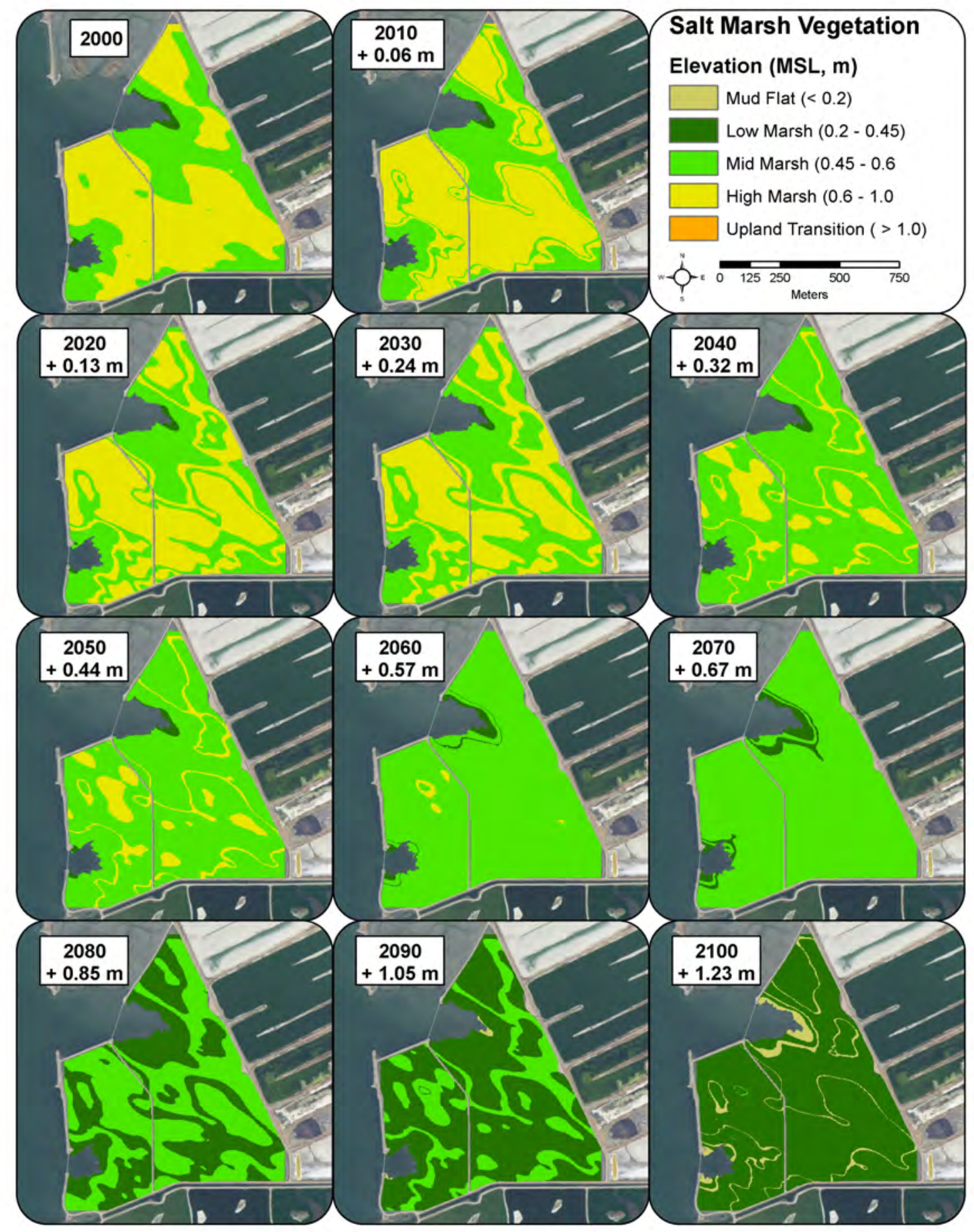

Figure D-9. Cogswell WARMER results in terms of plant communities relative to mean sea level (MSL), in meters (m): mudflat, low, mid, or high marsh, or upland transition. 


\section{Appendix E. Colma Marsh}

\section{Introduction}

Colma Creek Public Shore contains Colma marsh (hereafter, "Colma") and is located in south San Francisco Bay just north of San Francisco International Airport. It is fed by Colma Creek, which has its headwaters at San Bruno Mountain. Colma is owned and maintained by the Port of San Francisco in San Mateo County. Colma provides important habitat for migratory shorebirds and the federally-endangered California clapper rail (Rallus longirostris obsoletus).

This study focused on 24.6 hectares (ha) of marsh. Beginning In 2006, a herbicide treatment was applied to the marsh in an attempt to control the invasive Spartina densiflora and the S. densiflora x S. foliosa hybrid. As a result of this treatment, vegetation at Colma was extremely sparse; therefore, vegetation surveys were not done. Elevation surveys were done in 2010 by using an RTK GPS, and a water-level logger was deployed in 2010 to monitor tidal inundation.

\section{Results}

\section{Elevation surveys}

A total of 537 elevation measurements were taken at Colma (fig. E-1). The elevation range was $0.38-2.31$ meters $(\mathrm{m})$ with a mean of $1.38 \mathrm{~m}$ (NAVD88). Over half (67 percent) of the survey points fell within 1.01-1.61 m, a $0.6 \mathrm{~m}$ range. Colma was the lowest marsh surveyed in this study, with 87 percent of the elevation points taken located below mean high water (MHW; Fig E-2). A 3-m resolution elevation model was developed in ArcGIS 9.3 (ESRI, Redlands, Calif.) Spatial Analyst by using the kriging method (fig. E-3). This baseline elevation model was used as the initial state in the WARMER sea-level rise (SLR) model; WARMER results were extrapolated across the elevation model. 


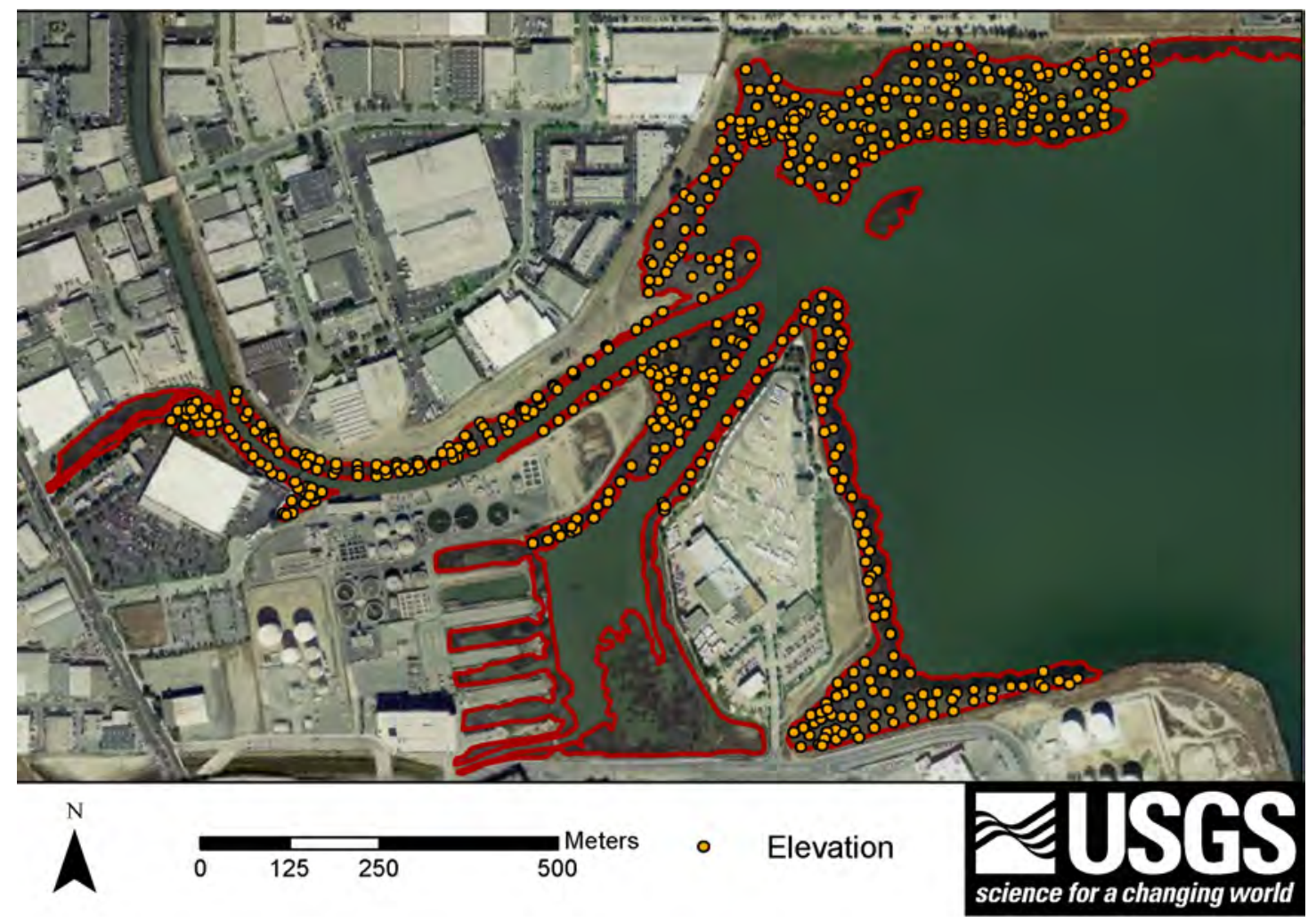

Figure E-1. Colma marsh with elevation survey points from 2010. 


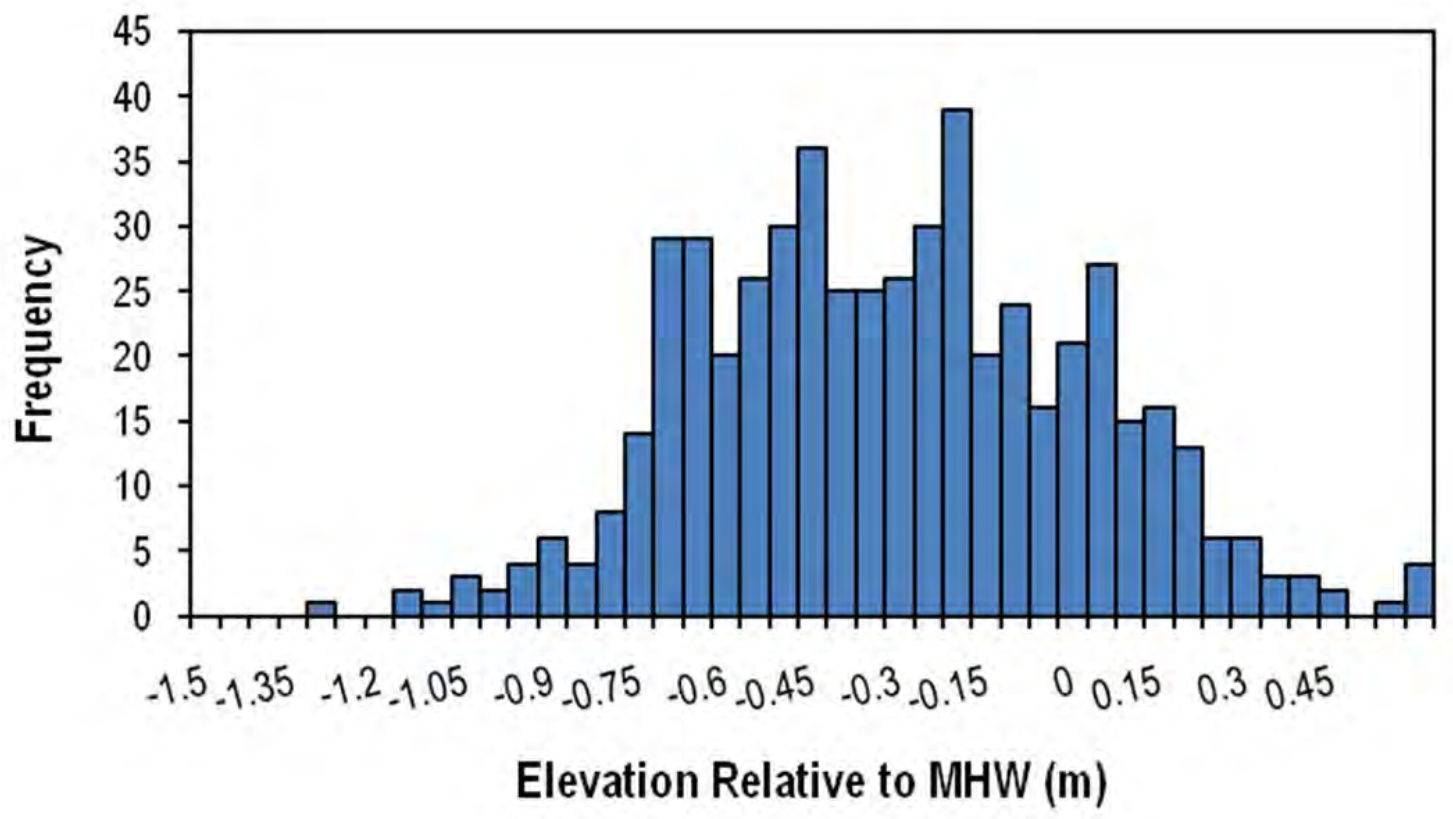

Figure E-2. Distribution of elevation samples relative to local mean high water (MHW), in meters (m), at Colma. 


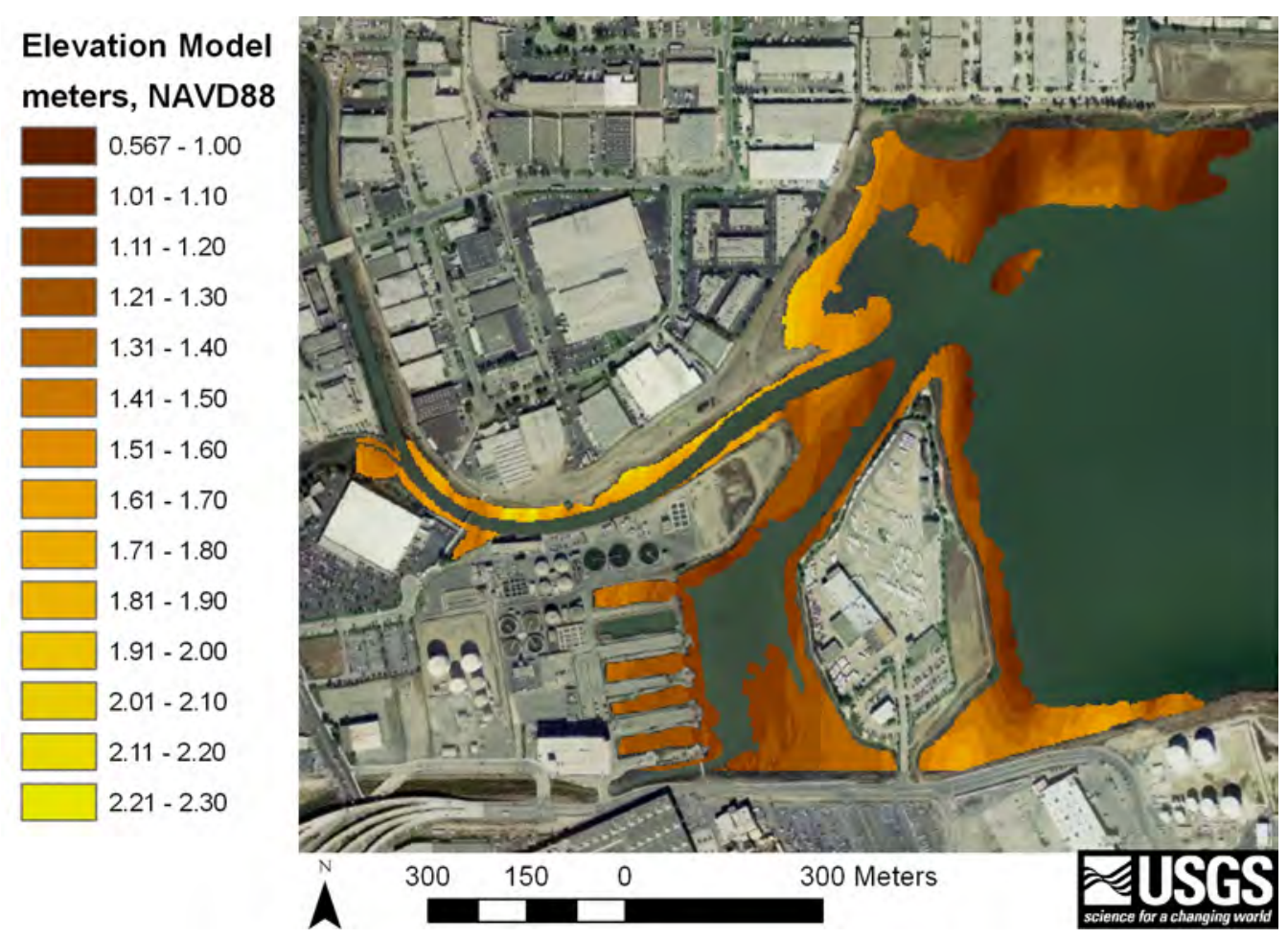

Figure E-3. Elevation model (3-meter resolution) developed from ground RTK GPS elevation data.

\section{Water-level monitoring}

Site-specific water level was monitored at Colma in 2010. Water level was measured by using one logger deployed in a second order channel. MHW was at $1.77 \mathrm{~m}$, and mean higher high water (MHHW) was at $1.97 \mathrm{~m}$ for the site (NAVD88). Water levels were recorded throughout the year to evaluate seasonal patterns in tides. The period when the marsh platform (defined as mean marsh elevation) was inundated most often was from January through February 2010 (fig. E-4). The loggers recorded above average water levels due to several record-breaking storms that brought low air pressure and substantial rainfall, resulting in higher-than-predicted tides. The cumulative rainfall in January 2010 was above average throughout the San Francisco Bay area, and daily rainfall records were broken in some locations (National Oceanic and Atmospheric Administration). This resulted in longer than normal periods of the marsh inundation. 


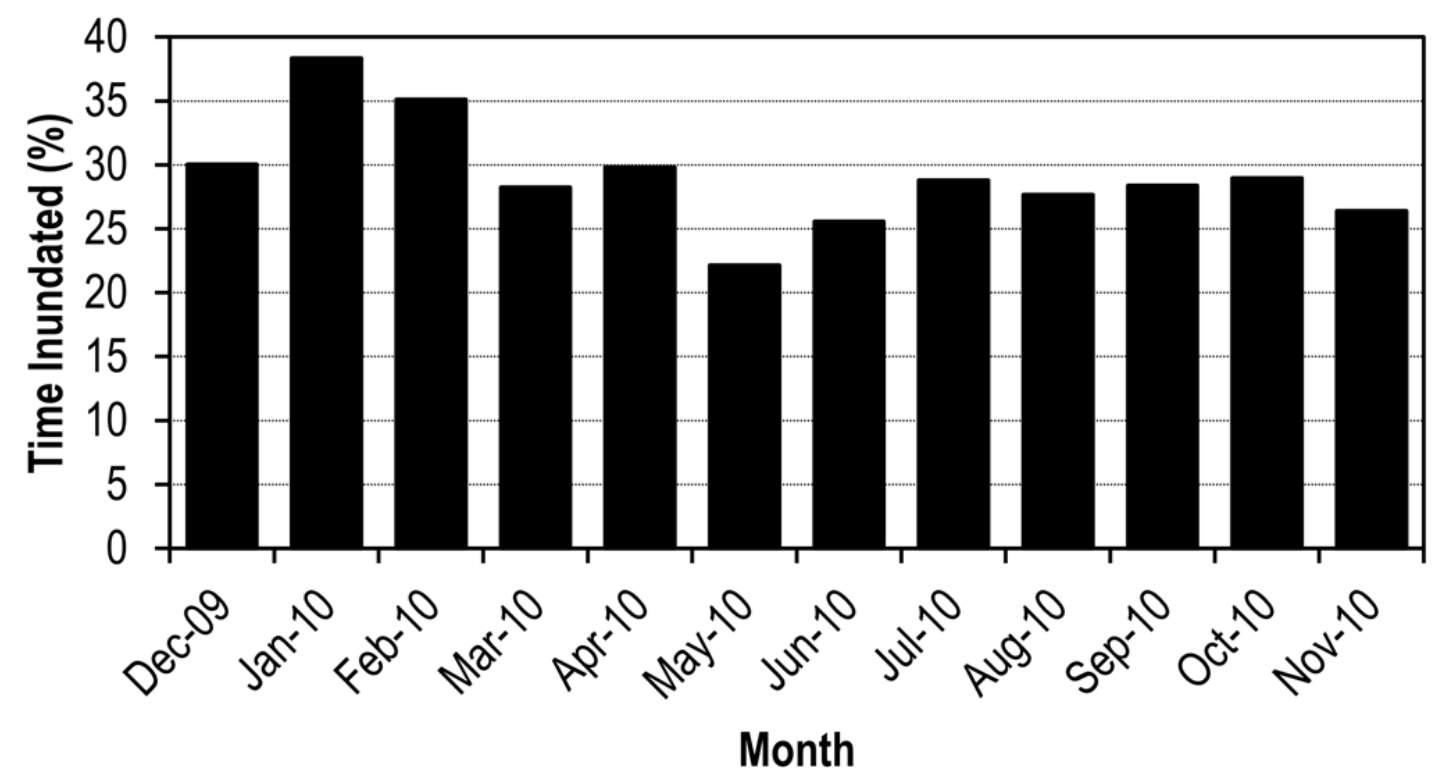

Figure E-4. Percentage of time Colma was inundated monthly based on the mean elevation of the marsh platform.

\section{Marsh elevation modeling}

WARMER results indicated that Colma will keep pace with local sea-level rise (SLR) through this century (figs. E-5 and E-6). Initial elevation was below MHW and was projected to increase slightly until 2060 ( $0.57 \mathrm{~m} \mathrm{SLR}$ ), when it begins to decline (fig. E-5). Colma was projected not to reach MHW elevations during the century. WARMER projected that elevation relative to MSL would peak in about 2050, at which time the SLR curve became exponential, and the marsh began subsiding (fig. E-6).

Vegetation data from the other 11 sites were categorized as mudflat, low, mid, high marsh, or upland transition plant communities and used to interpret the WARMER SLR results (figs. E-7 and E-8). Upland transition (greater than $1.0 \mathrm{~m} \mathrm{MSL)} \mathrm{was}$ characterized by coyote bush (Baccharis pilularis). High marsh (0.7-1.0 m MSL) was characterized by Frankenia salina and Jaumea carnosa, whereas mid marsh $(0.45-0.7 \mathrm{~m}$ MSL) was dominated by Sarcocornia pacifica. Low marsh (0.2-0.45 m MSL) was characterized by Spartina spp. or, in brackish areas, by Schoenoplectus spp. Mudflat habitat (less than $0.2 \mathrm{~m} \mathrm{MSL}$ ) was unvegetated or sparsely covered with Spartina spp. Assuming high sediment deposition, Colma was projected to transition from a mudflat to mid-marsh plant community by 2030 (figs. E-7 and E-8). By 2100, Colma was projected to be primarily composed of low marsh. The high suspended-sediment concentrations in south San Francisco Bay could allow Colma to maintain its elevation relative to SLR. However, the absence of established vegetation due to the recent herbicide treatment could result in erosion and loss of sediment trapping ability. As a result of the chemical treatment, Colma currently functions as a mudflat.

The WARMER model parameters for Colma were extrapolated by using sediment core data near Laumeister marsh, thus predictions need to be interpreted with caution because local sedimentation processes are likely very different between these marshes. To improve results, local site-specific sediment core data could be collected along with suspended sediment concentrations to characterize sediment deposition potential. 


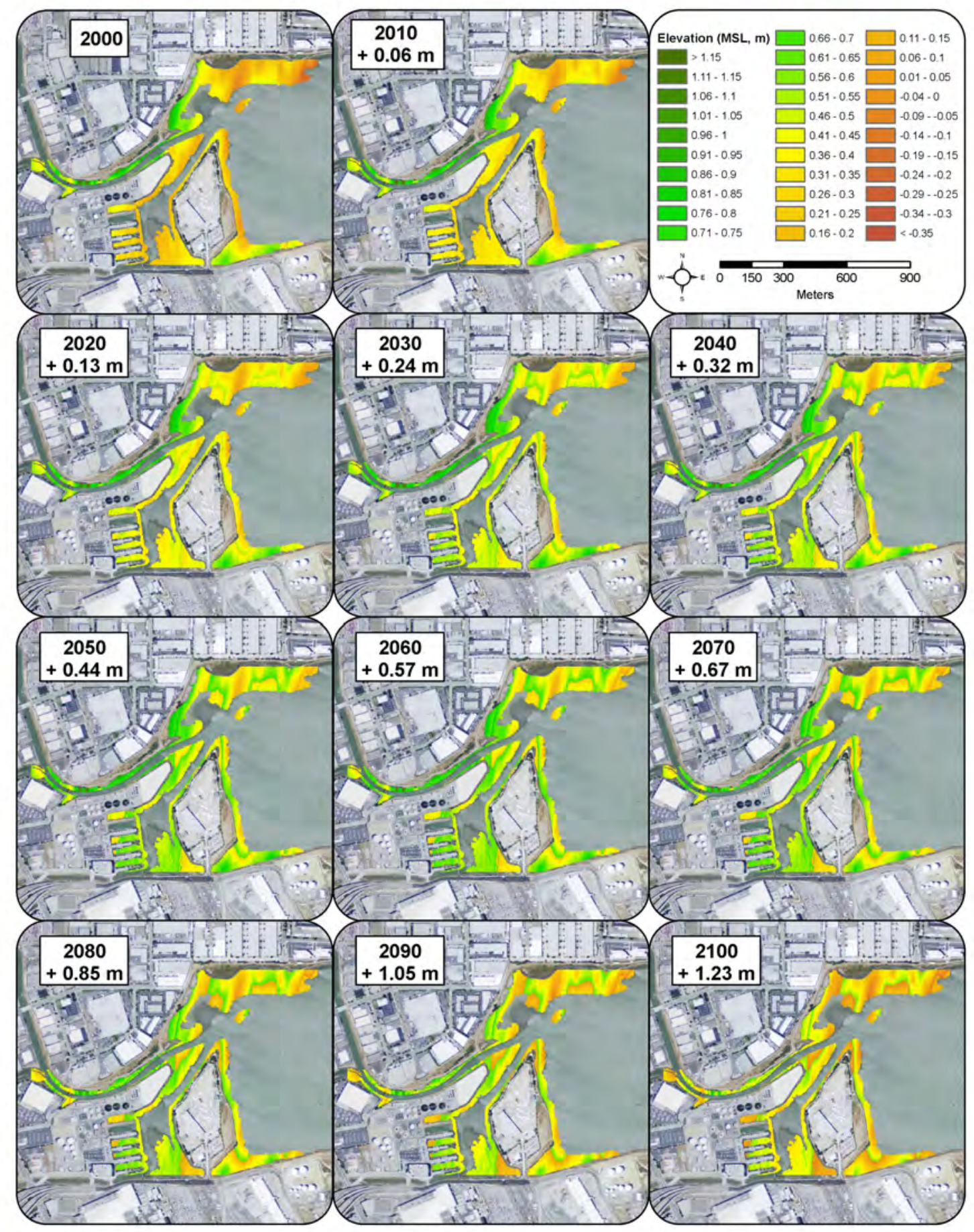

Figure E-5. WARMER results for Colma. WARMER accounts for changes in relative sea-level, subsidence, inorganic sediment accumulation, above and belowground organic matter productivity, compaction, and decay. Non-linear sea-level rise projections for California were used (Cayan and others, 2009). [MSL, mean sea level; m, meters] 


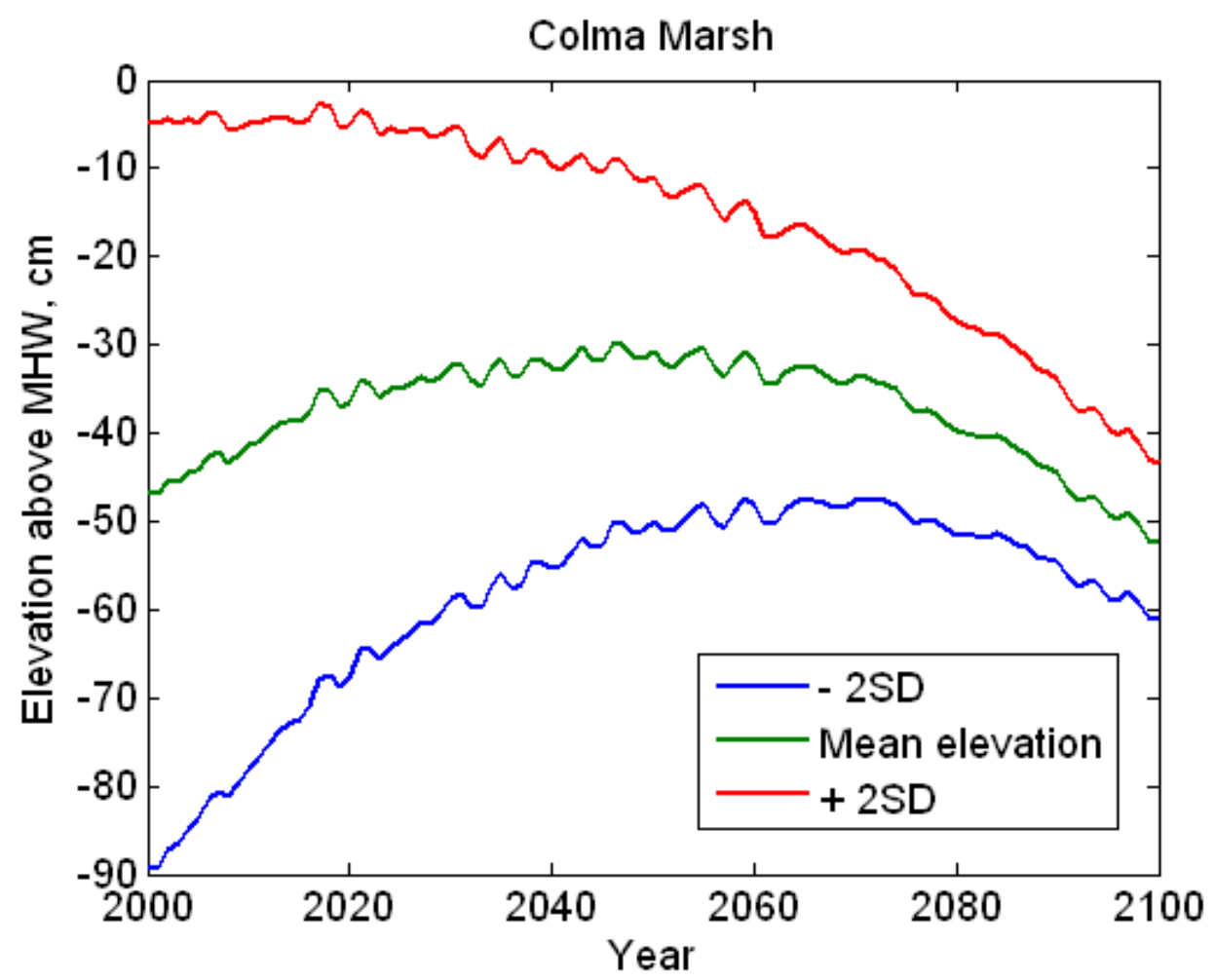

Figure E-6. WARMER scenarios for marsh elevation change at Colma. Elevation above mean high water $(\mathrm{MHW})$, in centimeters $(\mathrm{cm})$, is plotted against model year with two standard deviations $(\mathrm{SD})$. 


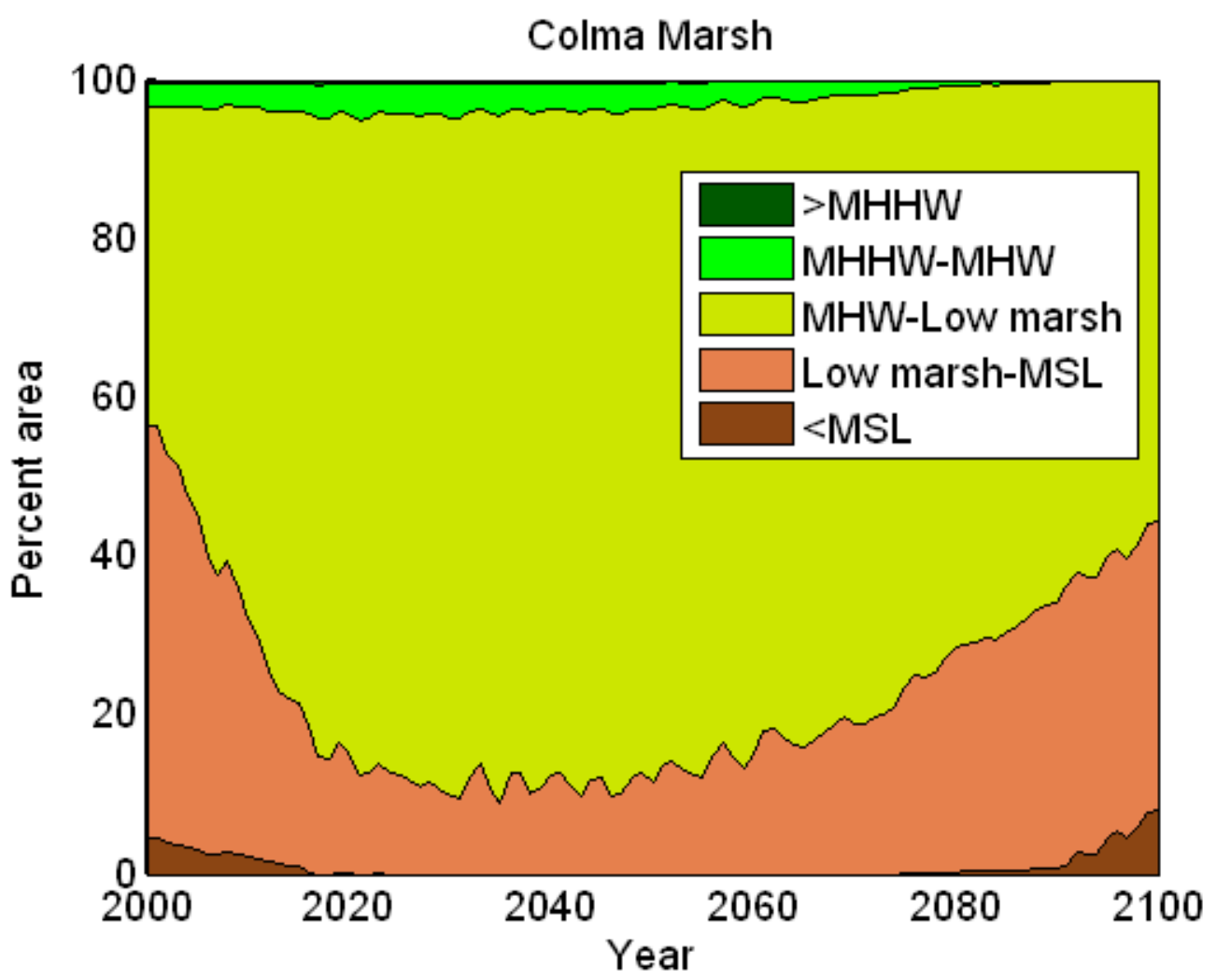

Figure E-7. Area of Colma within a given tidal range for the duration of the simulation period.

[MHHW, mean higher high water; MHW, mean high water; MSL, mean sea level; >, greater than; <, less than] 


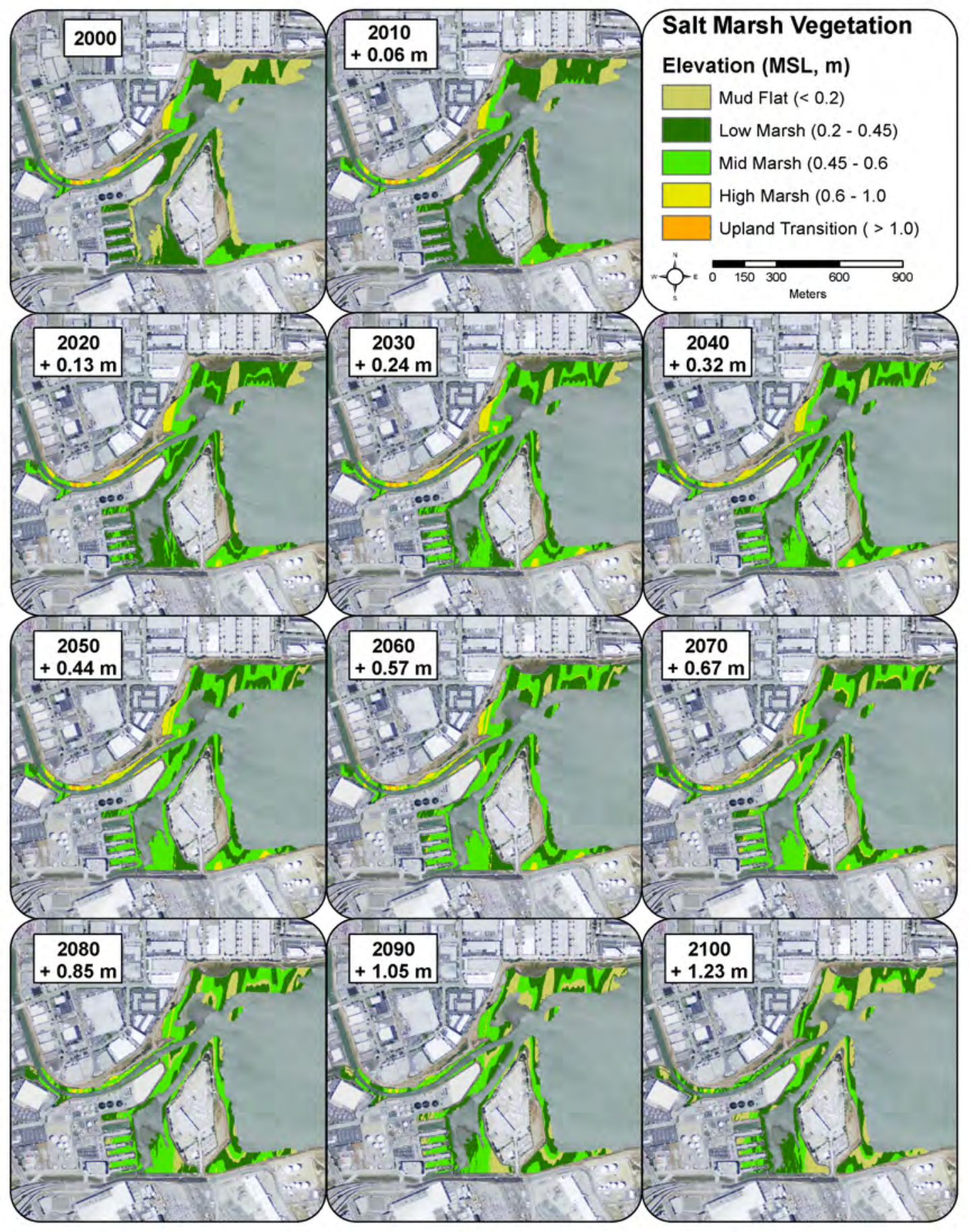

Figure E-8. Colma WARMER results in terms of plant communities relative to mean sea level (MSL), in meters (m): mudflat, low, mid, or high marsh, or upland transition. 


\section{Appendix F. Coon Island Marsh}

\section{Introduction}

Coon Island marsh (hereafter, "Coon Island") is located in Napa County along the Napa River and is bordered on the east by Mud Slough. Coon Island is influenced by tidal flow from San Pablo Bay as well as freshwater flow from the Napa River. It is surrounded by salt pond restoration sites in the Napa Sonoma Marshes Wildlife Area. The marsh is owned by California Department of Fish and Game and is home to federally endangered species, including the salt marsh harvest mouse (Reithrodontomys raviventris) and California clapper rail (Rallus longirostris obsoletus).

This study focused on 98.7 hectares (ha) of Coon Island. Elevation and vegetation surveys were done in 2009 by using an RTK GPS. To monitor tidal inundation and salinity, two water level loggers were deployed between 2009 and 2010.

\section{Results}

\section{Elevation surveys}

A total of 799 elevation measurements were taken at Coon Island (fig. F-1). The elevation range was 0.82-2.07 meters $(\mathrm{m})$, with a mean of $1.83 \mathrm{~m}$ (NAVD88). Over half of the survey points fell within 1.70-1.90 m. Coon Island was one of the lower marshes surveyed, with the majority (71 percent) of survey points at elevations below mean high water (MHW; fig. F-2).

A 3-m resolution elevation model was developed in ArcGIS 9.3 (ESRI, Redlands, Calif.) Spatial Analyst by using the kriging method (fig. F-3). This baseline elevation model was used as the initial state in the WARMER sea-level rise (SLR) model;

WARMER results were extrapolated across the elevation model. 


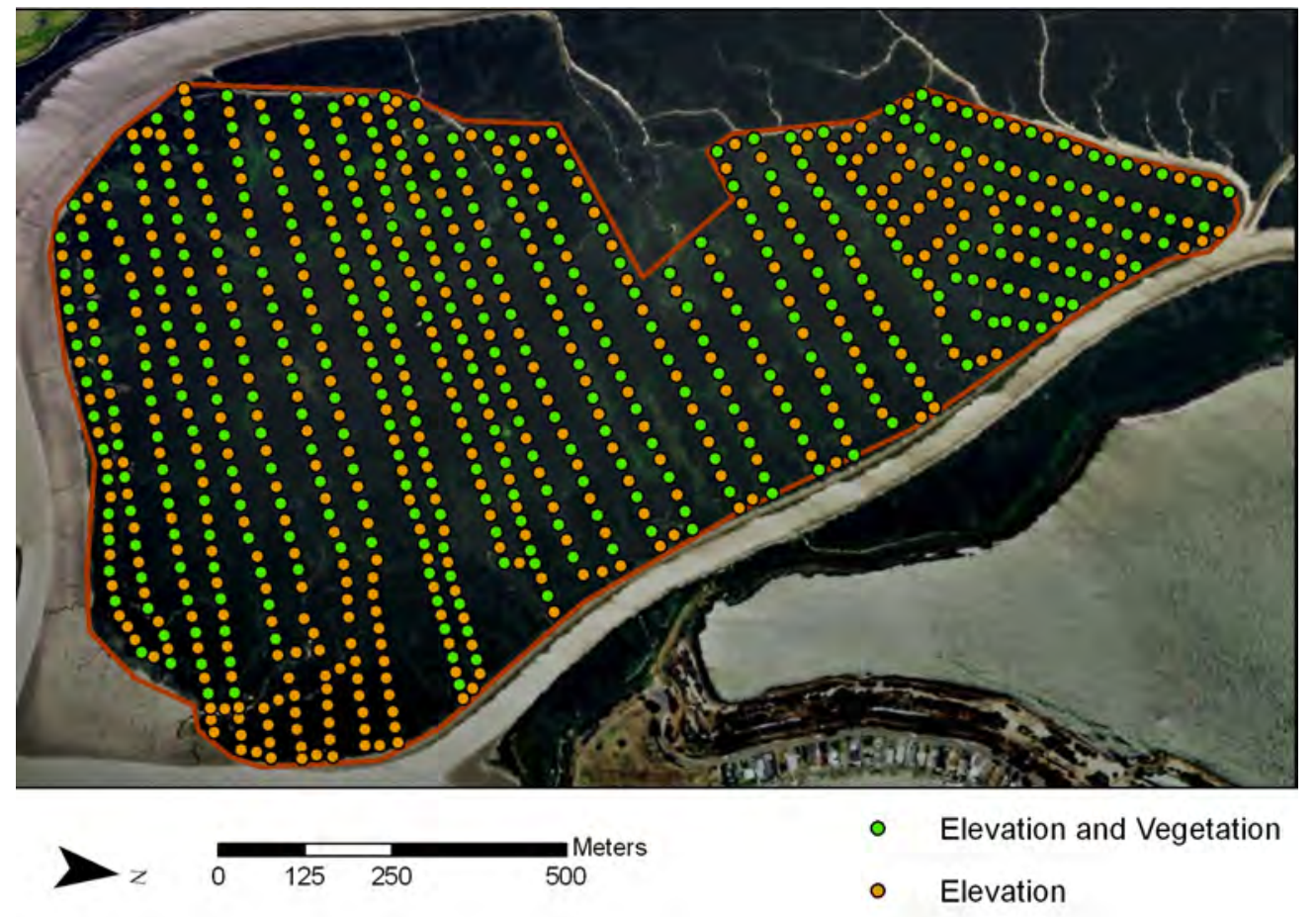

Figure F-1. Coon Island Marsh with elevation and vegetation survey points from 2009. 


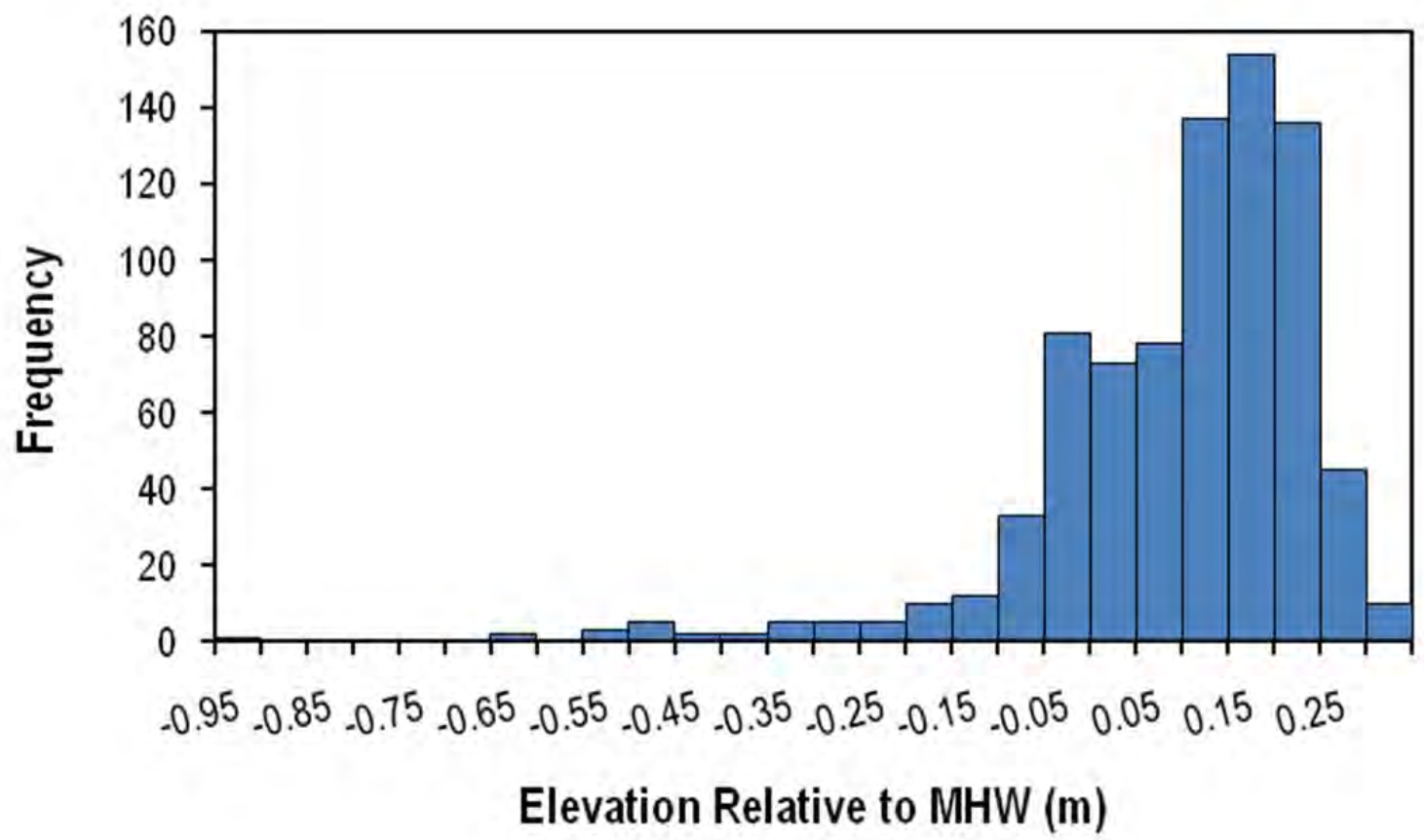

Figure F-2. Distribution of elevation samples relative to local mean high water (MHW), in meters (m), at Coon Island.

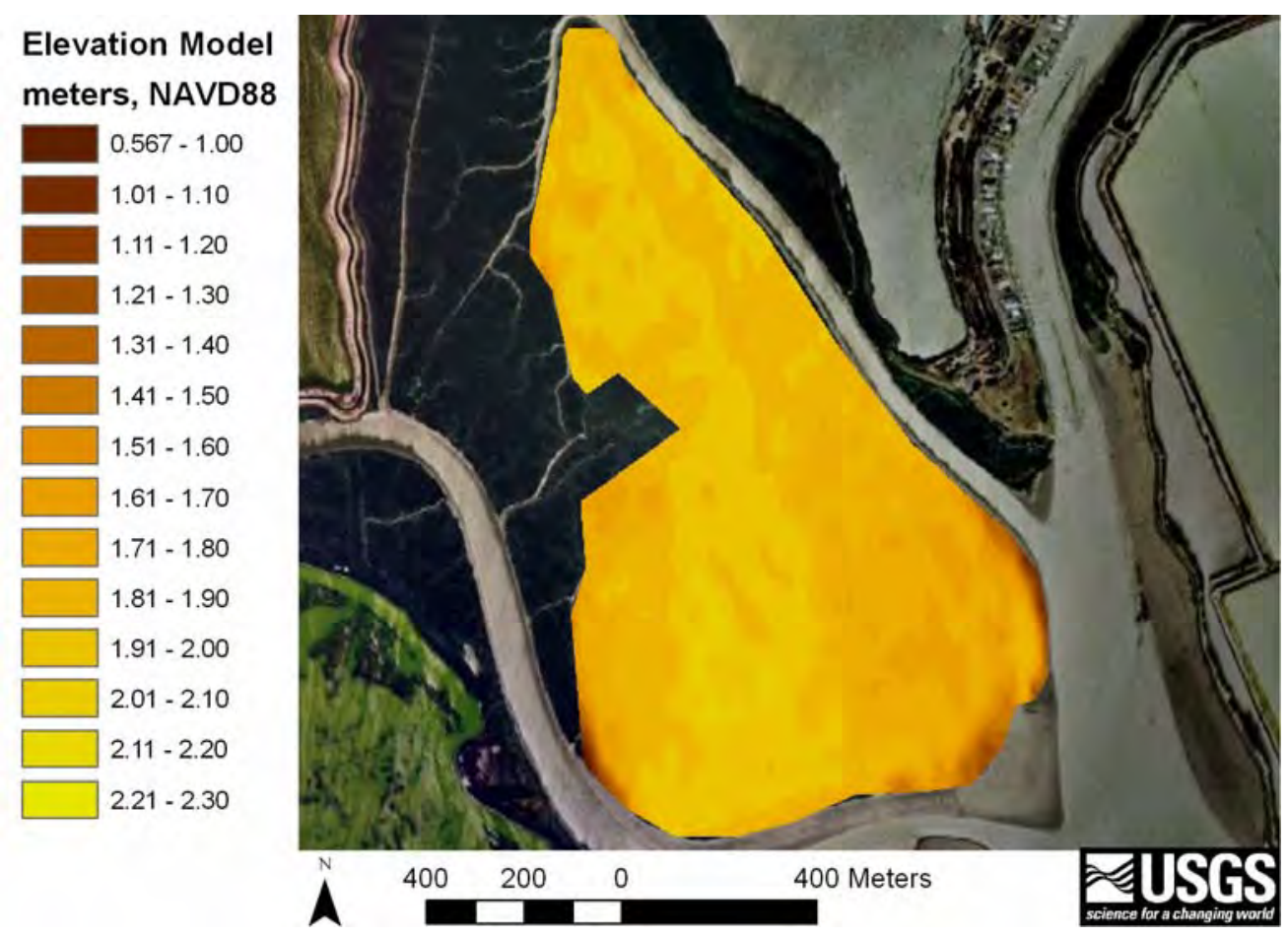

Figure F-3. Elevation model (3-meter resolution) developed from ground RTK GPS elevation data. 


\section{Vegetation surveys}

Vegetation and elevation were surveyed concurrently at Coon Island in November and December of 2009. A total of 364 locations (fig. F-1) were measured for vegetation composition, height, and percentage cover (table F-1). We did not distinguish between invasive and native Spartina spp., nor among Schoenoplectus spp., in the survey. Vegetation in marshes is sensitive to soil salinity, inundation patterns, and disturbance; therefore, a stratification of vegetation species relative to MHW (fig. F-4) was observed within this low-slope marsh. 
Table F-1.

Mean marsh elevation relative to mean high water (MHW), average, and max height, percentage cover with standard deviations (SD), and presence by species at Coon Island.

[cm, centimeter; $\mathrm{m}$, meter; $\mathrm{n}$, sample number]

\begin{tabular}{lcccccccccc}
\hline Species & $\begin{array}{c}\text { Elevation } \\
(\text { MHW, } \mathbf{m})\end{array}$ & $\begin{array}{c}\text { Elevation } \\
\text { SD }(\text { MHW, } \\
\mathbf{m})\end{array}$ & $\begin{array}{c}\text { Mean } \\
\text { Height } \\
(\mathbf{c m})\end{array}$ & $\begin{array}{c}\text { Mean } \\
\text { Height } \\
\text { SD } \\
(\mathbf{c m})\end{array}$ & $\begin{array}{c}\text { Max } \\
\text { Height } \\
(\mathbf{c m})\end{array}$ & $\begin{array}{c}\text { Max } \\
\text { Height } \\
\text { SD }(\mathbf{c m})\end{array}$ & $\begin{array}{c}\text { Cover } \\
\text { (percent) }\end{array}$ & $\begin{array}{c}\text { Cover } \\
\text { SD } \\
\text { (percent) }\end{array}$ & $\begin{array}{c}\text { Presence } \\
(\text { percent) }\end{array}$ \\
\hline Sarcocornia pacifica & 0.09 & 0.09 & 50.11 & 12.69 & 57.79 & 13.74 & 75.60 & 27.90 & 320 & 87.91 \\
Spartina spp. & -0.37 & 0.13 & 91.00 & 27.62 & 103.33 & 20.82 & 26.67 & 17.56 & 3 & 0.82 \\
Schoenoplectus spp. & -0.02 & 0.13 & 86.29 & 24.84 & 96.66 & 26.72 & 26.57 & 22.66 & 140 & 38.46 \\
Grindelia stricta & 0.11 & 0.06 & 73.25 & 24.98 & 83.75 & 27.22 & 32.25 & 15.60 & 20 & 5.49 \\
Jaumea carnosa & 0.12 & 0.10 & 27.18 & 8.67 & 33.46 & 14.74 & 36.96 & 26.56 & 28 & 7.69 \\
Frankenia salina & 0.12 & 0.01 & 35.50 & 20.51 & 39.50 & 21.92 & 55.00 & 21.21 & 2 & 0.55 \\
Distichlis spicata & 0.15 & 0.03 & 28.60 & 9.37 & 29.80 & 9.52 & 1.80 & 0.45 & 5 & 1.37 \\
Lepidium latifolium & 0.13 & 0.07 & 91.50 & 10.47 & 104.61 & 18.37 & 25.28 & 21.84 & 18 & 4.95 \\
Atriplex triangularis & 0.09 & 0.08 & 21.00 & 4.64 & 26.20 & 9.31 & 11.40 & 13.50 & 5 & 1.37 \\
Baccharis pilularis & 0.19 & - & 60.00 & - & 95.00 & - & 60.00 & - & 1 & 0.27 \\
Baccharis douglasii & 0.14 & 0.00 & 75.00 & 14.14 & 83.50 & 19.09 & 55.00 & 28.28 & 2 & 0.55 \\
Juncus spp. & 0.11 & 0.10 & 53.00 & 14.28 & 59.33 & 15.13 & 7.83 & 10.94 & 6 & 1.65 \\
\hline
\end{tabular}




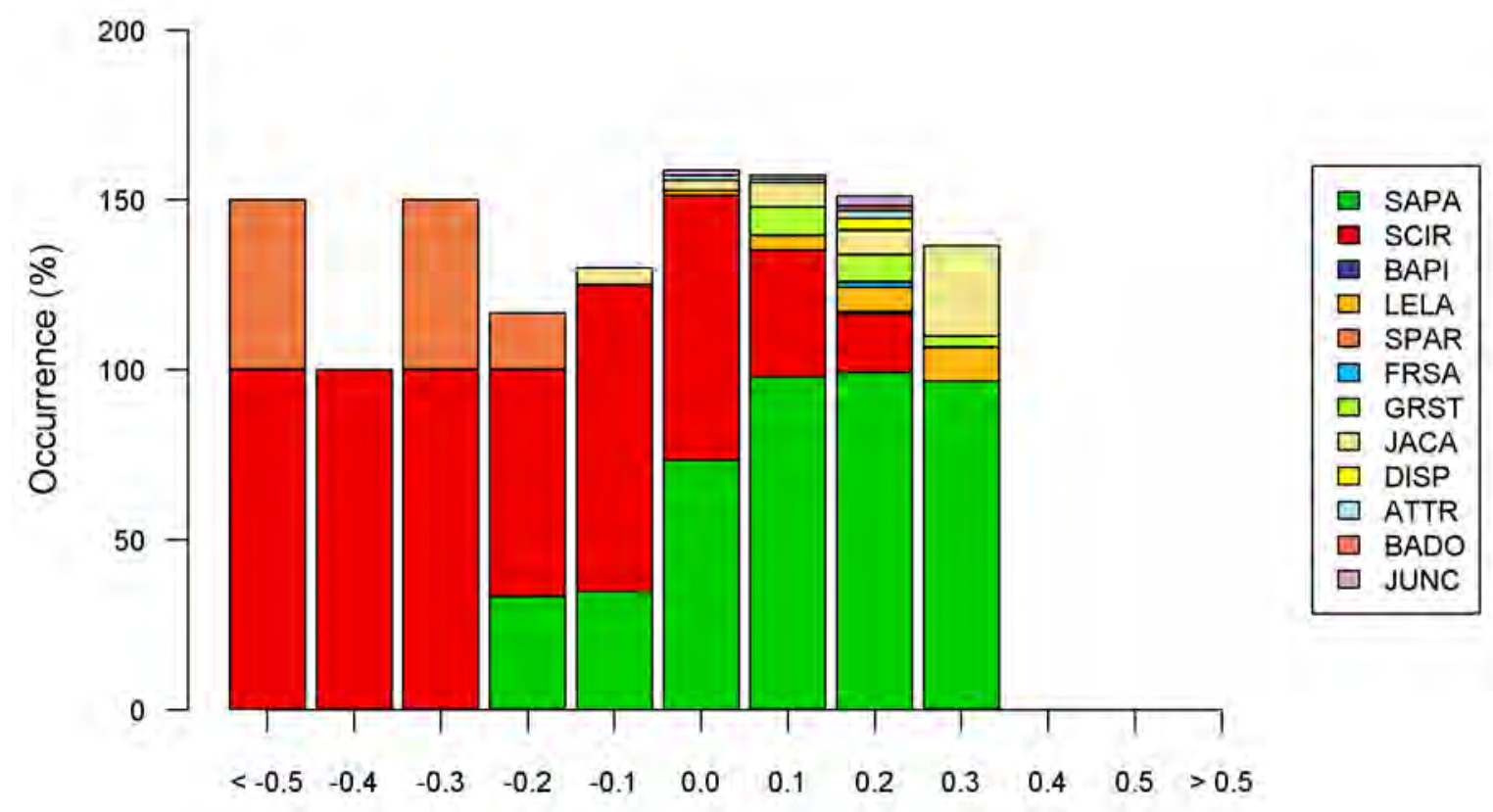

Elevation Relative to MHW (m)

Figure F-4. Stratification of vegetation species was observed relative to mean high water (MHW) in meters $(\mathrm{m})$. Species codes: SAPA: = Sarcocornia pacifica; SCIR = Schoenoplectus spp.; BAPI = Baccaris pilularis; LELA = Lepidium latifolium; SPAR = Spartina spp.; FRSA = Frankenia salina; GRST = Grindelia stricta; JACA = Jaumea carnosa; DISP = Distichlis spicata; ATTR = Atriplex triangularis; $\mathrm{BADO}=$ BaccKaris douglasii; JUNC = Juncus spp.

\section{Water-level monitoring}

Site-specific water level was monitored at Coon Island from December 2009 to November 2010. Water level was measured by using two data loggers: one deployed at the mouth of a second order channel and the other in the marsh interior. MHW was at $1.78 \mathrm{~m}$, and mean higher high water (MHHW) at $1.94 \mathrm{~m}$ for the site (NAVD88). Water levels were recorded throughout the year to evaluate seasonal patterns in tides. The period when the marsh platform (defined as mean elevation) was inundated most often was from January 2010 through February 2010 (fig. F-5). During those months, above average water levels were recorded because of several record breaking storms that brought low air pressure and substantial rainfall, resulting in higher than predicted tides. The cumulative rainfall in January 2010 was above average throughout the San Francisco Bay area, and daily rainfall records were broken in some locations (National Oceanic and Atmospheric Administration). This resulted in longer inundation periods of the marsh platform. Mean salinity during 2010 at Coon Island was $11.8(\mathrm{SD}=6.1)$ practical salinity scale. 


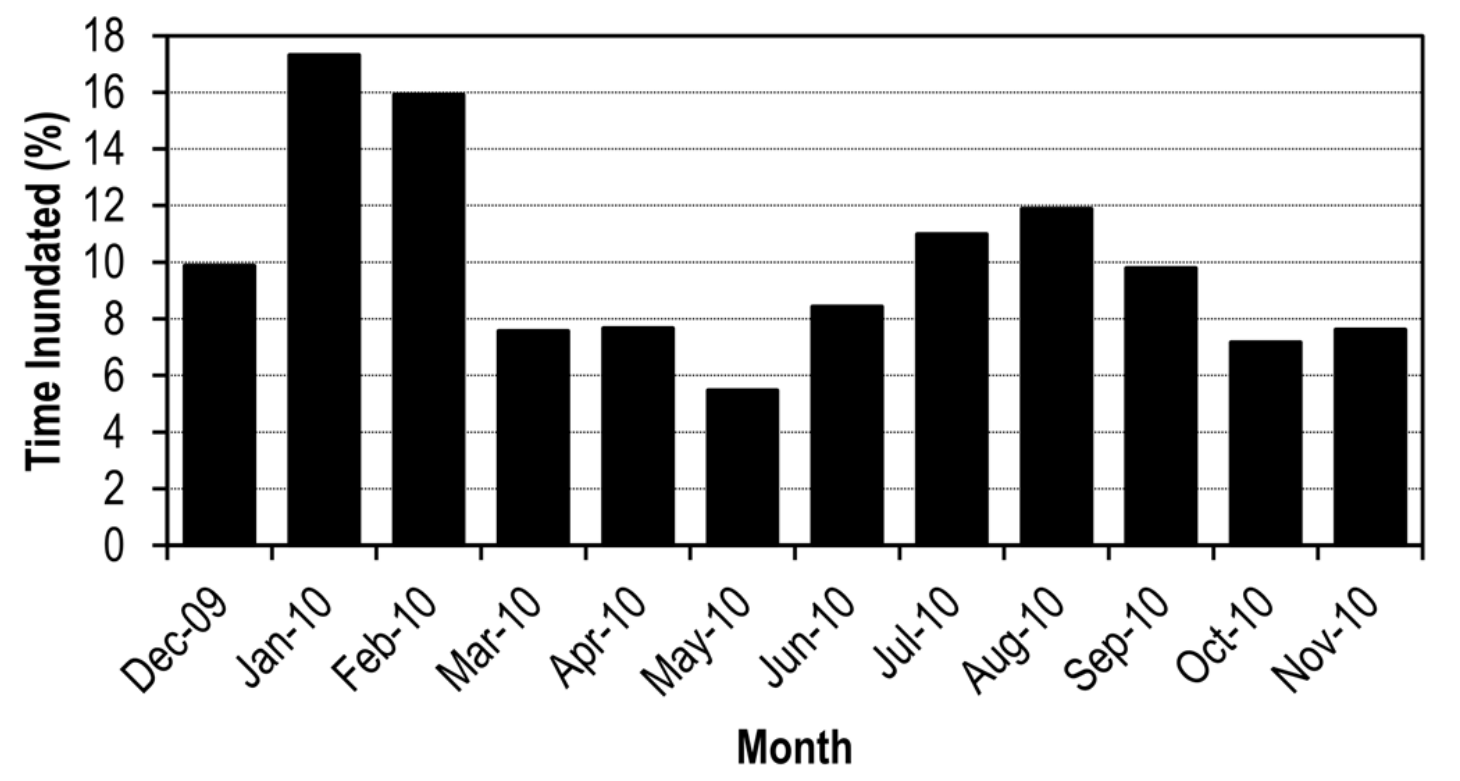

Figure F-5. Percentage of time Coon Island is inundated monthly based on the mean elevation of the marsh platform.

\section{Marsh elevation modeling}

WARMER results indicated that Coon Island will not keep pace with local SLR through this century. WARMER projected a gradual reduction in elevation relative to MHW over time, with a more dramatic decline after 2060 (Fig F-6). By 2090, the marsh was projected to be under MSL and would, therefore, transition to a mudflat (fig. F-7). 


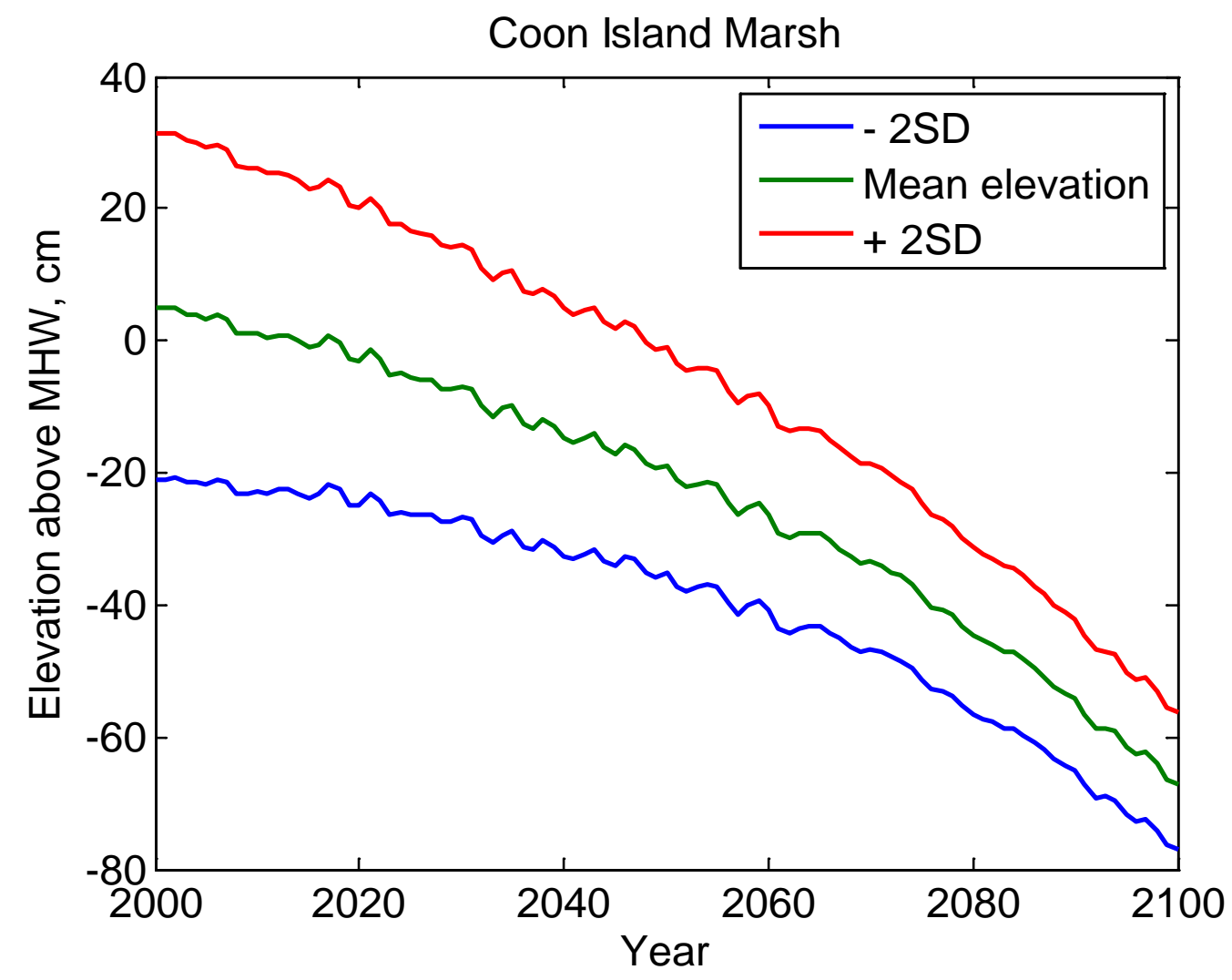

Figure F-6. WARMER scenarios of marsh elevation change at Coon Island. Elevation above mean high water (MHW), in centimeters (cm), is plotted against model year with two standard deviations (SD). 


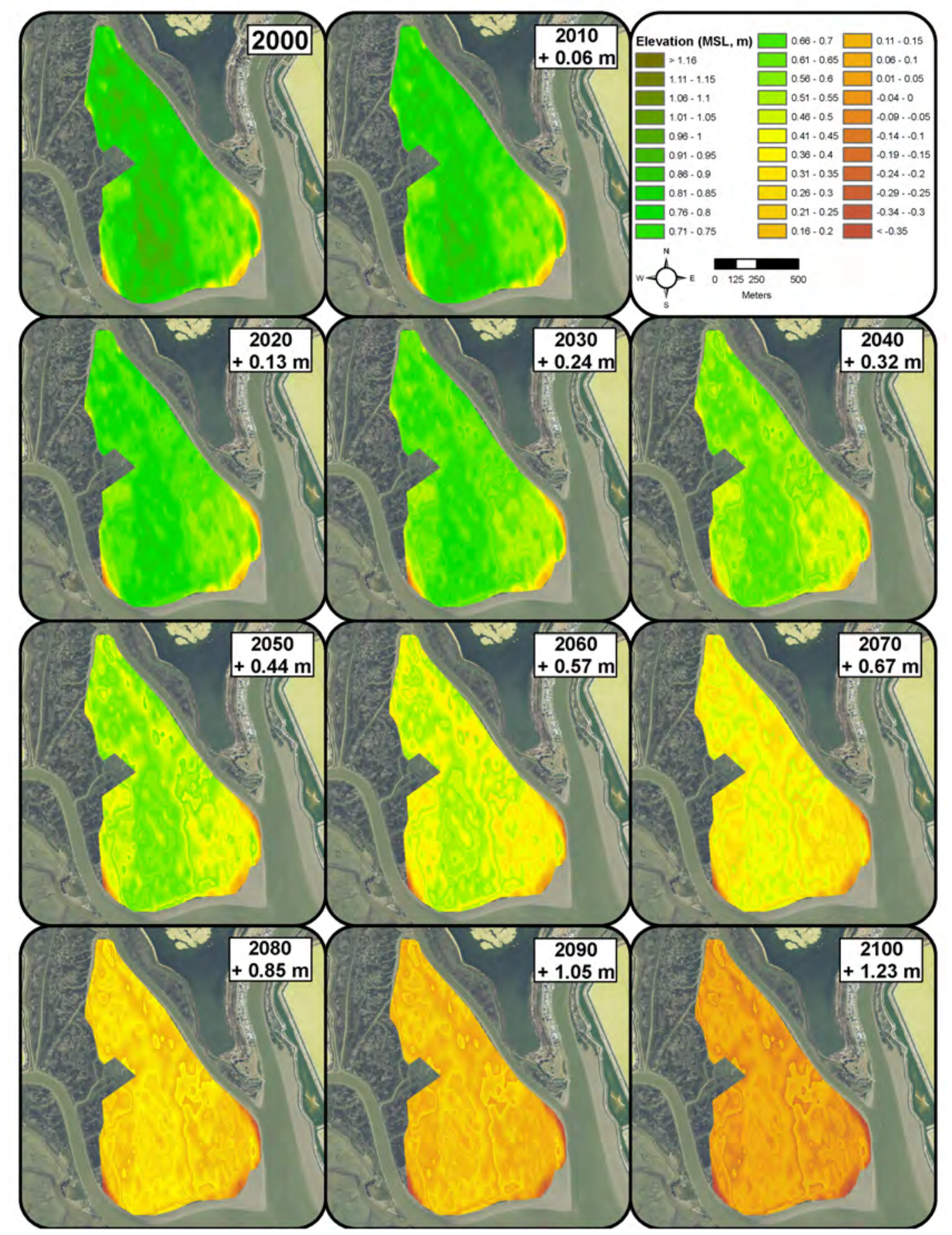

Figure F-7. WARMER results for Coon Island. WARMER accounts for changes in relative sealevel, subsidence, inorganic sediment accumulation, above and belowground organic matter productivity, compaction, and decay. Non-linear sea-level rise projections for California were used (Cayan and others, 2009). [MSL, mean sea level; m, meters] 
Elevation relative to the local tidal datum can be tied to vegetation observations. Thus, vegetation data were categorized as mudflat, low, mid, high marsh, or upland transition plant communities and used to interpret the WARMER SLR results (figs. F-8 and F-9). Upland transition (greater than $1.0 \mathrm{~m}$ MSL) was characterized by coyote bush (Baccharis pilularis). High marsh (0.7-1.0 m MSL) was characterized by Frankenia salina and Jaumea carnosa, whereas mid marsh (0.45-0.7 m MSL) was dominated by Sarcocornia pacifica. Low marsh (0.2-0.45 m MSL) was characterized by Spartina spp. or, in brackish areas, by Schoenoplectus spp. Mudflat habitat (less than $0.2 \mathrm{~m}$ MSL) was unvegetated or sparsely covered with Spartina spp. Currently, vegetation at Coon Island is primarily high and mid-marsh plant communities. The amount of high-marsh vegetation was projected to increase between 2010 (0.06 m SLR) and $2030(0.57 \mathrm{~m}$ SLR). By 2060 (0.57 m SLR), WARMER projected a considerable increase in low-marsh vegetation. After 2060 ( $0.57 \mathrm{~m} \mathrm{SLR})$, the elevation of the marsh rapidly decreased, and, by 2090 ( $1.05 \mathrm{~m} \mathrm{SLR})$, the marsh became primarily mudflat. The WARMER model parameters for Coon Island were collected by using sediment core data from the site.

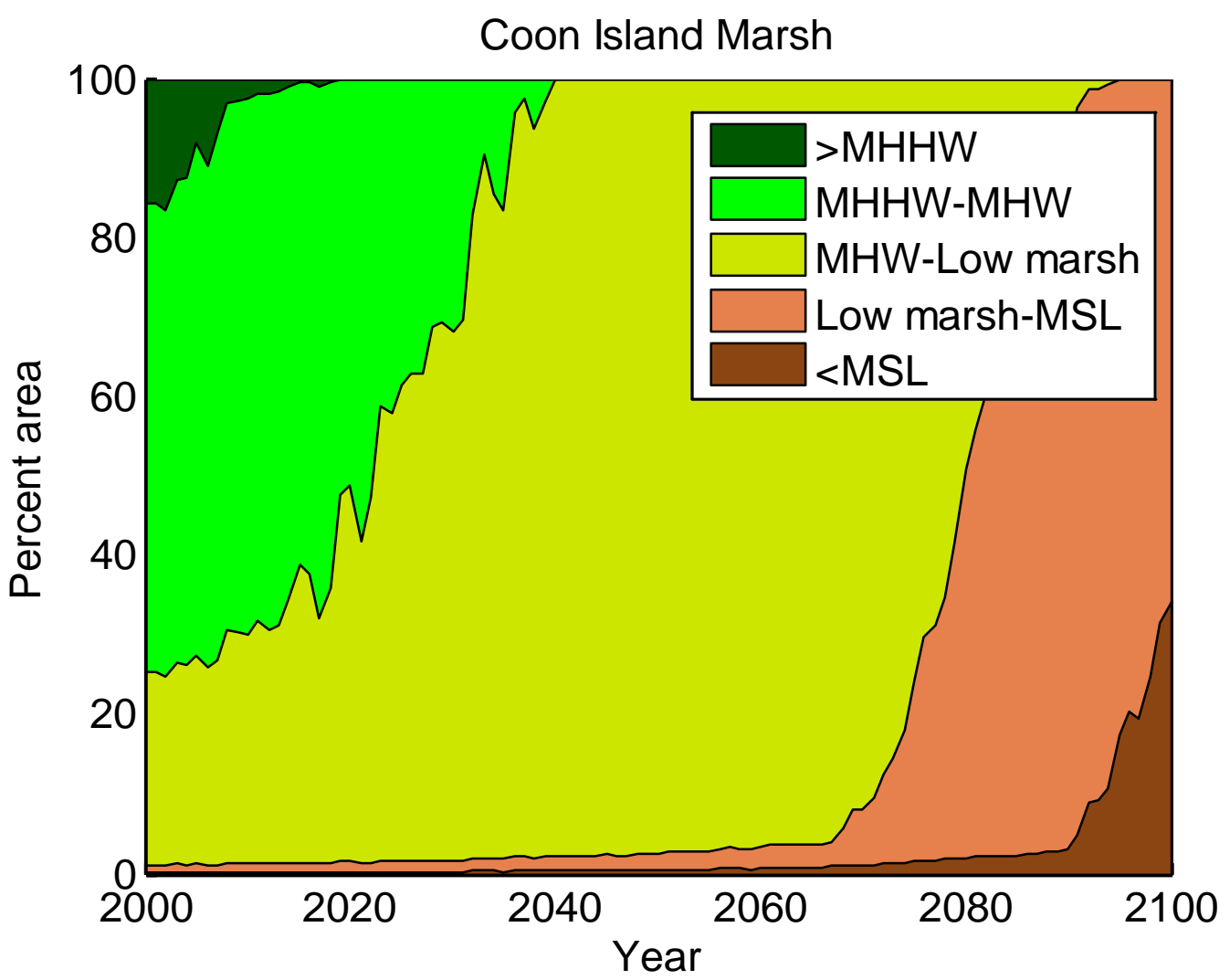

Figure F-8. Area of Coon Island within a given tidal range for the duration of the simulation period. [MHHW, mean higher high water; MHW, mean high water; MSL, mean sea level; >, greater than; <, less than] 


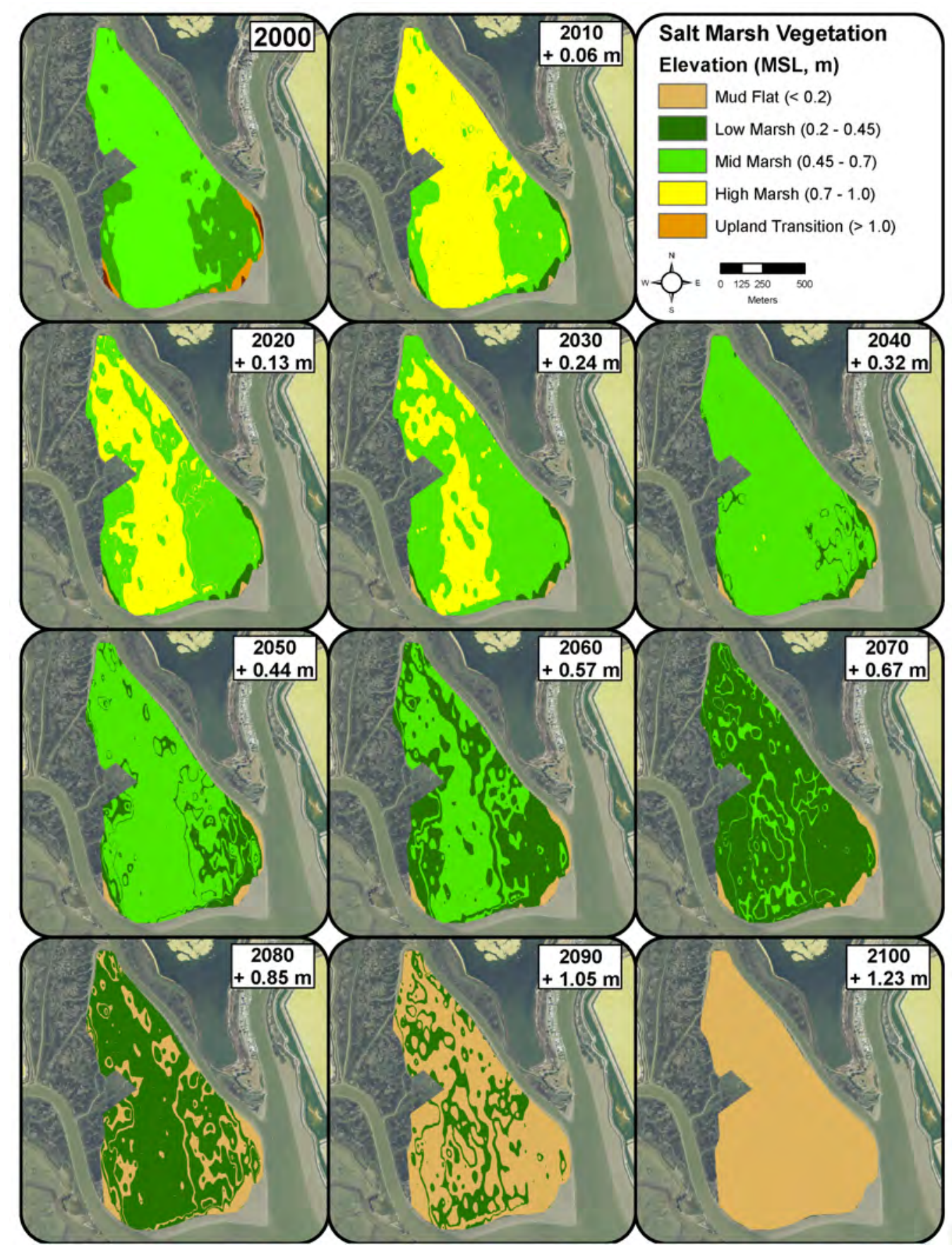

Figure F-9. Coon Island WARMER results in terms of plant communities relative to mean sea level (MSL), in meters (m): mudflat, low, mid, or high marsh, or upland transition. 


\section{Appendix G. Corte Madera Marsh}

\section{Introduction}

Corte Madera Marsh (hereafter, "Corte Madera") is located in Marin County along San Pablo Bay and at the mouth of Corte Madera Creek. Corte Madera is part of the 400 hectare (ha) Corte Madera Ecological Reserve, which is owned and managed by the California Department of Fish and Game. It was designated as an Ecological Reserve in 1975 and contains federally endangered California clapper rails (Rallus longirostris obsoletus), which occupy the low intertidal zone dominated by cordgrass (Spartina spp.). It also contains San Pablo song sparrows (Melospiza melodia samuelis) and California black rails (Laterallus jamaicensis coturniculus), California species of concern.

This study focused on 76.8 ha of Corte Madera. Elevation and vegetation surveys were done in 2010 , by using an RTK GPS. To monitor tidal inundation, two water-level loggers were deployed during 2009-2010.

\section{Results}

\section{Elevation surveys}

A total of 744 elevation measurements were taken at Corte Madera (fig. G-1). The elevation range was $1.31-2.08$ meters $(\mathrm{m})$, with a mean of $1.63 \mathrm{~m}$ and a range of $0.77 \mathrm{~m}$ (NAVD88). Over half (80 percent) of the survey points fell within 1.5-1.8 $\mathrm{m}$. Corte Madera was among the lowest marshes surveyed in this study, with 72 percent of the elevation points located below mean high water (MHW; fig. G-2). A 3-m resolution elevation model was developed in ArcGIS 9.3 (ESRI, Redlands, Calif.) Spatial Analyst by using the kriging method (fig. G-3). This baseline elevation model was used as the initial state in the WARMER sea-level rise (SLR) model; WARMER results were extrapolated across the elevation model. 


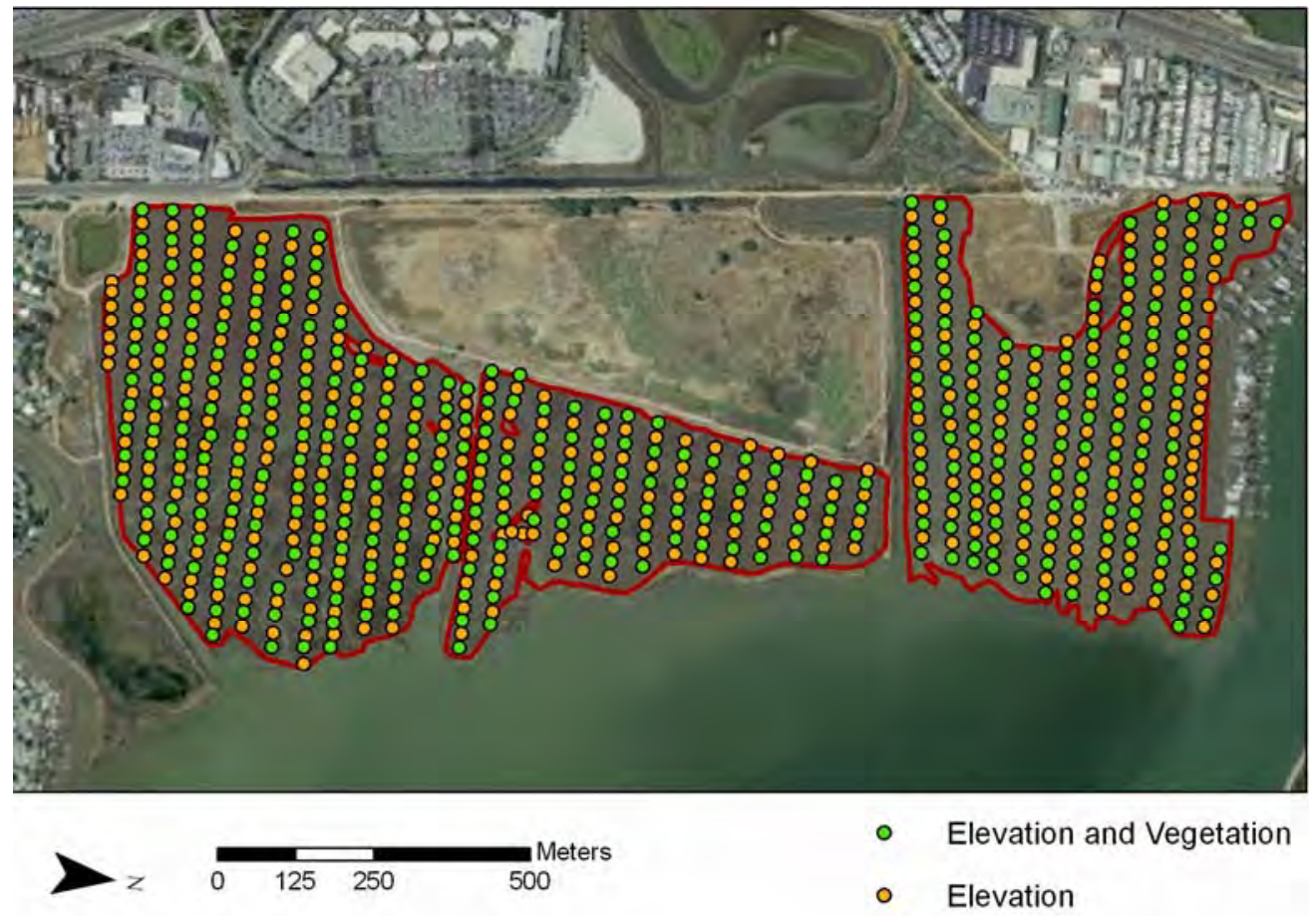

Figure G-1. Corte Madera with elevation and vegetation survey points from 2009.

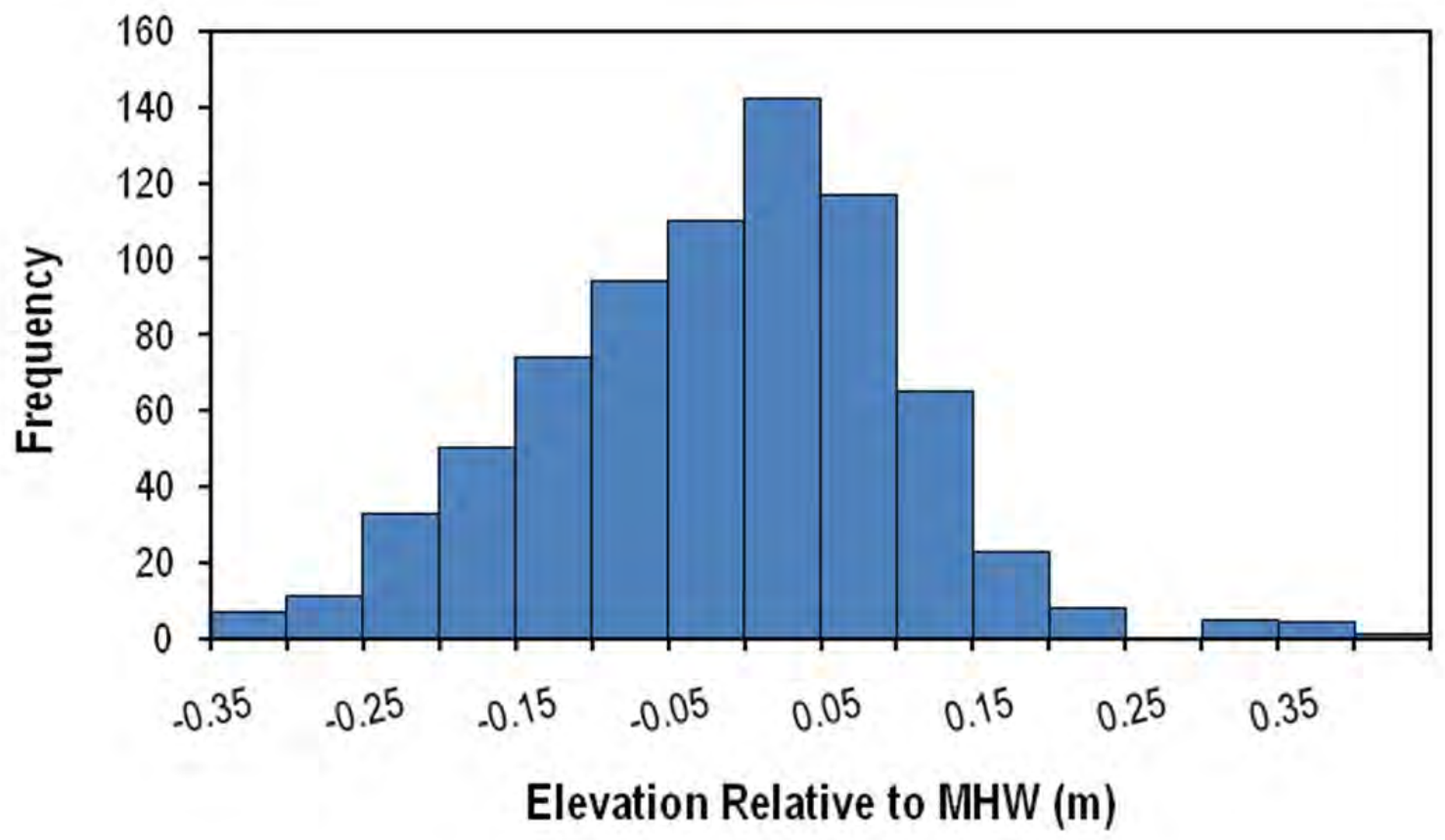

Figure G-2. Distribution of elevation samples relative to local mean high water (MHW), in meters $(\mathrm{m})$, at Corte Madera marsh. 


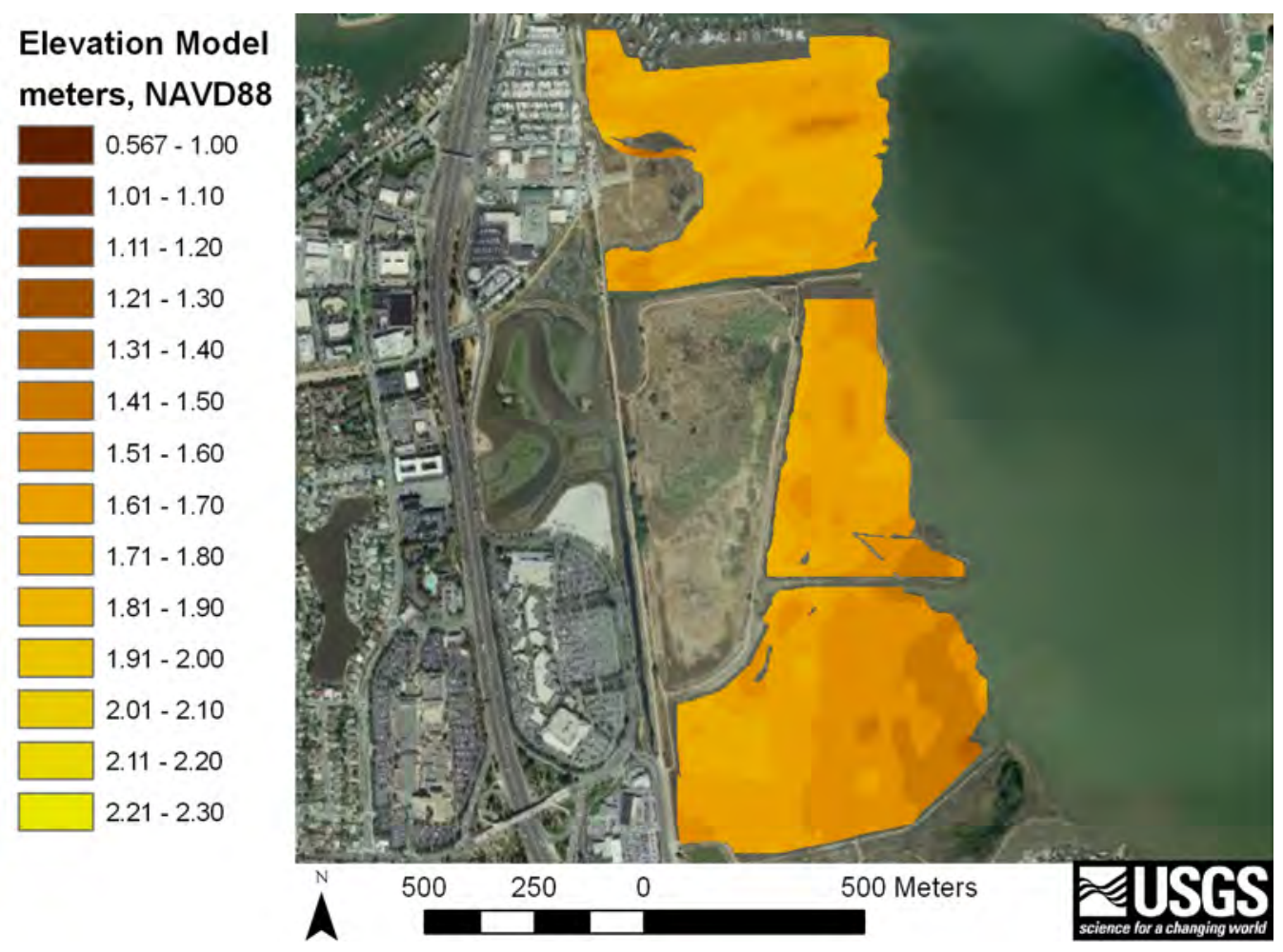

Figure G-3. Elevation model (3-meter resolution) developed from ground RTK GPS elevation data.

\section{Vegetation surveys}

Vegetation and elevation were surveyed concurrently at Corte Madera in March 2010. A total of 361 locations (fig. G-1) were measured for vegetation composition, height, and percentage cover (table G-1). We did not distinguish between invasive and native Spartina spp., nor among Schoenoplectus spp., in the survey. Vegetation in marshes is sensitive to soil salinity, inundation patterns, and disturbance; therefore, a stratification of vegetation species relative to MHW (fig. G-4) was observed within this low-slope marsh. 
Table G-1. Mean marsh elevation relative to mean high water (MHW), average, and max height, percentage cover with standard deviations (SD), and presence by species at Corte Madera.

[cm, centimeter; m, meter; $n$, sample number]

\begin{tabular}{|c|c|c|c|c|c|c|c|c|c|c|}
\hline Species & $\begin{array}{c}\text { Elevation } \\
(M H W \\
m)\end{array}$ & $\begin{array}{c}\text { Elevation } \\
S D \\
(M H W \\
m)\end{array}$ & $\begin{array}{l}\text { Mean } \\
\text { Height } \\
(\mathrm{cm})\end{array}$ & $\begin{array}{l}\text { Mean } \\
\text { Height } \\
\text { SD (cm) }\end{array}$ & $\begin{array}{c}\text { Max } \\
\text { Height } \\
\text { (cm) }\end{array}$ & $\begin{array}{c}\text { Max } \\
\text { Height } \\
\text { SD (cm) }\end{array}$ & $\begin{array}{c}\text { Cover } \\
\text { (percent) }\end{array}$ & $\begin{array}{c}\text { Cover } \\
\text { SD } \\
\text { (percent) }\end{array}$ & $n$ & $\begin{array}{l}\text { Presence } \\
\text { (percent) }\end{array}$ \\
\hline Sarcocornia pacifica & -0.06 & 0.12 & 27.14 & 7.46 & 38.10 & 9.65 & 70.07 & 33.92 & 351 & 97.23 \\
\hline Spartina spp. & -0.17 & 0.08 & 36.43 & 10.32 & 51.39 & 15.19 & 23.79 & 25.19 & 99 & 27.42 \\
\hline Grindelia stricta & 0.08 & 0.12 & 41.57 & 20.80 & 49.14 & 21.26 & 15.14 & 10.73 & 14 & 3.88 \\
\hline Jaumea carnosa & -0.02 & 0.05 & 12.14 & 3.07 & 15.35 & 3.02 & 24.97 & 30.36 & 37 & 10.25 \\
\hline Frankenia salina & 0.21 & 0.19 & 14.00 & 9.90 & 17.50 & 12.02 & 9.00 & 1.41 & 2 & 0.55 \\
\hline Distichlis spicata & 0.00 & 0.08 & 21.16 & 6.07 & 28.21 & 6.65 & 29.99 & 27.76 & 126 & 34.90 \\
\hline Lepidium latifolium & -0.01 & 0.08 & 18.60 & 7.55 & 23.70 & 10.09 & 11.30 & 9.20 & 10 & 2.77 \\
\hline
\end{tabular}




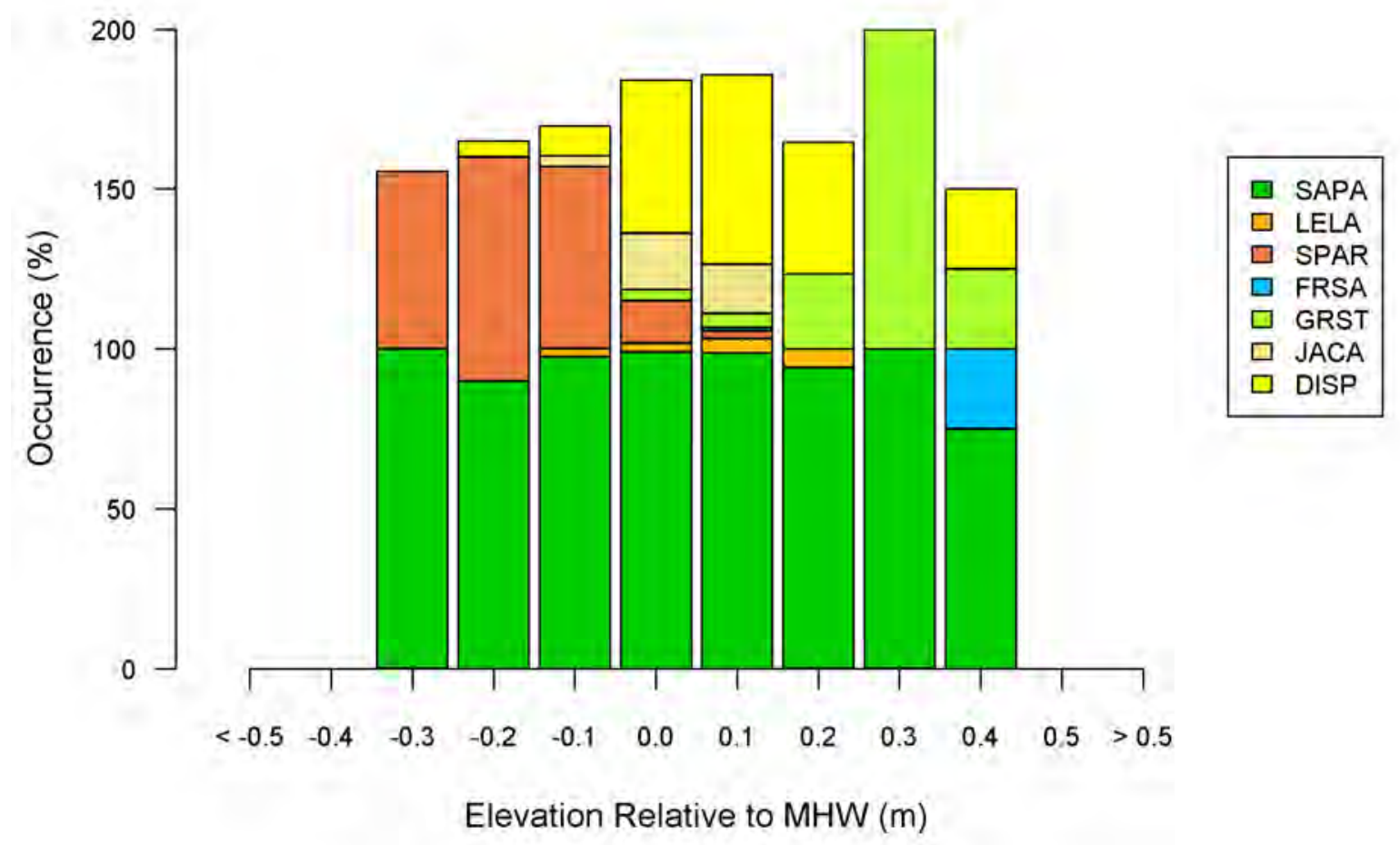

Figure G-4. Stratification of vegetation species was observed relative to mean high water (MHW) in meters (m). Species codes: SAPA = Sarcocornia pacifica; LELA = Lepidium latifolium; SPAR = Spartina spp.; FRSA = Frankenia salina; GRST: = Grindelia stricta; JACA = Jaumea carnosa; DISP = Distichlis spicata.

Water-level monitoring

Water levels were recorded throughout the year to evaluate seasonal patterns in tides. Site-specific water level was monitored from August 2010 through July 2011 (fig. G-5). Water level was measured by using two data loggers: one deployed at the mouth of a second order channel and another in the marsh interior. MHW was at $1.70 \mathrm{~m}$, and mean higher high water (MHHW) was at $1.87 \mathrm{~m}$ for the site (NAVD88). 


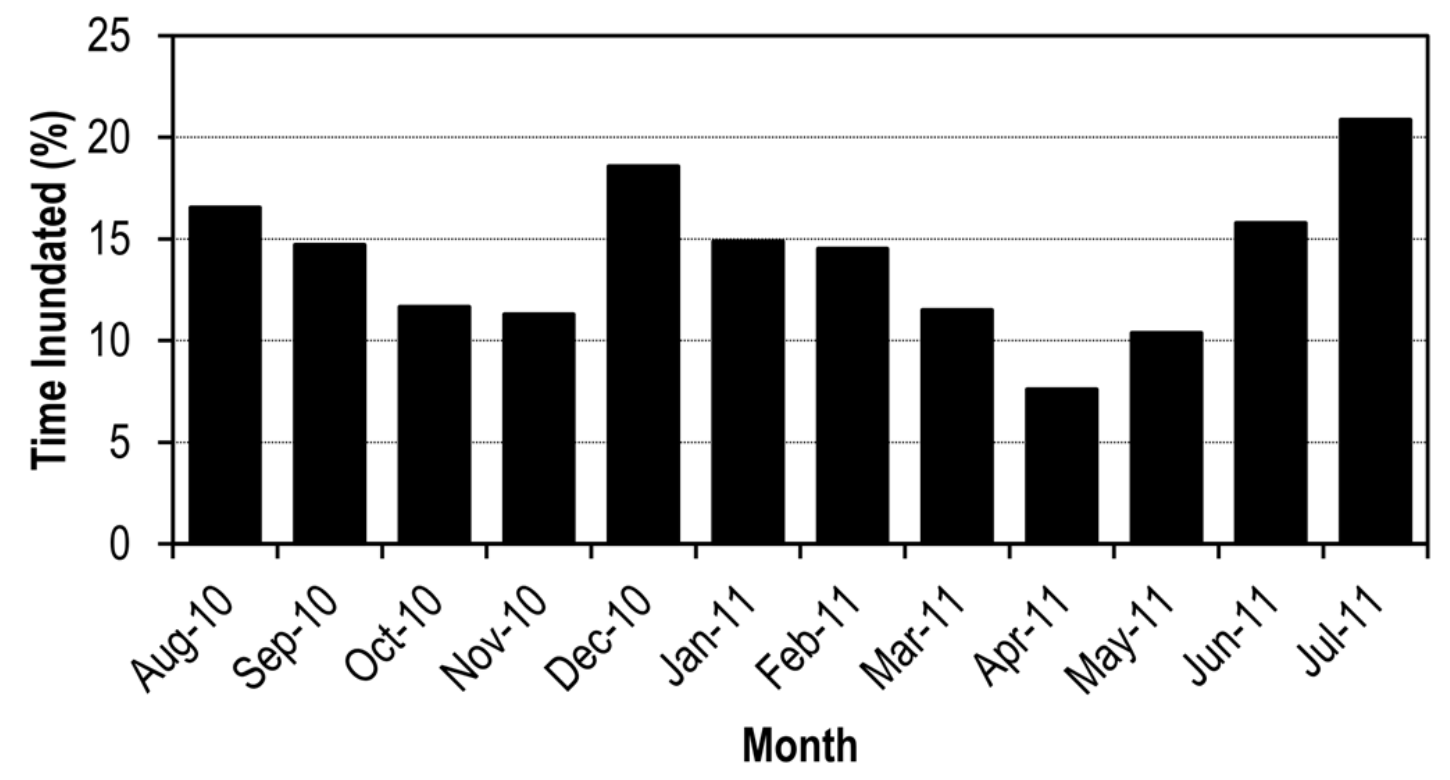

Figure G-5. Percentage of time Corte Madera was inundated monthly based on the mean elevation of the marsh platform.

\section{Marsh elevation modeling}

Corte Madera was one of the lowest marshes relative to MHW in this study, second only to Colma marsh. Sites with lower accretion rates and starting elevations that were located lower in the tidal range became inundated more frequently, making them more susceptible to SLR. WARMER results indicated that Corte Madera will not keep pace with local SLR through this century. WARMER projected a reduction in elevation relative to MHW through 2100, with a more dramatic decline after 2060 (fig. G-6). By 2090, the marsh was projected to be under mean sea level (MSL) and to transition to a mudflat (fig. G-7). 


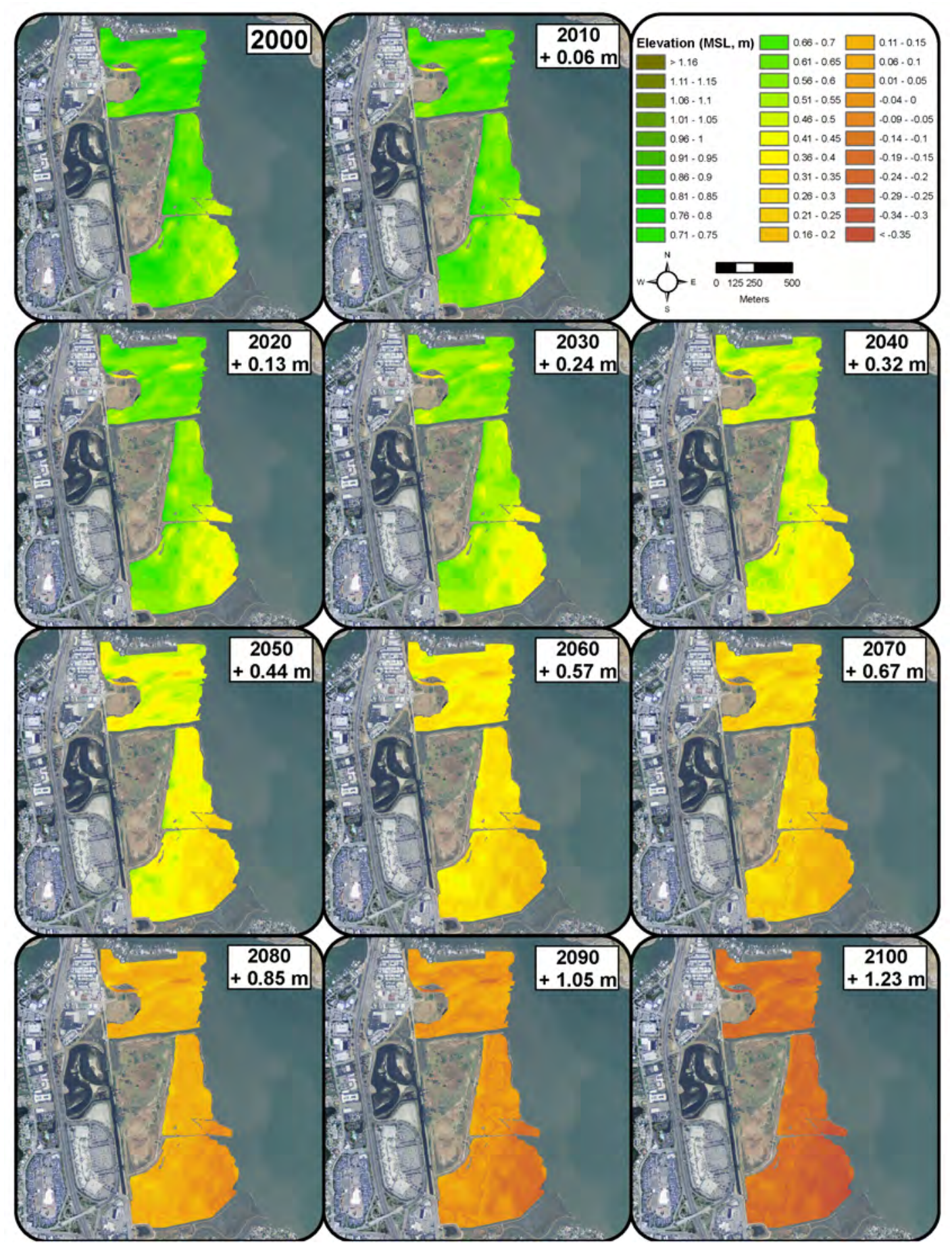

Figure G-6. WARMER results for Corte Madera. WARMER accounts for changes in relative seallevel, subsidence, inorganic sediment accumulation, above and belowground organic matter productivity, compaction, and decay. Non-linear sea-level rise projections for California were used (Cayan and others, 2009). [MSL, mean sea level; m, meters] 


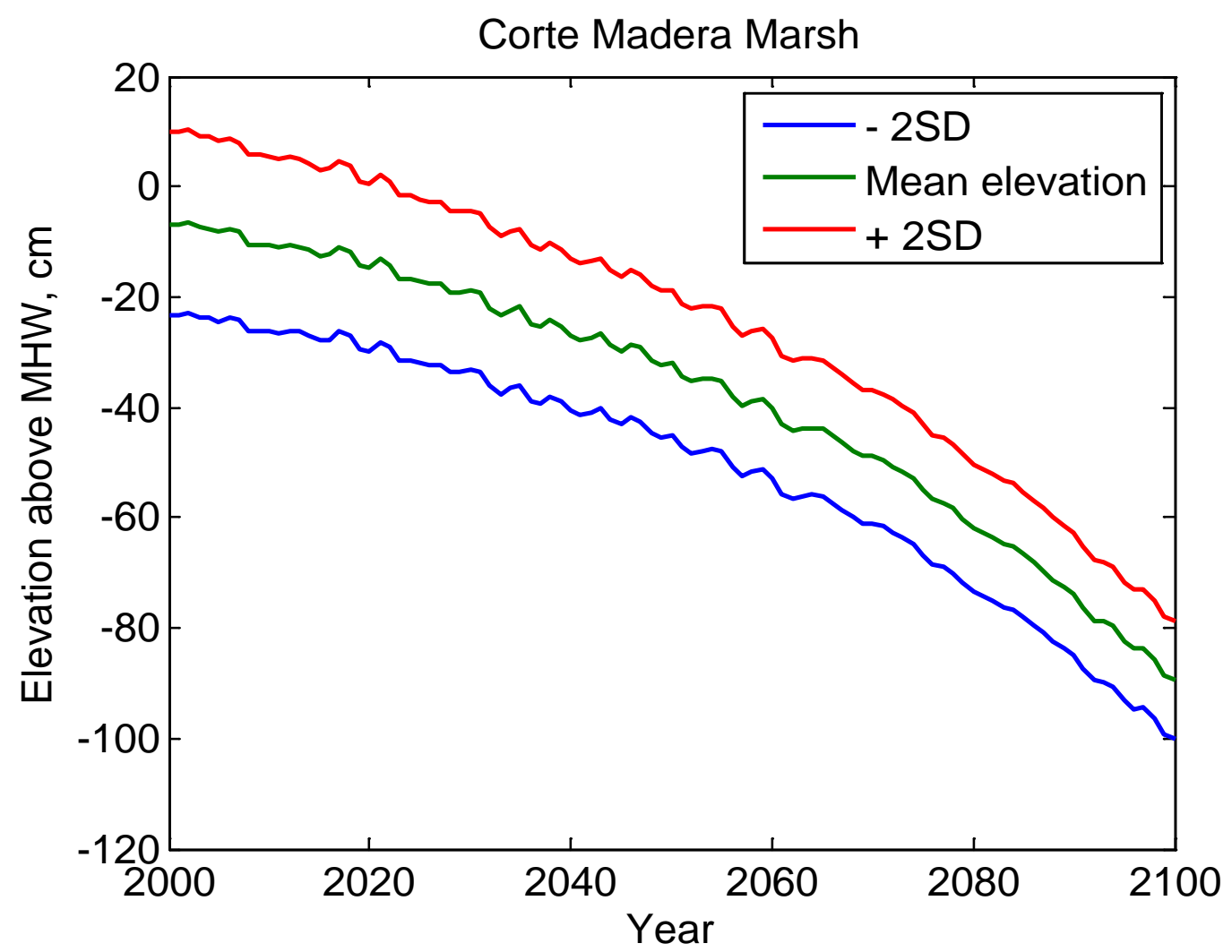

Figure G-7. WARMER scenarios for Corte Madera elevation change. Elevation above mean high water (MHW), in centimeters $(\mathrm{cm})$, is plotted against model year with two standard deviations (SD).

Elevation relative to the local tidal datum can be tied to vegetation observations. Vegetation data were categorized as mudflat, low, mid, high marsh, or upland transition plant communities and used to interpret the WARMER SLR results (figs. G-8 and G-9). Upland transition (greater than $1.0 \mathrm{~m} \mathrm{MSL}$ ) was characterized by coyote bush (Baccharis pilularis). High marsh (0.7-1.0 m MSL) was characterized by Frankenia salina and Jaumea carnosa, whereas mid marsh (0.45-0.7 m MSL) was dominated by Sarcocornia pacifica. Low marsh (0.2-0.45 m MSL) was characterized by Spartina spp. or, in brackish areas, by Schoenoplectus spp. Mudflat habitat (less than $0.2 \mathrm{~m} \mathrm{MSL)} \mathrm{was}$ unvegetated or sparsely covered with Spartina spp. Currently, vegetation at Corte Madera is prominently mid marsh with approximately one-quarter high-marsh habitat. All highmarsh vegetation was projected to disappear by 2030 ( $0.24 \mathrm{~m} \mathrm{SLR})$. Nearly all midmarsh vegetation was projected to disappear by 2060 ( $0.57 \mathrm{~m} \mathrm{SLR})$, and, by 2080 ( 0.85 SLR), Corte Madera was projected to be primarily mudflat.

The WARMER model parameters for Corte Madera were extrapolated by using sediment core data from China Camp Marsh, thus predictions need to be interpreted with caution because local sedimentation processes could differ between these marshes. To improve results, local site-specific sediment core data could be collected along with suspended-sediment concentrations to characterize sediment deposition potential. 


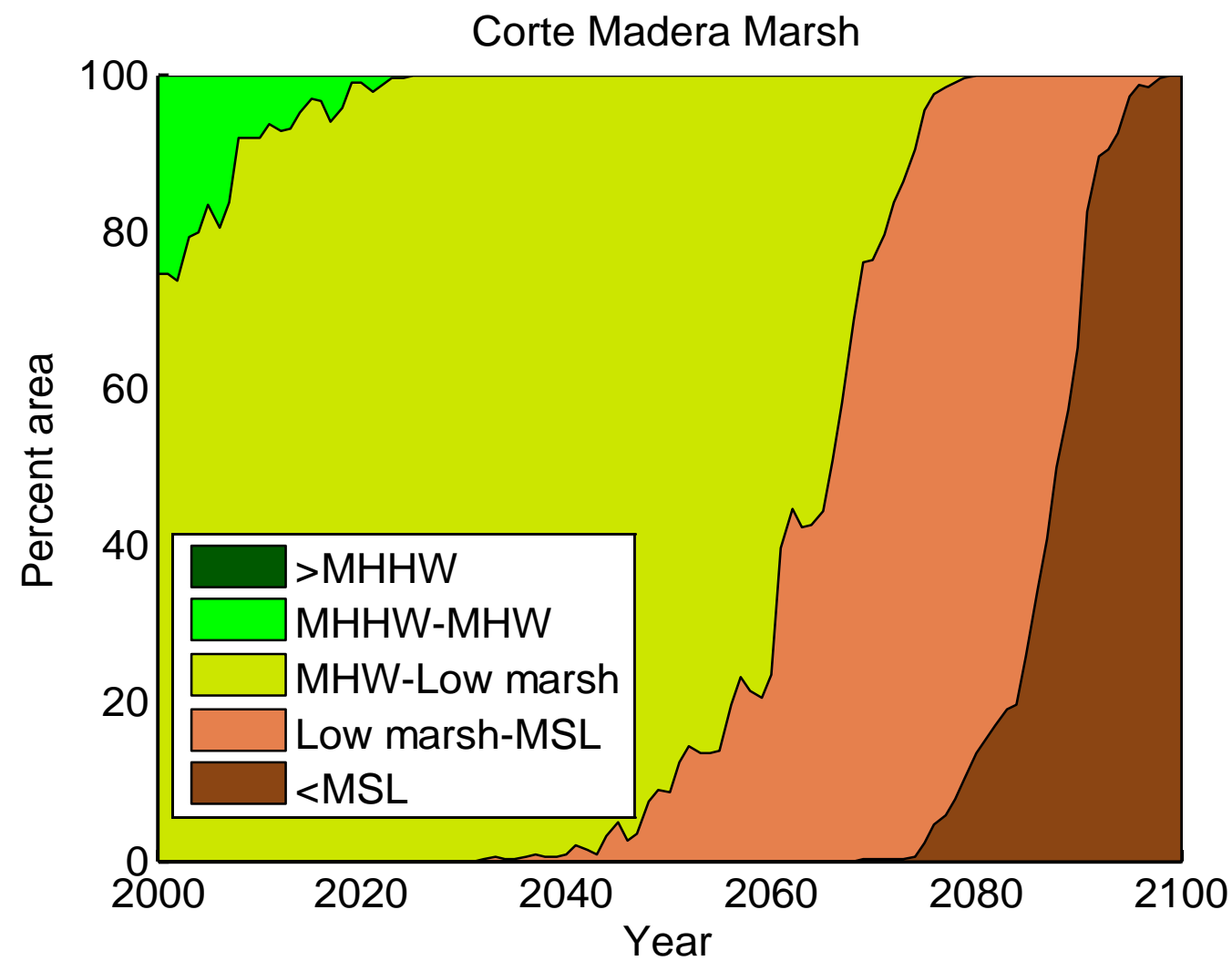

Figure G-8. Area of Corte Madera within a given tidal range for the duration of the simulation period. [MHHW, mean higher high water; MHW, mean high water; MSL, mean sea level; >, greater than; <, less than] 


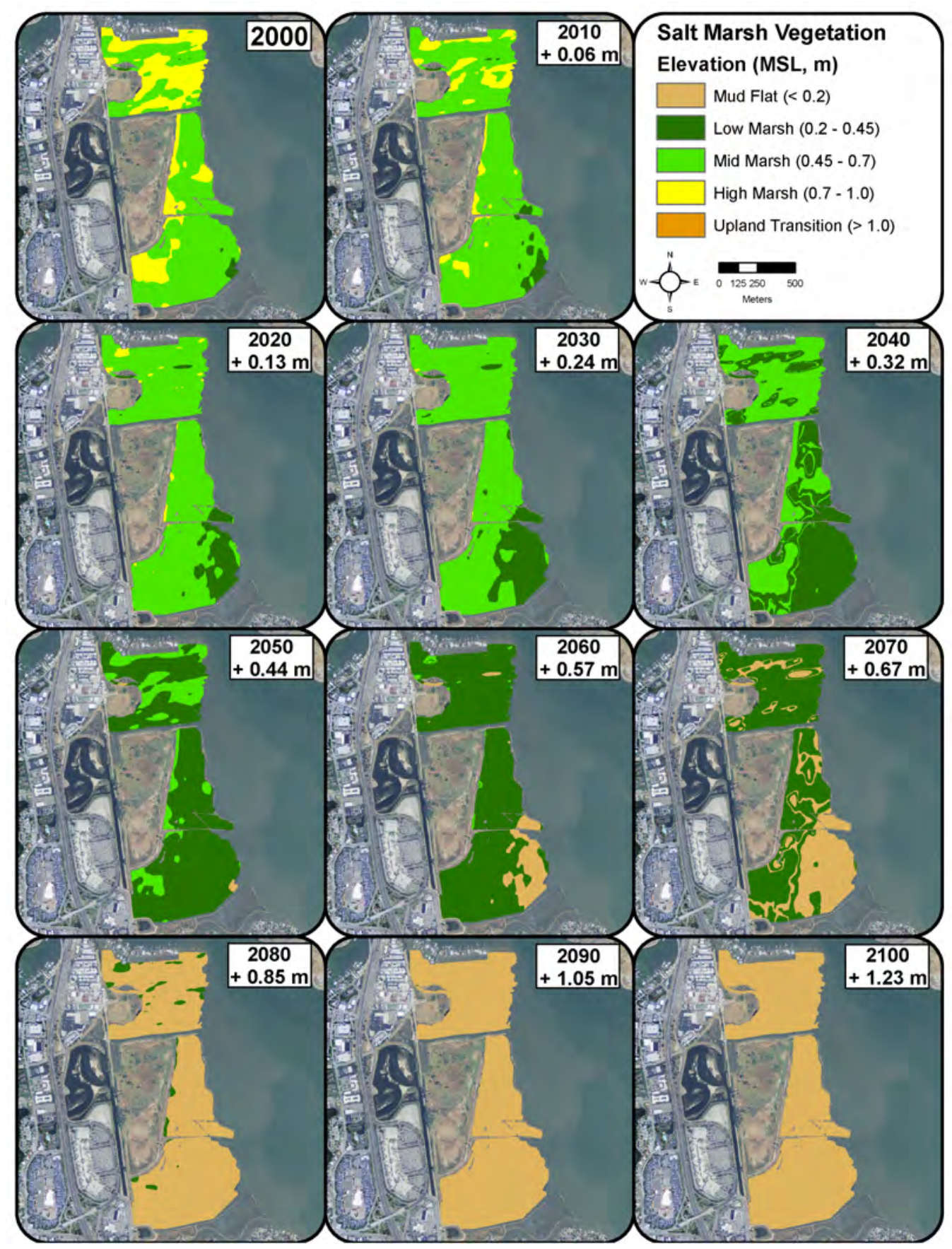

Figure G-9. Corte Madera WARMER results in terms of plant communities relative to mean sea level (MSL), in meters (m): mudflat, low, mid, or high marsh, or upland transition.. 


\section{Appendix H. Fagan Slough Marsh}

\section{Introduction}

Fagan Slough Marsh (hereafter, "Fagan") is located in Napa County along the Napa River. It has been managed by the California Department of Fish and Game since 1979 and is part of the Fagan Slough Ecological Reserve. The marsh is influenced by tidal flow from San Pablo Bay by way of Steamboat Slough (north) and Fagan Slough (south) and receives freshwater input from the Napa River. Fagan is surrounded by salt evaporation ponds, private property, and small upland areas with live oaks. Fagan provides habitat for state listed species, such as the California black rail (Laterallus jamaicensis) and federal endangered species, such as salt marsh harvest mouse (Reithrodontomys raviventris) and California clapper rail (Rallus longirostris obsoletus).

This study focused on 67.9 hectares (ha) of Fagan. Elevation and vegetation surveys were completed in 2010 by using an RTK GPS. To monitor tidal inundation, two water level loggers were deployed and monitored during 2010-2011.

\section{Results}

\section{Elevation surveys}

A total of 481 elevation measurements were taken at Fagan (fig. H-1). The elevation range was 1.16-2.25 meters (m) with a mean of $1.90 \mathrm{~m}$ (NAVD88). Over half (66 percent) of the survey points fell within 1.9-2.0 m, a $0.1 \mathrm{~m}$ range. Fagan is a relatively high elevation marsh, with 88 percent of survey points at elevations above mean high water (MHW; fig H-2). A 3-m resolution elevation model was developed in ArcGIS 9.3 (ESRI, Redlands, Calif.) Spatial Analyst by using the kriging method (fig. H$3)$. This baseline elevation model was used as the initial state in the WARMER sea-level rise (SLR) model; WARMER results were extrapolated across the elevation model. 


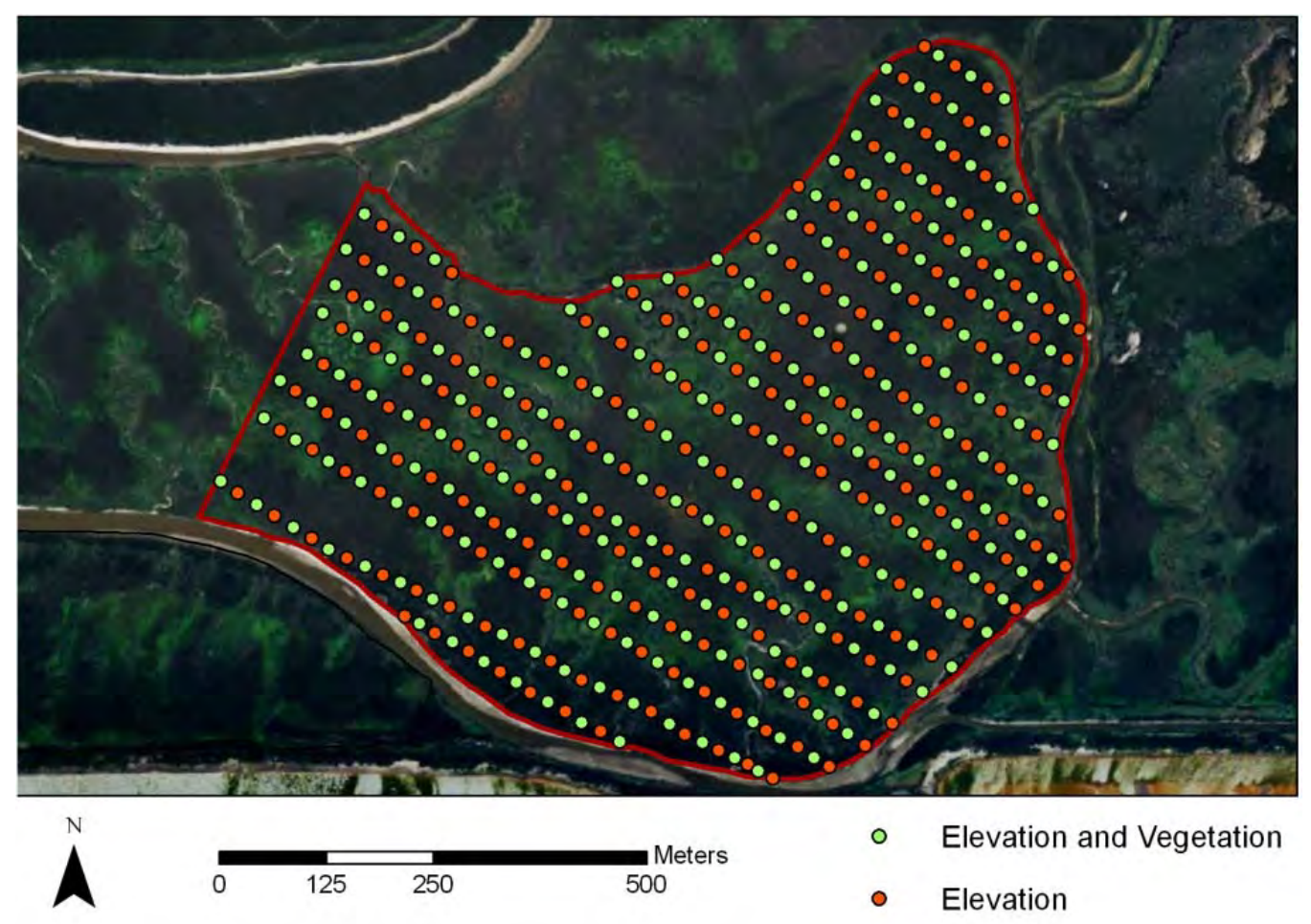

Figure H-1. Fagan Marsh with elevation and vegetation survey points from 2010.

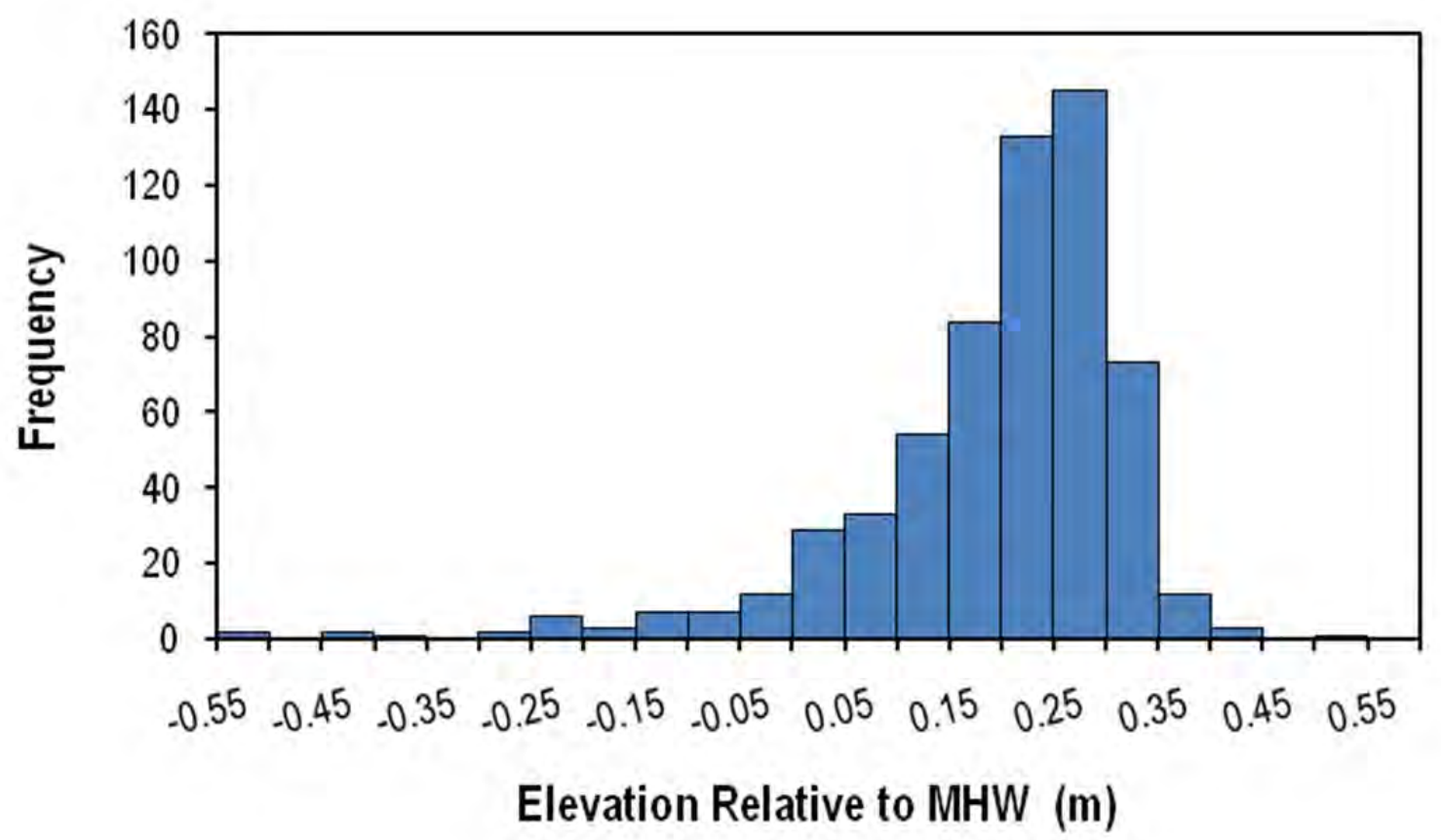

Figure H-2. Distribution of elevation samples relative to local mean high water (MHW), in meters (m), at Fagan Marsh. 


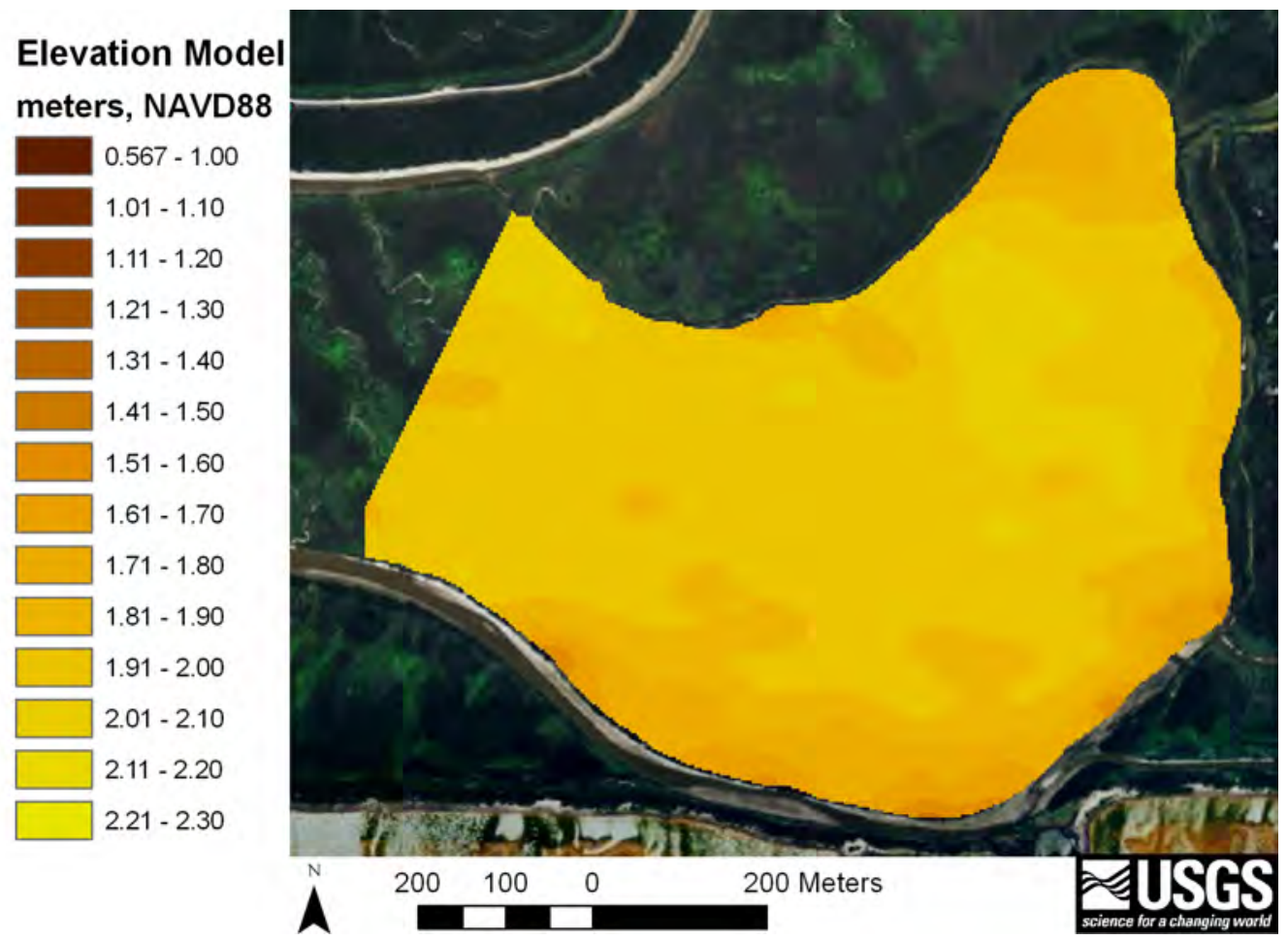

Figure H-3. Elevation model (3-meter resolution) developed from ground RTK GPS elevation data.

\section{Vegetation surveys}

Vegetation and elevation were surveyed at Fagan concurrently in April and July 2010. A total of 241 locations (fig. H-1) were measured for vegetation composition, height, and percentage cover (table H-1). We did not distinguish between invasive and native Spartina spp., nor among Schoenoplectus spp., in the survey. Vegetation in marshes is sensitive to soil salinity, inundation patterns, and disturbance; therefore, a stratification of vegetation species relative to $\mathrm{MHW}$ (fig. H-4) was observed within this low-slope marsh. Fagan also had relatively high marsh-species richness, with 17 species recorded. 
Table H-1. Mean marsh elevation relative to mean high water (MHW), average, and max height, percentage cover with standard deviations (SD), and presence by species at Fagan.

[cm, centimeter; m, meter; $n$, sample number]

\begin{tabular}{|c|c|c|c|c|c|c|c|c|c|c|}
\hline Species & $\begin{array}{l}\text { Elevation } \\
(M H W, m)\end{array}$ & $\begin{array}{c}\text { Elevation } \\
\text { SD } \\
(M H W \\
m) \\
\end{array}$ & $\begin{array}{c}\text { Mean } \\
\text { Height } \\
\text { (cm) }\end{array}$ & $\begin{array}{l}\text { Mean } \\
\text { Height } \\
\text { SD (cm) }\end{array}$ & $\begin{array}{c}\text { Max } \\
\text { Height } \\
\text { (cm) }\end{array}$ & $\begin{array}{c}\text { Max } \\
\text { Height } \\
\text { SD } \\
(\mathrm{cm}) \\
\end{array}$ & $\begin{array}{c}\text { Cover } \\
\text { (percent) }\end{array}$ & $\begin{array}{l}\text { Cover SD } \\
\text { (percent) }\end{array}$ & $n$ & $\begin{array}{l}\text { Presence } \\
\text { (percent) }\end{array}$ \\
\hline Sarcocornia pacifica & 0.16 & 0.11 & 36.97 & 10.57 & 49.24 & 12.95 & 61.57 & 36.47 & 267 & 86.69 \\
\hline Spartina spp. & 0.03 & - & - & - & - & - & 35.00 & - & 1 & 0.32 \\
\hline Schoenoplectus spp. & 0.11 & 0.14 & 77.88 & 30.11 & 94.56 & 35.55 & 15.58 & 21.08 & 157 & 50.97 \\
\hline Grindelia stricta & 0.05 & 0.02 & 81.50 & 14.85 & 81.50 & 14.85 & 47.50 & 60.10 & 2 & 0.65 \\
\hline Jaumea carnosa & 0.03 & - & 38.00 & - & 40.00 & - & 55.00 & - & 1 & 0.32 \\
\hline Frankenia salina & 0.16 & - & 40.00 & - & 44.00 & - & 77.00 & - & 1 & 0.32 \\
\hline Distichlis spicata & 0.20 & 0.03 & 26.80 & 7.36 & 29.40 & 6.88 & 14.00 & 26.89 & 5 & 1.62 \\
\hline Lepidium latifolium & 0.14 & 0.13 & 92.23 & 26.66 & 101.40 & 27.79 & 44.02 & 34.28 & 53 & 17.21 \\
\hline Atriplex triangularis & 0.09 & 0.17 & 27.50 & 13.50 & 34.14 & 16.44 & 9.57 & 8.39 & 14 & 4.55 \\
\hline Triglochin concinna & 0.24 & 0.04 & 41.13 & 8.54 & 52.25 & 11.21 & 27.75 & 26.86 & 8 & 2.60 \\
\hline Typha angustifolia & -0.11 & 0.21 & 107.75 & 22.53 & 126.67 & 27.98 & 26.33 & 36.27 & 12 & 3.90 \\
\hline Potentilla anserina & 0.18 & 0.07 & 25.87 & 6.89 & 30.73 & 7.50 & 11.72 & 13.26 & 78 & 25.32 \\
\hline Baccharis pilurais & 0.23 & 0.03 & 96.50 & 17.79 & 96.50 & 17.79 & 79.75 & 28.05 & 4 & 1.30 \\
\hline Artemisia spp. & 0.13 & 0.01 & 33.33 & 19.73 & 39.33 & 17.93 & 11.33 & 4.04 & 3 & 0.97 \\
\hline $\begin{array}{l}\text { Ruppia maritima } \\
\text { occidentalis }\end{array}$ & 0.12 & 0.05 & 36.50 & 3.54 & 36.50 & 3.54 & 4.00 & 1.41 & 2 & 0.65 \\
\hline Cotula coronopifolia & -0.11 & - & 25.00 & - & 29.00 & - & 25.00 & - & 1 & 0.32 \\
\hline Juncus spp. & 0.19 & 0.06 & 55.36 & 15.13 & 67.00 & 20.60 & 7.14 & 14.77 & 22 & 7.14 \\
\hline
\end{tabular}




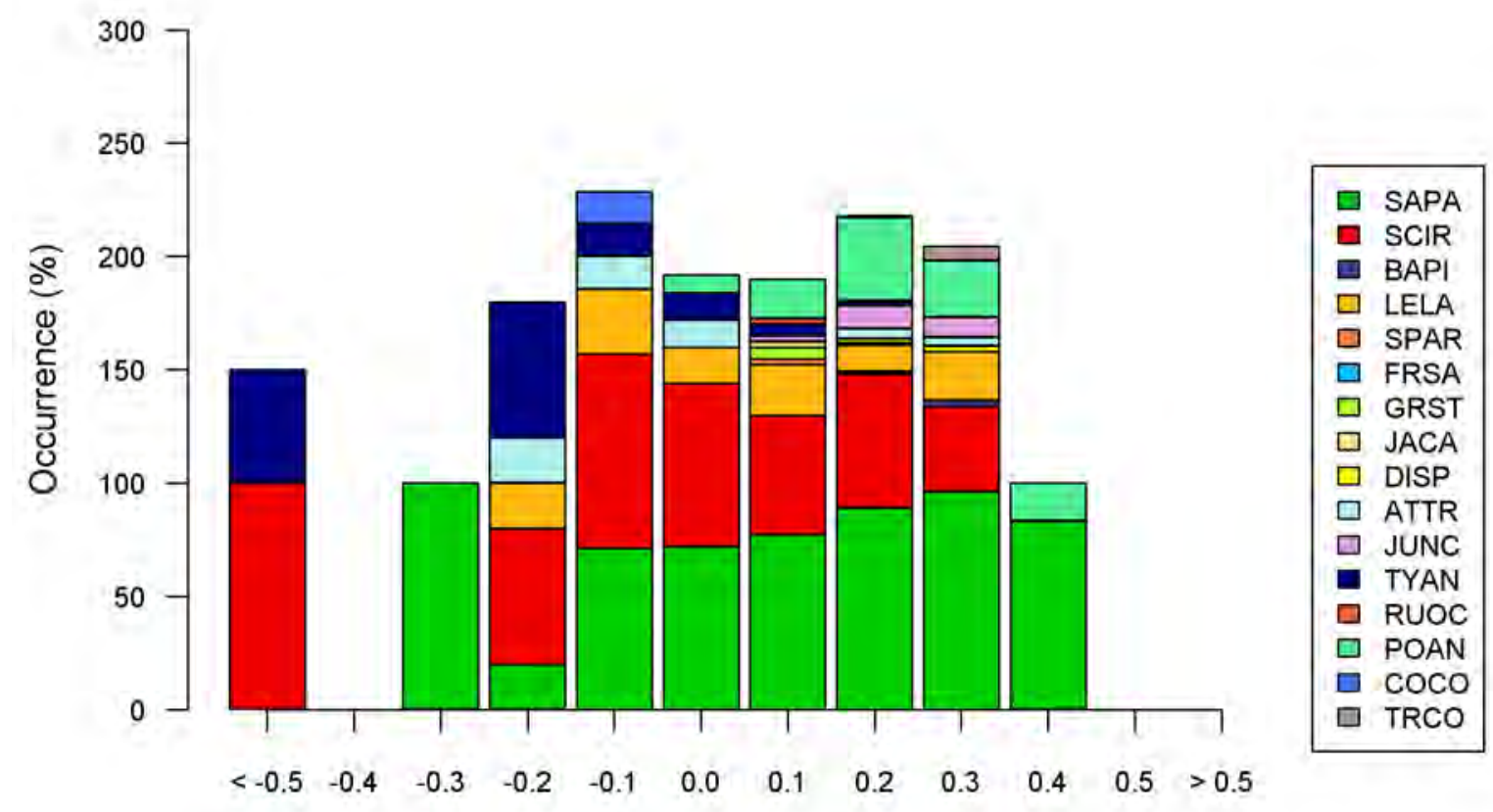

Elevation Relative to $\mathrm{MHW}(\mathrm{m})$

Figure H-4. Stratification of vegetation species was observed relative to mean high water (MHW), in meters (m). Species codes: SAPA = Sarcocornia pacifica; SCIR = Schoenoplectus spp.; BAPI = Baccaris pilularis; LELA = Lepidium latifolium; SPAR = Spartina spp.; FRSA = Frankenia salina; GRST = Grindelia stricta; JACA = Jaumea carnosa; DISP = Distichlis spicata; ATTR = Atriplex triangularis; JUNC = Juncus spp; TYAN = Typha angustifolia; RUOC = Ruppia maritima occidentalis; POAN = Potentilla anserina; $\mathrm{COCO}=$ Cotula coronopifolia; TRCO $=$ Triglochin concinna .

\section{Water-level monitoring}

Site-specific water levels were monitored at Fagan from July 2010 to June 2011. Water level was measured by using two data loggers: one deployed at the mouth of a second order channel and one in the marsh interior. MHW was at $1.75 \mathrm{~m}$, and mean higher high water (MHHW) at $1.90 \mathrm{~m}$ for the site (NAVD88). Inundation patterns were recorded throughout the year to evaluate seasonal patterns. The period when the salt marsh platform (defined as mean elevation) was inundated most often was June 2011 (fig. H-5). 


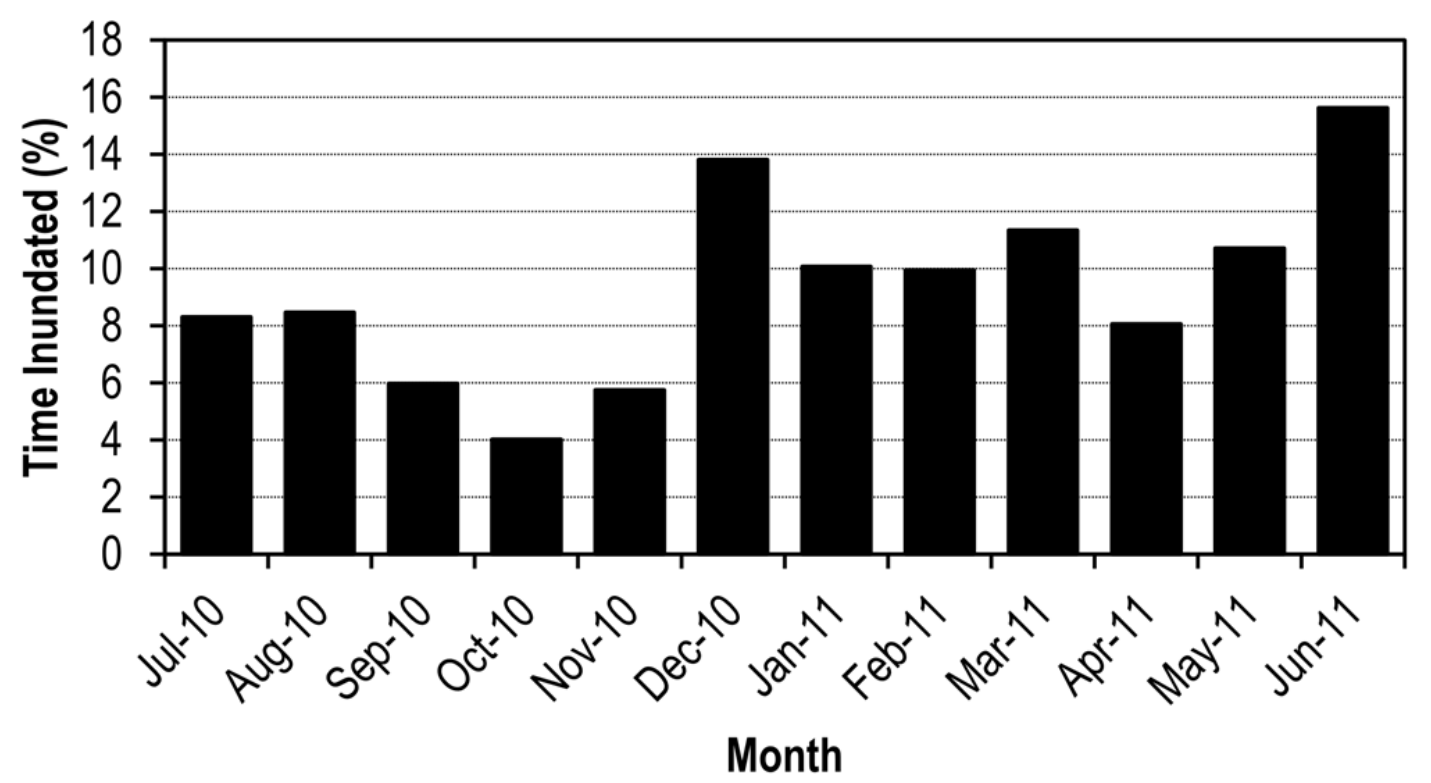

Figure H-5. Percentage of time Fagan was inundated monthly based on the mean elevation of the marsh platform.

\section{Marsh elevation modeling}

WARMER projected that Fagan will not keep pace with local SLR through this century. WARMER results showed a gradual reduction in elevation relative to MHW over time, with a more dramatic decline after 2060 (fig. H-6). By 2090, Fagan was projected to be under mean sea level (MSL) and, therefore, to transition to a mudflat (fig. $\mathrm{H}-7)$. 


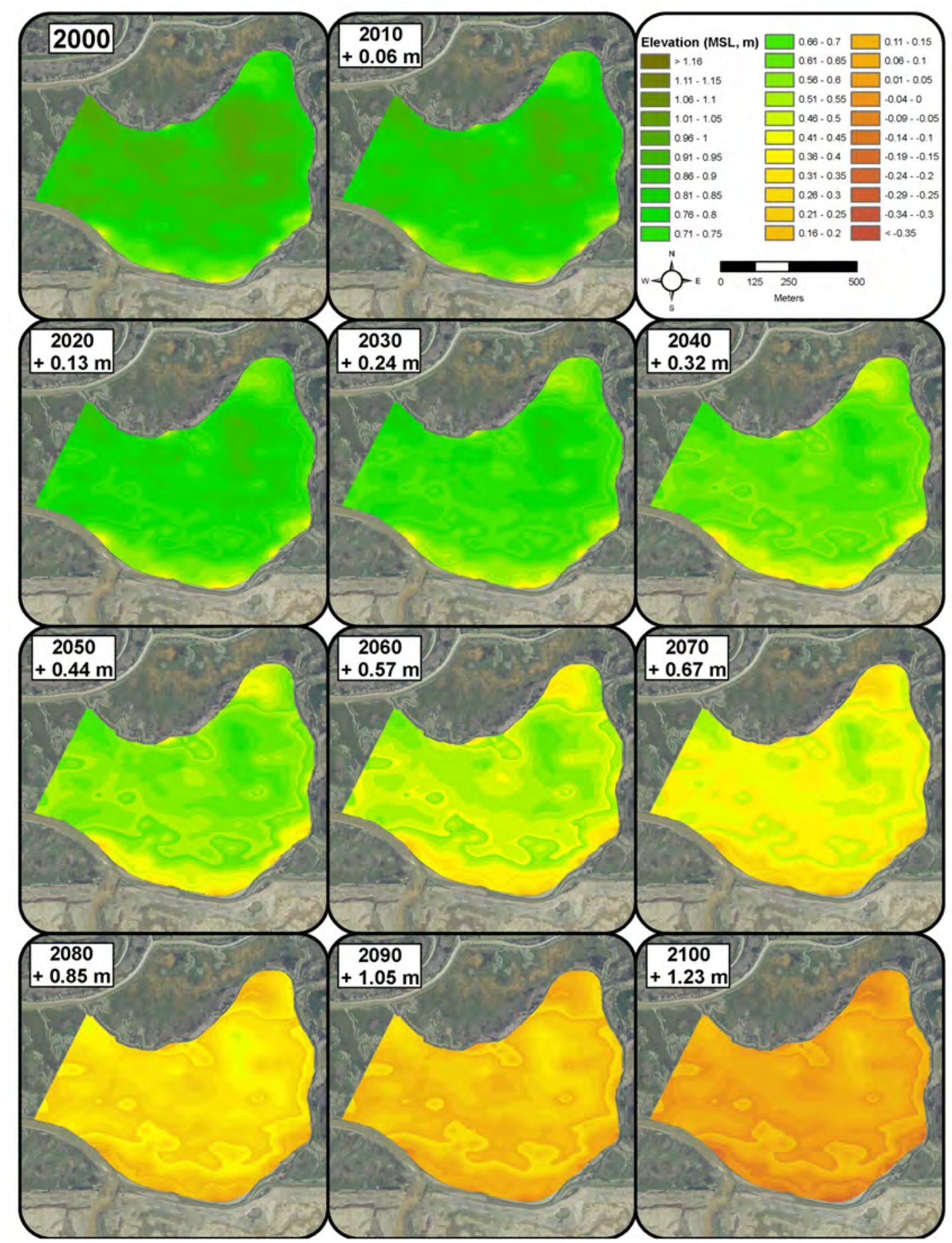

Figure H-6. WARMER results for Fagan. WARMER accounts for changes in relative sea-level, subsidence, inorganic sediment accumulation, above and below ground organic matter productivity, compaction, and decay. Non-linear sea-level rise projections for California were used (Cayan and others, 2009). [MSL, mean sea level; m, meters] 


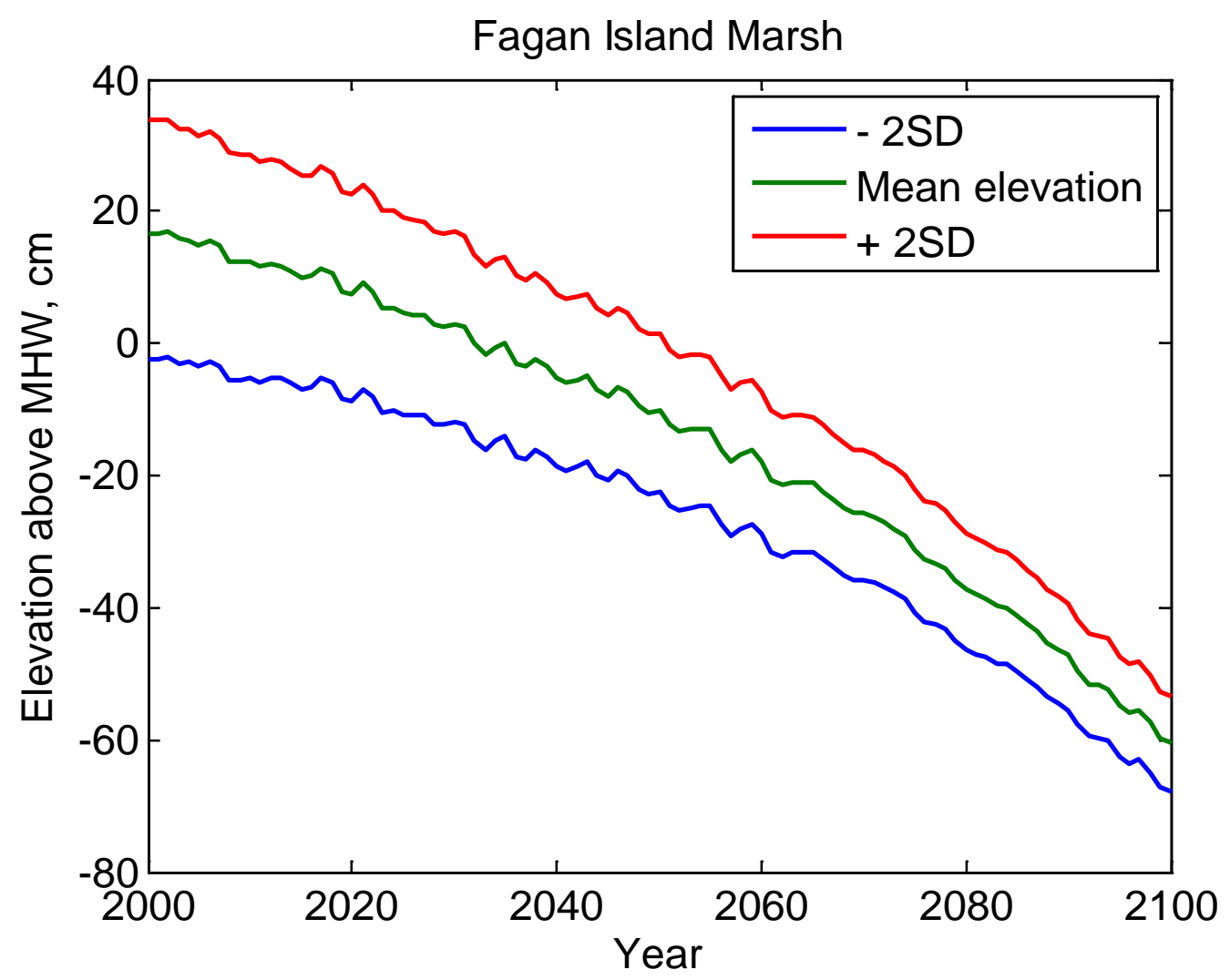

Figure H-7. WARMER scenarios for Fagan elevation change. Elevation above mean high water $(\mathrm{MHW})$, in centimeters $(\mathrm{cm})$, is plotted against model year with two standard deviations (SD).

Elevation relative to the local tidal datum can be tied to vegetation observations. Vegetation data were categorized as mudflat, low, mid, high marsh, or upland transition plant communities and used to interpret the WARMER SLR results (figs. H-8 and H-9). Upland transition (greater than $1.0 \mathrm{~m} \mathrm{MSL}$ ) was characterized by coyote bush (Baccharis pilularis). High marsh (0.7-1.0 m MSL) was characterized by Frankenia salina and Jaumea carnosa, whereas mid marsh (0.45-0.7 m MSL) was dominated by Sarcocornia pacifica. Low marsh (0.2-0.45 m MSL) was characterized by Spartina spp. or, in brackish areas, by Schoenoplectus spp. Mudflat habitat (less than $0.2 \mathrm{~m} \mathrm{MSL)} \mathrm{was}$ unvegetated or sparsely covered with Spartina spp. Currently, Fagan is roughly 90 percent high-marsh habitat. The amount of high marsh was projected to steadily decline until 2060 (0.57 m SLR), at which point all high marsh transitions to mid and low marsh. A transition to mud flat was projected by 2090 (1.05 m SLR).

The WARMER model parameters for Fagan were extrapolated by using sediment core data from Coon Island, thus predictions need to be interpreted with caution because local sedimentation processes could differ between these marshes. To improve results, local site-specific sediment core data could be collected along with suspended-sediment concentrations to characterize sediment deposition potential. 


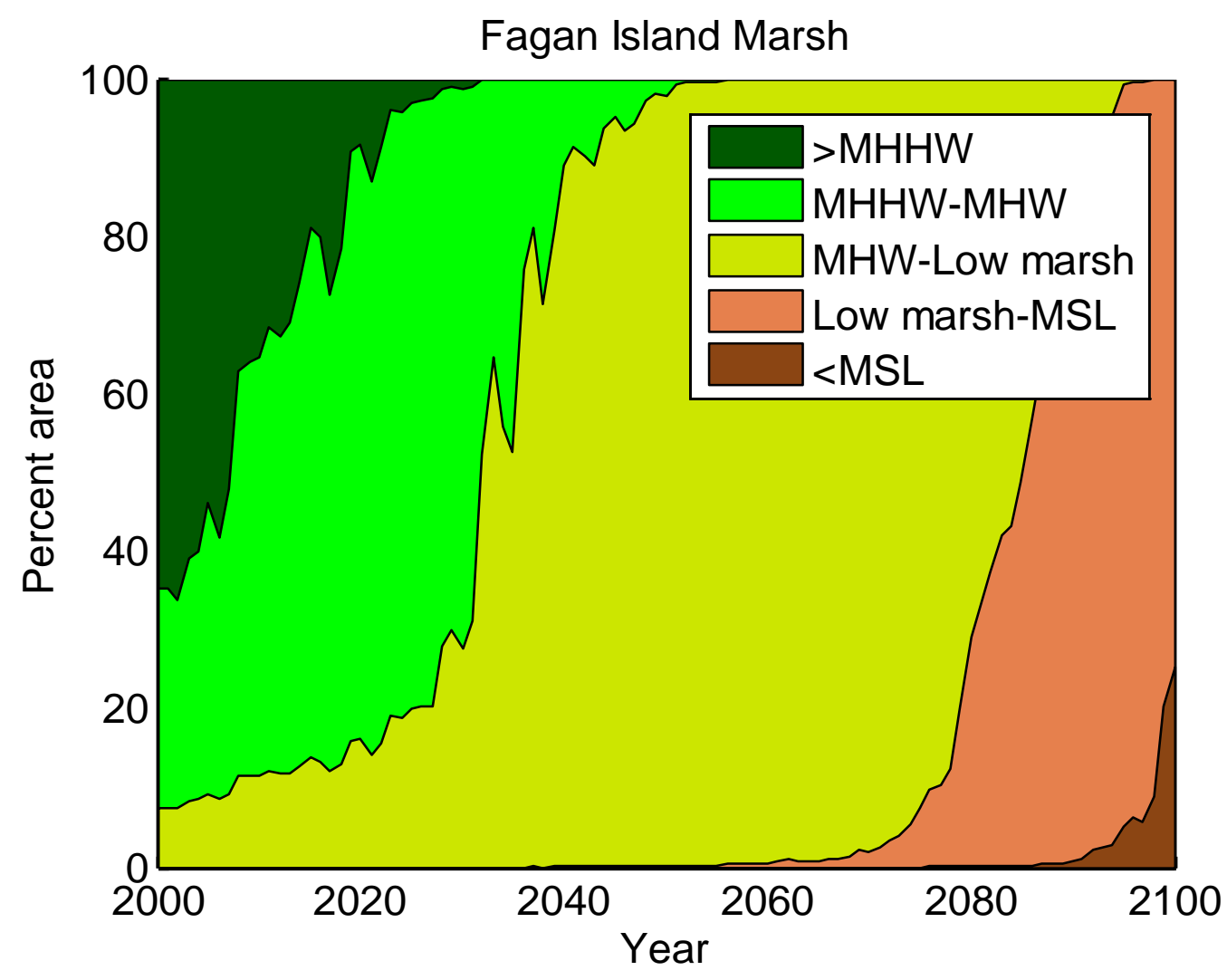

Figure H-8. Area of Fagan within a given tidal range for the duration of the simulation period. [MHHW, mean higher high water; MHW, mean high water; MSL, mean sea level; >, greater than; <, less than] 


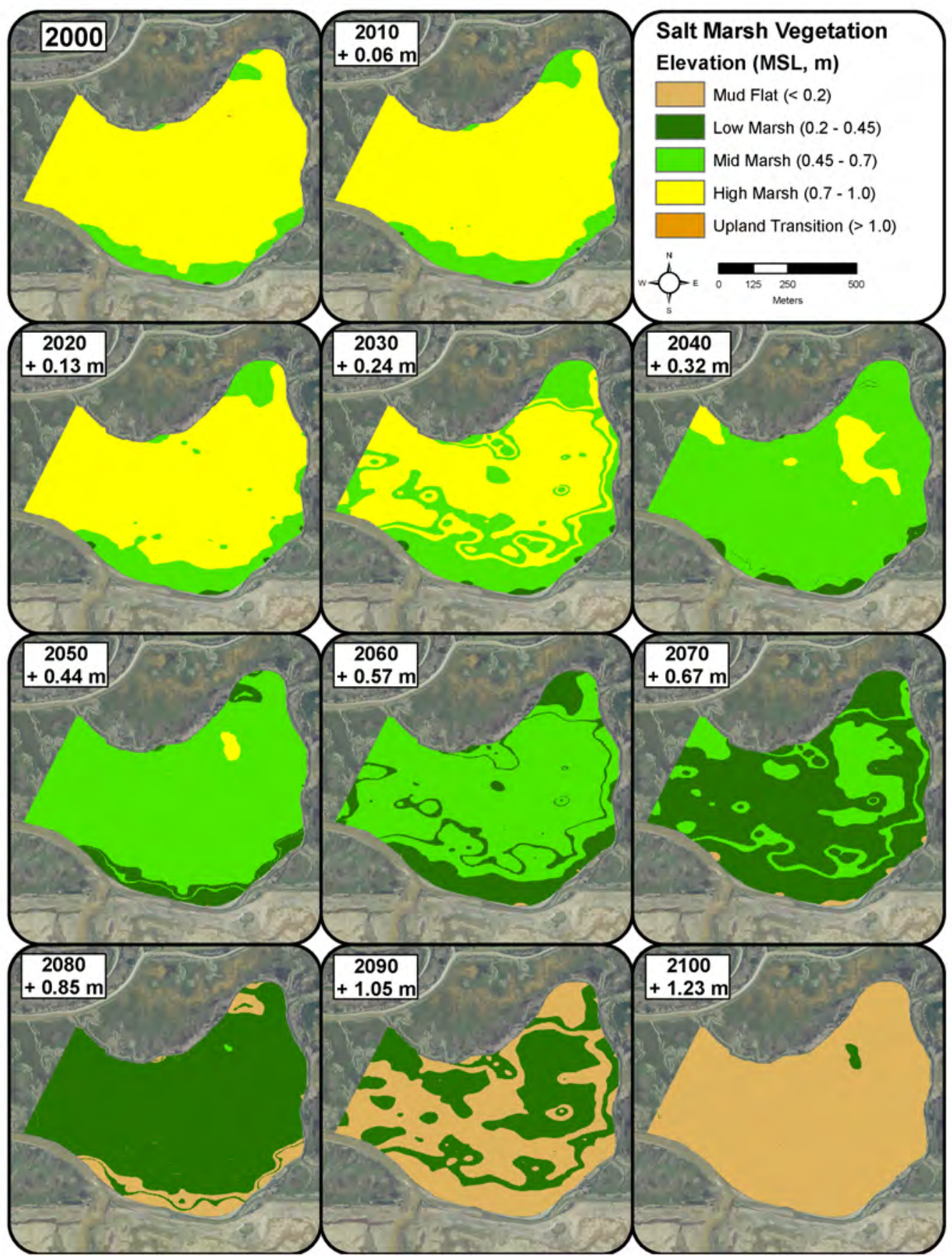

Figure H-9. Fagan WARMER results in terms of plant communities relative to mean sea level (MSL), in meters (m): mudflat, low, mid, or high marsh, or upland transition. 


\section{Appendix I. Gambinini Marsh}

\section{Introduction}

Gambinini marsh (hereafter, "Gambinini") is privately owned and is located in Sonoma County along the Petaluma River at the northern tip of the Petaluma marsh complex. The Petaluma marsh complex is the largest marsh in California that has never been diked or drained for agriculture. Because of its proximity to the Petaluma River, Gambinini is influenced by flow from the Petaluma River as well as tidal flow from San Pablo Bay. This marsh is surrounded by oak woodlands and light grazing. This marsh provides important habitat for species of concern, including the California black rail (Laterallus jamaicensis).

This study focused on 24.8 hectares (ha) of Gambinini. Elevation and vegetation surveys were done in winter of 2009 by using an RTK GPS. To monitor tidal inundation and salinity, two water level loggers were deployed during 2009-2010.

\section{Results}

\section{Elevation surveys}

A total of 217 elevation measurements were taken at Gambinini (fig. I-1). The elevation range was 1.27-2.10 meters $(\mathrm{m})$, with a mean of $1.86 \mathrm{~m}$ (NAVD88). Over half (70 percent) of the survey points fell within $1.80-1.95 \mathrm{~m}$, a $0.15 \mathrm{~m}$ range (fig. I-2). The majority ( 81 percent) of survey points were located at elevations above mean high water (MHW). A 3-m resolution elevation model was developed in ArcGIS 9.3 (ESRI, Redlands, Calif.) Spatial Analyst by using the kriging method (fig. I-3). This baseline elevation model was used as the initial state in the WARMER sea-level rise (SLR) model; WARMER results were extrapolated across the elevation model. 

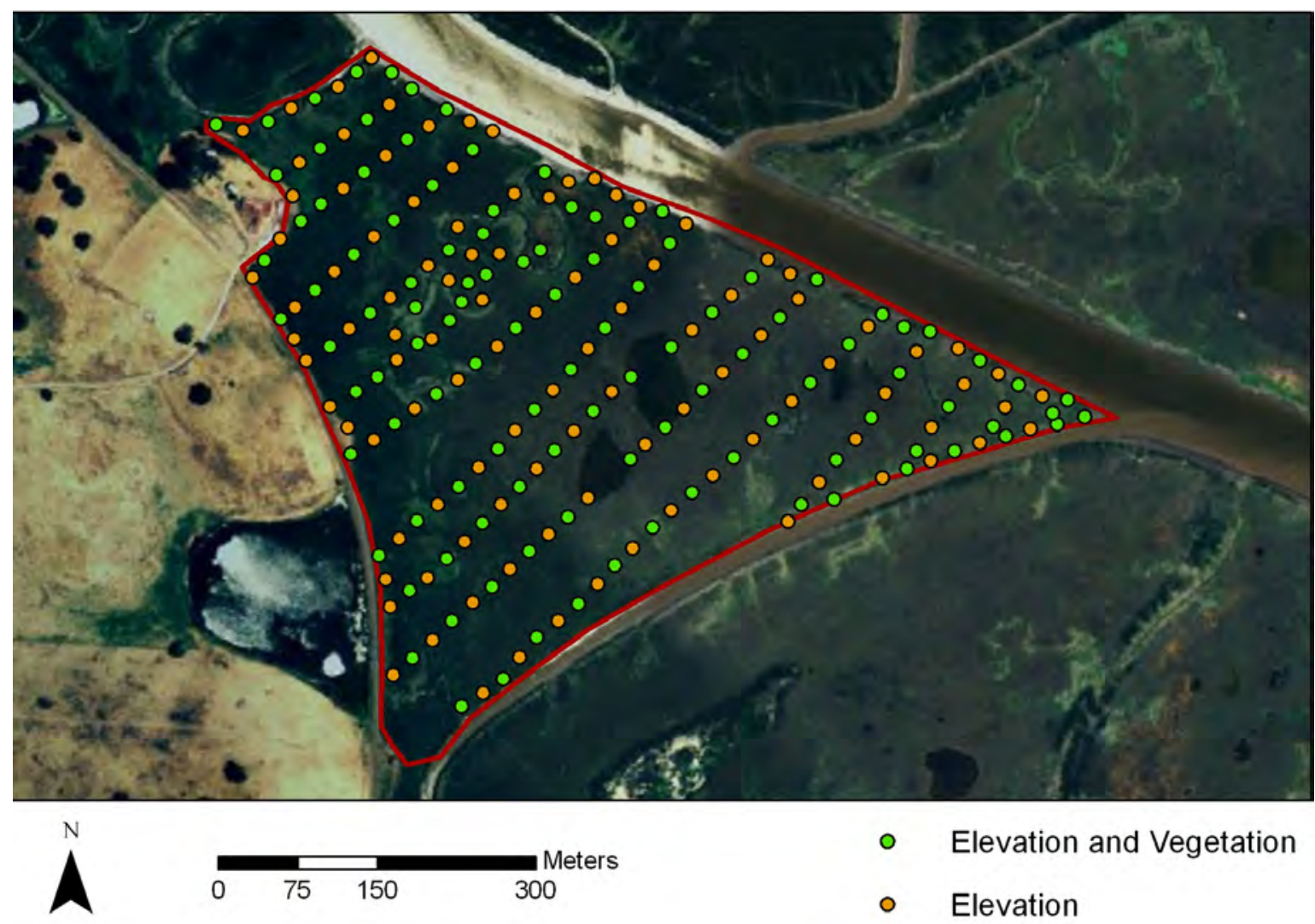

- Elevation and Vegetation

- Elevation

Figure I-1. Gambinini marsh with elevation and vegetation survey points from 2009. 


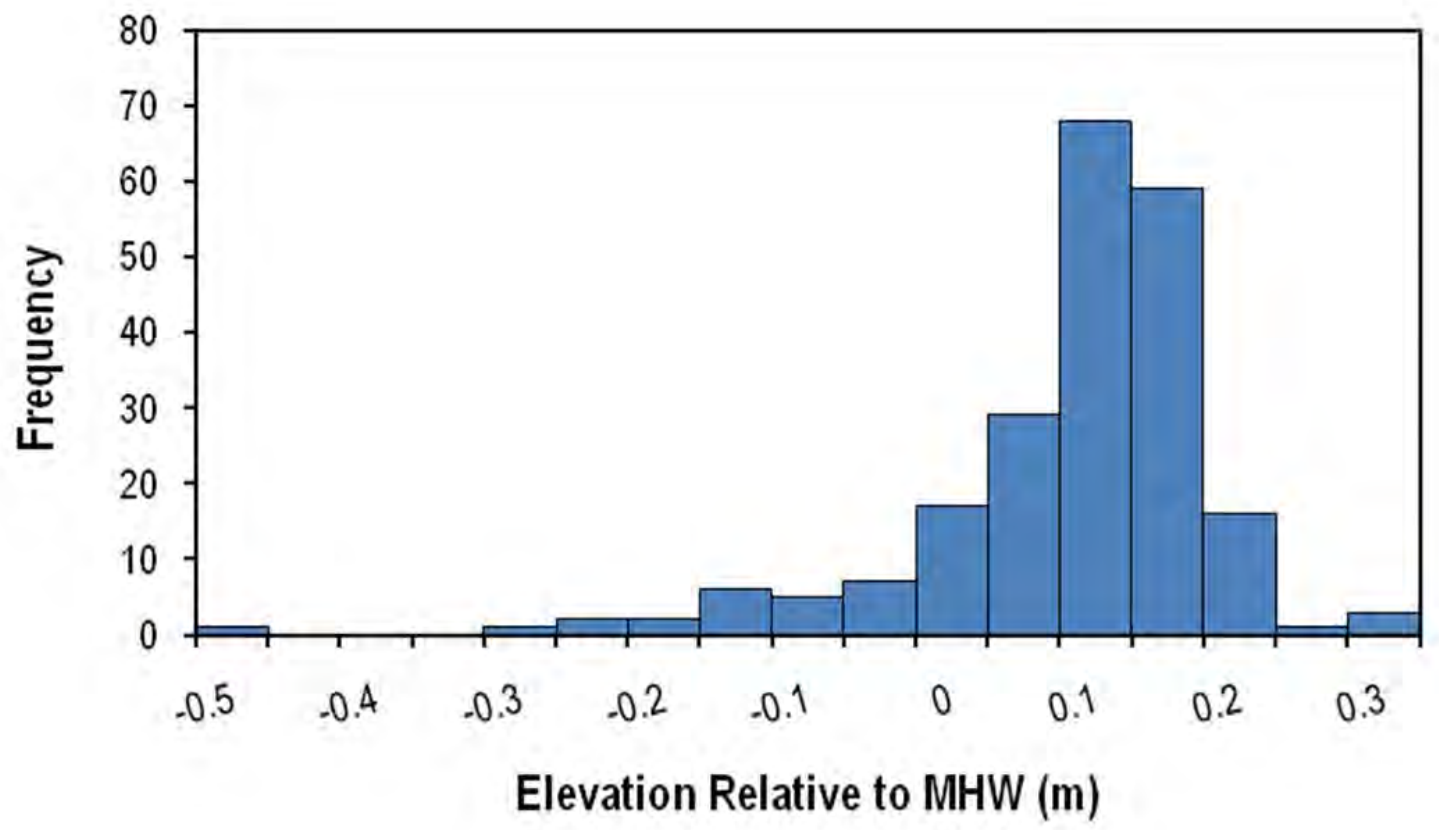

Figure I-2. Distribution of elevation samples relative to local mean high water (MHW), in meters $(\mathrm{m})$, at Gambinini marsh. 


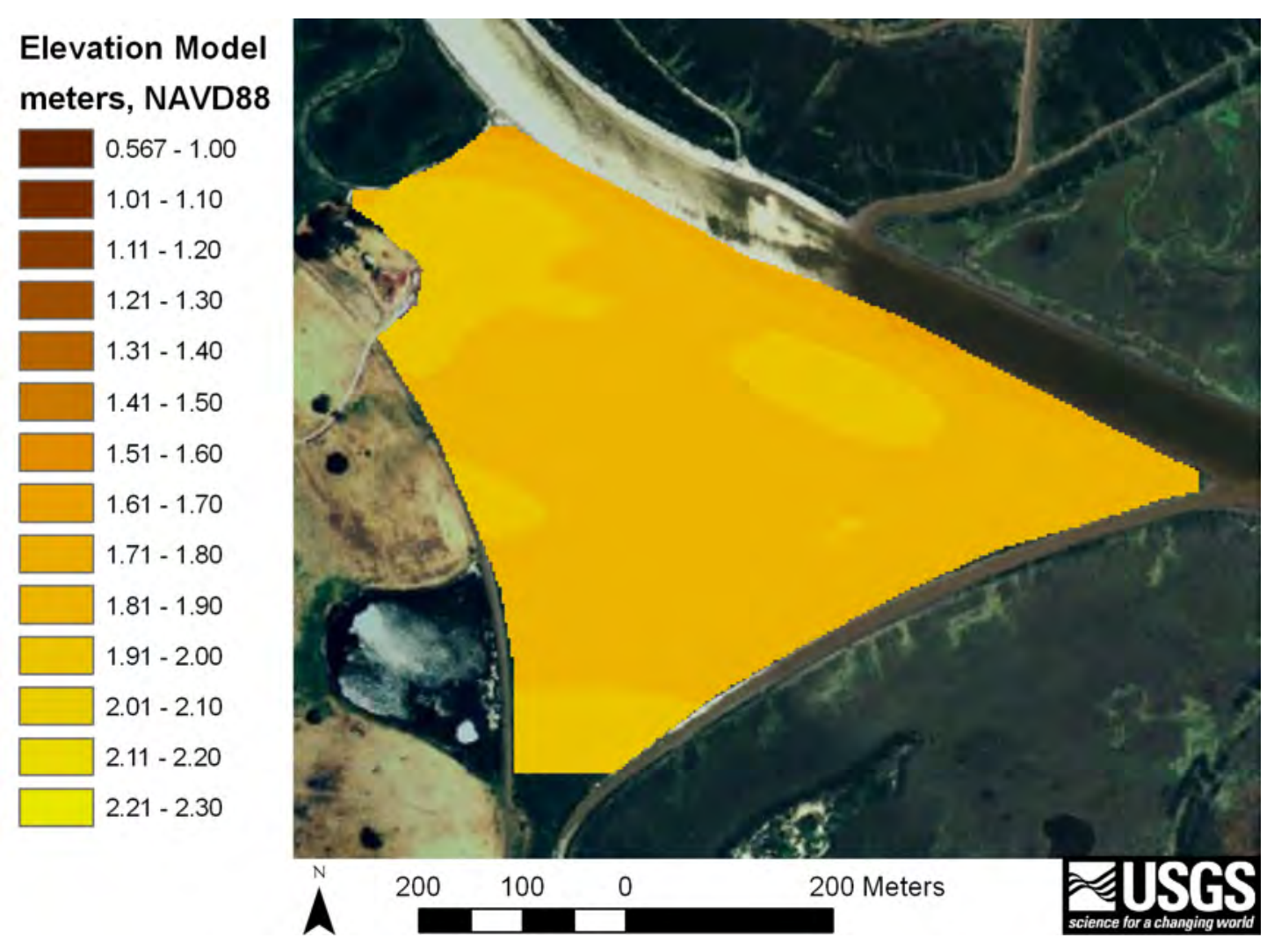

Figure I-3. Elevation model (3-meter resolution) developed from ground RTK GPS elevation data.

\section{Vegetation surveys}

Vegetation and elevation were surveyed concurrently at Gambinini in October of 2009. A total of 110 locations (fig. I-1) were measured for vegetation composition, height, and percentage cover (table I-1). We did not distinguish between invasive and native Spartina spp., nor among Schoenoplectus spp., in the survey. Vegetation in marshes is sensitive to soil salinity, inundation patterns, and disturbance; therefore, a stratification of vegetation species relative to MHW (fig. I-4) was observed within this low-slope marsh. 
Table I-1. Mean marsh elevation relative to mean high water (MHW), average, and max height, percentage cover with standard deviations (SD), and presence by species at Gambinini.

[cm, centimeter; m, meter; $n$, sample number]

\begin{tabular}{lcccccccccc}
\hline Species & $\begin{array}{c}\text { Elevation } \\
(\mathbf{M H W} \\
\mathbf{m})\end{array}$ & $\begin{array}{c}\text { Elevation } \\
\text { SD } \\
(\mathbf{M H W} \\
\mathbf{m})\end{array}$ & $\begin{array}{c}\text { Mean } \\
\text { Height } \\
(\mathbf{c m})\end{array}$ & $\begin{array}{c}\text { Mean } \\
\text { Height } \\
\text { SD }(\mathbf{c m})\end{array}$ & $\begin{array}{c}\text { Max } \\
\text { Height } \\
(\mathbf{c m})\end{array}$ & $\begin{array}{c}\text { Max } \\
\text { Height } \\
\text { SD }(\mathbf{c m})\end{array}$ & $\begin{array}{c}\text { Cover } \\
\text { (percent) }\end{array}$ & $\begin{array}{c}\text { Cover } \\
\text { SD } \\
\text { (percent) }\end{array}$ & $\begin{array}{c}\text { Presence } \\
(\mathbf{p e r c e n t})\end{array}$ \\
\hline Sarcocornia pacifica & 0.06 & 0.10 & 27.83 & 9.58 & 40.46 & 11.82 & 87.50 & 23.70 & 109 & 99.09 \\
Schoenoplectus spp. & -0.10 & 0.14 & 27.50 & 15.20 & 33.25 & 19.96 & 14.00 & 17.72 & 4 & 3.64 \\
Grindelia stricta & -0.03 & 0.06 & 45.00 & 20.00 & 60.40 & 27.26 & 26.20 & 37.48 & 5 & 4.55 \\
Jaumea carnosa & -0.03 & - & 12.00 & - & 17.00 & - & 75.00 & - & 1 & 0.91 \\
Frankenia salina & 0.11 & 0.09 & 25.00 & 2.08 & 30.57 & 5.97 & 28.29 & 22.60 & 7 & 6.36 \\
Distichlis spicata & 0.13 & 0.06 & 15.78 & 4.79 & 20.78 & 4.74 & 33.22 & 31.29 & 9 & 8.18 \\
Lepidium latifolium & 0.07 & 0.08 & 87.53 & 30.30 & 104.00 & 30.67 & 23.24 & 19.41 & 17 & 15.45 \\
\hline
\end{tabular}




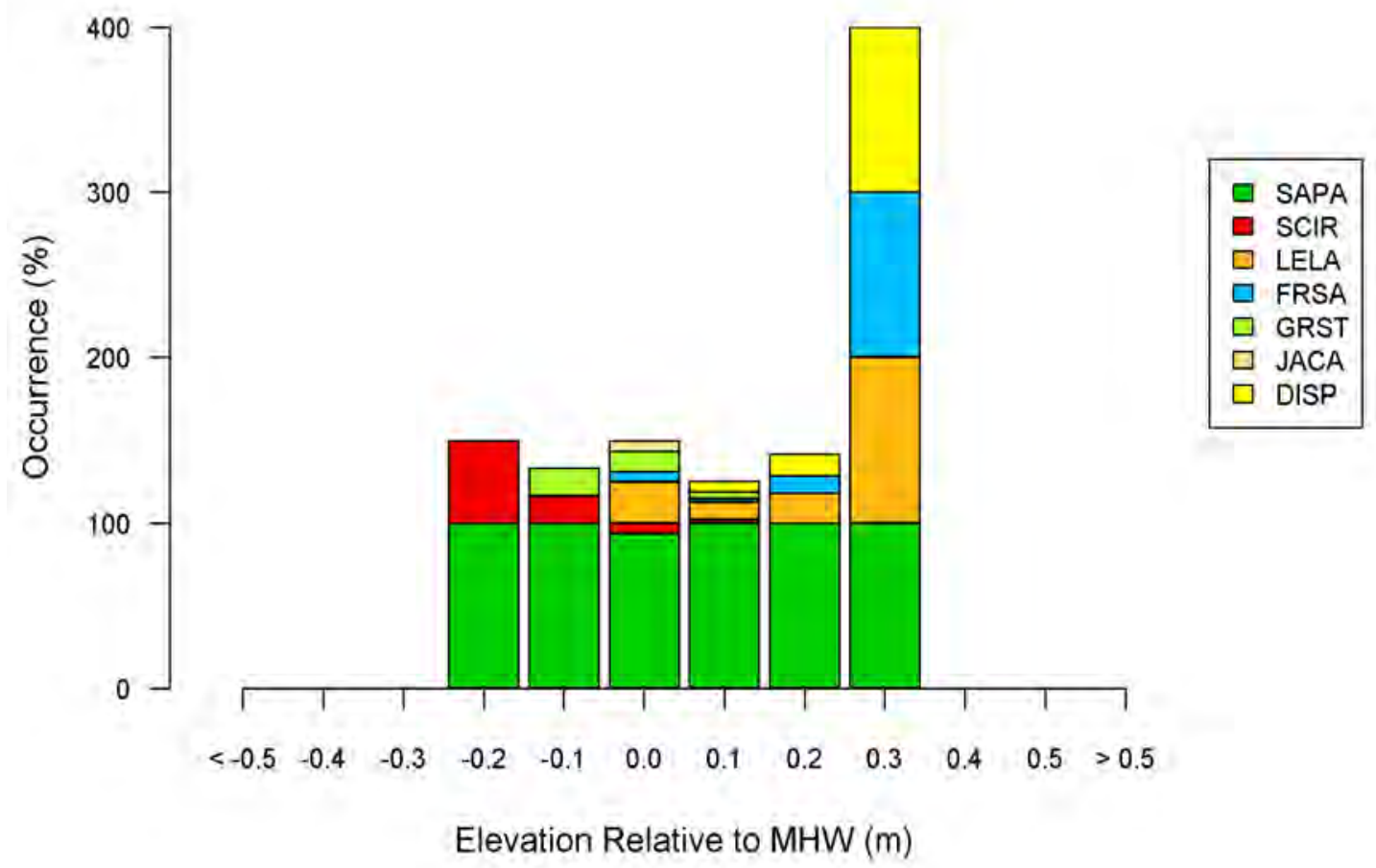

Figure I-4. Stratification of vegetation species was observed relative to mean high water $(\mathrm{MHW})$, in meters $(\mathrm{m})$. Species codes: SAPA = Sarcocornia pacifica; $\mathrm{SCIR}=$ Schoenoplectus spp.; LELA = Lepidium latifolium; FRSA = Frankenia salina; GRST = Grindelia stricta; JACA = Jaumea carnosa; DISP = Distichlis spicata.

\section{Water-level monitoring}

Site-specific water level was monitored between December 2009 and December 2010; data were unavailable for August 2010 as a result of equipment failure. Water level was measured by using two data loggers: one deployed at the mouth of a second order channel and one in the marsh interior. MHW was at $1.80 \mathrm{~m}$, and mean higher high water (MHHW) at $1.96 \mathrm{~m}$, for the site (NAVD88). Water levels were recorded throughout the year to evaluate seasonal patterns in tides. The period when the marsh platform (defined as mean elevation) was inundated most often was January 2010 (fig. I-5). Above average water levels were recorded in January because of several record breaking storms that brought low air pressure and substantial rainfall, resulting in higher than predicted tides. In January 2010, the cumulative rainfall was above average throughout the San Francisco Bay area, and daily rainfall records were broken in some locations (National Oceanic and Atmospheric Administration). This resulted in longer inundation periods of the marsh platform. Mean salinity during 2010 at Gambinini was $12.8(\mathrm{SD}=8.2)$ practical salinity scale. 


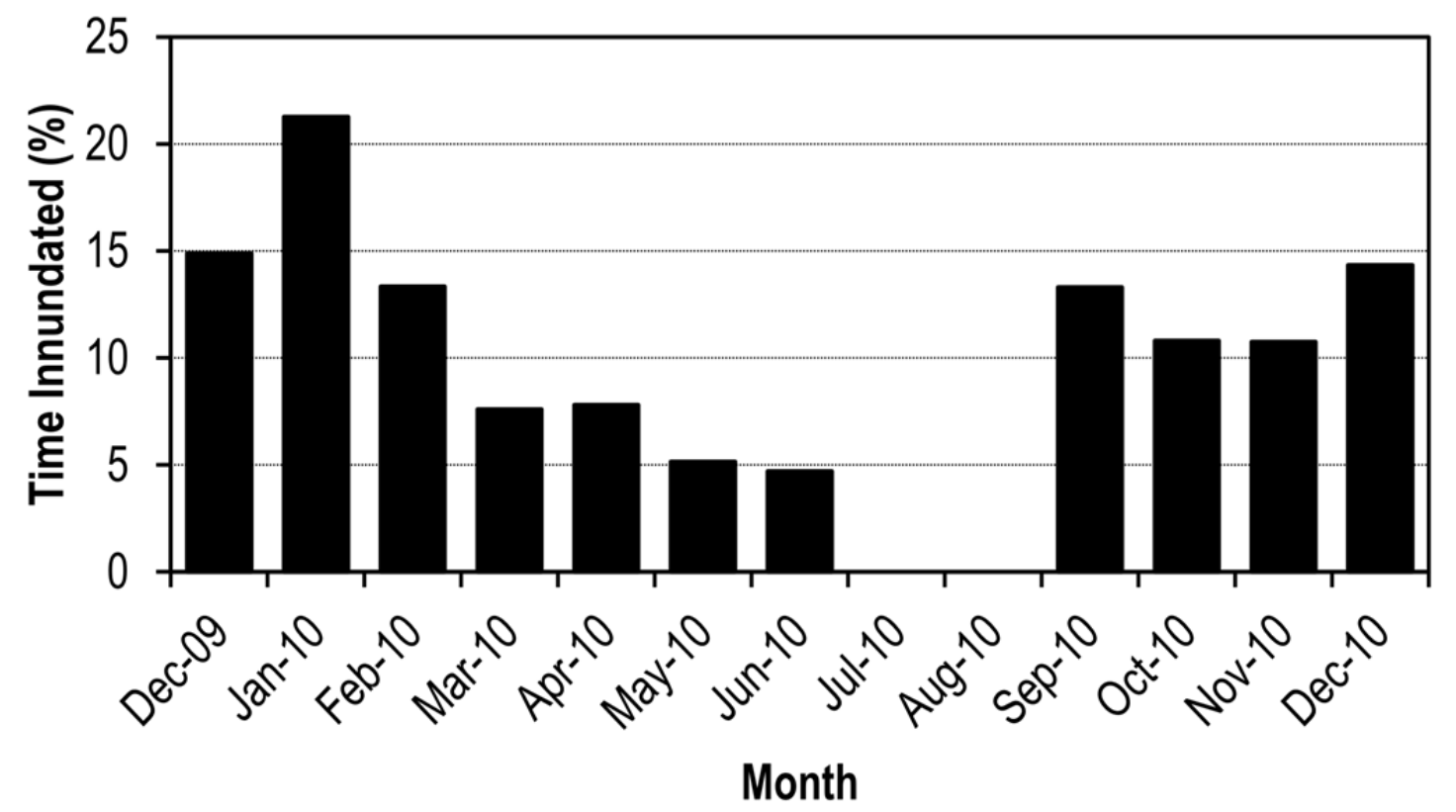

Figure I-5. Percentage of time Gambinini was inundated monthly based on the mean elevation of the marsh platform. Data were not available for August because of equipment failure.

\section{Marsh-elevation modeling}

WARMER results indicated that Gambinini is unlikely to keep pace with local SLR through this century. Initial elevation was relatively high compared to other study sites; however, results showed a gradual reduction in elevation relative to MHW over time, with a more dramatic decline after 2080 (fig. I-6). By 2080, the marsh was projected to be under mean sea level (MSL) and to function as a mudflat (fig. I-7). 


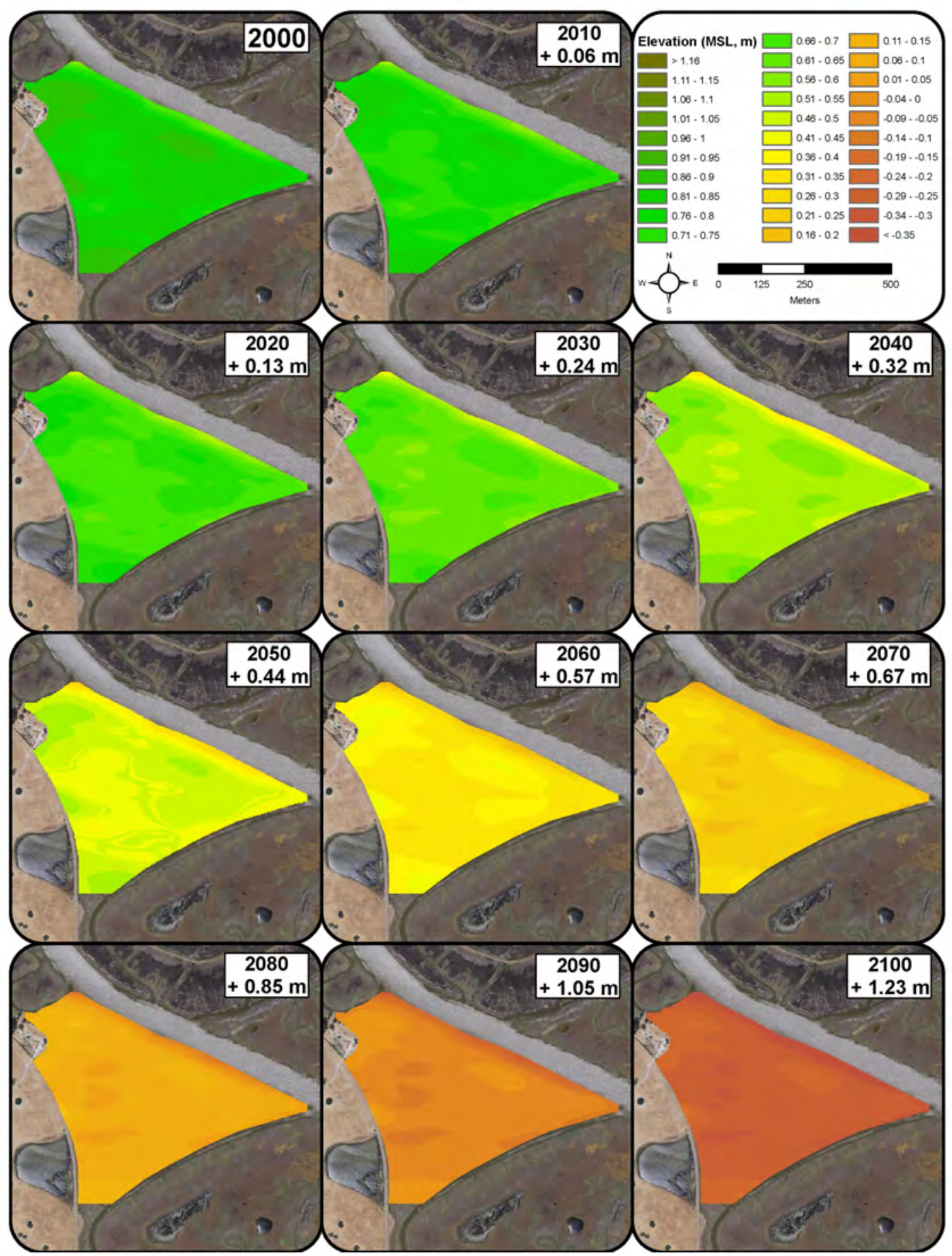

Figure I-6. WARMER results for Gambinini. WARMER accounts for changes in relative sea-level, subsidence, inorganic sediment accumulation, above and below ground organic matter productivity, compaction, and decay. Non-linear sea-level rise projections for California were used (Cayan and others, 2009). [MSL, mean sea level; m, meters] 


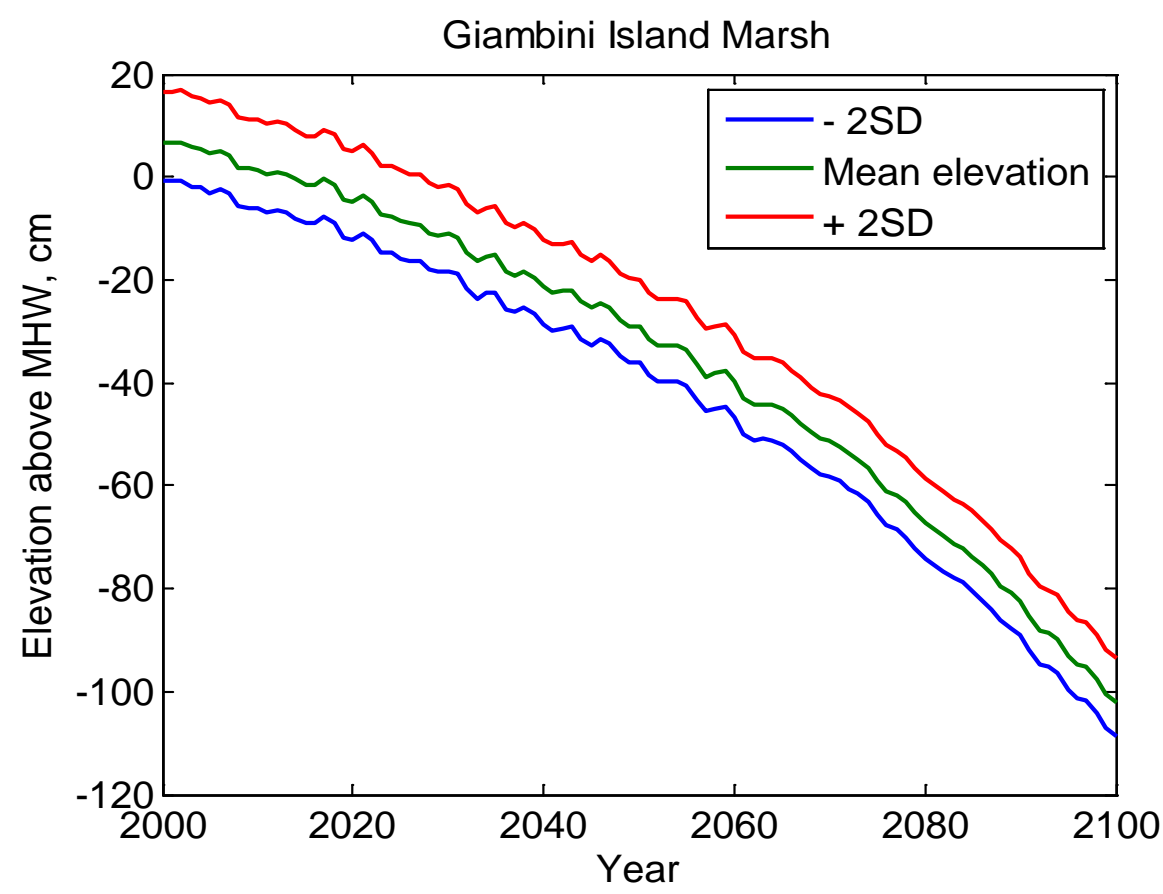

Figure 1-7. Modeled scenarios of marsh elevation change for Gambinini. Elevation above mean high water (MHW), in centimeters $(\mathrm{cm})$, is plotted against model year.

Elevation relative to the local tidal datum can be tied to vegetation observations. Vegetation data were categorized as mudflat, low, mid, high marsh, or upland transition plant communities and used to interpret the WARMER SLR results (figs. I-8 and I-9). Upland transition (greater than $1.0 \mathrm{~m} \mathrm{MSL}$ ) was characterized by coyote bush (Baccharis pilularis). High marsh (0.7-1.0 m MSL) was characterized by Frankenia salina and Jaumea carnosa, whereas mid marsh (0.45-0.7 m MSL) was dominated by Sarcocornia pacifica. Low marsh (0.2-0.45 m MSL) was characterized by Spartina spp. or, in brackish areas, by Schoenoplectus spp. Mudflat habitat (less than $0.2 \mathrm{~m} \mathrm{MSL}$ ) was unvegetated or sparsely covered with Spartina spp. Currently, Gambinini is primarily composed of high- and mid-marsh plant communities. WARMER showed a steady decline in the amount of high marsh beginning in 2020 (0.06 m SLR). By 2040 (0.32 m SLR), all high marsh was projected to transition to mid marsh. By 2060 (0.57 m SLR), most of Gambinini was projected to be low marsh, and by 2080 ( $0.85 \mathrm{~m} \mathrm{SLR})$, WARMER projected that the entire marsh would be below MSL and transition to a mudflat.

The WARMER model parameters for Gambinini were extrapolated by using sediment core data from Petaluma Marsh, thus predictions need to be interpreted with caution because local sedimentation processes could differ between these marshes. In addition, quality control issues with the Petaluma sediment cores resulted in the removal of data that indicated high sedimentation rates. The Petaluma River is a major source of sediment to San Francisco Bay; thus, it is likely that the inputs to WARMER are underestimating accretion potential. To improve results, local site-specific sediment core data could be collected along with suspended-sediment concentrations to characterize sediment deposition potential. 


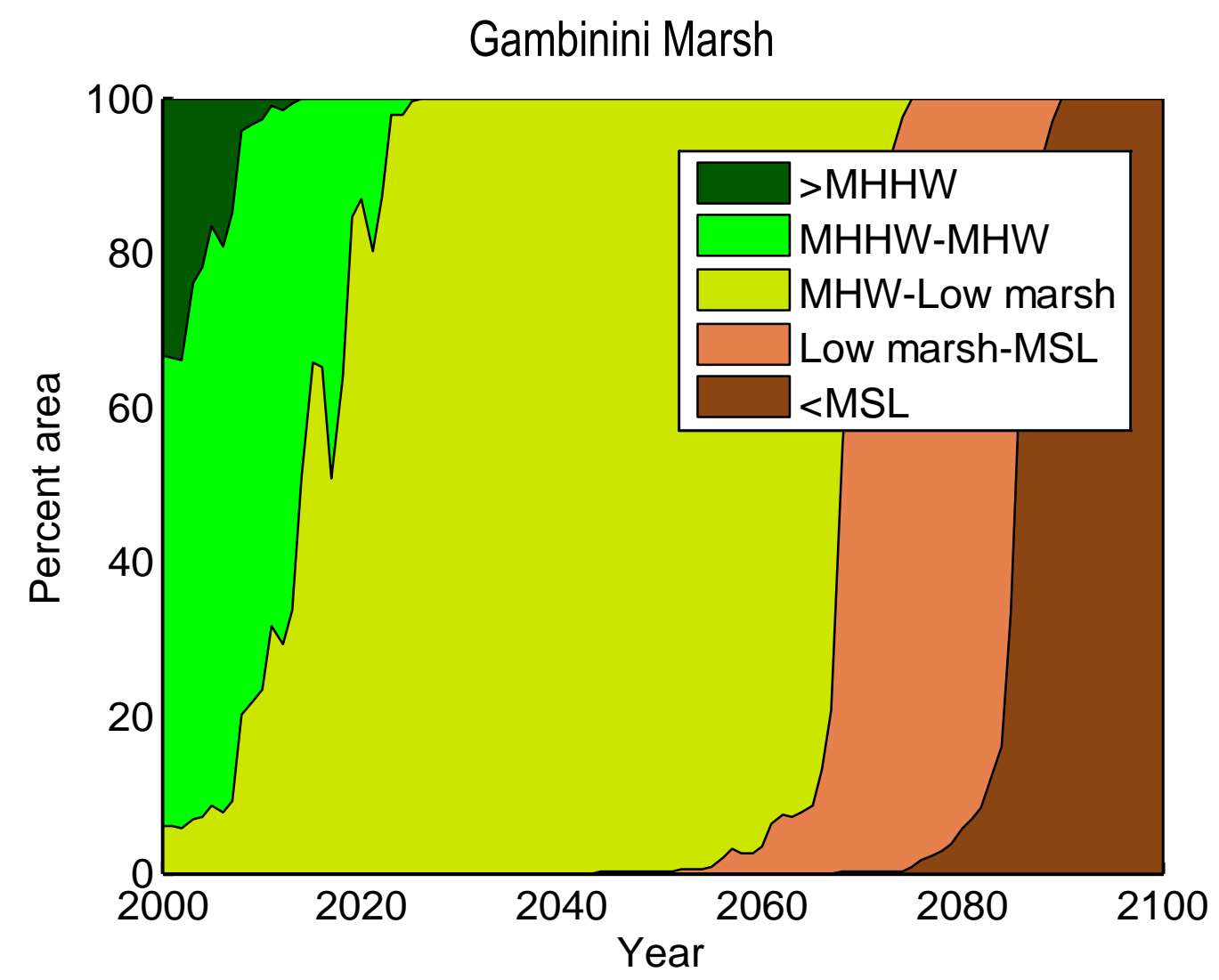

Figure I-8. Area of Gambinini within a given tidal range for the duration of the simulation period. [MHHW, mean higher high water; MHW, mean high water; MSL, mean sea level; >, greater than; <, less than] 


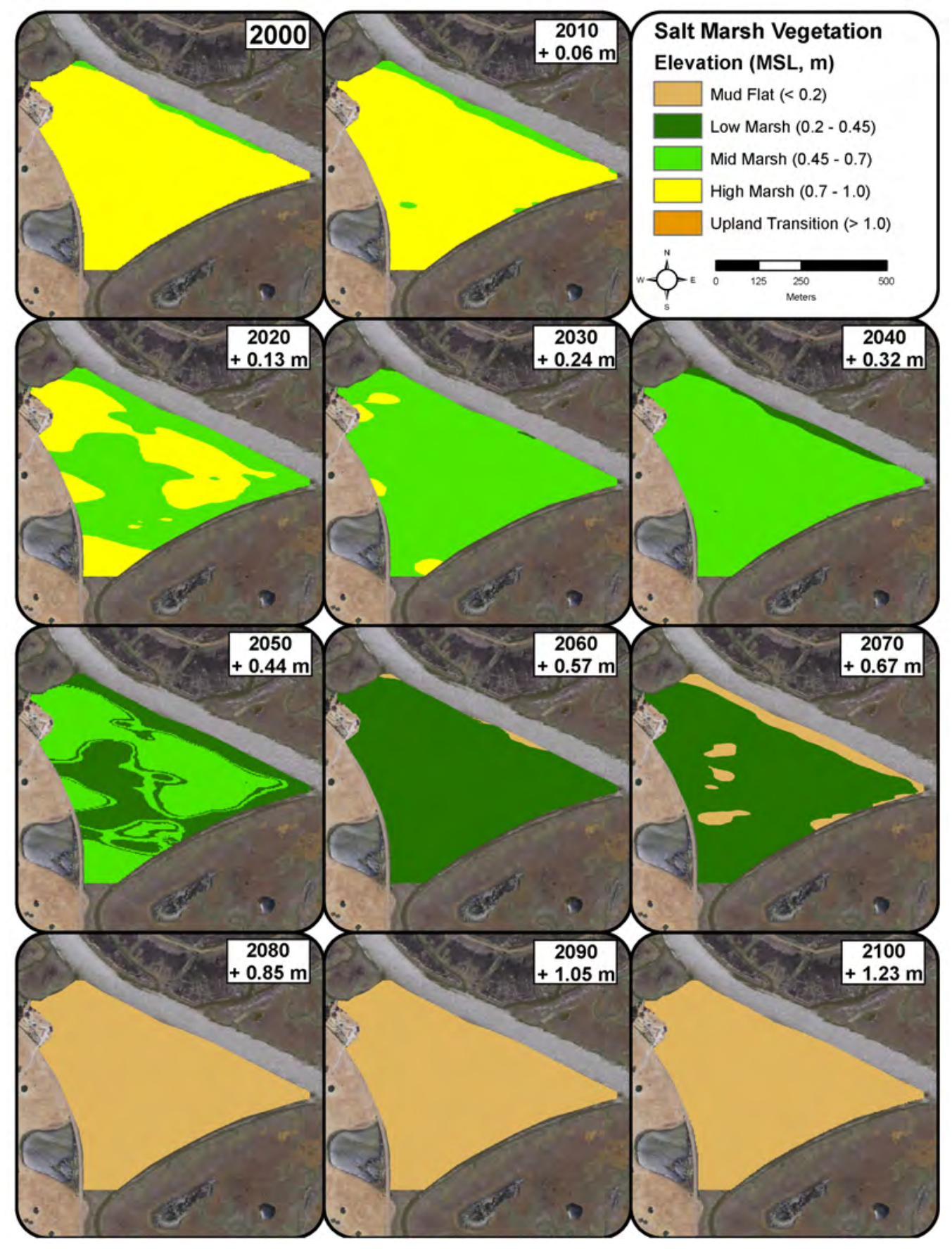

Figure I-9. Gambinini WARMER results in terms of plant communities relative to mean sea level (MSL), in meters (m): mudflat, low, mid, or high marsh, or upland transition. 


\section{Appendix J. Laumeister Marsh}

\section{Introduction}

Located in south San Francisco Bay in Santa Clara county, Laumeister Marsh (hereafter, "Laumeister") is owned by the City of Palo Alto. It is managed by the U.S. Fish and Wildlife Service as part of Don Edwards National Wildlife Refuge, which is the largest refuge in San Francisco Bay estuary. Laumeister is recognized as an important stopover on the Pacific Flyway and is home for endangered species such as the California clapper rail (Rallus longirostris obsoletus).

The focus of this study was on 36.8 hectares (ha) at Laumeister marsh. Elevation and vegetation surveys were done in 2009-2010 by using an RTK GPS. To monitor tidal inundation and salinity, two water level loggers were deployed from 2009 to 2010.

\section{Results}

\section{Elevation surveys}

A total of 717 elevation measurements were taken at Laumeister (fig. J-1). The elevation range was 1.15-2.20 meters (m), with a mean of $1.98 \mathrm{~m}$ (NAVD88). Over half (53 percent) of the survey points fell within $1.95-2.05 \mathrm{~m}$, a $0.1 \mathrm{~m}$ range. A majority (86 percent) of the survey points were above mean high water (MHW; fig J-2). Laumeister was the second highest marsh surveyed in this study. A 3-m resolution elevation model was developed in ArcGIS 9.3 (ESRI, Redlands, Calif.) Spatial Analyst by using the kriging method (fig. J-3). This baseline elevation model was used as the initial state in the WARMER sea-level rise (SLR) model; WARMER results were extrapolated across the elevation model. 


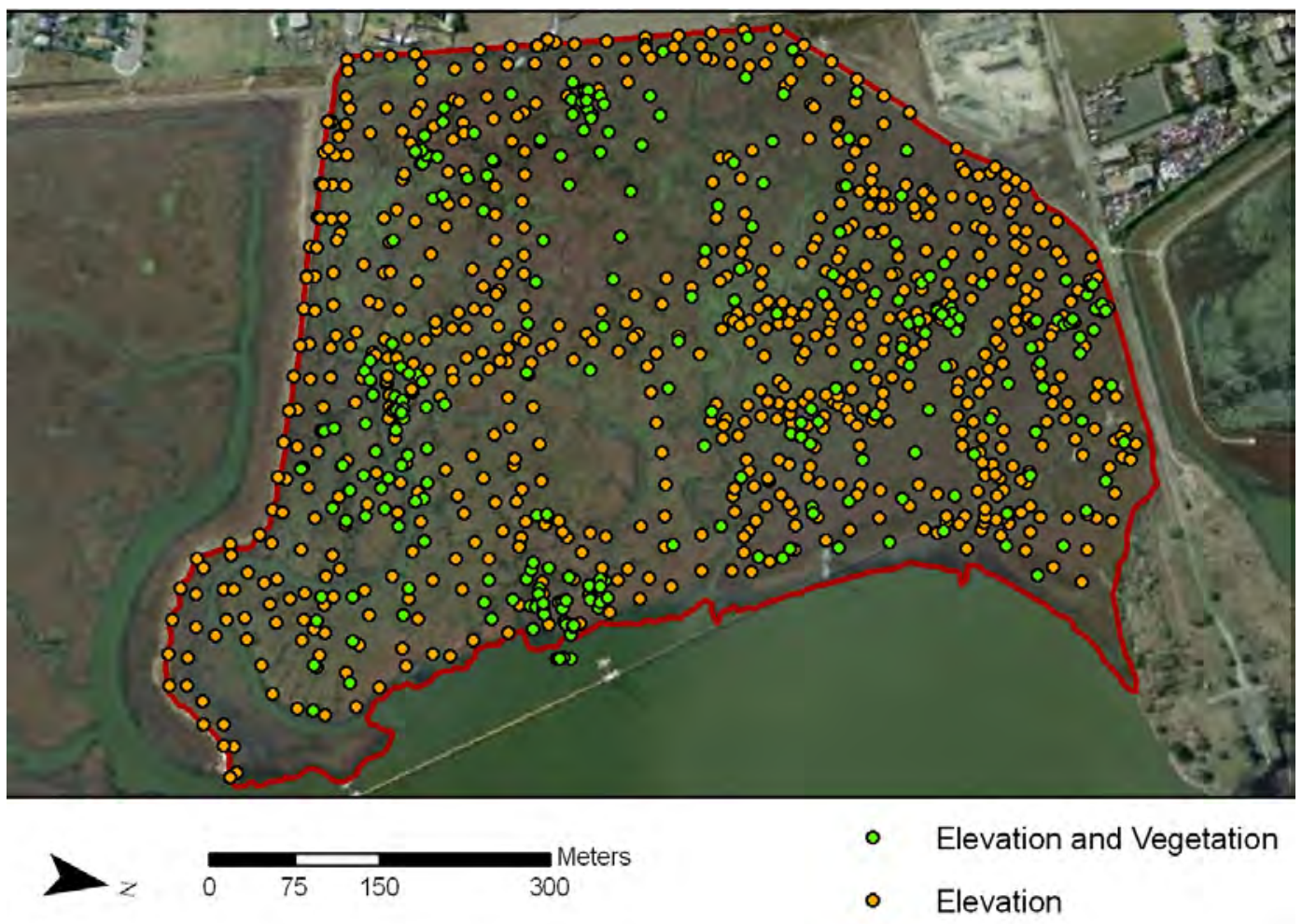

Figure J-1. Laumeister Marsh with elevation and vegetation survey points from 2009 and 2010. 


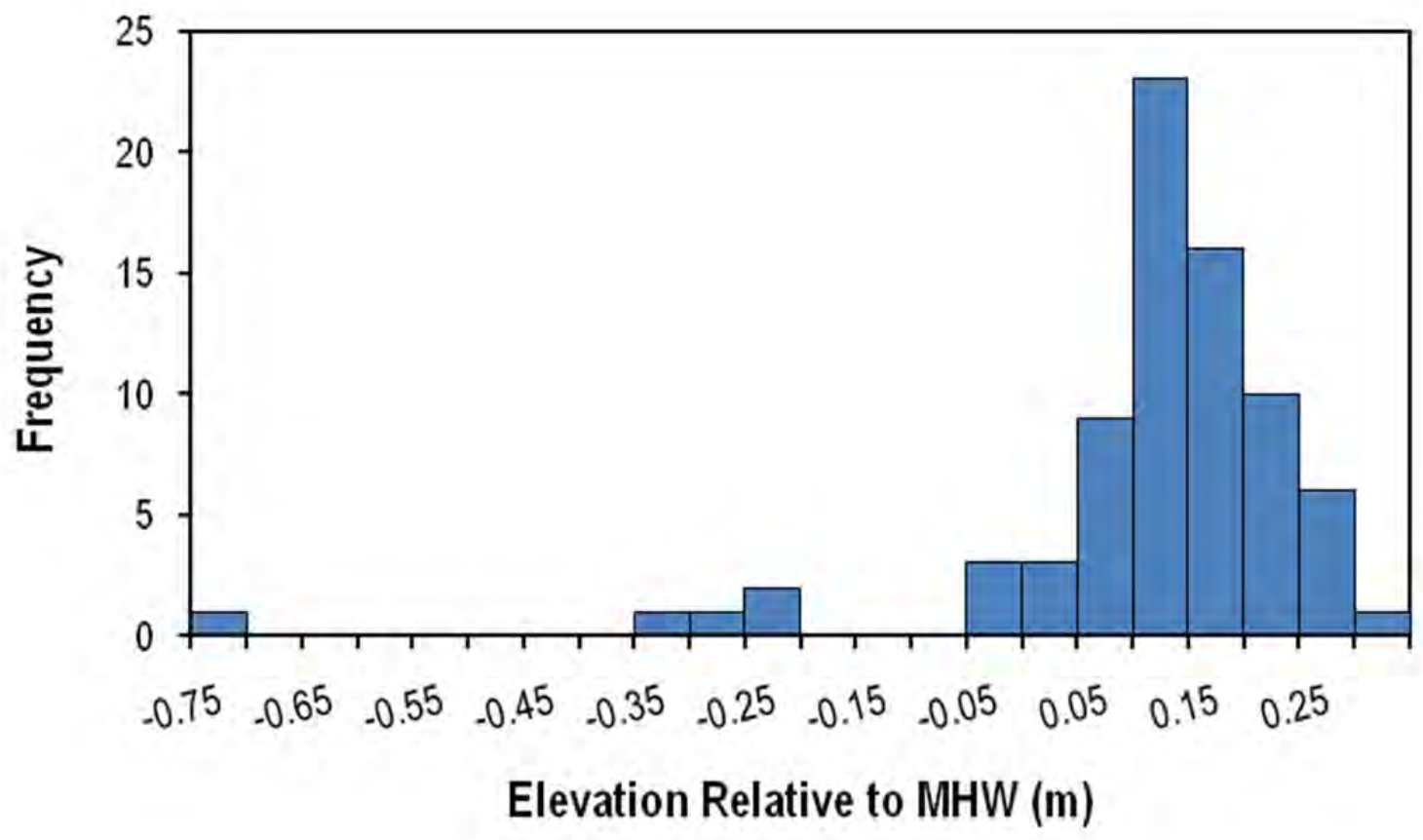

Figure J-2. Distribution of elevation samples relative to local mean high water (MHW), in meters ( $m$ ) at Laumeister Marsh. 


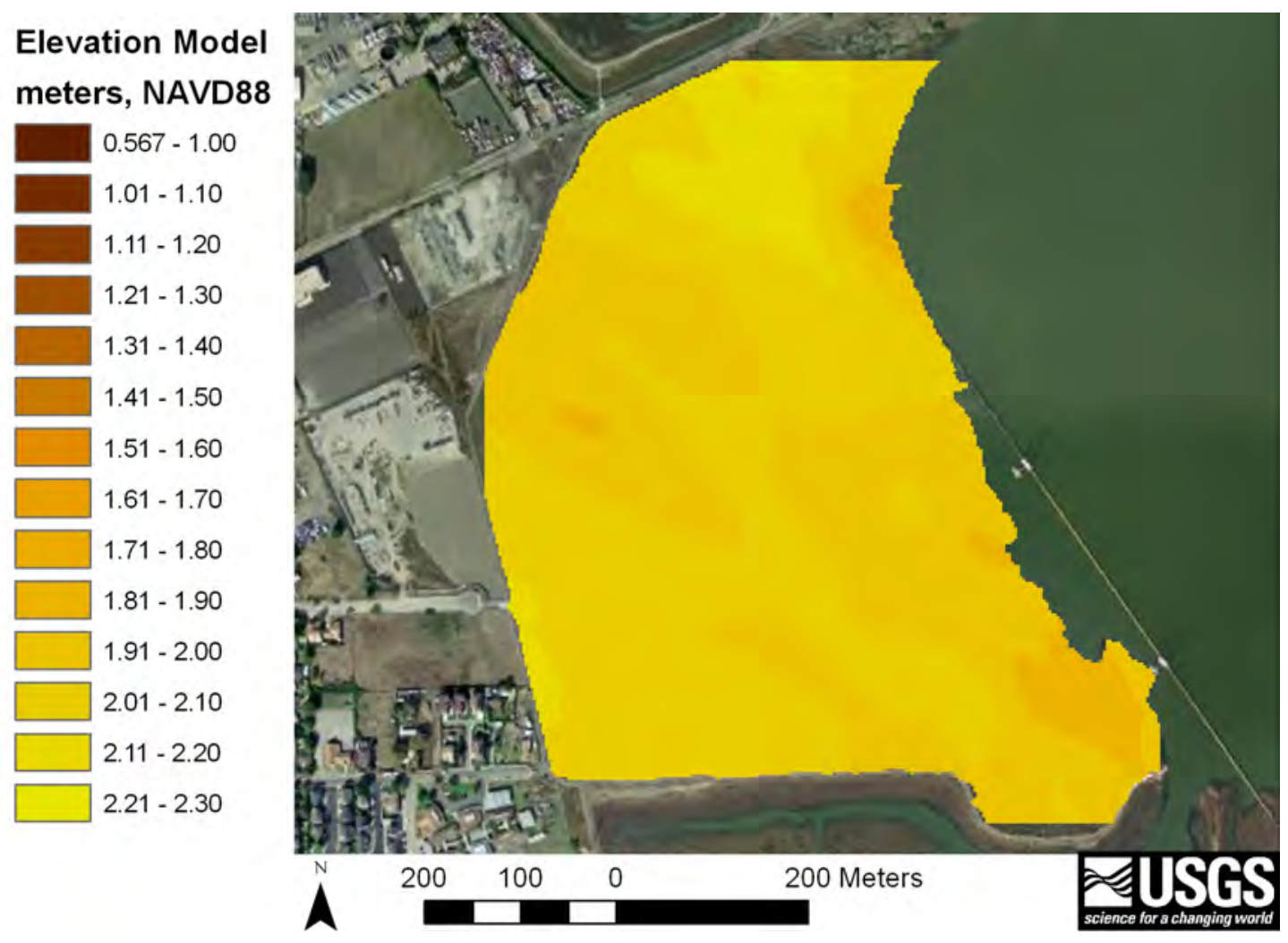

Figure J-3. Elevation model (3-meter resolution) developed from ground RTK GPS elevation data.

\section{Vegetation surveys}

Vegetation and elevation were surveyed concurrently in 2010. A total of 72 locations (fig. J-1) were surveyed for vegetation composition, height, and percentage cover (table J-1). We did not distinguish between invasive and native Spartina spp., nor among Schoenoplectus spp., in the survey. Vegetation in marshes is sensitive to soil salinity, inundation patterns, and disturbance; therefore, stratification of vegetation species relative to MHW (fig. J-4) was observed within this low-slope marsh. 
Table J-1. Mean marsh elevation relative to mean high water (MHW), average, and max height, percentage cover with standard deviations (SD), and presence by species at Laumeister.

[cm, centimeter; m, meter; $n$, sample number]

\begin{tabular}{lcccccccccc}
\hline Species & $\begin{array}{c}\text { Elevation } \\
\text { (MHW, } \\
\mathbf{m})\end{array}$ & $\begin{array}{c}\text { Elevation } \\
\text { SD } \\
(\mathbf{M H W} \\
\mathbf{m})\end{array}$ & $\begin{array}{c}\text { Mean } \\
\text { Height } \\
(\mathbf{c m})\end{array}$ & $\begin{array}{c}\text { Mean } \\
\text { Height } \\
\text { SD }(\mathbf{c m})\end{array}$ & $\begin{array}{c}\text { Max } \\
\text { Height } \\
\text { (cm) }\end{array}$ & $\begin{array}{c}\text { Max } \\
\text { Height } \\
\text { SD (cm) }\end{array}$ & $\begin{array}{c}\text { Cover } \\
\text { (percent) }\end{array}$ & $\begin{array}{c}\text { Cover } \\
\text { SD } \\
\text { (percent) }\end{array}$ & $\begin{array}{c}\text { Presence } \\
\text { (percent) }\end{array}$ \\
\hline Sarcocornia pacifica & 0.07 & 0.15 & 29.95 & 7.59 & 39.34 & 8.60 & 72.42 & 34.57 & 62 & 86.11 \\
Spartina spp. & 0.00 & 0.14 & 57.56 & 12.86 & 68.78 & 11.35 & 28.41 & 31.28 & 27 & 37.50 \\
Grindelia stricta & 0.08 & 0.21 & 64.20 & 12.97 & 72.20 & 14.76 & 27.10 & 31.09 & 20 & 27.78 \\
Jaumea carnosa & 0.08 & 0.07 & 14.67 & 4.04 & 21.33 & 2.89 & 55.00 & 37.75 & 3 & 4.17 \\
Frankenia salina & 0.25 & - & 30.00 & - & 33.00 & - & 30.00 & - & 1 & 1.39 \\
Distichlis spicata & 0.08 & 0.17 & 23.69 & 6.07 & 32.76 & 6.87 & 57.41 & 30.61 & 29 & 40.28 \\
Lepidium latifolium & -0.08 & 0.46 & 28.50 & 7.85 & 44.00 & 6.73 & 46.25 & 44.98 & 4 & 5.56 \\
\hline
\end{tabular}




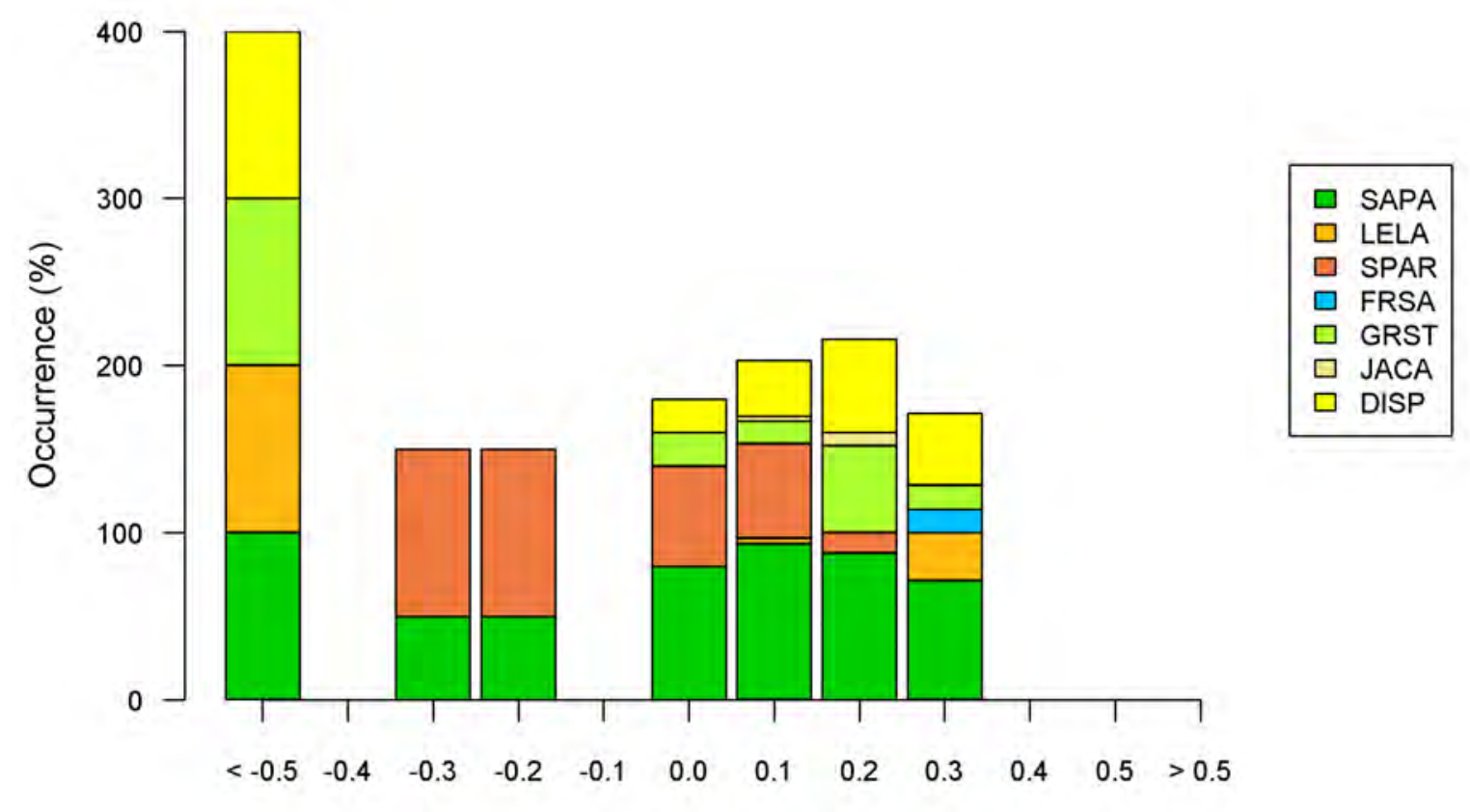

Elevation Relative to $\mathrm{MHW}(\mathrm{m})$

Figure J-4. Stratification of vegetation species was observed relative to mean high water (MHW), in meters $(m)$. Species codes: SAPA = Sarcocornia pacifica; LELA = Lepidium latifolium; SPAR = Spartina spp.; FRSA = Frankenia salina; GRST = Grindelia stricta; JACA = Jaumea carnosa; DISP = Distichlis spicata. 


\section{Water-level monitoring}

Site-specific water level was monitored for 1 year between December 2009 and December 2010. Water level was measured by using two data loggers: one deployed at the mouth of a second order channel and one in the marsh interior. Water levels were recorded throughout the year to evaluate seasonal patterns in tides. MHW was at $1.92 \mathrm{~m}$, and mean higher high water (MHHW) at $2.09 \mathrm{~m}$, for the site (NAVD88). The period when the marsh platform (defined as mean elevation) was inundated most often was from December 2009 through February 2010 (fig. J-5). Above average water levels were recorded during those months because of several record breaking storms that brought low air pressure and substantial rainfall, resulting in higher than predicted tides. The cumulative rainfall in January 2010 was above average throughout the San Francisco Bay area, and daily rainfall records were broken in some locations (National Oceanic and Atmospheric Administration). This resulted in longer inundation periods of the marsh platform. Mean salinity during 2010 at Laumeister was $13.4(\mathrm{SD}=7.9)$ practical salinity scale.

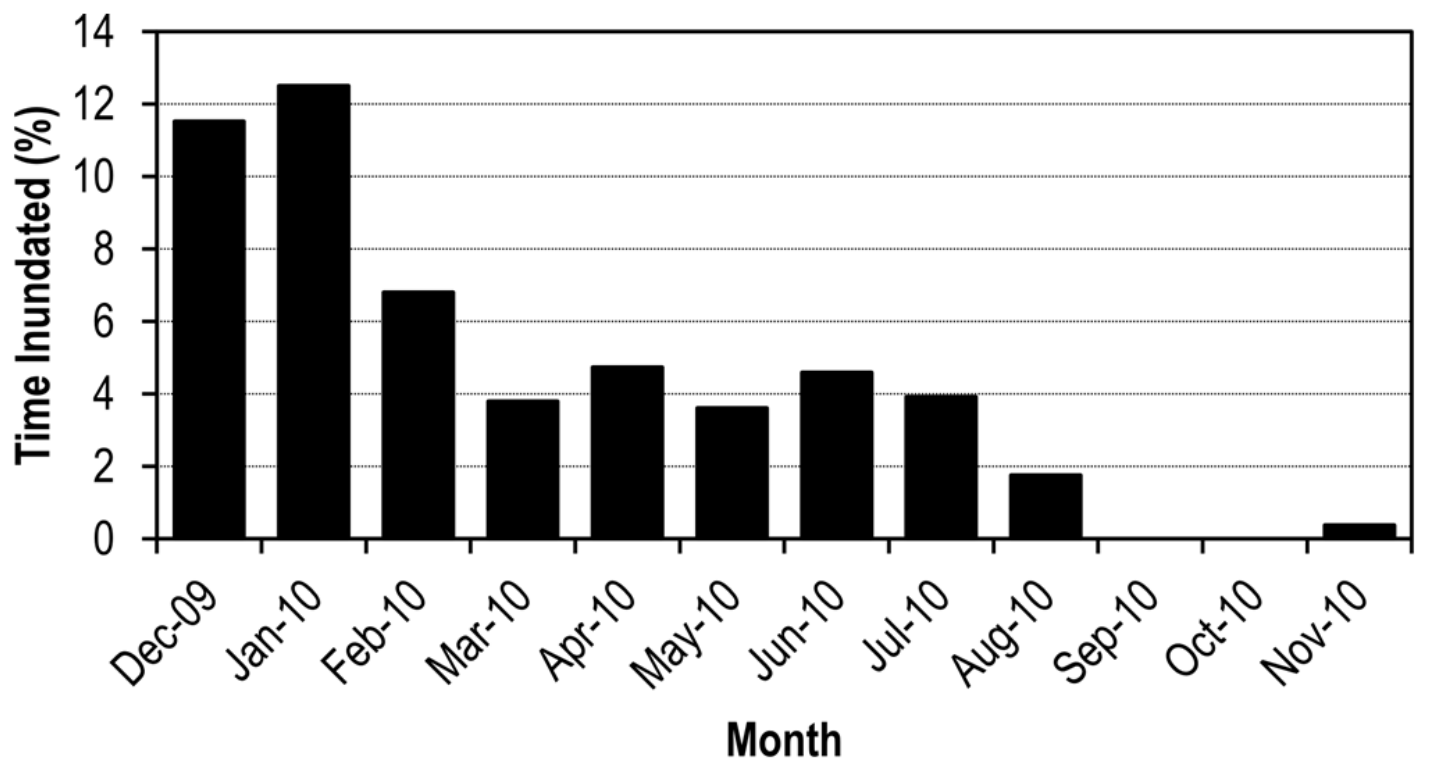

Figure J-5. Percentage of time Laumeister was inundated monthly based on the mean elevation of the marsh platform.

\section{Marsh elevation modeling}

Laumeister had high initial elevation and accretion rates, which allowed it Wlsustain marsh elevation longer than other study sites. Despite this, WARMER results indicated that Laumeister would not keep pace with local SLR through this century. WARMER results showed a gradual reduction in elevation relative to MHW over time, with a more dramatic decline after 2060; by 2050, the marsh was projected to be below MHW (fig. J$6)$. By 2100, Laumeister was projected to remain approximately $0.4 \mathrm{~m}$ above mean sea level (MSL; fig. J-7). 


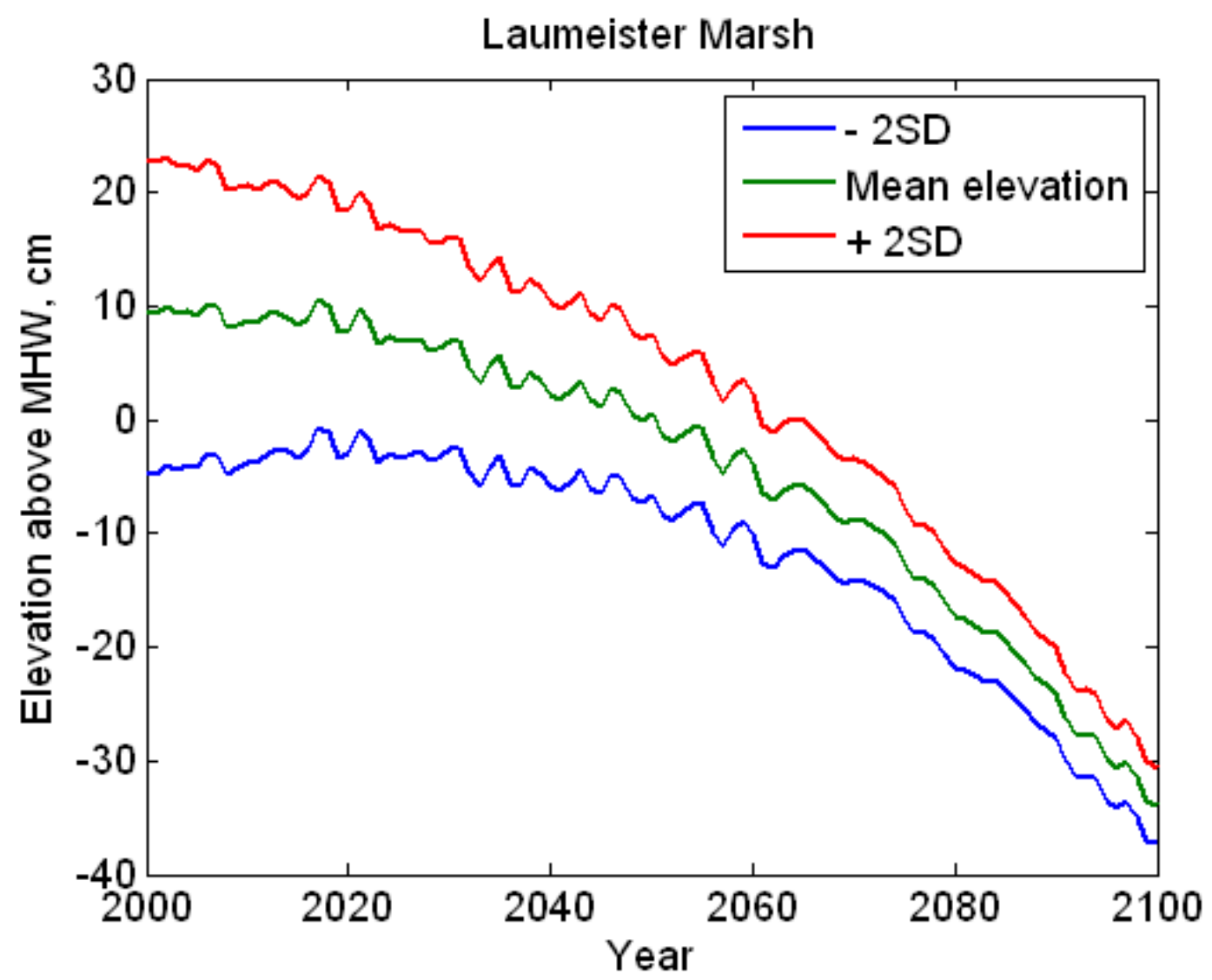

Figure J-6. WARMER scenarios of marsh elevation change for Laumeister. Elevation above mean high water (MHW), in centimeters (cm), is plotted against model year with two standard deviations (SD). 


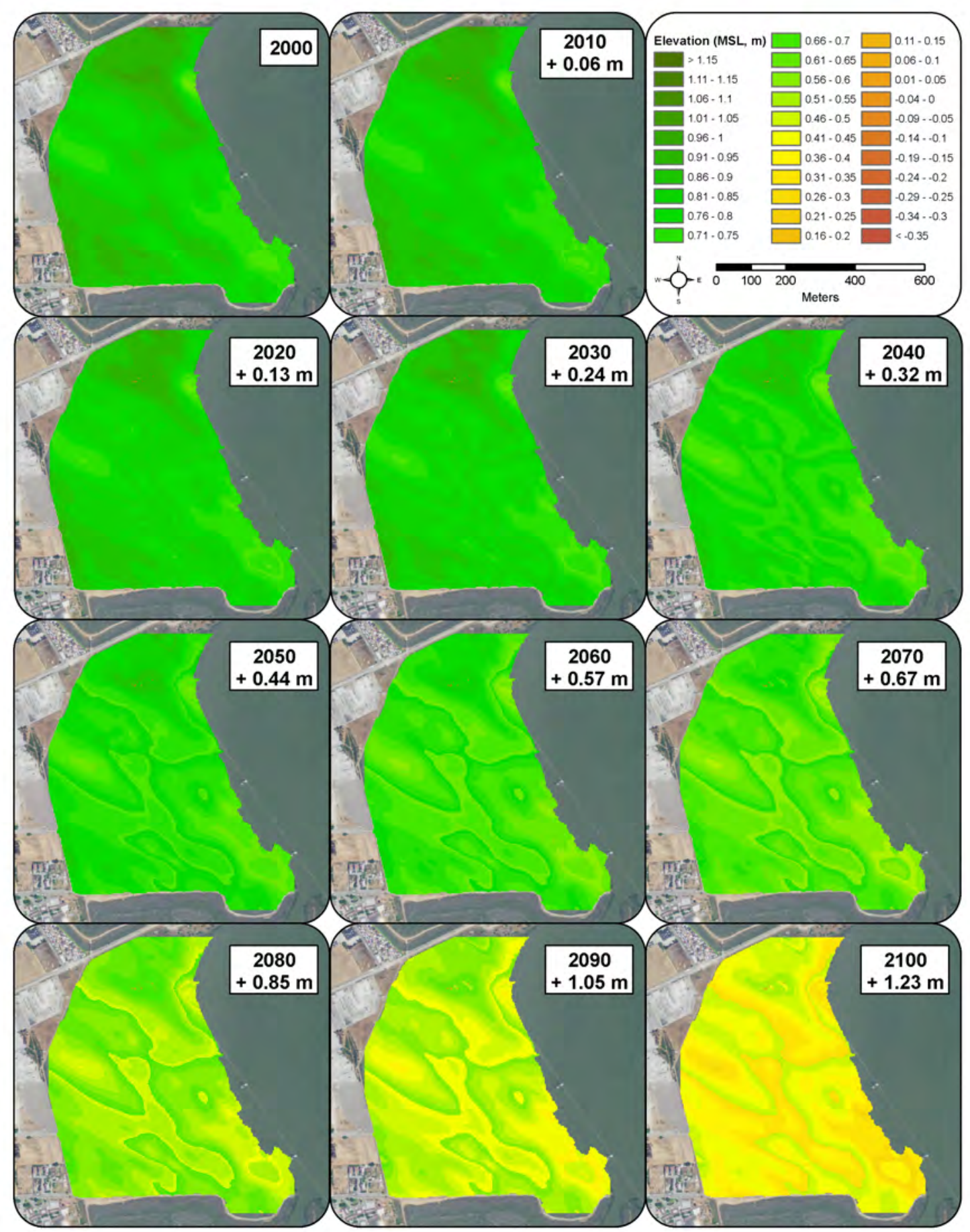

Figure J-7. WARMER results for Laumeister. WARMER accounts for changes in relative sealevel, subsidence, inorganic sediment accumulation, above and belowground organic matter productivity, compaction, and decay. Non-linear sea-level rise projections for California were used (Cayan and others, 2009). [MSL, mean sea level; m, meters] 
Elevation relative to the local tidal datum can be tied to vegetation observations. Thus, vegetation data were categorized as mudflat, low, mid, high marsh, or upland transition plant communities and used to interpret the WARMER SLR results (figs. J-8 J-9). Upland transition (greater than 1.0 m MSL) was characterized by coyote bush (Baccharis pilularis). High marsh (0.7-1.0 m MSL) was characterized by Frankenia salina and Jaumea carnosa, whereas mid marsh (0.45-0.7 m MSL) was dominated by Sarcocornia pacifica. Low marsh (0.2-0.45 m MSL) was characterized by Spartina spp. or, in brackish areas, by Schoenoplectus spp. Mudflat habitat (less than $0.2 \mathrm{~m}$ MSL) was unvegetated or sparsely covered with Spartina spp. Currently, Laumeister is primarily composed of high-marsh vegetation, and low marsh is dominated with Spartina. Model results showed that high accretion rates, due, in part, to high suspended-sediment concentrations in south San Francisco Bay, would sustain high-marsh habitat through 2060 ( $0.57 \mathrm{~m} \mathrm{SLR})$. Once the rate of sea-level rise increased in the second half of the century, Laumeister would begin to lose relative elevation and transition to predominantly mid-marsh habitat by 2080 (0.85 m SLR). By 2100, Laumeister would transition predominantly to low-marsh habitat (1.23 m SLR).

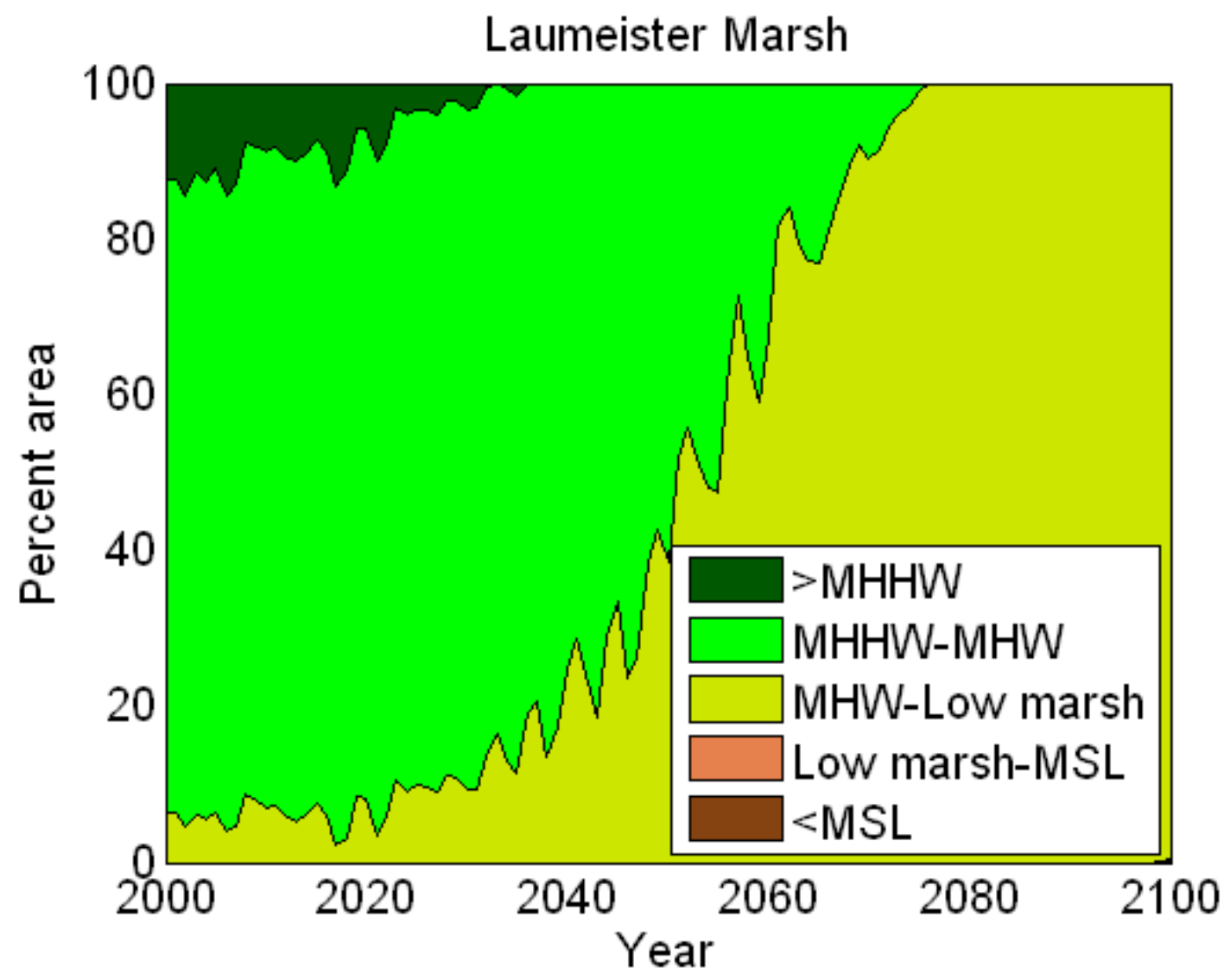

Figure J-8. Area of Laumeister within a given tidal range for the duration of the simulation period. [MHHW, mean higher high water; MHW, mean high water; MSL, mean sea level; >, greater than; <, less than] 


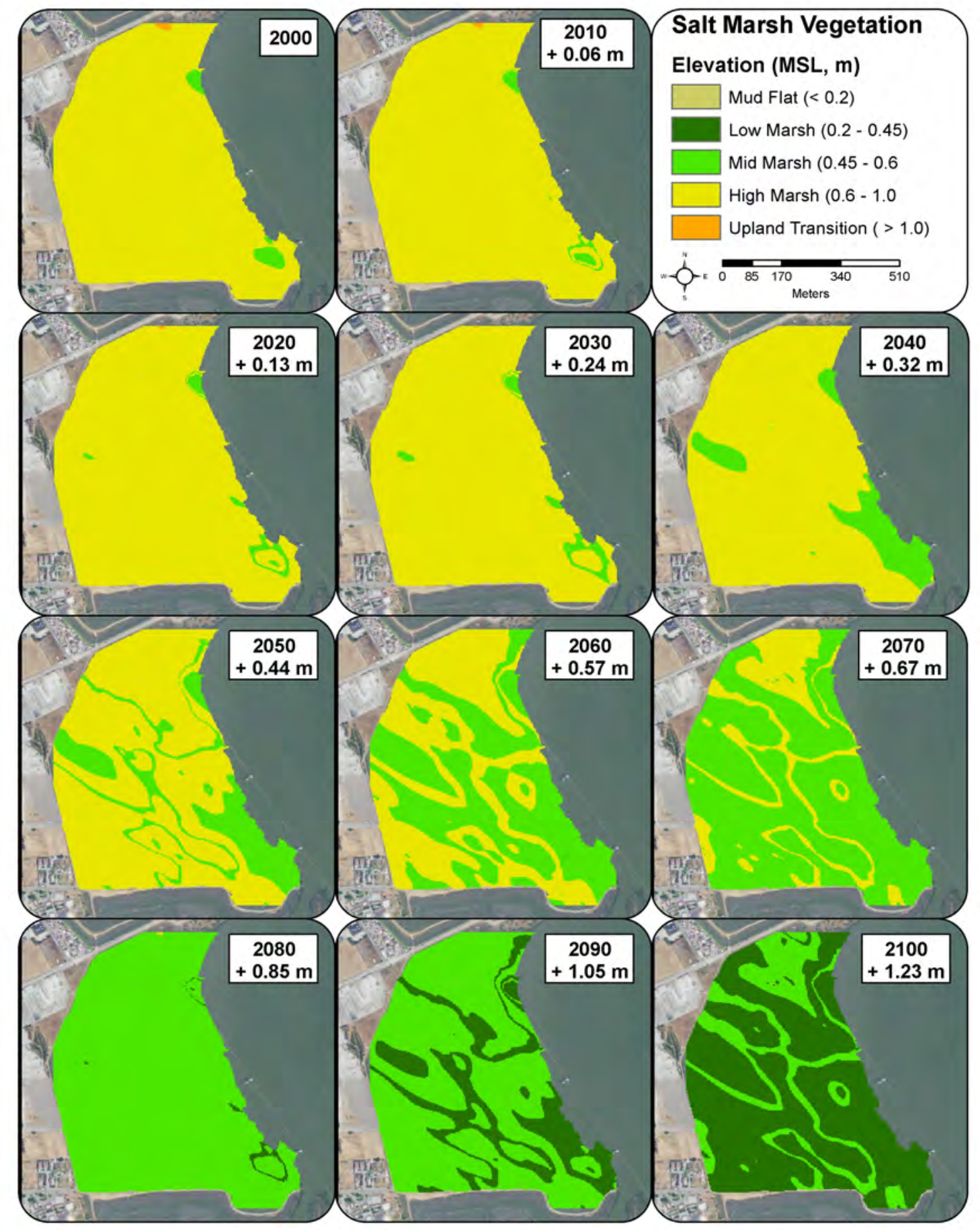

Figure J-9. Laumeister WARMER results in terms of plant communities relative to mean sea level (MSL), in meters (m): mudflat, low, mid, or high marsh, or upland transition. 


\section{Appendix K. Petaluma Marsh}

\section{Introduction}

Petaluma Marsh (hereafter, "Petaluma") is located in Sonoma County on the Petaluma River and adjacent to Petaluma Slough. It is owned and managed by the California Department of Fish and Game. Petaluma is influenced by tidal flow from San Pablo Bay as well as freshwater flow from the Petaluma River. This site is part of the largest remaining natural tidal salt marsh in California and is recognized as an important habitat for many state listed species, such as the California black rail (Laterallus jamaicensis), and federally endangered species, such as WHsalt marsh harvest mouse (Reithrodontomys raviventris).

This study focused on 80.6 hectares (ha) of Petaluma marsh. Elevation and vegetation surveys were done in 2009 by using an RTK GPS. To monitor tidal inundation and salinity, four water level loggers were deployed in 2009.

\section{Results}

\section{Elevation surveys}

A total of 655 elevation measurements were taken at Petaluma (fig. K-1). The elevation range was $0.87-2.28$ meters $(\mathrm{m})$, with a mean of $1.82 \mathrm{~m}$ (NAVD88). Petaluma was one of the highest elevation marshes surveyed. Nearly three-fourths (74.8 percent) of the survey points were within $1.75-1.90 \mathrm{~m}$, a $0.15 \mathrm{~m}$ range (fig. K-2). The majority (89 percent) of survey points were at elevations above mean high water (MHW). A 3-m resolution elevation model was developed in ArcGIS 9.3 (ESRI, Redlands, Calif.) Spatial Analyst by using the kriging method (fig. K-3). This baseline elevation model was used as the initial state in the WARMER sea-level rise model; WARMER results were extrapolated across the elevation model. 


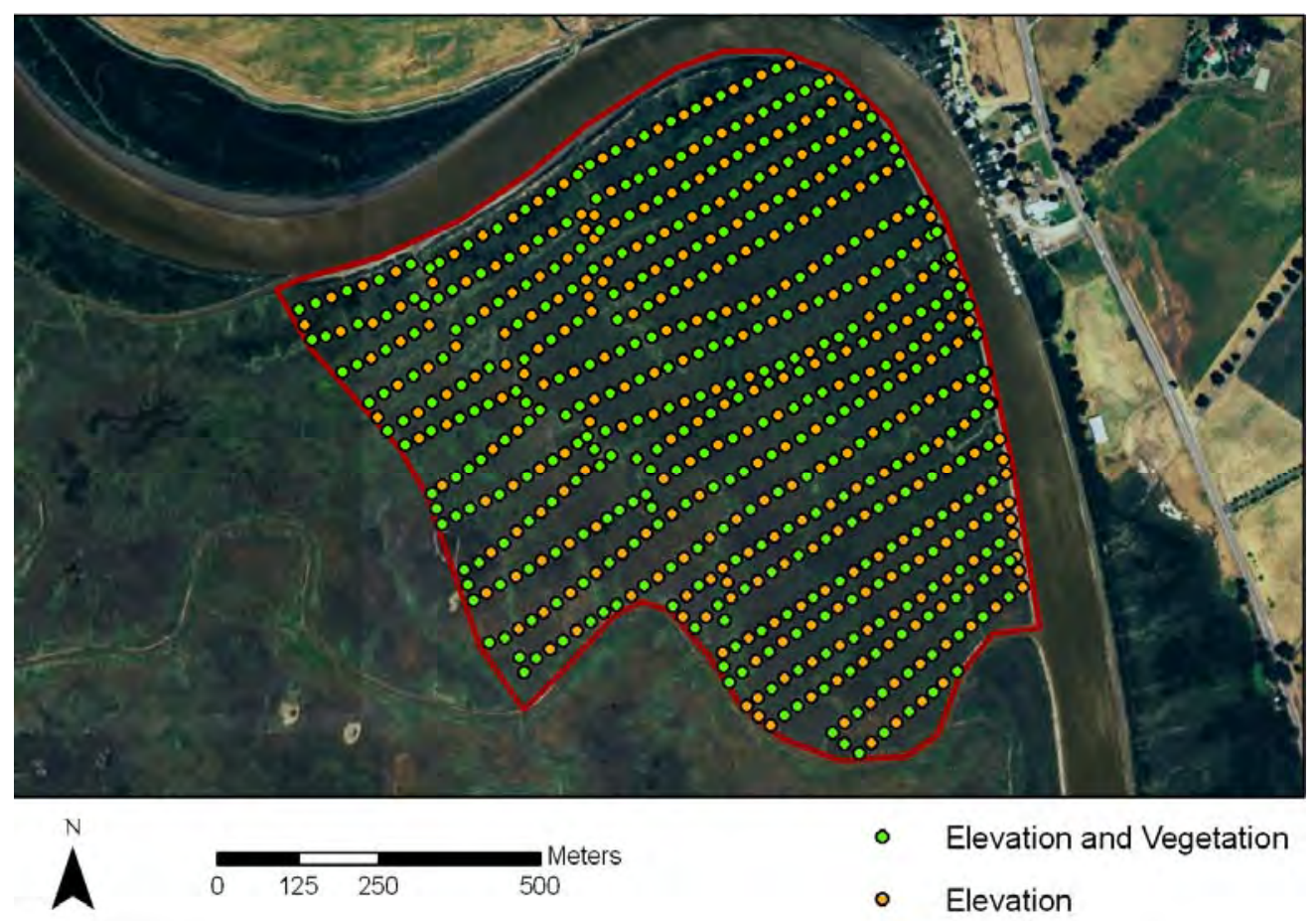

Figure K-1. Petaluma Marsh with elevation and vegetation survey points from 2009.

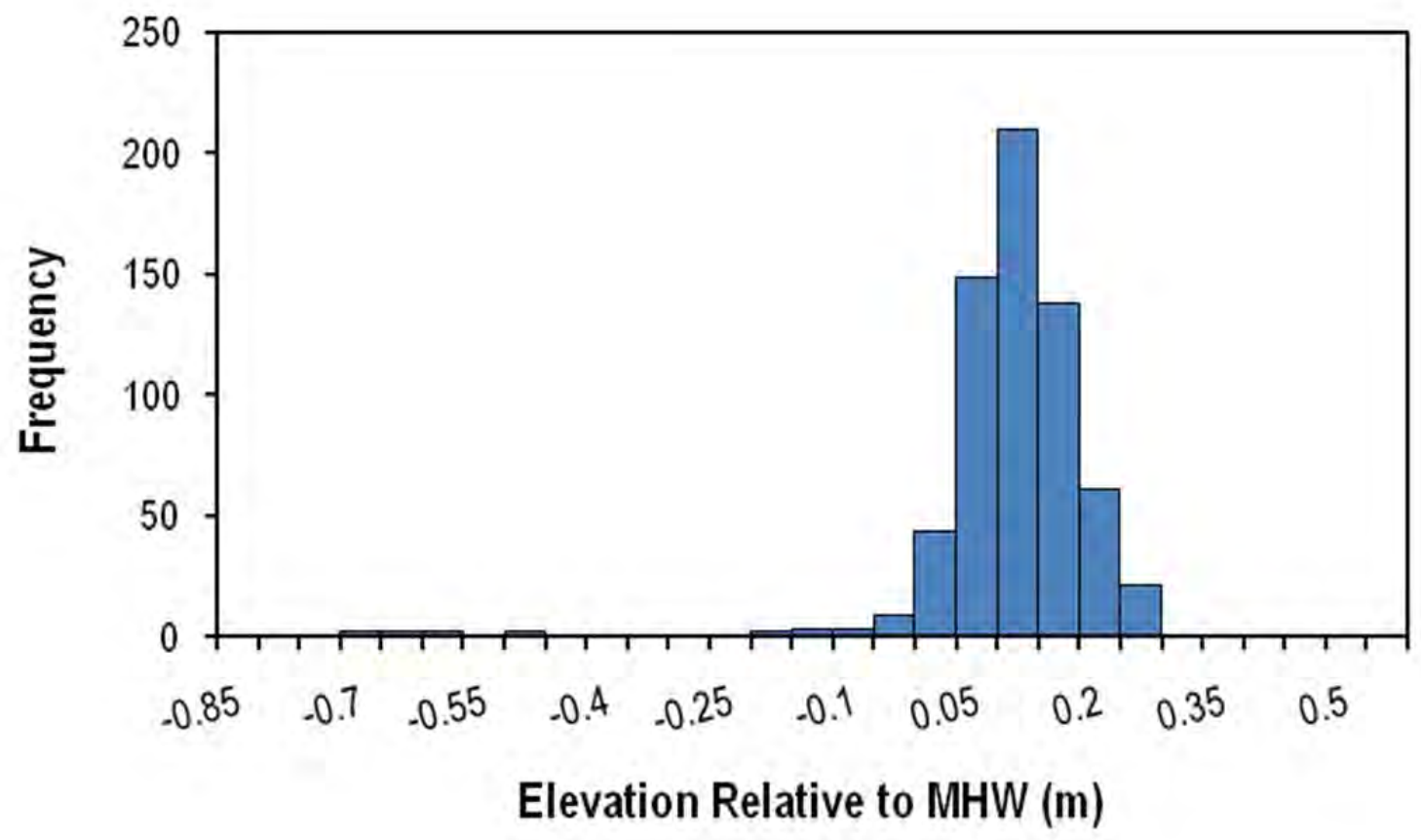

Figure K-2. Distribution of elevation samples relative to local mean high water (MHW), in meters (m), at Petaluma Marsh. 


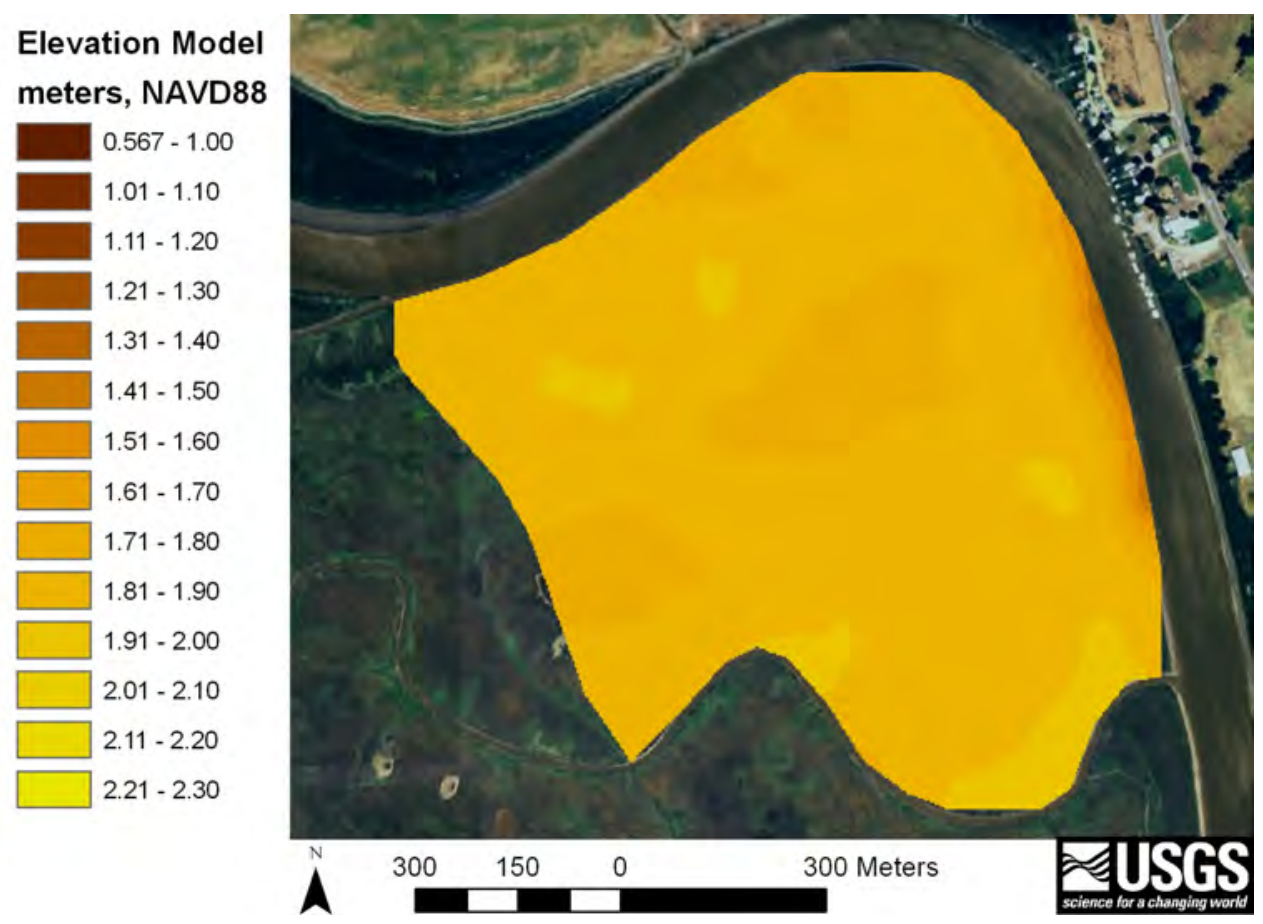

Figure K-3. Elevation model (3-meter resolution) developed from ground RTK GPS elevation data.

\section{Vegetation surveys}

Vegetation and elevation surveys were done concurrently in October-November of 2009. A total of 357 locations (fig. K-1) were measured for vegetation composition, height, and percentage cover (table K-1). We did not distinguish between invasive and native Spartina spp., nor among Schoenoplectus spp., in the survey. Vegetation in marshes is sensitive to soil salinity, inundation patterns, and disturbance; therefore, stratification of vegetation species relative to MHW (fig. K-4) was observed within this low-slope marsh. 
Table K-1. Mean marsh elevation relative to mean high water (MHW), average, and max height, percentage cover with standard deviations (SD), and presence by species at Petaluma.

[cm, centimeter; m, meter; $n$, sample number]

\begin{tabular}{|c|c|c|c|c|c|c|c|c|c|c|}
\hline Species & $\begin{array}{c}\text { Elevation } \\
\text { (MHW, } \\
m)\end{array}$ & $\begin{array}{c}\text { Elevation } \\
S D \\
(M H W \\
m)\end{array}$ & $\begin{array}{l}\text { Mean } \\
\text { Height } \\
(\mathrm{cm})\end{array}$ & $\begin{array}{l}\text { Mean } \\
\text { Height } \\
\text { SD (cm) }\end{array}$ & $\begin{array}{c}\text { Max } \\
\text { Height } \\
\text { (cm) }\end{array}$ & $\begin{array}{c}\text { Max } \\
\text { Height } \\
\text { SD (cm) }\end{array}$ & $\begin{array}{c}\text { Cover } \\
\text { (percent) }\end{array}$ & $\begin{array}{c}\text { Cover } \\
\text { SD } \\
\text { (percent) }\end{array}$ & $n$ & $\begin{array}{r}\text { Presence } \\
\text { (percent) }\end{array}$ \\
\hline Sarcocornia pacifica & 0.08 & 0.07 & 39.82 & 10.98 & 49.22 & 11.30 & 84.53 & 24.69 & 345 & 96.91 \\
\hline Schoenoplectus spp. & -0.07 & 0.24 & 63.04 & 26.68 & 71.57 & 30.38 & 15.04 & 14.43 & 23 & 6.46 \\
\hline Grindelia stricta & 0.11 & 0.07 & 66.22 & 21.25 & 75.67 & 24.71 & 25.06 & 18.94 & 18 & 5.06 \\
\hline Jaumea carnosa & 0.06 & 0.05 & 16.97 & 5.32 & 20.40 & 6.51 & 21.05 & 21.95 & 62 & 17.42 \\
\hline Frankenia salina & 0.11 & 0.06 & 31.20 & 8.16 & 35.80 & 8.50 & 47.02 & 33.15 & 46 & 12.92 \\
\hline Distichlis spicata & 0.04 & 0.04 & 21.18 & 5.38 & 24.82 & 6.03 & 20.27 & 22.38 & 33 & 9.27 \\
\hline Lepidium latifolium & 0.11 & 0.08 & 96.22 & 18.89 & 106.06 & 18.63 & 24.94 & 16.54 & 36 & 10.11 \\
\hline Baccharis pilu(Dris & 0.30 & 0.19 & 71.67 & 38.84 & 84.00 & 35.68 & 55.00 & 39.69 & 3 & 0.84 \\
\hline
\end{tabular}




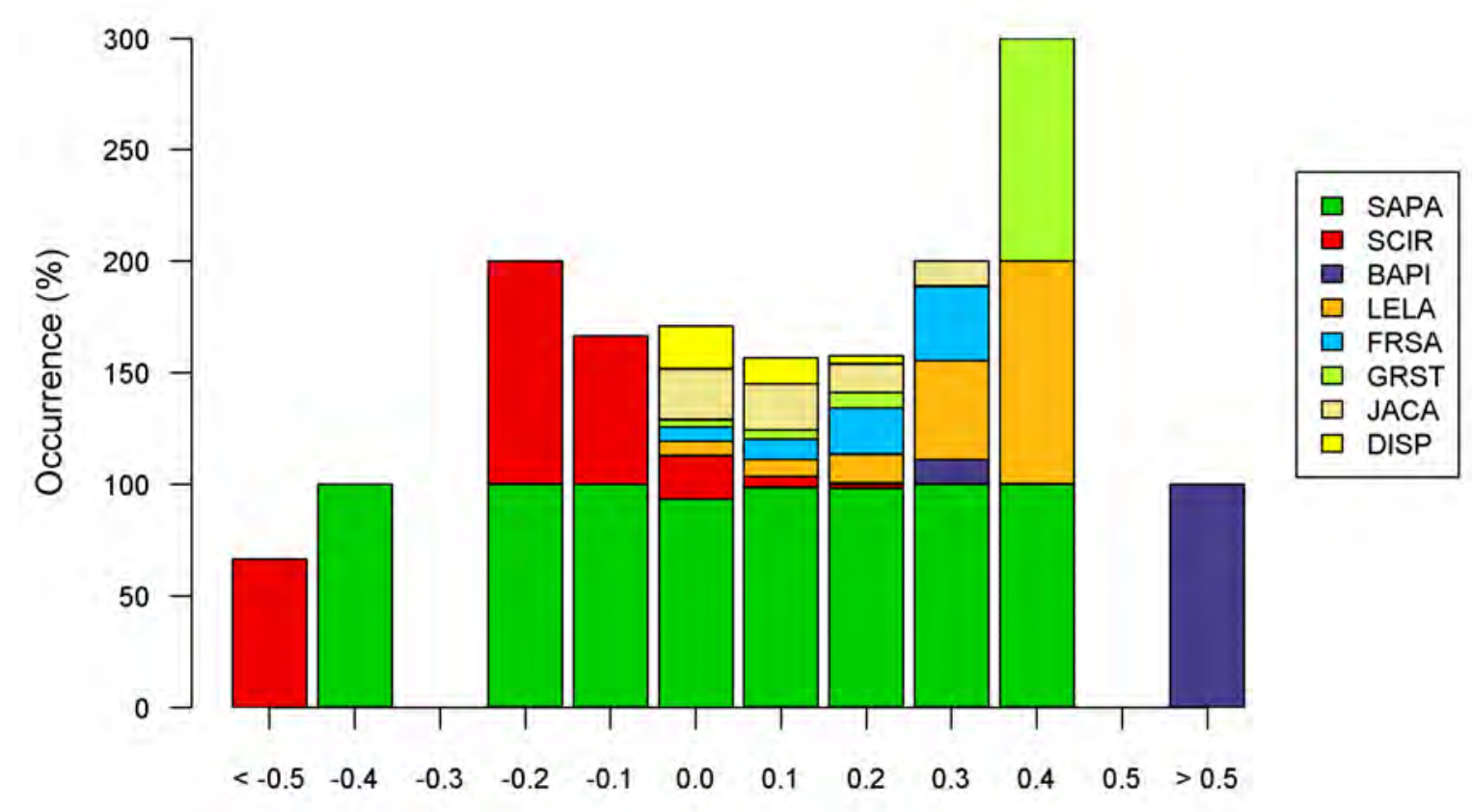

Elevation Relative to $\mathrm{MHW}(\mathrm{m})$

Figure K-4. Stratification of vegetation species was observed relative to mean high water (MHW), in meters (m). Species codes: SAPA = Sarcocornia pacifica; SCIR = Schoenoplectus spp.; BAPI = Baccaris pilularis; LELA = Lepidium latifolium; FRSA = Frankenia salina; GRST = Grindelia stricta; JACA = Jaumea carnosa; DISP = Distichlis spicata.

\section{Water-level monitoring}

Site-specific water level was monitored for 1 year from December 2009 to November 2010. Water level was measured by using four data loggers: two deployed at the mouth of second order channels and two in the marsh interior. Water levels were recorded throughout the year to evaluate seasonal patterns in tides. MHW was at $1.76 \mathrm{~m}$, and mean higher high water (MHHW) at $1.92 \mathrm{~m}$, for the site (NAVD88). The period when the marsh platform (defined as mean elevation) was inundated most often was from January 2010 through February 2010 (fig. K-5). During those months, above average water levels were recorded because of several recordbreaking storms that brought low air pressure and substantial rainfall, resulting in higher than predicted tides. The cumulative rainfall in January 2010 was above average throughout the San Francisco Bay area, and daily rainfall records were broken in some locations (National Oceanic and Atmospheric Administration). This resulted in longer inundation periods of the marsh platform. Mean salinity during 2010 at Petaluma was $14.4(\mathrm{SD}=8.3)$ practical salinity scale. 


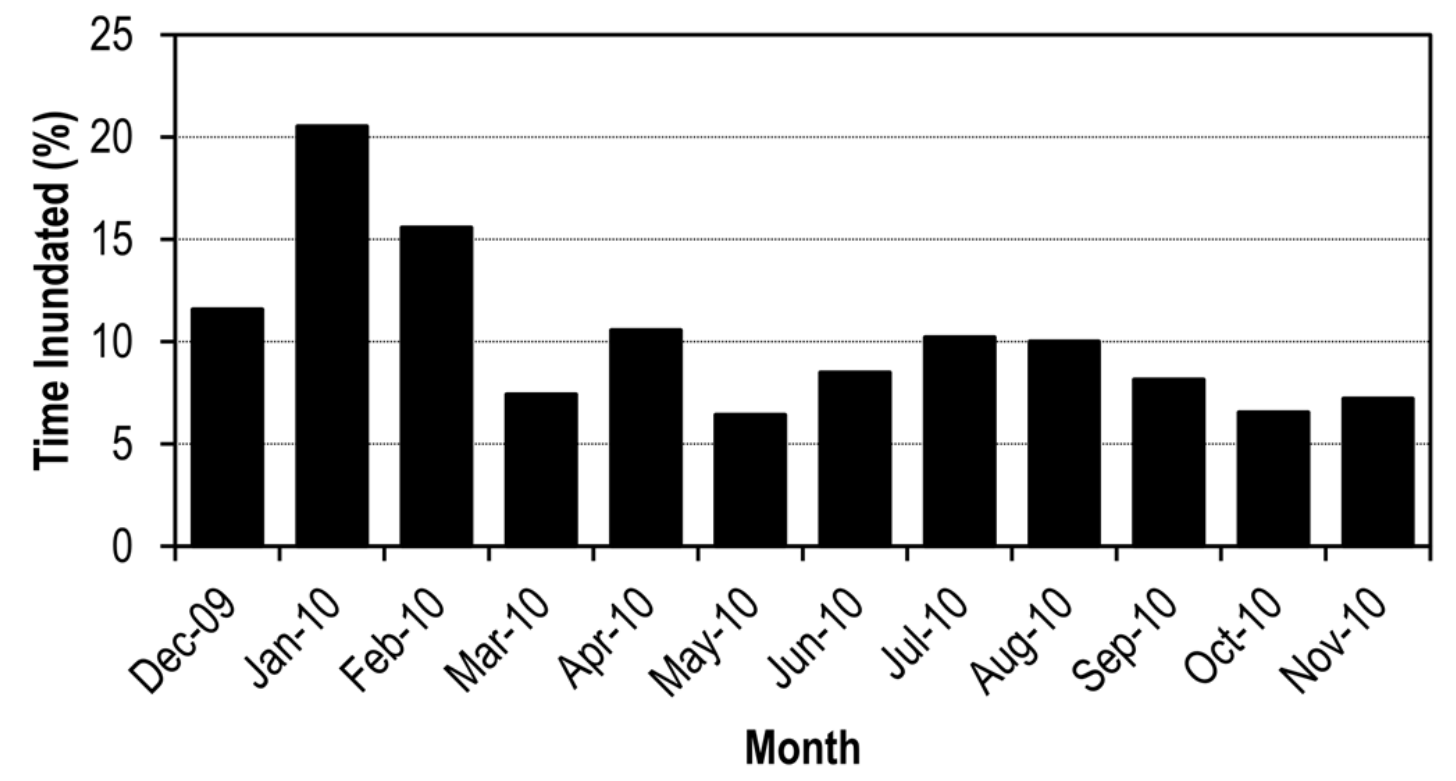

Figure K-5. Percentage of time Petaluma Marsh was inundated monthly based on the mean elevation of the marsh platform.

Marsh-elevation modeling

WARMER results indicated that Petaluma will not keep pace with local SLR through this century. WARMER results projected a gradual reduction in elevation relative to MHW over time, with a more dramatic decline after 2060 (Fig K-6). By 2080, the marsh was projected to be under mean sea level (MSL) and therefore, to transition to a mudflat (fig. K-7). 


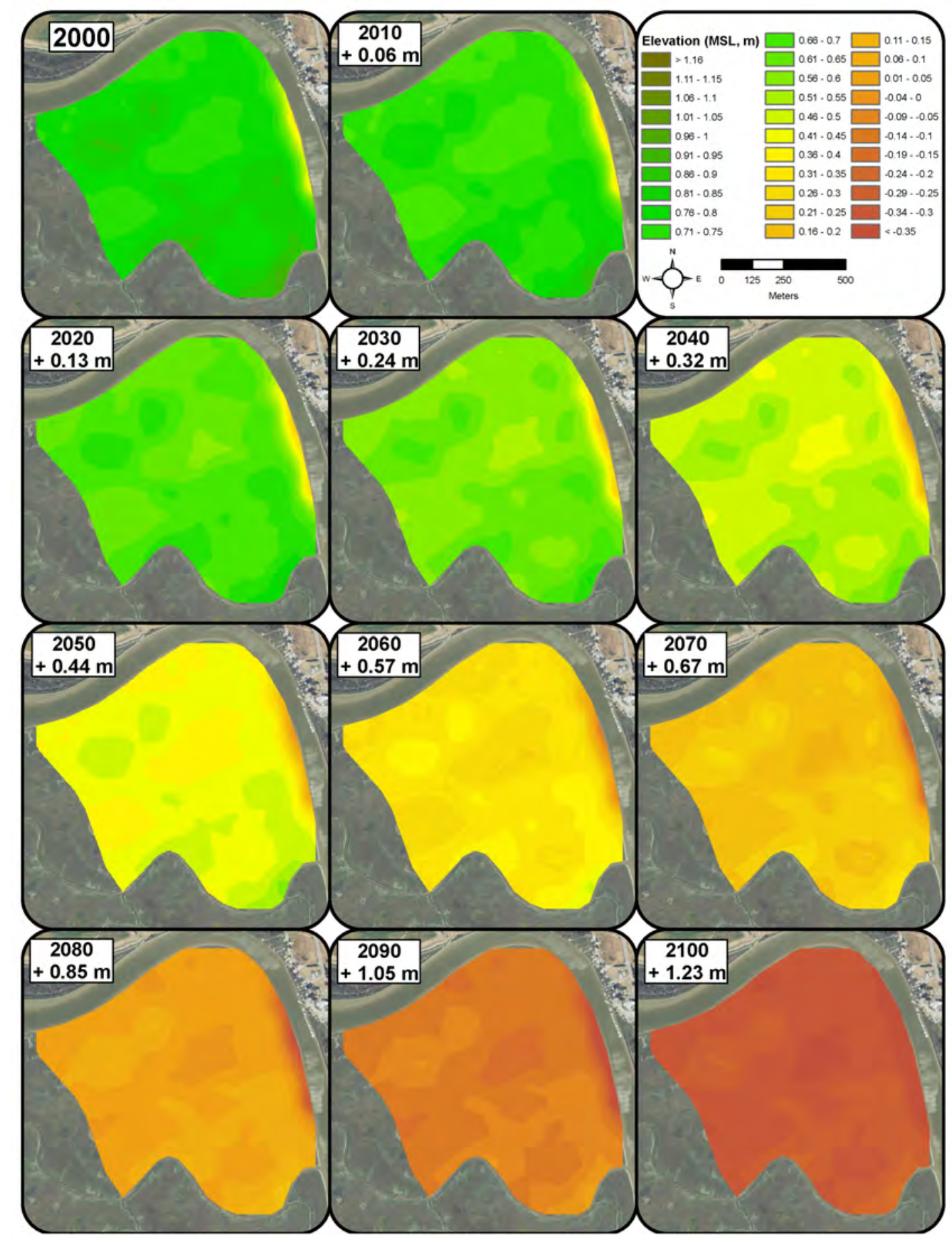

Figure K-7. WARMER results for Petaluma marsh. WARMER accounts for changes in relative sea-level, subsidence, inorganic sediment accumulation, above and below ground organic matter productivity , compaction, and decay. Non-linear sea-level rise projections for California were used (Cayan and others, 2009). [MSL, mean sea level; m, meters] 


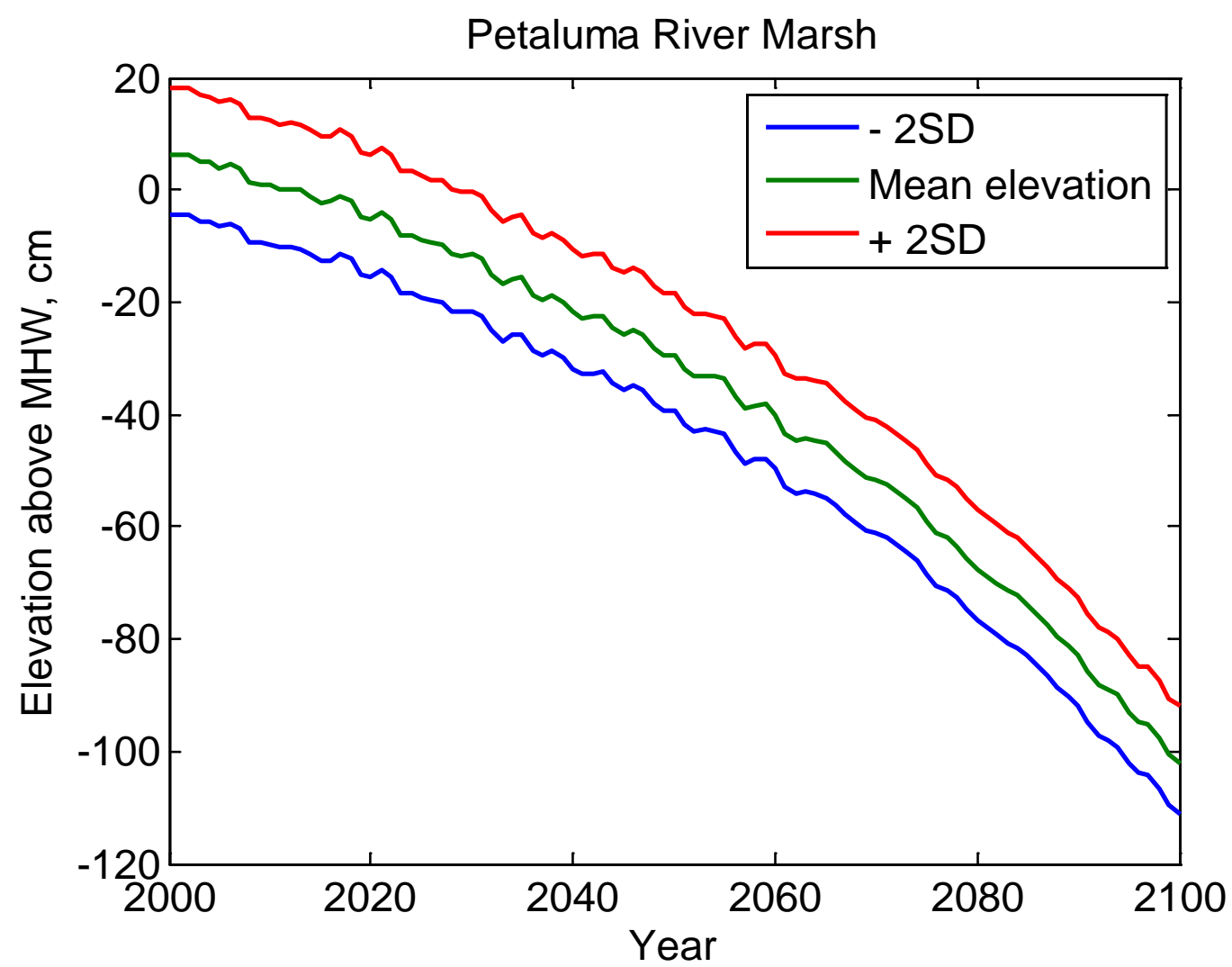

Figure K-6. WARMER scenarios for Petaluma marsh elevation change. Elevation above mean high water (MHW), in centimeters $(\mathrm{cm})$, is plotted against model year with two standard deviations (SD).

Elevation relative to the local tidal datum can be tied to vegetation observations. Vegetation data were categorized as mudflat, low, mid, high marsh, or upland transition plant communities and used to interpret the WARMER SLR results (figs. K-8 - K-9). Upland transition (greater than $1.0 \mathrm{~m}$ MSL) was characterized by coyote bush (Baccharis pilularis). High marsh (0.7-1.0 m MSL) was characterized by Frankenia salina and Jaumea carnosa, whereas mid marsh (0.45-0.7 m MSL) was dominated by Sarcocornia pacifica. Low marsh (0.2-0.45 m MSL) was characterized by Spartina spp. or, in brackish areas, by Schoenoplectus spp. Mudflat habitat (less than $0.2 \mathrm{~m}$ MSL) was unvegetated or sparsely covered with Spartina spp. Currently, Petaluma is roughly 90 percent high marsh. However, by 2030 ( $0.24 \mathrm{~m} \mathrm{SLR})$, WARMER projected Petaluma to transition almost completely to mid marsh (figs. K-9 and K10). Petaluma was projected to transition to low marsh, dominated by Spartina spp. and Schoenoplectus spp., by 2060 (0.57 m SLR). By 2080 (0.85 m SLR), the marsh would likely lose vegetation and become primarily mudflat.

Quality-control issues with the Petaluma sediment cores resulted in the removal of data that indicated high sedimentation rates. The Petaluma River is a major source of sediment to San Francisco Bay; thus, it is likely that the inputs to WARMER underestimated accretion potential. 


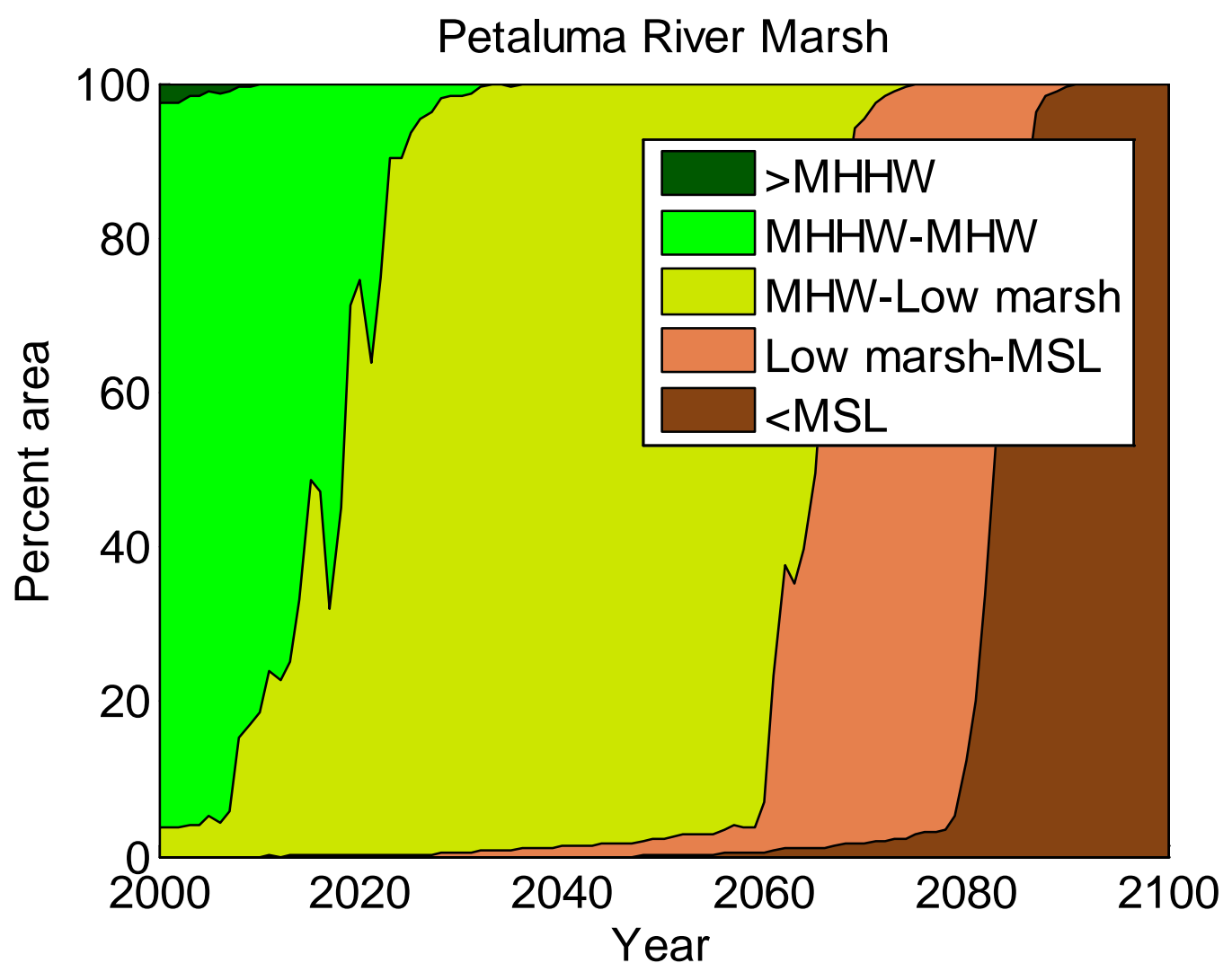

Figure K-8. Area of Petaluma within a given tidal range for the duration of the simulation period. $[\mathrm{MHHW}$, mean higher high water; MHW, mean high water; MSL, mean sea level; >, greater than; <, less than] 


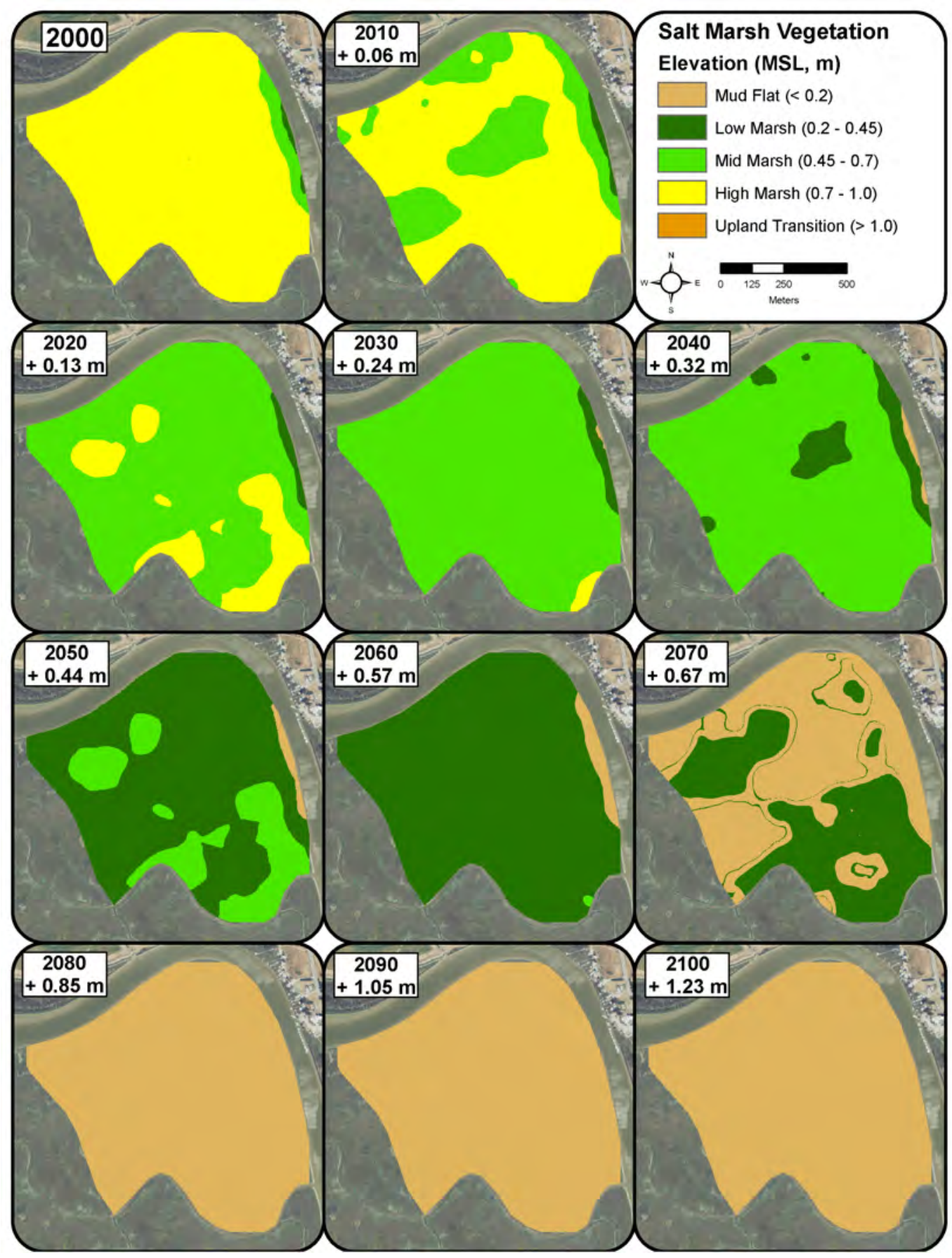

Figure K-9. Petaluma WARMER results in terms of plant communities relative to mean sea level (MSL), in meters (m): mudflat, low, mid, or high marsh, or upland transition. 


\section{Appendix L. San Pablo Bay Marsh}

\section{Introduction}

San Pablo Bay National Wildlife Refuge marsh (hereafter, "San Pablo") is located on the north shore of San Pablo Bay in Sonoma, Solano, and Napa Counties. It is owned and managed by the U.S. Fish and Wildlife Service, with adjacent lands owned and managed by California Fish and Game and Sonoma LandTrust. It is one of the largest areas of intact marsh in the San Francisco Bay estuary. San Pablo supports federally and state-listed species, such as the salt marsh harvest mouse (Reithrodontomys raviventris) and the California black rail (Laterallus jamaicensis). San Pablo is also an important stopover on the Pacific Flyway and provides critical migratory and wintering habitat for shorebirds. San Pablo is influenced both by the tides and by freshwater input from Petaluma River, Sonoma Creek, and Napa River.

Because of the size of San Pablo, we split data analysis into two sections: 962.6 hectares (ha) on the northeast side and 449.5 ha on the northwest, separated by Sonoma Creek. Elevation and vegetation surveys were done in 2008-2009 by using an RTK GPS. To monitor tidal inundation and salinity, water-level loggers were deployed in 2009.

\section{Results}

Elevation

A total of 1,396 elevation measurements were made at San Pablo (figs. L-1 and L-2). The elevation range was $0.56-3.11$ meters $(\mathrm{m})$, with a mean of $1.94 \mathrm{~m}$ (NAVD88). Of the survey points, 58 percent fell within 1.7-2.1 m. Over half (64 percent) of the survey points were at elevations above mean high water (MHW; fig. L-3). A 3-m resolution elevation model was developed in ArcGIS 9.3 (ESRI, Redlands, Calif.) Spatial Analyst by using the kriging method (figs. L-4 and L-5). This baseline elevation model was used as the initial state in the WARMER sea-level rise (SLR) model; WARMER results were extrapolated across the elevation model. 


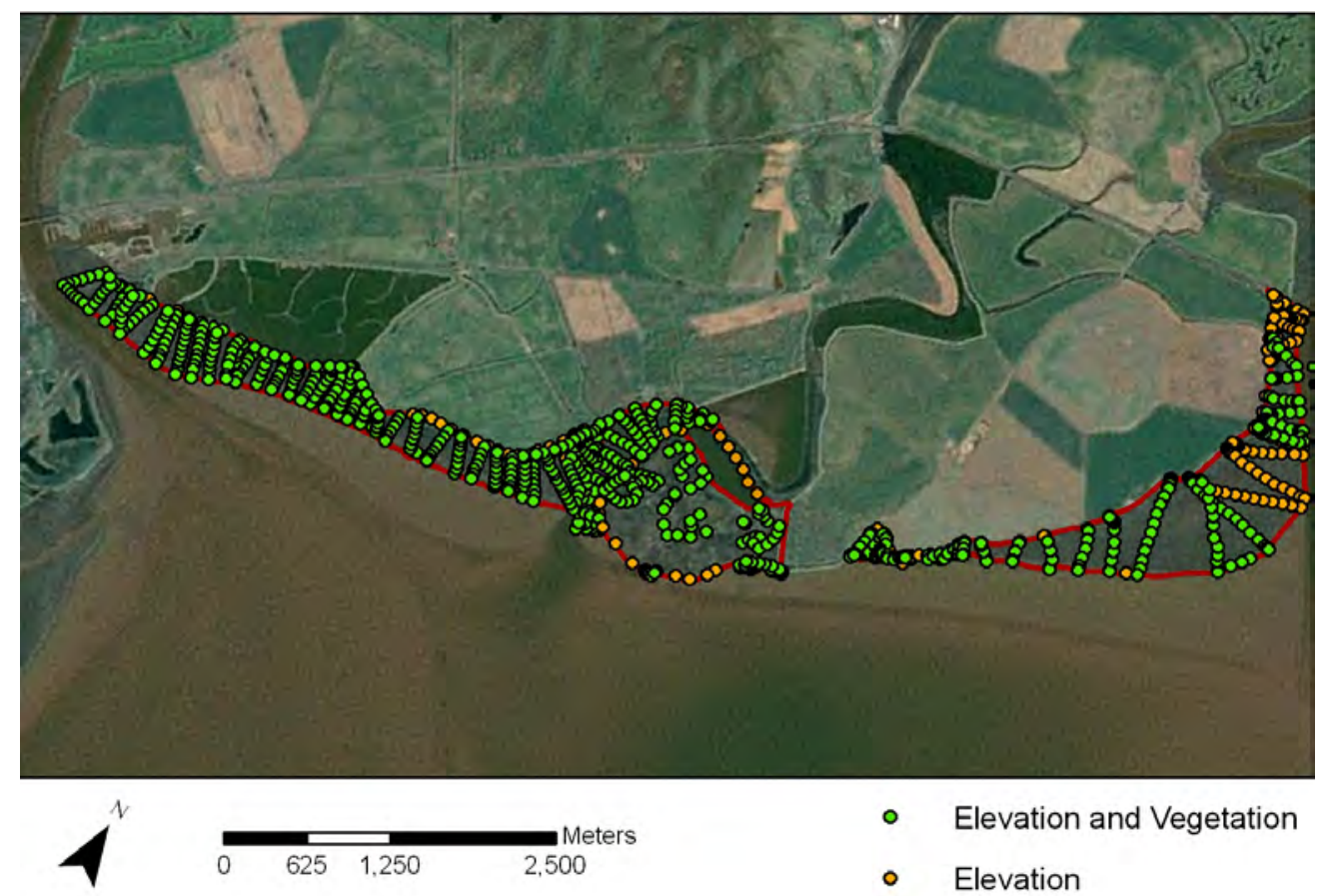

Figure L-1. Western portion of San Pablo with elevation and vegetation survey points from 2009.

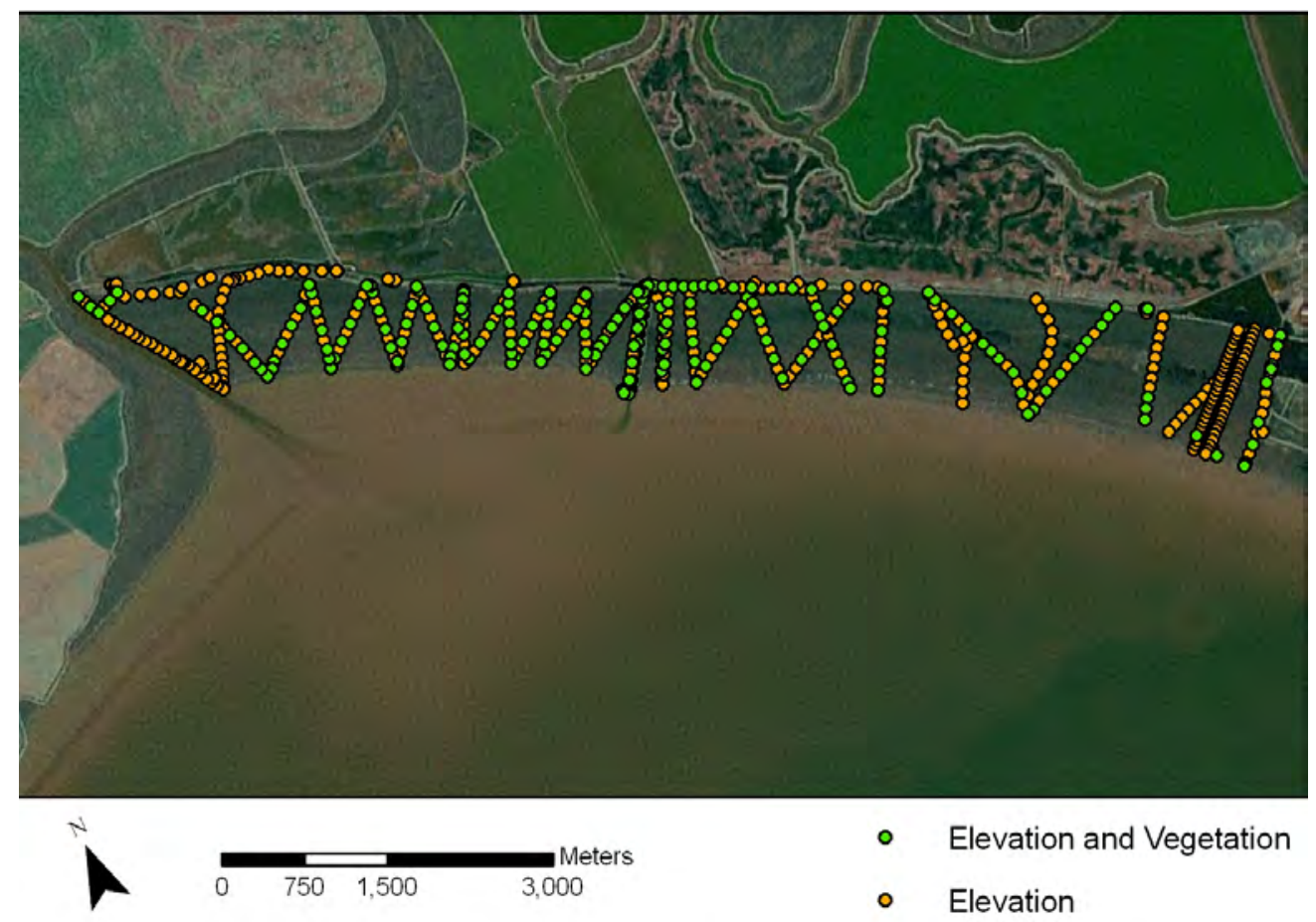

Figure L-2. Eastern portion of San Pablo with elevation and vegetation survey points from 2008. 


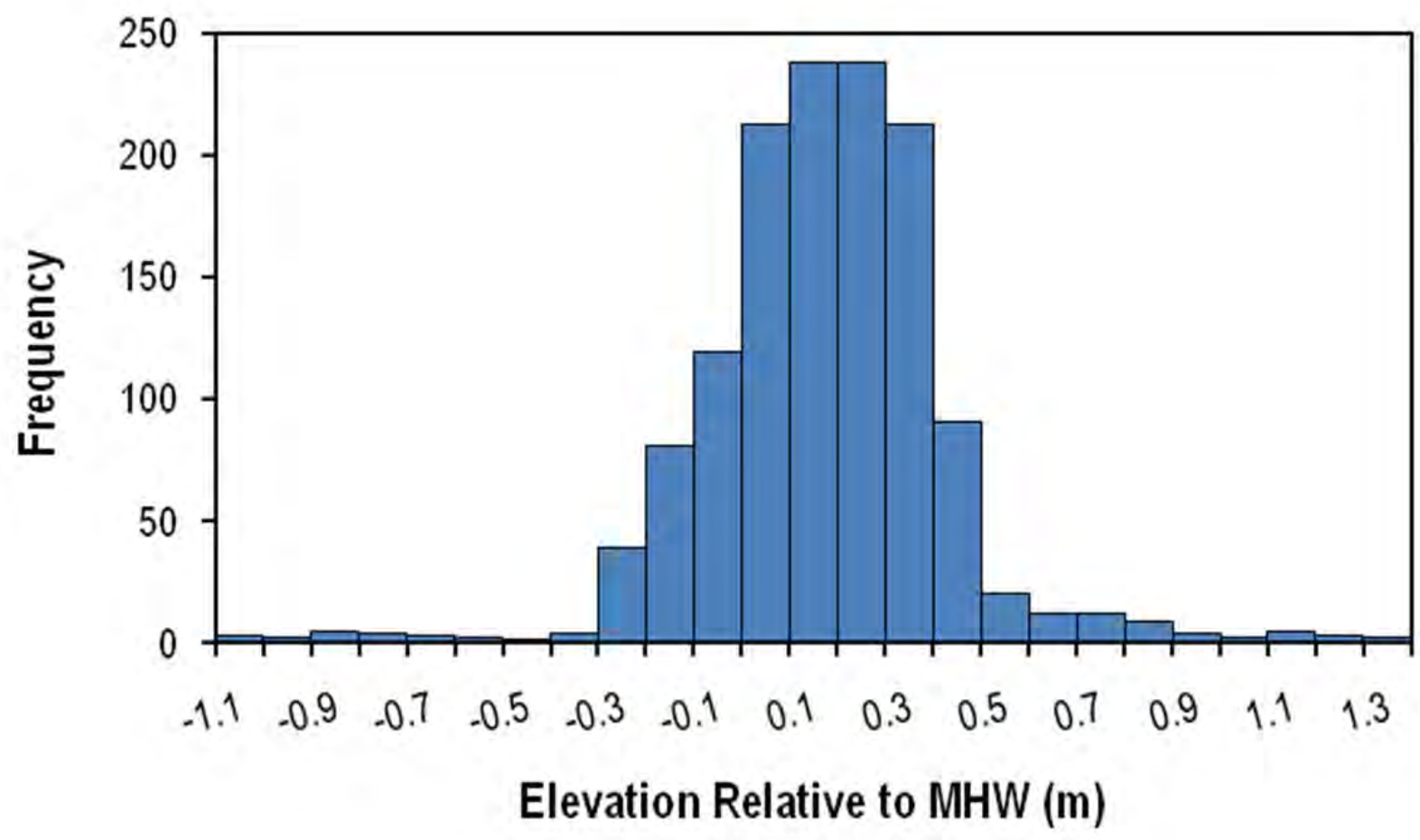

Figure L-3. Distribution of elevation relative to local mean high water (MHW), in meters ( $m$ ), for all San Pablo data. 


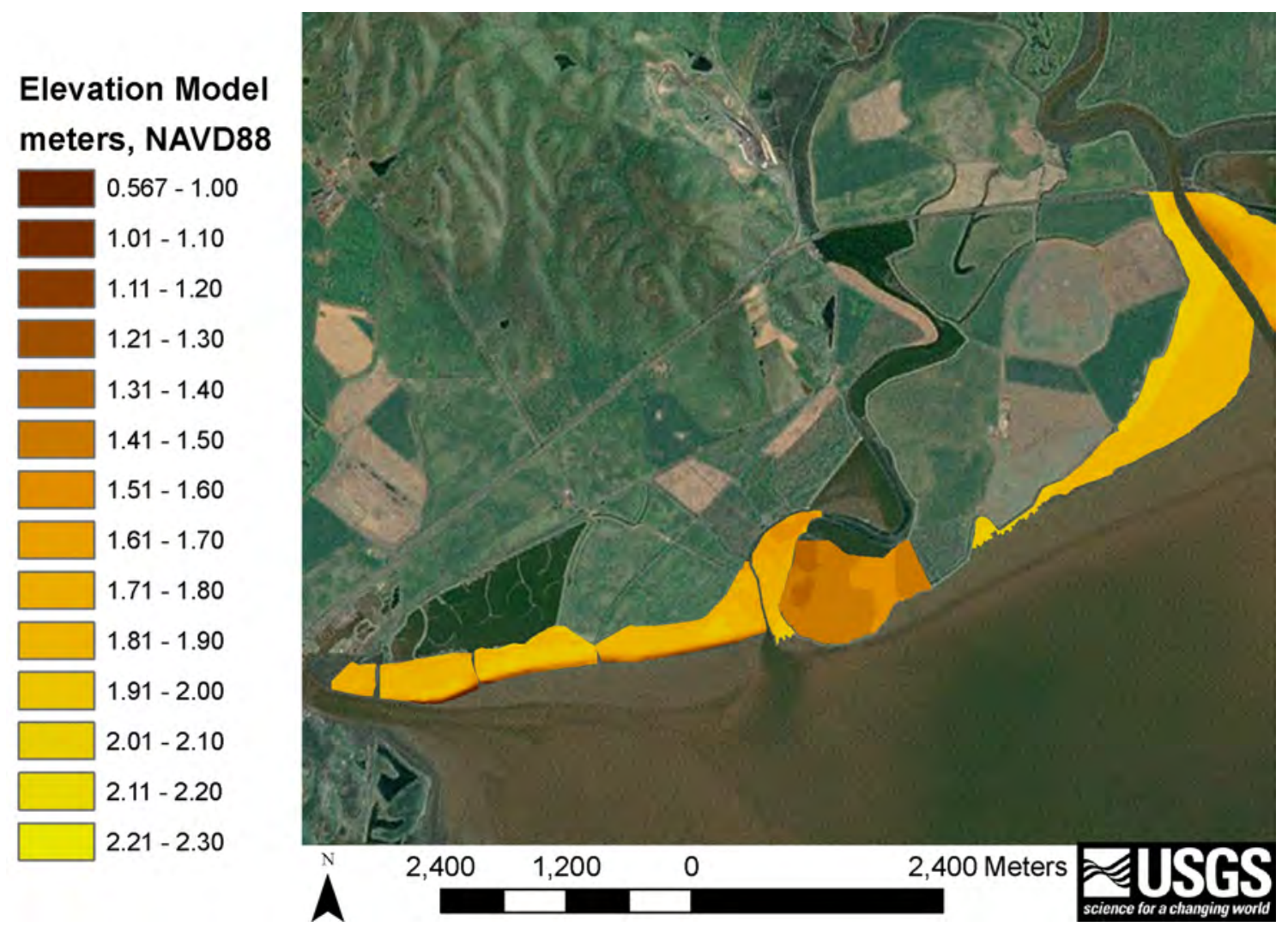

Figure L-4. Elevation model (3-meter resolution) developed from ground RTK GPS elevation data for west San Pablo. 


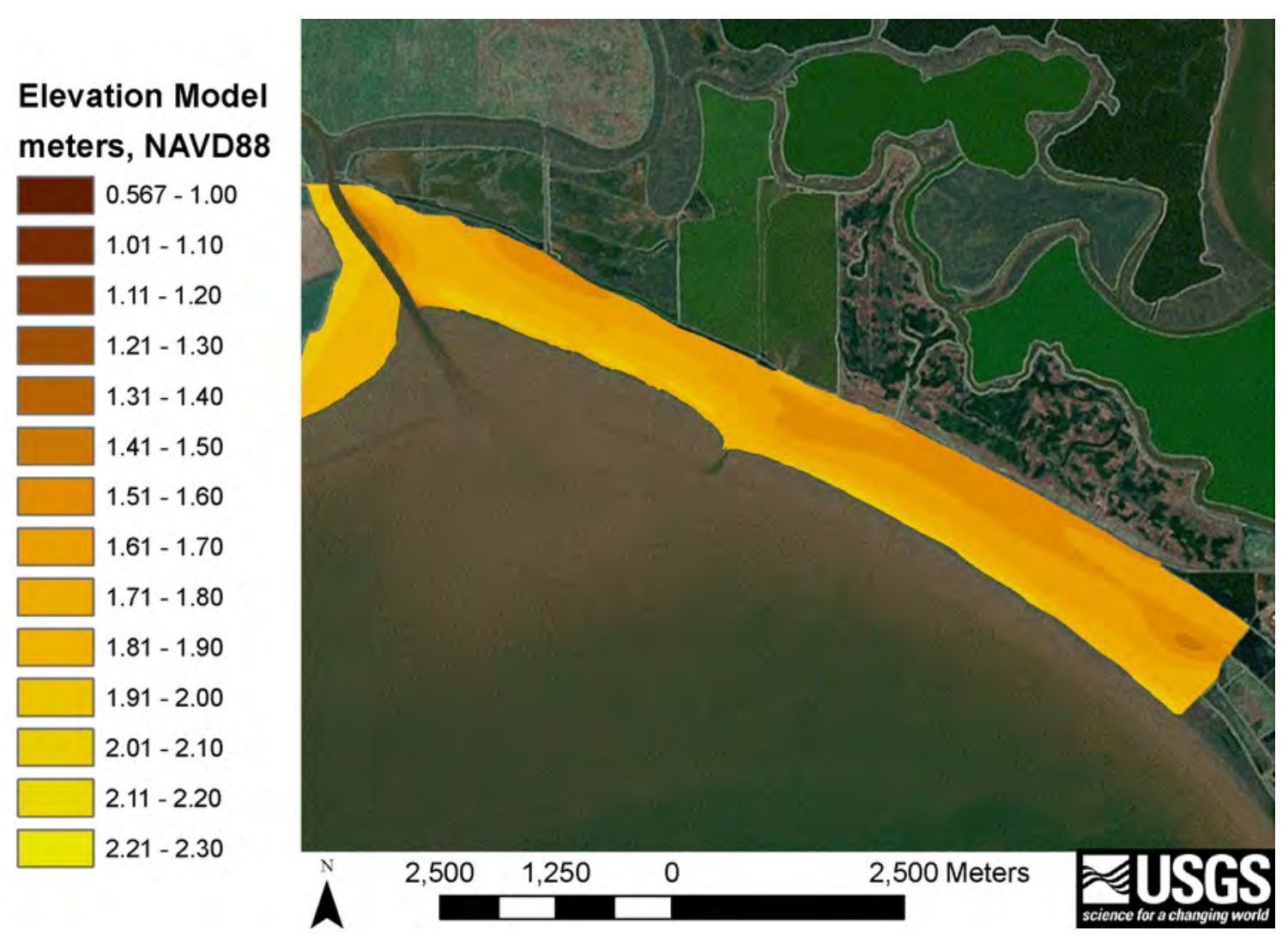

Figure L-5. Elevation model (3-meter resolution) developed from ground RTK GPS elevation data for east San Pablo.

\section{Vegetation}

Vegetation and elevation were surveyed concurrently at San Pablo in the summers of 2008 and 2009. A total of 888 locations (fig. L-1) were measured for vegetation composition, height, and percentage cover (tables L-1 and L-2). We did not distinguish between invasive and native Spartina spp., nor among Schoenoplectus spp., in the survey. Vegetation in marshes is sensitive to soil salinity, inundation patterns, and disturbance; therefore, stratification of vegetation relative to MHW (figs. L-6 - L-7) was observed within this low-slope marsh. 
Table L-1. Mean marsh elevation relative to mean high water (MHW), average, and max height, percentage cover with standard deviations (SD), and presence by species at west San Pablo.

[cm, centimeter; $\mathrm{m}$, meter; $\mathrm{n}$, sample number]

\begin{tabular}{lcccccccccc}
\hline & $\begin{array}{c}\text { Elevation } \\
\text { SpHW, }\end{array}$ & $\begin{array}{c}\text { Elevation } \\
\text { SD } \\
(\mathbf{M H W} \\
\mathbf{m})\end{array}$ & $\begin{array}{c}\text { Mean } \\
\text { Height } \\
(\mathbf{c m})\end{array}$ & $\begin{array}{c}\text { Mean } \\
\text { Height } \\
\text { SD } \\
(\mathbf{c m})\end{array}$ & $\begin{array}{c}\text { Max } \\
\text { Height } \\
(\mathbf{c m})\end{array}$ & $\begin{array}{c}\text { Max } \\
\text { Height } \\
\text { SD } \\
(\mathbf{c m})\end{array}$ & $\begin{array}{c}\text { Cover } \\
(\text { percent) }\end{array}$ & $\begin{array}{c}\text { Cover } \\
\text { SD } \\
\text { (percent) }\end{array}$ & $\begin{array}{c}\text { Presence } \\
(\text { percent) }\end{array}$ \\
\hline Sarcocornia pacifica & 0.08 & 0.19 & 44.41 & 12.49 & 52.82 & 13.56 & 76.43 & 33.73 & 579 & 84.90 \\
Spartina spp. & -0.38 & 0.34 & 70.95 & 17.84 & 77.51 & 16.98 & 36.02 & 25.43 & 63 & 9.24 \\
Schoenoplectus & -0.21 & 0.19 & 31.08 & 33.15 & 32.42 & 34.75 & 15.58 & 23.36 & 12 & 1.76 \\
spp. & & & & & & & & & & \\
Grindelia stricta & 0.03 & 0.18 & 67.38 & 16.17 & 73.49 & 17.62 & 34.90 & 29.49 & 71 & 10.41 \\
Jaumea carnosa & -0.06 & 0.21 & 16.45 & 8.26 & 20.00 & 9.86 & 57.24 & 34.31 & 33 & 4.84 \\
Frankenia salina & 0.17 & 0.27 & 20.92 & 10.53 & 25.50 & 11.77 & 40.47 & 32.05 & 76 & 11.14 \\
Distichlis spicata & 0.09 & 0.28 & 13.83 & 8.57 & 17.11 & 10.90 & 56.49 & 32.87 & 53 & 7.77 \\
Lepidium latifolium & 0.18 & 0.24 & 46.67 & 32.31 & 48.33 & 33.54 & 18.11 & 18.81 & 9 & 1.32 \\
Atriplex triangularis & 0.07 & 0.41 & 20.00 & 16.96 & 22.00 & 18.23 & 12.60 & 20.98 & 5 & 0.73 \\
Baccharis pilurais & 0.37 & 0.30 & 76.50 & 27.02 & 85.90 & 34.91 & 46.00 & 32.35 & 20 & 2.93 \\
\hline
\end{tabular}


Table L-2. Mean marsh elevation relative to mean high water (MHW), average, and max height, percentage cover with standard deviations (SD), and presence by species at east San Pablo.

[cm, centimeter; m, meter; n, sample number]

\begin{tabular}{lcccccccccc}
\hline Species & $\begin{array}{c}\text { Elevation } \\
(\text { MHW, } \mathbf{m})\end{array}$ & $\begin{array}{c}\text { Elevation } \\
\text { SD }(\text { MHW, } \\
\mathbf{m})\end{array}$ & $\begin{array}{c}\text { Mean } \\
\text { Height } \\
(\mathbf{c m})\end{array}$ & $\begin{array}{c}\text { Mean } \\
\text { Height } \\
\text { SD }(\mathbf{c m})\end{array}$ & $\begin{array}{c}\text { Max } \\
\text { Height } \\
(\mathbf{c m})\end{array}$ & $\begin{array}{c}\text { Max } \\
\text { Height } \\
\text { SD }(\mathbf{c m})\end{array}$ & $\begin{array}{c}\text { Cover } \\
\text { (percent) }\end{array}$ & $\begin{array}{c}\text { Cover } \\
\text { SD } \\
\text { (percent) }\end{array}$ & $\begin{array}{c}\text { Presence } \\
\text { (percent) }\end{array}$ \\
\hline Sarcocornia pacifica & 0.05 & 0.16 & 42.64 & 14.26 & 54.40 & 14.75 & 72.07 & 32.27 & 166 & 80.58 \\
Spartina spp. & -0.16 & 0.25 & 66.13 & 17.44 & 74.38 & 16.26 & 21.94 & 17.25 & 16 & 7.77 \\
Schoenoplectus spp. & 0.13 & 0.14 & 90.00 & 14.14 & 107.50 & 10.61 & 15.00 & 7.07 & 2 & 0.97 \\
Grindelia stricta & 0.21 & 0.10 & 50.00 & 22.14 & 59.17 & 26.45 & 44.33 & 38.82 & 6 & 2.91 \\
Frankenia salina & 0.10 & - & 26.00 & - & 42.00 & - & 98.00 & - & 1 & 0.49 \\
Lepidium latifolium & 0.31 & 0.10 & 72.00 & 21.80 & 84.42 & 18.97 & 31.83 & 36.90 & 12 & 5.83 \\
Baccharis pilurais & 0.30 & 0.71 & 50.00 & 21.21 & 67.00 & 1.41 & 22.50 & 3.54 & 2 & 0.97 \\
\hline
\end{tabular}




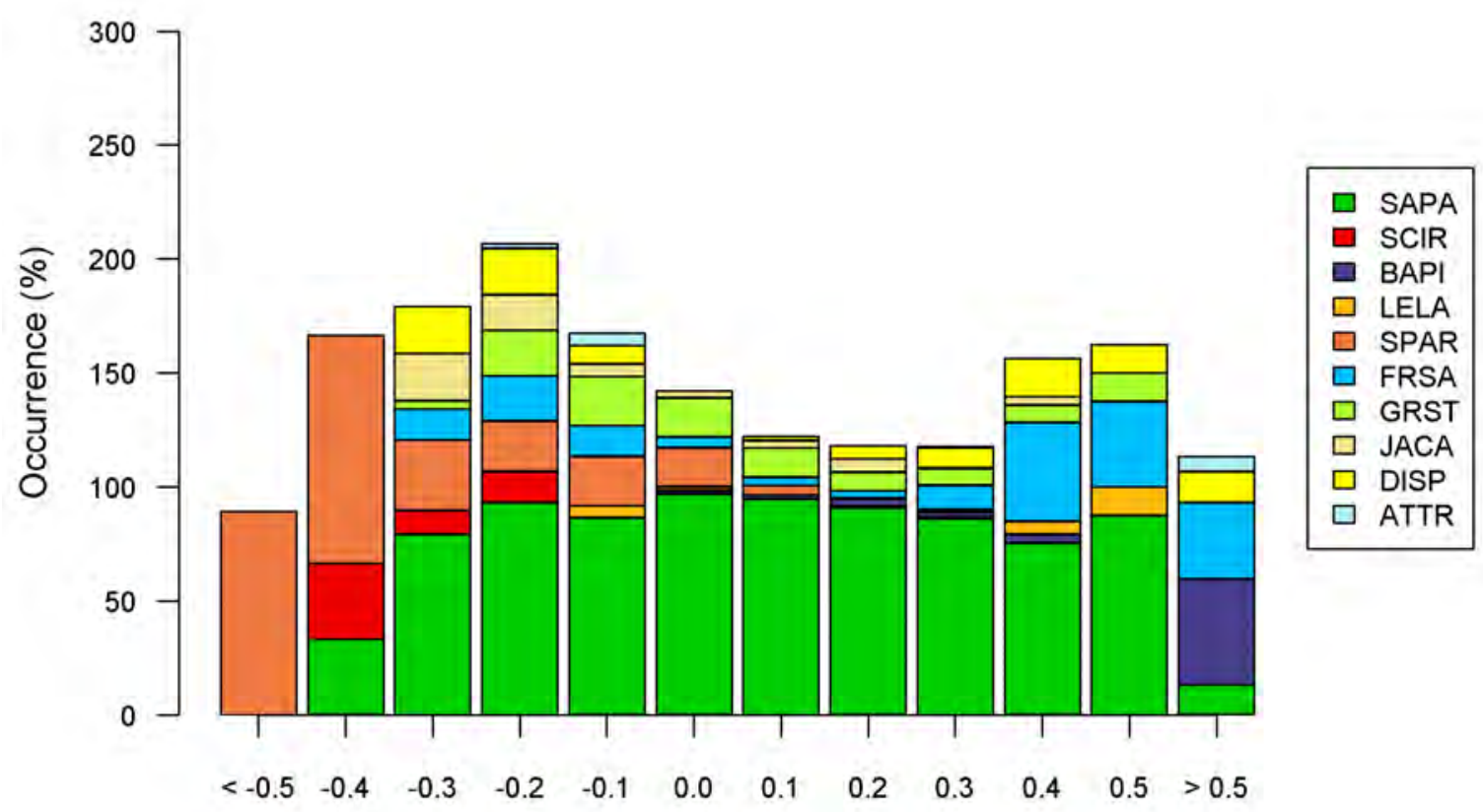

Elevation Relative to $\mathrm{MHW}(\mathrm{m})$

Figure L-6. Stratification of vegetation species was observed relative to mean high water (MHW), in meters (m), at west San Pablo. Species codes: SAPA = Sarcocornia pacifica; SCIR = Schoenoplectus spp.; BAPI: Baccaris pilularis; LELA = Lepidium latifolium; SPAR = Spartina; FRSA = Frankenia salina; GRST = Grindelia stricta; JACA = Jaumea carnosa; DISP = Distichlis spicata; ATTR = Atriplex triangularis. 


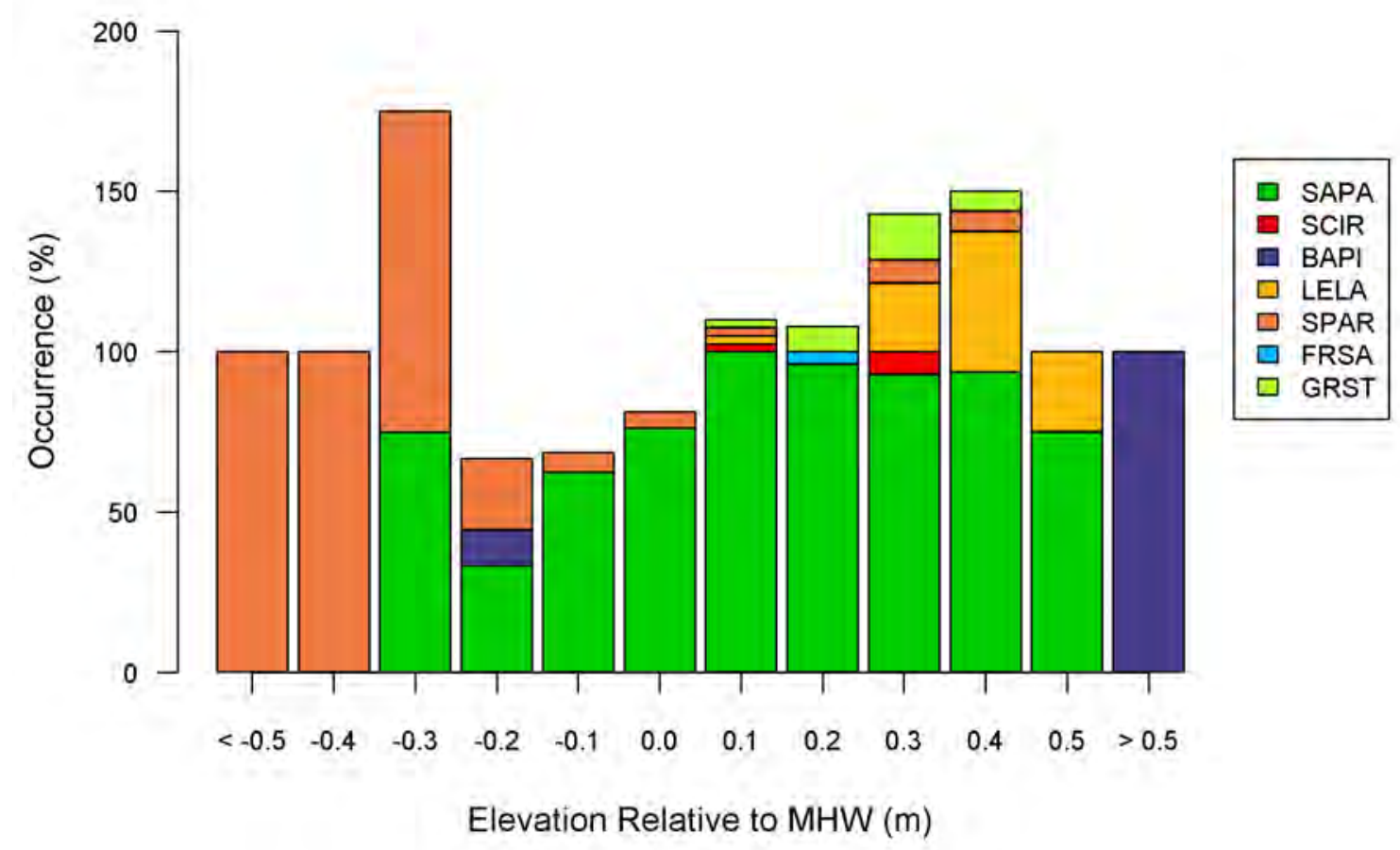

Figure L-7. Stratification of vegetation species was observed relative to mean high water (MHW), in meters $(\mathrm{m})$, at east San Pablo. Species codes: SAPA = Sarcocornia pacifica; SCIR = Schoenoplectus spp.; BAPI = Baccaris pilularis; LELA = Lepidium latifolium; SPAR = Spartina spp.; FRSA = Frankenia salina; GRST = Grindelia stricta.

Water-level monitoring

Site-specific water level was monitored for 1 year between December 2009 and November 2011. Water level was measured by using four data loggers: two deployed at the mouth of second order channels and two in the marsh interior. Mean high water (MHW) was at $1.68 \mathrm{~m}$, and mean higher high water (MHHW) at $1.85 \mathrm{~m}$, for the site (NAVD88). Water levels were recorded throughout the year to evaluate seasonal patterns in tides. The period when the marsh platform (defined as mean marsh elevation) was inundated most often was $n$ January when the diurnal high tides were highest (fig. L-8). Mean salinity during 2010 at San Pablo was 19.0 $(\mathrm{SD}=5.9)$ practical salinity scale. 


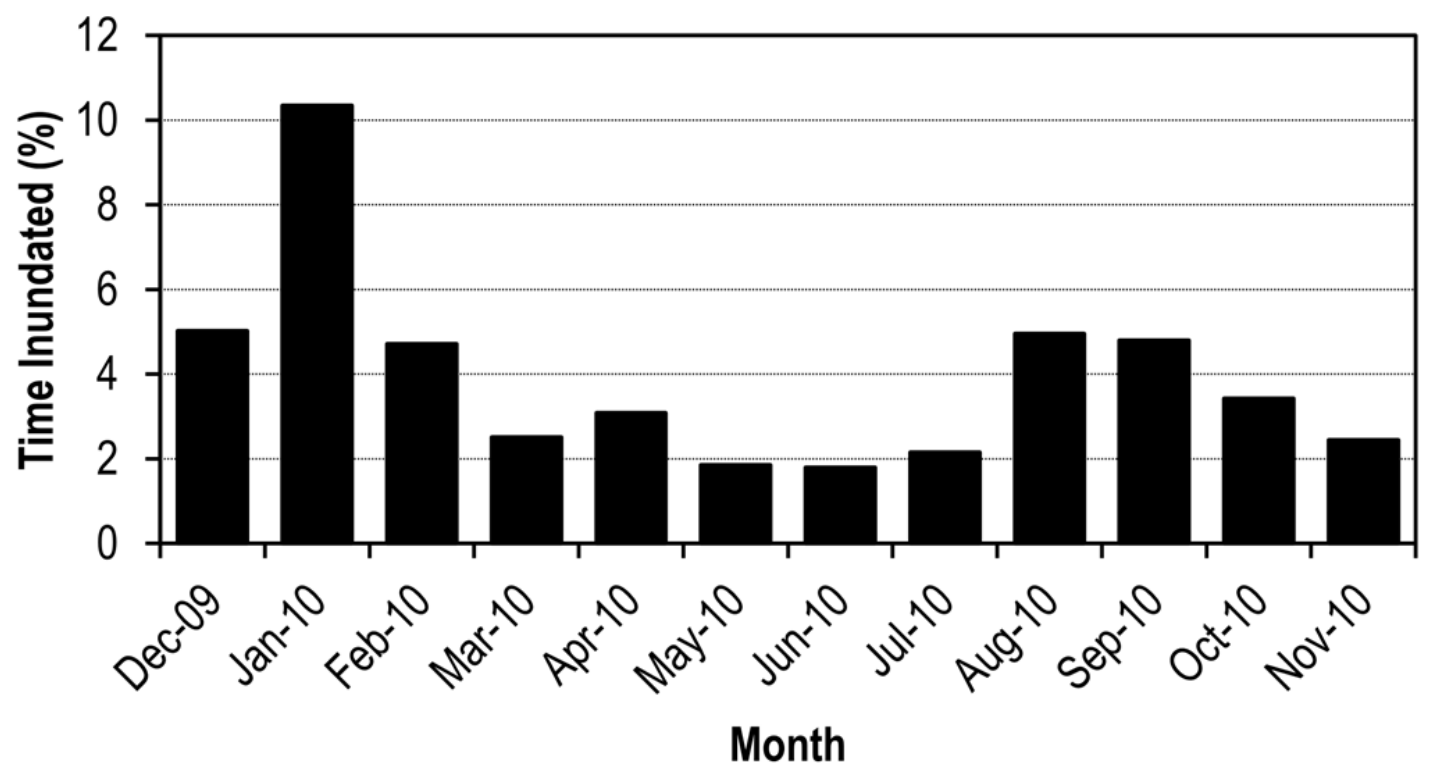

Figure L-8. Percentage of time all of San Pablo was inundated monthly based on the mean elevation of the marsh platform.

\section{Marsh elevation modeling}

WARMER results indicated that San Pablo will not keep pace with local SLR through this century. Results showed a gradual reduction in elevation relative to MHW over time, with a more dramatic decline after 2060 (fig. L-9). By 2090, the marsh was projected to be under MSL and, therefore, to transition to a mudflat (figs. L-10 and L-11). 


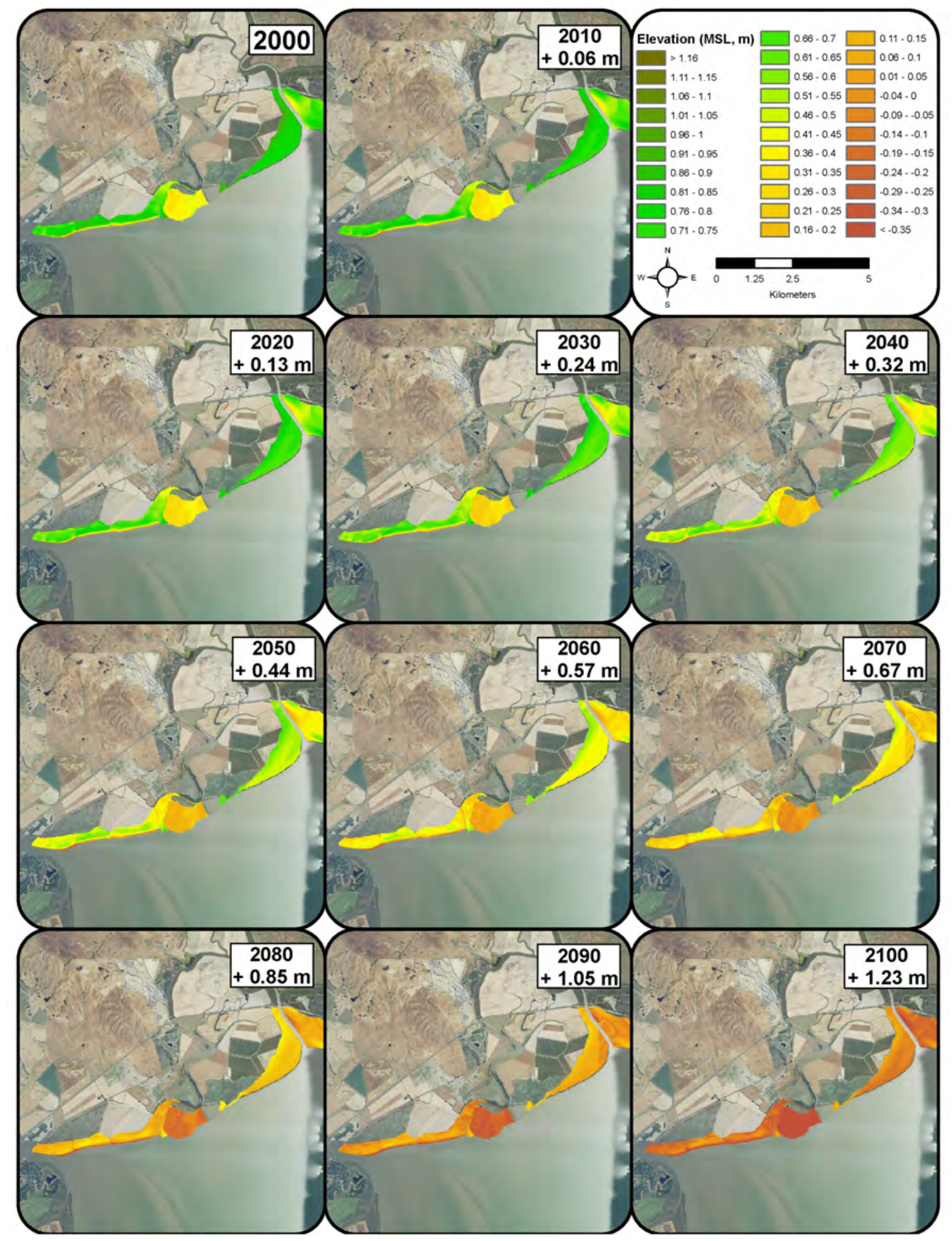

Figure L-9. WARMER results for west San Pablo. WARMER accounts for changes in relative sea-level, subsidence, inorganic sediment accumulation, above and belowground organic matter productivity, compaction, and decay. Non-linear sea-level rise projections for California were used (Cayan and others, 2009). [MSL, mean sea level; m, meters] 


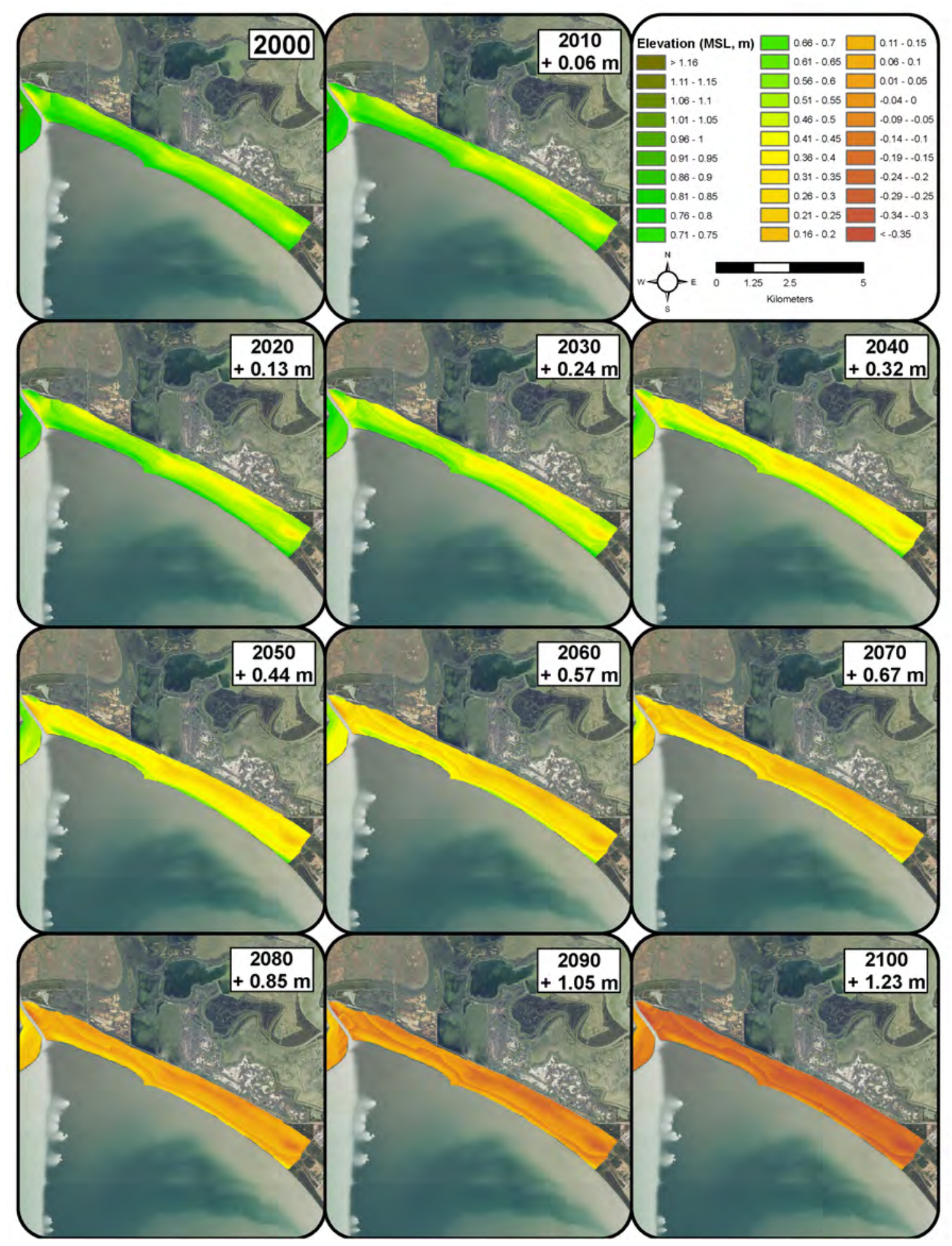

Figure L-10. WARMER results for east San Pablo. WARMER accounts for changes in relative sea-level, subsidence, inorganic sediment accumulation, above and below ground organic matter productivity, compaction, and decay. Non-linear sea-level rise projections for California were used (Cayan and others, 2009). [MSL, mean sea level; m, meters] 


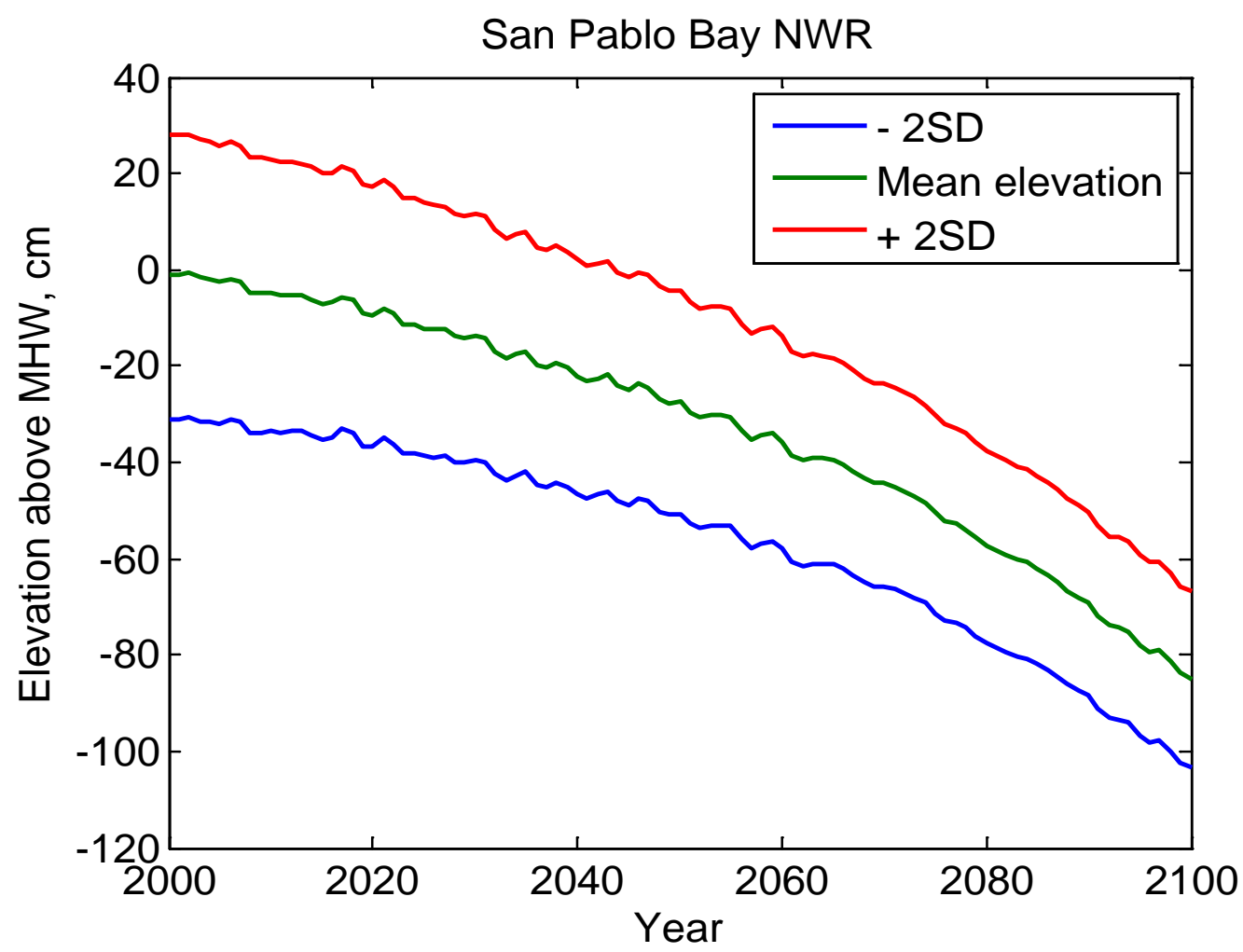

Figure L-11. WARMER scenarios for San Pablo elevation change. Elevation above mean high water (MHW), in centimeters (cm), is plotted against model year with two standard deviations (SD).

Elevation relative to the local tidal datum can be tied to vegetation observations. Vegetation data were categorized as mudflat, low, mid, high marsh, or upland transition plant communities and used to interpret the WARMER SLR results (figs. L-12 - L-14). Upland transition (greater than $1.0 \mathrm{~m} \mathrm{MSL}$ ) was characterized by coyote bush (Baccharis pilularis). High marsh (0.7 - 1.0 m MSL) was characterized by Frankenia salina and Jaumea carnosa, whereas mid marsh $(0.45-0.7 \mathrm{~m} \mathrm{MSL})$ was dominated by Sarcocornia pacifica. Low marsh (0.2-0.45 m MSL) was characterized by Spartina spp. or, in brackish areas, by Schoenoplectus spp. Mudflat habitat (less than $0.2 \mathrm{~m}$ MSL) was unvegetated or sparsely covered with Spartina spp. Currently, west San Pablo is primarily mid and high marsh. High marsh was projected to increase from 2000 through 2020 (0.13 m SLR). All high marsh vegetation was projected to be gone by 2040 (0.32 m SLR). Mid marsh was projected to dominate until 2060 (0.57 m SLR), at which time it transitions to low marsh. A transition to mudflat was projected by $2080(0.85 \mathrm{~m}$ SLR).

East San Pablo is also primarily mid-marsh habitat, with some high-marsh vegetation bordering San Pablo Bay. All high marsh was projected to be mostly gone by $2020(0.13 \mathrm{~m}$ SLR), with mid marsh projected to be gone by 2050 (0.44 m SLR). Low marsh was projected to dominate until 2070 ( $0.67 \mathrm{~m} \mathrm{SLR}$ ), at which time east San Pablo would transition below MSL to a mudflat. All vegetation was gone by 2090 (1.05 m SLR)

The WARMER model parameters for San Pablo Bay were extrapolated by using sediment core data from China Camp marsh; thus, predictions need to be interpreted with caution because local sedimentation processes could differ between these marshes. To improve results, local site-specific sediment core data could be collected along with suspended-sediment concentrations to characterize sediment deposition potential. 


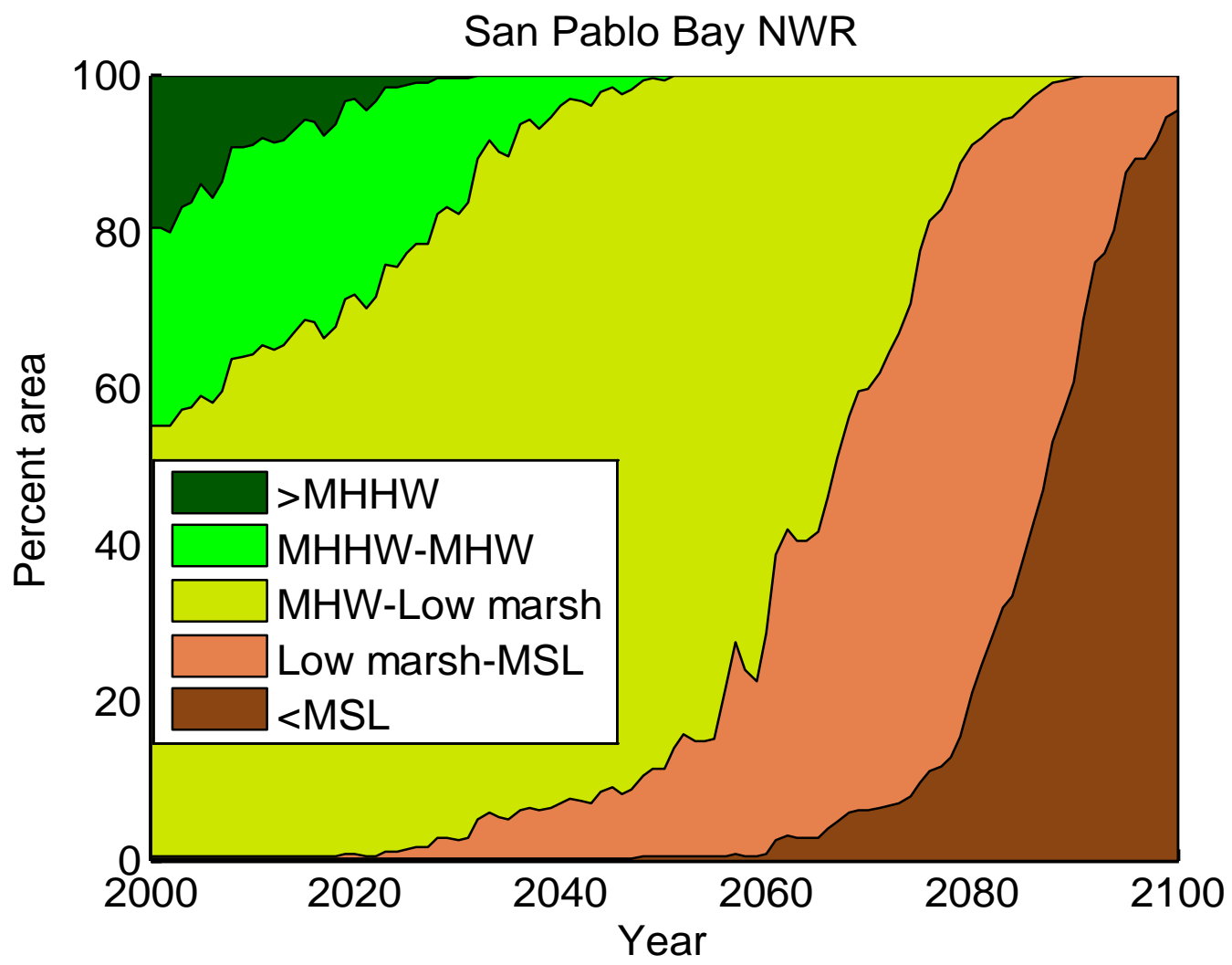

Figure L-12. Area of San Pablo within a given tidal range for the duration of the simulation period. $[\mathrm{MHHW}$, mean higher high water; MHW, mean high water; MSL, mean sea level; >, greater than; <, less than] 


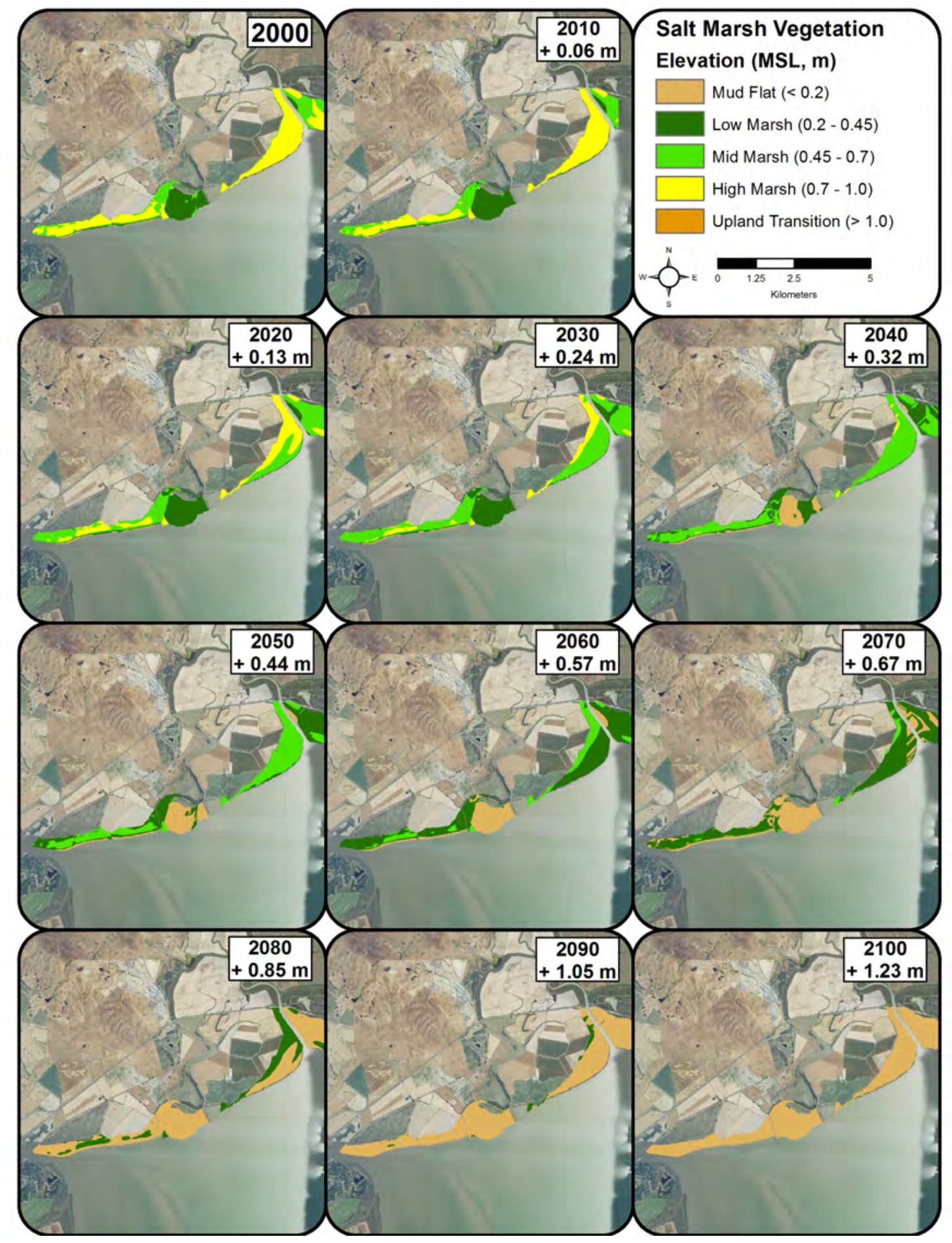

Figure L-13. West San Pablo WARMER results in terms of plant communities relative to mean sea level (MSL), in meters (m): mudflat, low, mid, or high marsh, or upland transition. 


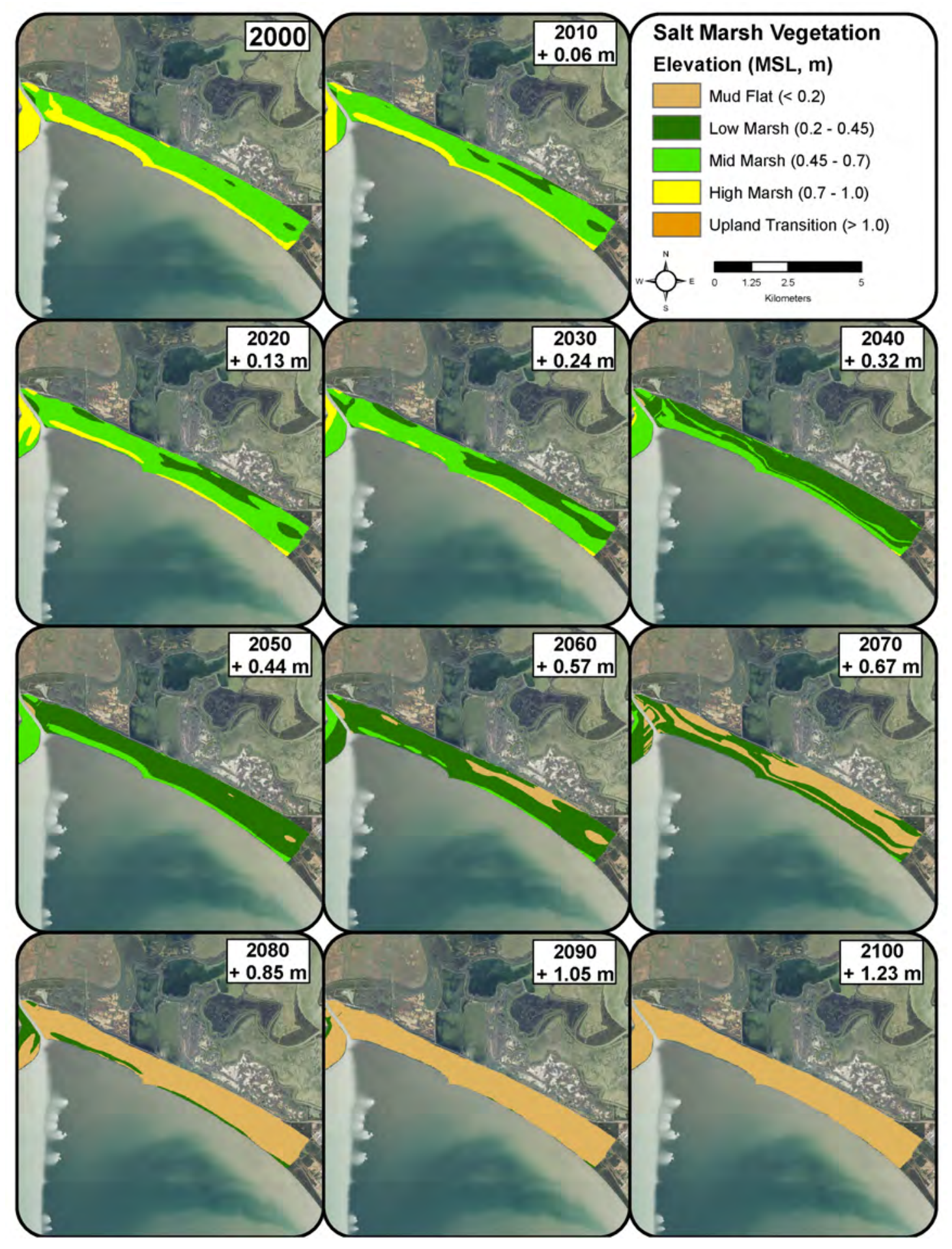

Figure L-14. East San Pablo WARMER results in terms of plant communities relative to mean sea level (MSL), in meters (m): mudflat, low, mid, or high marsh, or upland transition. 